University of Louisville

ThinkIR: The University of Louisville's Institutional Repository

Electronic Theses and Dissertations

$12-2014$

\title{
The formation of a sacred political site : the birthplace of Mao Zedong at Shaoshan
}

Zhe Dong 1988-

University of Louisville

Follow this and additional works at: https://ir.library.louisville.edu/etd

Part of the Architectural History and Criticism Commons, Asian Art and Architecture Commons, Asian History Commons, Chinese Studies Commons, and the Historic Preservation and Conservation Commons

\section{Recommended Citation}

Dong, Zhe 1988-, "The formation of a sacred political site : the birthplace of Mao Zedong at Shaoshan" (2014). Electronic Theses and Dissertations. Paper 1716.

https://doi.org/10.18297/etd/1716

This Master's Thesis is brought to you for free and open access by ThinkIR: The University of Louisville's Institutional Repository. It has been accepted for inclusion in Electronic Theses and Dissertations by an authorized administrator of ThinkIR: The University of Louisville's Institutional Repository. This title appears here courtesy of the author, who has retained all other copyrights. For more information, please contact thinkir@louisville.edu. 
THE FORMATION OF A SACRED POLITICAL SITE: THE BIRTHPLACE OF

MAO ZEDONG AT SHAOSHAN

By

Zhe Dong

B.A., Tianjin University, 2012

\begin{abstract}
A Thesis
Submitted to the Faculty of the

College of Arts and Sciences of the University of Louisville

in Partial Fulfillment of Requirements

for the Degree of
\end{abstract}

Master of Arts

Department of Fine Arts

University of Louisville

Louisville, Kentucky

December 2014 
Copyright 2014 by Zhe Dong

All rights reserved 

THE FORMATION OF A SACRED POLITICAL SITE: THE BIRTHPLACE OF

MAO ZEDONG AT SHAOSHAN

By

Zhe Dong

B.A., Tianjin University, 2012

A Thesis Approved on

November 25, 2014

by the following Thesis Committee:

Delin Lai

Thesis Director

Benjamin Hufbauer

Second Committee Member

Christopher Fulton

Third Committee Member

Shawn Parkhurst

Fourth Committee Member 


\section{ACKNOWLEDGEMENT}

I would like to thank my advisor, Dr. Delin Lai, for his patient mentoring and guidance, which have been of great value in my exploration of the academia and completing my M.A. program. I would also like to thank other committee members, Dr. Benjamin Hufbauer, Dr. Christopher Fulton, and Dr. Shawn Parkhurst, for their assistance and understanding over the past years. I am grateful for the help from many other scholars, including Zhang Xi, Huang Yuling, Cai Dedao, Eileen Yanoviak, Tracey Eckersley, Jonathan Lippman, for their valuable help during my education. I would also like to express my deep gratitude to Chiayun Chiang who accompanied me over these years in Louisville. I proffer my greatest appreciation to my parents, Chen Li and Dong Yunzhan, for their endless love and support. 


\section{ABSTRACT \\ THE FORMATION OF A SACRED POLITICAL SITE: THE BIRTHPLACE OF MAO ZEDONG AT SHAOSHAN}

\section{Zhe Dong}

November 25, 2014

Between 1949 and 1966, Mao Zedong's cult of personality swelled into a kind of secular religion in China, and his birthplace, the remote village of Shaoshan, became a sacred site and a signal representative of national commemorative culture. This study rediscovers Shaoshan's memorial projects undertaken during this period and explores how they embody the complex interplay between art/architecture and politics and the artistic tensions between rural and urban settings in post-Revolutionary China. The text focuses on four endeavors: the historic preservation of Mao's Old House; the urban renovation plans advanced during the Great Leap Forward; the Exhibition Pavilion constructed by Guangdong architects in 1964; and the Socialist Realist landscape paintings of Shaoshan. Beyond illustrating the development of a distinct rural aesthetic, these works offer a window into the codification of Chinese communist ideology and the ritualized worship practices reflected in and enacted by much art of the era. Ultimately, the study aims to inspire more interdisciplinary study on Shaoshan specifically and, given the site's significance, to achieve a more 
complete understanding of Chinese art and architecture overall. 


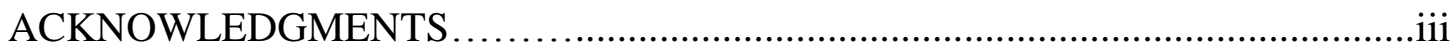

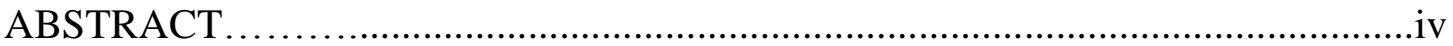

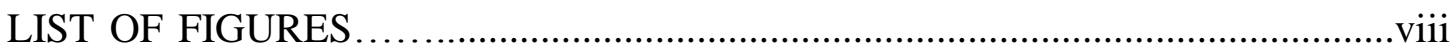

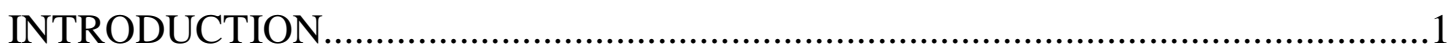

CHAPTER I: MAO'S CODIFICATION OF CHINESE COMMUNISM AND THE

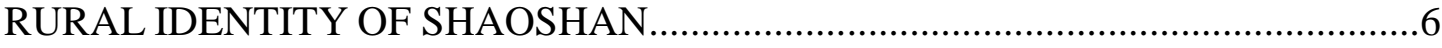

Shaoshan and Mao's Family: A Dual Rural Heritage...........................................6

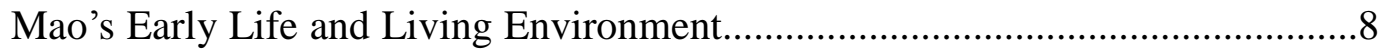

Mao’s Revolutionary Career and His “Sinification of Marxism”.........................10

Mao's Touchstones: The Peasantized Revolution and the Rural Identity of

Shaoshan ............................................................13

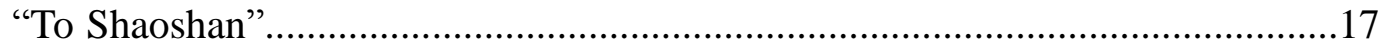

CHAPTER II: MAO'S OLD HOUSE: THE MATERIAL CORE OF

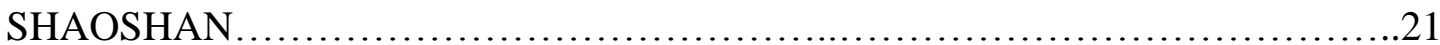

Mao's Old House in Shaoshan Before and Around 1950...................................22

The "Authentic" Restoration of Mao's House...................................................24

Building a Discourse: Tour Guide, Exhibition, and Museum............................27

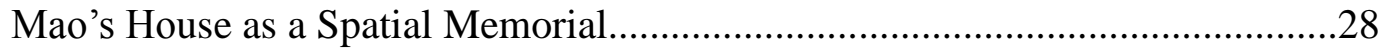

CHAPTER III: COSMOPOLITANISM VS RURAL IDENTITY: URBAN

PLANNING DURING THE GREAT LEAP FORWARD .........................................34

An Agreement between Zhang Pinghua and Tao Zhu.........................................36

Two Urban Plans: Jin Zeguang and the Shaoshan Administration.......................40 
Option A: Monumental Forms from the Cosmopolitan Style in Beijing..... .45

Option B: The Rural Identity, the Local Memorial Core in Shaoshan.

CHAPTER IV: THE COSMOPOLITAN TRANSFORMATION OF SHAOSHAN:

BUILDING THE EXHIBITION PAVILION IN 1964.

Circumstance and Perseverance: A Reconsideration of the Memorial Offering in

1963.

Tao's "Three Ought To" Principle .58

Explaining Tao's Garden Layout.

The Exhibition Pavilion of Comrade Mao Zedong's Old House. .67

The Title and the Exhibition of the Exhibition Pavilion. .71

A Milestone in Mao's Cult of Personality..... . .74

CHAPTER V: THE VISUALIZATION OF RURAL IDENTITY: THE LANDSCAPE PAINTINGS OF SHAOSHAN .78

Li Xiongcai's Naturalism. . .78

Fu Baoshi’s Shaoshan Scroll: A Pastoral Homeland............................................79

Socialist Realist Guidelines in Mid-20th Century China....................................83

The Poetic Paintings of 'To Shaoshan': A Revolutionized Community. .86

The Integration of the Revolutionized Community and the Pastoral Homelan....88

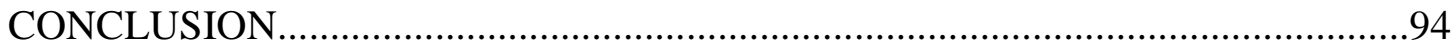

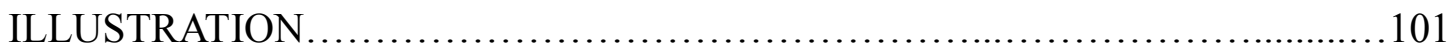

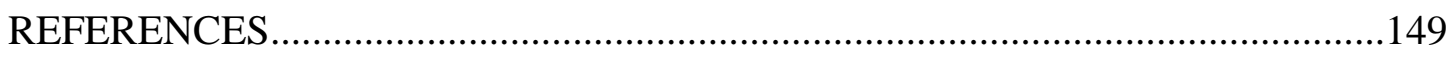

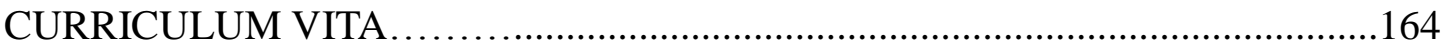




\section{LIST OF FIGURES}

FIGURE

PAGE

1. Tourist map of Shaoshan village..................................101 (1)

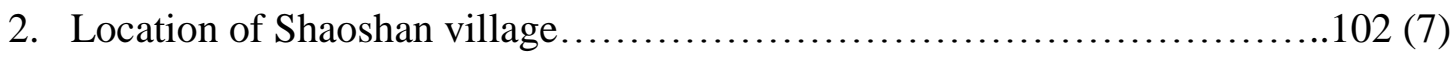

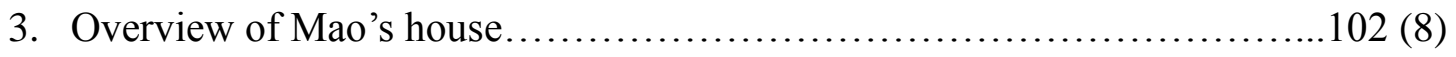

4. Plan of Mao's farmhouse.............................................103 (8)

5. Facade of Mao's house .........................................103 (9)

6. Interior of Mao's parents' room.................................. 104 (9)

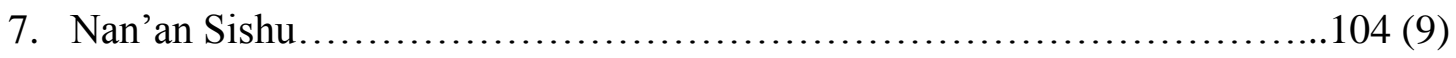

8. Mao's Ancestral Temple..........................................105 (9)

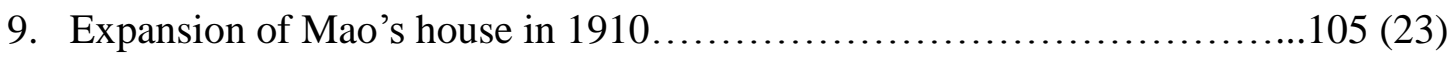

10. MAO Zedong, "Guanyu liji tingzhi zai shaoshan wei maozedong jianfang gei huangkecheng deng de xin", [Letter to Huang Kecheng to stop building a house for Mao Zedong in Shaoshan] .....................................106 (23)

11. Some of the revolutionary relics collected in Shaoshan...................107 (27)

12. Young Mao's portrait in the Shaoshan Album..........................107 (31)

13. Next plate in Shaoshan: Ariel view of Mao's old house..................109 (31)

14. Next plate: A closer photograph of Mao's house.......................109 (31)

15. Next plate: The front door of the house.......................... 109 (31)

16. Following plates: the central hall and other rooms of the house...........109 (31) 
17. Kitchen of Mao's house as shown in Shaoshan

$110(32)$

18. Farm where Mao dried rice as shown in Shaoshan

$111(32)$

19. People arriving at Shaoshan Railway Station and marching to Mao's

house.

20. Kitchen in Mao's house.

21. Old Shaoshan Cultural Center

22. Urban planning of Zunyi's memorial center in 1959 $114(45)$

23. Perspectives of the proposed Memorial Pavilion in Zunyi

24. Perspectives of the proposed Memorial Pavilion in Zunyi.

25. Great Hall of People

26. Museum of Chinese History. $116(48)$

27. Plan of the No.1 Proposal for the Beijing Lu Xun's Memorial $116(50)$

28. Plan of the No.4 Proposal

29. Plan of the selected proposal

30. Renderings of Beijing Lu Xun's Memorial $118(51)$

31. Renderings of Beijing Lu Xun's Memorial

32. Plan of the garden that surrounded Lu Xun's Memorial in Shanghai

33. Rendering of Lu Xun's Memorial in Shanghai

34. Plan of Lu Xun's Memorial in Shanghai

35. Façade of Lu Xun's Memorial in Shanghai

36. Shaoshan visitor statistics from 1953 to 1990 $122(56)$

37. Ke Yuan (Ke Garden), Dongguan City, Guangdong Province, China $123(61)$ 
38. Xia Changshi. Principal Building of the Sun Yat-sen Hospital, Guangzhou, Guangdong Province. $123(62)$

39. Mo Bozhi, Sketches of Shuangxi Villa. The Works of Mo Bozhi $123(63)$

40. Zhuang Shaopang. Diagram showing the transition of exterior and interior of Shuangxi Villa

41. Photos of Shuangxi Villa.

42. Mo Bozhi, plan of the Mountain Villa. $125(66)$

43. Photos of the Mountain Villa

44. Plan of the Exhibition Pavilion for Comrade Mao Zedong's Old House....126 (68)

45. Facade of the Exhibition Pavilion for Comrade Mao Zedong's Old House $127(68)$

46. Section of the Exhibition Pavilion for Comrade Mao Zedong's Old House $127(68)$

47. Overview of the Exhibition Pavilion of Comrade Mao Zedong's Old House $128(68)$

48. "Water yard" of the museum $128(68)$

49. "Green yard" of the museum

50. Interior garden and corridor of the Exhibition Pavilion

51. Quadrille pavement of the museum $130(68)$

52. Decorative detail in the yard. $130(68)$

53. Delicate moldings of the museum

54. Entrance of the museum $132(69)$ 
55. Facade of the museum.

56. F-shaped structural detail of the museum

57. Delicate details and artificial materials

58. Wooden upper structure of the museum $134(70)$

59. Visitors to the Exhibition Pavilion

60. Li Xiongcai. Maozedong tongzhi guju cewang. [Distant View of Comrade Mao's Old House]. $135(79)$

61. Li Xiongcai. Cong Zhaodaisuo tiaowang shaoshan xuexiao. [Distant View of Shaoshan School from the Guesthouse]

62. Li Xiongcai. Shaoshan wenhua guan. [Shaoshan Cultural

Center] $136(79)$

63. Fu Baoshi. Shaoshan tu. [Shaoshan Scroll] $136(80)$

64. Fu Baoshi. Maozhuxi guju. [Chairman Mao’s Old House]

65. Fu Baoshi. Sketch of the Shaoshan Scroll ...

66. Song Wenzhi. Shaoshan zhaohui. [Dawn in Shaoshan]

67. Li Xiongcai. Shaoshan zhaohui. [Dawn in Shaoshan]....

68. Fu Baoshi. Maozhuxi qilv dao shaoshan shiyi tu. [Poetic Painting of Chairman Mao’s qilyu “To Shaoshan”] $139(86)$

69. Fu Baoshi. Maozhuxi qilv dao shaoshan shiyi tu. [Poetic Painting of Chairman Mao's qilyu "To Shaoshan"] $140(86)$

70. Fu Baoshi. Maozhuxi qilv dao shaoshan shiyi tu. [Poetic Painting of Chairman Mao's qilyu “To Shaoshan”] $141(86)$ 
71. Peng Zhaomin. Maozhuxi 1959 nian hui shaoshan. [Chairman Mao Returning to Shaoshan in 1959].

72. Fu Duzhu. mao zedong tongzhi zai shaoshan zuzhi xue chi hui [Comrade Mao

Zedong Organized xue chi hui in Shaoshan]

73. Chen Ziyun. dailu [Guide the Way]

74. Chen Ziyun. Huanying maozedong tongzhi hui shaoshan kaocha nongmin yundong. [Welcome Comrade Mao Zedong Back to Shaoshan to Investigate Peasant Movement]

75. Li Keran. Maozhuxi guju. [Chairman Mao’s Old House]

76. Li Keran. Geming shengdi shaoshan. [Sacred Revolutionary Site

Shaoshan]

77. Li Keran. Shaoshan geming shengdi maozhuxi jiuju. [Chairman Mao’s Old House, Shaoshan the Sacred Revolutionary Site]

78. Badge that reads "Souvenir for the visit to Chairman Mao's Old House in

Shaoshan; November 15, 1966"

79. Poster from the Cultural Revolution to advertise the railway station in

Shaoshan $146(96)$

80. Young Mao's statue in Shaoshan, constructed in 1967

81. Demolition scene of the Exhibition Pavilion of Chairman Mao's Old

House 


\section{INTRODUCTION}

On December 26th, 1893, Mao Zedong was born in Shaoshan, a small village in the center of Hunan Province. At that time, as well as when the People's Republic of China (PRC) was established in 1949, the village was suffering under crushing poverty. Several generations on, however, it stands as one of the most prosperous areas in the province. ${ }^{1}$ Much of this success may be attributed to tourism, which welcomes millions every year. The principal attraction, of course, is Mao himself and the role of Shaoshan, improved by legend, in forming his character. ${ }^{2}$

A typical tour of Shaoshan involves two hours of walking, during which tourists experience a series of landmarks. They visit Mao's rustic farmhouse, the picturesque fields and ponds, an exquisite museum modeled on ancient gardens, a grand-scale traditional temple, and a huge bronze statue set on a spacious square (Figure 1). These spots are united in commemorating Mao, yet each has its own symbolic language, producing a multivalent memorial network. These monuments situate visitors in different behavioral patterns, ritual traditions, and even historical discourses bearing competing ideologies and plural interpretations of Mao. The memorial landscape of Shaoshan raises some intriguing questions: How were these dissimilar constructions conceived and negotiated? What aesthetics do they embody? What ideologies do they

\footnotetext{
${ }^{1}$ For an economic survey of Shaoshan, see Shaoshan City Chorography Committee, Shao Shan Shi Zhi, 19912005 [Shaoshan City chronicle, 1991-2005](Haikou: Hainan Press, 2010), 185-189; Planning Board of the Shaoshan Revolutionary Committee, Hunan Sheng Shaoshan Qu Guomin Jingji Tongji Ziliao: 1969-1979 [Statistics of the national economy in Shaoshan District, Hunan Province: 1969-1979](1980); and Statistical Bureau of Shaoshan District, Xiangtan City, Xiangtan Shi Shaoshan Qu Guomin Jingji Tongji Ziliao: 1949-1989 [Statistics of the national economy in Shaoshan District. Xiangtan City: 1949-1989](1990). From the Hunan Provincial Library.

${ }^{2}$ For Shaoshan visitor statistics, see Shaoshan City, Shao Shan Shi Zhi, 164-178.
} 
contain and project, and how did the physical buildings interact with the specific political power? And what can Shaoshan teach us Socialist Realist art and architecture in the mid-twentieth century?

This thesis will investigate artistic representations of Shaoshan as a microcosm of broader artistic trends in Communist China. It will emphasize the interaction between ideological initiatives and art production, the features in art and architecture that enabled political coding, and the dynamics in artistic representations of Mao and his birthplace over different periods. The purpose here is twofold: first, that the research of art and architecture will shed light on the function of commemorative rituals and political ideologies in Chinese cultures; second, that the political perspective in memorial studies will help identify the character of art and architecture in the particular context of Communist China.

The commemorative culture in Shaoshan was deeply influenced by Mao's cult of personality. This movement did not emerge organically but was manufactured and launched by the Communist Party of China (CPC) in the early 1940s to promote the Chinese Communist Revolution and contest the Nationalist Party's (or Kuomintang, henceforth KMT) cultification of Jiang Jieshi. In the early 1950s, with communism triumphant, the CPC turned its focus from ideological propaganda to the practical matter of economic development and thus ordered restraints on Mao's cult of personality. However, Stalinism's fall in the Soviet Union and the upheavals in Eastern Europe soon motivated Mao to resume his cult and reinforce China's ideological engagement. He openly supported the cult of personality in China, launched the Great Leap Forward, imprisoned dissenting officials, and deployed other ideological pedagogies such as the Four Purifications and Socialist Education Movement. All these campaigns produced and deepened the disagreement between 
Mao and Liu Shaoqi's bureaucratic system. Finally, faced with the economic and humanitarian failures, including a famine that killed millions, brought about by the Great Leap Forward, Mao was forced to cede certain powers in the early 1960s. Around the same time, Mao's followers, including Lin Biao and Tao Zhu, began to mount another boom of Mao advertisement. Mao, preparing to stage a political comeback, was brewing his cult of personality anew.

In the dynamic political environment surrounding, and surrounded by, the early phases of Mao's rule, the artistic commemoration of Mao in Shaoshan underwent several mutations and manifested varied, shifting characteristics. This thesis analyzes this evolution by studying a representative example from each stage, namely, the historic preservation of Mao's Old House, the plans for urban renewal drafted during the Great Leap Forward, the Exhibition Pavilion of Comrade Mao Zedong's Old House in the early 1960s, and the landscape paintings inspired by Socialist Realism. Through these case studies, the thesis delineates Shaoshan's incremental development into a national sanctuary from 1949 to 1966.

The first chapter discusses the specific ideology that directed Mao's commemoration in Shaoshan. I begin with a description of the living environment in Mao's birthplace and then connect Mao's rural upbringing with his revolutionary biography. Next, I review the major tenets of Mao's "Sinification of Marxism," used to codify and legitimize the peasant society from which Chinese communism, and Mao himself, was born. I conclude by describing how this theory engendered Shaoshan's rural identity in official ideology and the public imagination and, therefore, how the theory oriented artistic and architectural treatment of Shaoshan.

The second chapter examines Shaoshan's memorial construction against the political background of the early 1950s. I begin by recalling the moderate political 
climate of the period and the official calls to restrain Mao's cult of personality in order to contextualize the decision to restore Mao's rustic farmhouse as a spatial memorial that was more a tribute to the $\mathrm{CPC}$ than to Mao personally. I continue by exploring how, in its claims to preserve Mao's authentic living environment, it tried to create a simulacrum of Mao's revolutionary breeding onto which visitors could project themselves; to display the house was, in effect, to share the forces that drove the revolution. I conclude by observing that, in constructing spatial memorials in Shaoshan and at other revolutionary sites, the government established a nationwide memorial system to provide experiential testament to the imagined community of Communist China.

The third chapter focuses on Shaoshan's transformation under the Great Leap Forward (1958-1961). I begin by chronicling Mao's reassertion of power and his calls to resume his cult of personality as a way to inspirit the public during this period of transition. I continue by describing the developments in urban architecture, such as public squares and the Ten Great Buildings in Beijing, to contextualize Shaoshan's own search for novel forms to honor Mao. Next, I analyze the competing directions-one urban and indebted to Beijing, the other more rural and romantic and faithful to Shaoshan's own character--in which two regional leaders, Tao Zhu and Zhang Pinghua, sought to direct this search. I conclude by connecting this debate to the larger tensions between cosmopolitan fashion and local tradition in Chinese memorial landscape.

The fourth chapter analyzes Mao's commemorative architecture in Shaoshan in the early 1960s. I begin by sketching the political adversities now faced by Mao and his loyalists, whose Great Leap Forward starved millions, and their subsequent recovery of his authority and reinvigoration of his cult. I continue by describing Tao 
and Zhang's persistent, clandestine efforts to build the Shaoshan Mao memorial, at last consummated in 1964 with the Exhibition Pavilion of Comrade Mao Zedong's Old House. I then detail how, in this building project, Tao developed a vernacular style to preserve Shaoshan's rural identity and, further, individuated the design by introducing architectural elements from the famed Lingnan gardens of southern China. I conclude by analyzing how the Exhibition Pavilion utilized its spatial arrangement to represent the Maoist social order and enact a ceremonial ritual in the secular religion of Mao.

The fifth chapter considers the Socialist Realist landscape paintings of Shaoshan made from the 1950s to the 1970s, with special focus on works by Li Xiongcai, Fu Baoshi, and Li Keran. I describe how, while early 1950s paintings of Shaoshan emphasized a simple naturalism, Fu Baoshi established a system of iconography in 1959 that infused this realism with ideological discipline; later, I note, Fu's pictorial iconography of Shaoshan's rural identity would be canonized as the official representation of Mao's birthplace. I go on to assess Fu's and others' works against the CPC's Socialist Realist guidelines, which favor the invented reality of Marxist ideologues to the consensual lived reality in art production.

The conclusion begins by scanning and comparing the memorial landscape in Shaoshan and elsewhere during and the Cultural Revolution and in post-Maoist China. I then recapitulate my major findings and note the deficit in extant research that my study has endeavored to fill. Finally, I declare my ultimate ambition for the project: to inspire more interdisciplinary study on Shaoshan in particular and, given the village's significance in Chinese politics and culture, to thereby achieve a more comprehensive understanding of Chinese art and architecture. 


\section{CHAPTER I}

\section{MAO'S CODIFICATION OF CHINESE COMMUNISM AND THE RURAL IDENTITY OF SHAOSHAN}

Mao Zedong was the preeminent figure of $20^{\text {th }}$-century China. Beginning in the mid-1930s, he directed the Chinese Communist Revolution and, upon its ascent to power in 1949, was the founding father of the PRC. His military and political triumphs were matched only by his ideological ascendancy. Maoist philosophy inspired and governed the conduct and beliefs of millions. His influence rarely diminished, and he held power until his death in 1977, an occasion lamented by his manifold worshipers.

Mao's communism was not like that of Eastern Europe. Coalescing around the peasant class, Maoism bore the marks of a regional rural identity in and around the Hunan Province from which Mao himself sprang and in which Mao's own sympathies were formed. In this chapter, I will first describe Mao's early experience, his living environment, and their influence on Mao's personality. I will then contend that in order to legitimize his revolutionary theory and expand his personal following, Mao devised a complex rural identity for his hometown, Shaoshan, and for the peasant society of China writ large. I will conclude by observing how Mao strategically codified this rural identity as part of the official ideology of the CPC under his control.

Shaoshan and Mao's Family: A Dual Rural Heritage 
For centuries before communism swept over China, there existed a small village in Hunan Province. It was remote from the commotion of the city, removed from the swirl and bustle of social and political change, seemingly untouched by time (Figure 2). The pristine naturalness of this village, called Shaoshan, was enshrined in the 1737 words of Dai Jong, a literati who resided nearby:

There is a place called Shaoshan in western Xiang. It has endless mountains, beautiful woods, fresh air and fertile fields, which can feed hundreds of residents[... . ] It is said that a beautiful natural environment will always bear human genius. Although far away from business and tourist routes, Shaoshan will certainly have its own descendants to carry its essence and achieve national fame. ${ }^{3}$

In China, it is customary to attribute the greatness of prominent personalities to the distinguished natural environments of their birthplaces. Following this tradition, Dai predicted that Shaoshan would have offspring that would reach national fame. Not even Dai could have anticipated what the favorite son of Shaoshan, Mao Zedong, would bring to the country and the world two centuries later.

Mao's roots in Shaoshan can be traced to the 14th century, when his ancestors immigrated to western Xiang and settled at the foot of Shao Mountain. ${ }^{4}$ To the north of the mountain, there was a small plane covered with rice fields and lotus ponds. Groves of bamboo grew freely and cottages were scattered as if at random. In the southeast of the plain, a $\mathrm{col}^{5}$ ran eastward, leading to several farmhouses resting on the hillside.

It was here that Mao's parents resided at the end of the $19^{\text {th }}$ century. Their house faced north with a pond in the front, the hillside in the back, and a grain-sunning yard

\footnotetext{
${ }^{3}$ Dai Jiong. "Zhong xiang shao shan mao shi shi xiu zu pu" [The first genealogy of the Mao family of Shaoshan in middle Xiang], 1737. Xiang is another name for Hunan Province.

4 The acknowledged ancestor of Mao's family in Hunan Province was Mao Taihua, who moved to the area in the $14^{\text {th }}$ century. One of Taihua's sons, Mao Qingyi, immigrated to the Mountain of Shaoshan.

${ }^{5} \mathrm{~A}$ col is a geographical area describing the concave section at the base of a mountain. It is usually a flat place with high altitude, suiting it for habitation.
} 
to the west (Figure 3). Mao's father was a shrewd, wealthy farmer involved in an assortment of businesses ranging from farm work and rice and livestock trade to tightfisted usury. Mao's mother ${ }^{6}$ was a pious practitioner of Buddhism. On December 26, 1893, their third son, Mao Zedong, was born in their bedroom. ${ }^{7}$

\section{Mao's Early Life and Living Environment}

Immediately after his birth, Mao was sent to live with his mother's family. He returned to Shaoshan at the age of four and lived there until for 13 years. Mao's childhood was a common one in rural Hunan, dominated by agricultural work From six onward, he would took cattle for grazing, plant rice and vegetables, carry manure into the plot, and sun millet in the yard. Outside of his farming activities, every month he and his pious mother worshiped the Guanyin ${ }^{8}$ statue exhibited in the baldachin in the central hall. His leisure time was often spent swimming in the pond fronting his home.

During this time the Maos owned five rooms of the farmhouse and shared the central hall with their neighbors. The entire building was modeled after the most ordinary farmhouse in rural Hunan. The plan, following the local tradition of shuang tou diao, ${ }^{9}$ had an inverted-U layout with the opening area as a public yard (Figure 4). The facade also borrowed a traditional composition called yi ming liang an, which is

\footnotetext{
6 The name of Mao's mother was long thought to be Wen Qimei. See Edgar Snow, Xi Xing Man Ji [Red star over China], trans. Dong Leshan (Beijing: Liberation Army Art Press, 2002), 92. However, sit was later uncovered that Wen's given name was Suqin, while Qimei denotes her seniority among her brothers and sisters. See Gao Jucun, "Mao ze dong he ta de fu qin mao yi chang, mu qin wen su qin" [Mao Zedong and his father, Mao Yichang, and mother, Wen Suqin), in Shao shan mao ze dong yan jiu [Shaoshan's study of Mao Zedong](Changsha: Hunan University Press, 2011), 100.

7 Their previous two sons passed away at an early age. After Mao, Mao's brother Zemin was born in 1896 and Zetan in 1905. Mao Shunsheng later adopted a daughter and named her Mao Zejian. See Shaoshan City Chorography, Shao Shan Shi Zhi, 541.

${ }^{8}$ A baldachin is a small domestic shrine inserted into the middle of the wall against the entrance, always displaying a divine statue or ancestral tablet for admiring. Guanyin is a bodhisattva venerated by East Asians.

9 Luo Shu, "Jian xi hu nan chuan tong min ju gou zao" [Study on the techniques of the traditional folk dwellings of Hunan], Yi Hai. (Jun. 2010): 148-149.
} 
to put the entrance in the center with gables flanking the sides (Figure 5). Rooms were dark, cramped, and connected one after another (Figure 6). All lighting relied on the small windows and doors. ${ }^{10}$ Adobe bricks exposed its crude surface to the interior. Overhead were rafters topped with a thatched roof. Building materials, including mud, gravel, straw, adobe bricks, and wooden beams, were all sourced locally. ${ }^{11}$ This modest rural farmhouse dotting the vast, silent countryside of Hunan was the site, the materials, of Mao's boyhood and adolescence.

At the age of eight, Mao began attending Nan'an Sishu elementary school, located a short distance from his home, and there received a traditional Chinese education. ${ }^{12}$. The masonry-timber structure had a yi ming liang an facade, similar to Mao's house, with a roofed entrance and flanking gables. While Mao's classroom was modest and dark, the building had some expensive materials, such as baked bricks and white plaster, which informed its public identity ${ }^{13}$ (Figure 7). Mao and his family also would visit the ancestral temple found just south of Nan'an Sishu (Figure 8). The building accommodated communal rituals and clan activities and, as such, included much-more-sophisticated ornaments. The facade took its shape from a four-poster pailou $^{14}$ with four red columns packing three white bays. Each bay was covered by

\footnotetext{
${ }^{10}$ Shaoshan did not have electricity until the 1950s.

11 The analysis of Mao's house comes from three sources: my own on-site observations; from Shaoshan Chorography Committee, Shao Shan Zhi [Shaoshan chronicle](1993), 307-308; and Shaoshan City Chorography, Shao Shan Shi Zhi, 149-150. For contemporary scholarship on the architectural material and techniques of Hunan traditional folk dwellings, see Wu Guozheng, Yu Hanwu, and Long Wanrong, "The building technique of traditional folk dwellings, taking the dwellings in Hunan as an example", Huazhong Architecture 25 (Nov. 2007):126-128; Yan Puhua, Chen Tao, and Liu Hongcheng, "Research on the apartment layout of traditional folk dwellings in Hunan," Chinese and Overseas Architecture (Aug. 2012): 49-51; Han Xumei. "Hu nan te se min ju yan jiu bi jiao" [A comparative study of traditional folk dwellings in Hunan], The Collected Works of the Contextual Architectural Cultural Forum (2005): 210-216; Luo, "Jian xi hu nan,"; Liu Wei, Xu Feng, and Xie Mingling, "" [The building technology of traditional folk houses adaptable to the central-north region of Hunan Province: Taking the ancient houses in Zhang Guying Village, Yueyang, as an example], Huazhong Architecture 27, (Mar. 2009): 172-175.

${ }^{12}$ For Mao's early activities, see Ross Terrill, 31-44 ; Jonathan D. Spence, Mao Zedong (New York: Viking, 1999), 1-15.

13 In ancient China, the building material and ornaments were closely correlated with the owner's social status. Official, religious, and public buildings always had more-expensive materials than civil residences.

${ }^{14}$ Pailou is a traditional Chinese architectural element, similar to an independent, highly decorated archway.
} 
layers of corbellings and flying eaves, with columns and beams decorated by sculptures such as dragons, cranes, elephants, and lions. The front door employed a pretentious semicircular arch, trying to resemble the front gate of a large building compound. In addition to the school and the temple, Mao and his mother would periodically visit local Buddhist monasteries as well. Such monasteries spoke of the eclecticism in local beliefs. One temple in Qingxi, for example, enshrined Guangong, Guanyin, and Shakyamuni, respectively, and even included a theater for leisure activities. $^{15}$

\section{Mao's Revolutionary Career and His "Sinification of Marxism"}

The description of Mao's living environment in Shaoshan delineates an ordinary peripheral place in rural Hunan. And Mao's adolescence appeared certain to continue this commonality. His experience to date had not strayed far from that of his father, hinting at the life of a landlord farmer. However, the dying of the Qing Dynasty provoked immense social unrest and, seemingly for the first time, humble Shaoshan was activated. The contemporary peasant revolts ${ }^{16}$ moved Mao to fight against the "ruling power" represented by his father, ${ }^{17}$ a posture escalated by his interaction with Western philosophy. ${ }^{18}$ As Ross Terrill depicts it, Mao became "a very Chinese kind of

\footnotetext{
15 The introductions of these local public buildings come from a combination of my own on-site observations and related literature. For information about Nan'an Sishu, see Shaoshan Chorography, Shao Shan Zhi, 310; and Shaoshan City Chorography, Shao Shan Shi Zhi, 150. For information about Mao's Ancestral Temple, see Shaoshan Chorography, Shao Shan Zhi,310-313, and Shaoshan City Chorography, Shao Shan Shi Zhi, 150-152. For information about the Buddhist temples, see Shaoshan Chorography, Shao Shan Zhi, 312-313, and Shaoshan City Chorography, Shao Shan Shi Zhi, 152-153.

16 The early 1900s saw several peasant uprisings in Shaoshan, including gelaohui (Fraternity Rally) at the turn of the century, the robbery riot in 1906, and the chidahu movement (Eat the Rich Family) in 1910. Nationally, the Taiping Rebellion would still have its influence. See Ross Terrill, Mao: A Biography, 10-11; and Snow, Xi Xing,, 96-97.

${ }^{17}$ In his conversation with Snow, Mao said his father was the ruling party, and his mother, he, and his brothers were the opposition party. Snow, Xi Xing, 93.

${ }^{18}$ Mao cited two influences to Snow: the book shengshi weiyan [Words of warning], written by Zheng Guanying in 1894, that he read and was impressed by; and a teacher who had studied in Japan and worked in an elementary school in Shaoshan. Ibid., 93-94.
} 
rebel in a very particular moment of historical change." 19

From 1910 to 1918, Mao left Shaoshan for schooling in Xiangxiang and the provincial capital, Changsha. After completing his education, he spent a year in Beijing absorbing communist ideology. He returned to Changsha in 1919, established the first Communist group in Hunan in 1920, and attended the CPC's First National Congress in Shanghai in 1921. In the years that followed, Mao worked as the CPC's representative to and led several peasant movements in Hunan Province. From 1923 to 1927, the CPC formed an alliance with China's Nationalist Party, the Kuomintang, and Mao assumed successive KMT posts, namely, organizing secretary, propaganda executive, and supervisor of peasant movements. When the KMT began to suppress communists in 1927, Mao declared that the CPC should begin military struggle against the KMT and he proceeded to lead the Autumn Harvest Uprising in Hunan and to found CPC military sites in Jiangxi Province. Despite once losing power in the early 1930s, Mao gradually rose through the ranks during the Long March and, after the CPC established itself in Shaanxi Province in 1935, seized absolute authority in the party. From there, Mao Zedong and the CPC commanded their soldiers to resist the Japanese imperialism and, later, KMT repression. He and his comrades founded the PRC in 1949. Mao was its first premiere. ${ }^{20}$

Much scholarship on the Chinese Communist Revolution has demonstrated that Mao Zedong's success in the CPC and in China owed much to his fusion of Marxist ideology and traditional Chinese revolutionary strategy. ${ }^{21}$ This regional

\footnotetext{
19 Terrill, Mao, 14.

20 “Mao Zedong," Wikipedia, last modified November 16, 2014, http://en.wikipedia.org/wiki/Mao Zedong.

${ }^{21}$ For some representative research on Mao's distinct approach in leading China's communist revolution, see Rebecca E. Karl, Mao Zedong and China in the Twentieth-Century World: A Concise History (Durham, NC: Duke University Press, 2010) ; Gao Hua, Hong taiyang shi zenyang shengqi de: yanan zhengfeng yundong de lailongqumai [On the red rose: The reasons and results of the rectification movement in Yan'an] (Hong Kong: Chinese University of Hong Kong Press, 2000); and Xu Yong and Xu Zengyang, "Zhongguo nongcun he nongmin wenti yanjiu de bainian huigu," [Reviewing the $20^{\text {th }}$-century studies of the Chinese rural and peasants issues in
} 
reinterpretation of Marxist ideology laid the theoretical foundation for Mao's

reconstruction of the CPC and China. In October 1938, Mao expounded on this

concept to other members of the CPC:

Being Marxists, communists are internationalists, but we can put Marxism into practice only when it is integrated with the specific characteristics of our country and acquires a definite national form[... .] For the Chinese Communist Party, it is a matter of learning to apply the theory of Marxism-Leninism to the specific circumstances of China. For the Chinese Communists who are part of the great Chinese nation, flesh of its flesh and blood of its blood, any talk about Marxism in isolation from China's characteristics is merely Marxism in the abstract, Marxism in a vacuum. Hence to apply Marxism concretely in China so that its every manifestation has an indubitably Chinese character, i.e., to apply Marxism in light of China's specific characteristics, becomes a problem which it is urgent for the whole Party to understand and solve. Foreign stereotypes must be abolished, there must be less singing of empty, abstract tunes, and dogmatism must be laid to rest. They must be replaced by the fresh, lively Chinese style and spirit which the common people of China love. ${ }^{22}$

Mao's localization of Marxist theory to China went a step beyond even this.

Examining the relationship between Mao's background and his unique appropriation

of communist thought, Gao Hua abstracts a phenomenon he calls the "Sinification of

Marxism":

[The Sinification of Marxism] intensively reflects Mao's fundamental understanding of and attitude toward the Marxist movements in China. It establishes the core of Maoist ideology[... . T The essential principle of Mao's Sinification of Marxism relies on his integration of one traditional legacy in Chinese history, the peasant rebellion, together with Marxist-Leninist theory of class conflict, military revolution, and the institutional structure of the CPSU (Communist Party of the Soviet Union). This integration produced a great modernized peasant revolution that was led by the CPC and aimed at overthrowing the KMT's governance[... .] The Sinification of Marxism opened the door for Chinese traditional elements to penetrate the CPC. Under its profound influence, the CPC, which had already been influenced by the customs of peasant rebellion, manifested itself with prominent peasantized characteristics. The double edge of the Sinification of Marxism was evident in CPC's future revolution [after the mid-1930s] and in the history of PRC. ${ }^{23}$

retrospect], Journal of Central China Normal University (Humanities and Social Sciences) (November 1999): 110.

22 This is a quote from Mao's report to the Sixth Plenary Session of the Sixth Central Committee of the Party in October 1938. Mao Zedong, "zhongguo gongchandang zai minzu zhanzheng zhong de diwei" [The role of the Chinese Communist Party in the National War], Marxist Internet Archive (Marxists. org), 2004, accessed November 17, 2014, https://www.marxists.org/reference/archive/mao/selected-works/volume-2/mswv2 10.htm.

23 Gao Hua, "hong taiyang”: 80. 
What distinguished Mao's rebellion from those before it was his exaltation of the peasantry, a fixture of Chinese culture, as the engine propelling the Revolution forward. And who better to make this case than Mao himself, his roots proudly fixed in rural Shaoshan. In the early phase of the Chinese Communist movement, however, this regional approach was heresy in the eyes of the founders of the $\mathrm{CPC}$, who favored a more universal approach. ${ }^{24}$ From 1920s to 1930 s, Mao took great pains to codify his regional "Sinification of Marxism" as he established his authority in the CPC. This assumed two forms, practical and theoretical. With the first, he applied rural Marxism by spearheading many remarkable enterprises, such as reconstructing the Red Army, founding militias in Jinggangshan, and leading the Long March. With the second, Mao tried to refashion Chinese Communist ideology on such that the emergence, rediscovery, and codification of the peasant society from which he himself sprang would occupy a significant position.

Mao's Touchstones: The Peasantized Revolution and the Rural Identity of Shaoshan

Mao's codification of peasant society in Chinese Communist ideology unfolded in three layers. First, Mao constructed an intimate consanguineous relationship between the peasant community and the philosophical framework of the Revolution by fixing the peasantry as one of the "specific characteristics" of the Communist movement. He assimilated the peasant rebels into his military troops, built his territories in the remote countryside, and openly pronounced the peasants an important subject in and instigator of the Revolution. The results of this approach

\footnotetext{
24 In the early phase of the Communist movement in China, the founders of the CPC including Chen Duxiu and Zhou Enlai followed closely the experience from Soviet Union and argued that the CPC should focus on city rather than rural areas, on working class rather than peasants. Mao's peasant movements in Hunan and Jiangxi province was criticized, for which Mao resigned his post. See Gao Hua, "hong taiyang”, 32-39.
} 
were undeniable: a full majority of CPC soldiers were peasants or closely connected to the rural community.

Mao's rural roots in Shaoshan were one prominent representative for this relationship between the CPC and the peasant community. To Mao, Shaoshan had and would continue to signal security, maternity, and unfailing clanship. He grew up in rural Hunan and "breathed in something of Hunan's lowland tradition [...] grew up a true son of Hunan." ${ }^{25}$ When he embarked on his revolutionary career, Mao "did not simply forget his family as thousands of young rebels of the era did [but kept] in touch with members of his family and [received] help from various of them." ${ }^{26} \mathrm{He}$ maintained a tight spiritual connection with his parents, his clan members, and his homeland fellows, and he would find refuge in Shaoshan during future political setbacks, in 1959 and $1966 .{ }^{27}$ By building this kindred relationship between the peasants and the Communist Revolution, Mao codified his own rural experience and made it a key ingredient of his political charisma.

The second layer of Mao's codification of the peasantry consisted less in romanticization or nostalgia and more in a realistic appraisal of the "specific characteristics" of Chinese society and its peasant constituents. Declaring that "no Investigation, no right to speak," ${ }^{28}$ Mao continually charged the $\mathrm{CPC}$ to

\footnotetext{
25 Terrill, Mao, 34.

${ }^{26}$ Ibid, 42.

27 After Mao participated in the CPC's early meetings in Shanghai, his idea about peasant movements was seen as heresy and he was suppressed by other Marxists. Faced with these difficulties, Mao returned to Shaoshan and lived there for months as a farmer in 1925. In 1959, the Chinese economy collapsed under the Great Leap Forward, and Mao launched a national field survey to investigate the situation. During this survey, Mao traveled to Shaoshan in June 1959. In the early 1960s Mao had severe disagreements with other party leaders because of the Great Leap Forward. In June, 1966, shortly before initiating the Cultural Revolution, Mao secretly visited Shaoshan and stayed there for weeks. It is said that while there, he prepared the final plan and sent several important orders for the revolution. See Ma Shexiang, Shao Shan Dang An [The Shaoshan archive](Beijing: Central Literature Press, 2001).

28 "No Investigation, no right to speak" was a quote and a representative viewpoint from Mao's article "fandui benben shuyi" (Oppose Book Worship) in May 1930. The work required Communists to use Marxist theory in social investigation in order to avoid dogmatism and subjectivism. See Mao Zedong. "Oppose Book Worship," Marxist Internet Archive (Marxists. org), 2004. Accessed Nov. 17, 2014.
} 
systematically study the conditions of the peasant class, an enterprise to which he himself had made groundbreaking contributions with such works as the Report on the Peasant Movement in Hunan in $1927 .{ }^{29}$ By this, Mao sought to uncover and publicize the rural blight suffered by the peasant and manifest these findings with solid materials and practical measurements. Their poverty now undeniable, their anger now justified, the peasants, Mao demonstrated, needed to mobilize to correct their condition, and the solution lay in revolution. He empowered not only the peasant class by building a rational foundation for the value to Chinese Communism, he empowered himself by seizing the authority to interpret the revolution.

The first two layers of Mao's codification of the peasantry involve how the peasantry should be treated and perceived by Chinese society writ large; the third layer addresses how the peasantry should treat and perceive itself. Proceeding from the assessments motivated by the second layer of codification, Mao and the CPC sought to remake the Chinese peasant class according to the communist dictates. This would begin with an effort to infuse the peasants with the spirit of revolution, an endeavor not at all unfamiliar to Mao. From the very onset of Mao's revolutionary career, rural Shaoshan offered him a place to experiment with his theories and incite rebellion. His success became a referential prototype for him as he made peasant mobilization the center of his agrarian revolution in the Chinese Soviet Republic, his

https://www.marxists.org/reference/archive/mao/selected-works/volume-6/mswv6_11.htm.; and "fandui benben zhuyi" (Oppose Book Worship), Baidu Wikipedia, last modified September 22, 2014, http://baike.baidu.com/view/431118.htm.

${ }^{29}$ Mao Zedong, 1927, hunan nongmin yundong kaocha baogao [The Report on Hunan Peasant Movement]. Mao Zedong. Selected Works of Mao Zedong, (Beijing: People's Publishing House, 1991). For scholarship on Mao's report, and its relationship with Shaoshan, see Wang Jianguo, "Hunan nongmin yundong kaocha baogao jige wenti de bianxi" [Analysis of several problems in the report on the Hunan peasant movement] Mao Zedong Thought Study (July 2008): 113-117; Womack, Brantly, “The Upheld Banner: The Development of Mao Zedong's Political Thought Observed from Report on the Peasant Movement in Hunan," Journal of Hunan University of Science \& Technology (Social Science Edition) (Nov. 2004): 23-34; Tan Luosong, Xie Wei, and Liu Jianqiang, "Maozedong yu shaoshan nongmin yundong" [Mao Zedong and the peasant movement in Shaoshan] Mao Zedong Thought Study (January 2012): 39-44; and Liu Jianqiang, "Shaoshan nongmin yundong yu hunan nongmin yundong kaocha baogao yiwen de fabiao." [Peasant Movements in Shaoshan and the publication of the report on the peasant movement in Hunan], Mao Zedong Thought Study (May 2012): 119-123. 
military campaigns during the Second Sino-Japanese War, and his People's Commune policy during the Great Leap Forward. ${ }^{30}$ The mobilization rested on a principle of always: the peasants must be always struggling, always yearning for progress, always united, always revolutionized. And to be revolutionized was to surrender unreservedly to communist ideology, expressed not only through military engagement, but also in economic production and cultural reformation in peacetime. While this grand ambition was not always achieved, it always occupied the center of Maoist ideology.

Mao's codification of his peasantized revolution manifested as a consanguineous relationship between the peasants and the Revolution; as a realistic recognition of the contemporary society and its peasant component; and as a Marxist-Leninist reinterpretation of the peasant rebellions. Shaoshan was the impeccable representative of the "peasantized" Communist Revolution, exhibiting the "specific characteristics of our country" and "definite national form" so essential to the Sinification of Marxism. And Mao's own background in Shaoshan was a fount of inspiration in this project. Mao drew from his life in Shaoshan to exemplify the intimate relationship between peasant and revolution, to highlight his awareness of and alarm at the conditions of the peasantry, and to affirm his ability to elevate them from these conditions - in effect, to accomplish the aims of the Revolution itself. In codifying this rural identity, then, Mao was also codifying his biography. He had become the subject of his own revolution.

After the Communist movement swept over China, the appreciation and

\footnotetext{
${ }^{30}$ In the Chinese Soviet Republic in and around Jiangxi province, Mao and the government established systematic policies of agrarian revolution aimed at destroying the dynastic social order and mobilizing the peasant class into Communist movement. During the Second Sino-Japanese War, the CPC announced relaxation in its agrarian policy in order to motivate more people, including land owners and rich peasants, to participate in the war. From 1958 to 1984, the PRC built a new type of peasant society, the People's commune, under its planned economy. The communes simulated the communist system of production and distribution. See "People's commune," Wikipedia, last modified Aug. 20, 2014, http://en.wikipedia.org/wiki/People's commune.; and "tudi geming," (Agrarian revolution), Baidu Wikipedia, last modified Oct. 23, 2014, http://baike.baidu.com/view/35443.htm.
} 
commemoration of Mao and his peasantized revolution emphasized on Shaoshan as well. From 1950s to 1960 s, the government cultivated a prominent commemorative culture to interpret Shaoshan's significance in Maoist historiography. Corresponding to Mao's three steps in codifying the peasantry, this interpretation of Shaoshan evolved through three different layers: one, the pastoral, kindred homeland of Mao and other revolutionaries; two, an agricultural district that reflected accurate characteristics of the peasant society; and three, a revolutionized community committed to the Communist movement.

These three facets in conceiving Shaoshan constituted to Shaoshan's distinct rural identity in the public imagination. This rural identity had a fundamental denotation as an agricultural society, with a rural setting, a peripheral status, and other distinguishing characteristics of peasant society. But it had two unique connotations as well: the intimate homeland for Mao and other comrades, and a revolutionized community engaged in Communist movements. And these three meanings of Shaoshan directly derived from Mao's definition of his peasantized revolution. The idea of the rural identity evolved together with Mao's theoretical construction of the "Sinification of Marxism" and finally developed into a remarkable concept in Maoist historiography. More broadly, as Mao and the CPC rebuilt the nation, the concept of the rural identity permeated the official ideology and deeply influenced the public imagination of the vast Chinese countryside.

\section{"To Shaoshan"}

After 1949, the CPC gradually nationalized the production of art and literature, and the government commissioned a great number of works to illustrate the success of the Communist Revolution. In this authoritarian background, one important concept 
in Maoist ideology, the rural identity of Shaoshan and other peasant communities, constituted a popular theme in art and literature. One important example from this group of works came from Mao himself, created when he returned to his hometown on June 25, 1959.

The trip was a turning point for Mao in his nationwide survey to measure the effects of the Great Leap Forward. As Mao traveled southward from China's northeast, he was persistently deceived by local officials, who sought to hide the agricultural setbacks of the Leap. ${ }^{31}$ In Shaoshan, however, he had more connections outside of the bureaucratic system. Here, Mao was able to marry his administrative objective to the renewing of kindred relations. He visited friends, hosted relatives, mourned over his parents' tomb, and bowed to a clanship tablet in an ancestral temple. He restored and utilized his threefold understanding of Shaoshan — as his ancestral homeland, an agricultural society, and a revolutionized community - to assist his survey. A conversation recorded in the Chronicle of Shaoshan from this time reveals his complex, multilayered appreciation of the village:

Mao (M) (in the farmhouse opposite to his home): "Is tu di lao guan ${ }^{32}$ alive in this house?'

A Local Resident (L): "No."

M: "What about shen liu hua?"

L: "Shen liu hua is my father. He is dead."

M: "What about si dao shi?"

L: "Dead long ago."

M (falls into a sentimental silence, and then looks around and asks): "How many families live here now?"

L: "It is the communal canteen now, and 13 families live here[... .]"

M: "How much rice does the field produce?"

L: "800 jin every mu."

M: "800 jin in one dao or two?"

L: "One."

M: "Don't fool around with me. I will thank god if [you] get 600 jin per mu."33

\footnotetext{
31 See Li Zhisui, The Private Life of Chairman Mao: The Memoirs of Mao's Personal Physician (London: Random House, 1994), 285-300.

32 tu di lao guan, shen liu hua, and si dao shi are nicknames for local people. Jin and mu are Chinese traditional measurements.

33 Ma S., Shao Shan, 75.
} 
With Mao's connection with the local community revived and the familiarity between himself and his comrades restored, he insisted on candor. Over time, some clan members forced Mao to confront the disaster raging beyond the ideological falsities perpetuated by his fellow politicos. ${ }^{34}$ The biography of Tao Zhu records that, in 1959, Mao clung to his belief of the official statistics "until he returned to Shaoshan, where farmers told him the truth." ${ }^{35}$ In the recollection of Mao's private doctor, Li Zhisui, “Mao's return to Shaoshan awakened him to reality, shaking him into a growing awareness that trouble was brewing. When he returned Wuhan, his previous ebullience had evaporated." ${ }^{36}$ The village of Shaoshan, once pioneering in organizing advanced People's Communes, was now the first place to dismiss communal canteens and abandon irrigation projects. ${ }^{37}$

Mao stayed in Shaoshan for two days. On the second night, he wrote a poem, "To Shaoshan," to commemorate the visit to his birthplace:

别梦依稀哭逝川, 故园三十二年前。(I used to weep in dreams, missing my beloved homeland which I parted from thirty two years ago.) 红旗卷起农奴戟, 黑手高悬霸主鞭。(When the red flag rolled up the peasant spear, when the doomed tyrant lashed his deadly whip.) 为有牺牲多壮志, 敢教日月换新天。(Only the sacrifice of lives speaks to our resolute aspirations, aspirations to reverse heaven and hell.) 喜看稻菽千重浪, 人物峥嵘变百年。(Behold the incessant waves of the endless paddy, the same as our people in an eternal progression. $)^{38}$

\footnotetext{
${ }^{34}$ I would posit that Mao's discovery of the truth was the result of a long period of observation in which his experience in Shaoshan was primary. Shaoshan's significance was also revealed by the fact that other top leaders such as Liu Shaoqi and Peng Dehuai came here to conduct field research.

35 Zheng and Shu, Taozhu Zhuan [A biography of Tao Zhu](Beijing: China's History of the Party Press, 2008), 271.

${ }^{36} \mathrm{Li}$, Private Life, 301-304.

${ }^{37}$ For Shaoshan's pioneering role in the Great Leap Forward campaign, see Wang Zhongjie, "Shao shan nong ye he zuo hua gao chao ji shi" [A record of the pinnacle of Shaoshan's agricultural cooperation], in Zai shao shan gong zuo de sui yue li [Days of working in Shaoshan], ed. Jiang Guoping (Beijing: China Federation of Literary and Art Circles Publishing Corporation, 2003), 388-391. For the dismissal of Shaoshan's communal canteen and irrigation projects, see Li, Private Life, 304.

38 The poem was published in the People's Daily on February 8, 1964. Later on, Mao changed the final sentence to '是使人民百万年' (people moving forward for millions of years). At the Lushan Conference, Mao consulted with others and revised the line again, to “遍地英雄下夕烟' (sunset illuminating the heroes who went across the fields for home after finishing farm work). See Ma S., Shao Shan, 88.
} 
We find here a profound illustration of the triple imagery Mao assigned to his birthplace. Mao shows a deep emotional engagement with his hometown in the first sentence, while the second sentence describes the local peasant movement. In the ending, Mao directly elevated the local community, the "incessant waves of the endless paddy," as "people in an eternal progression" as the main cast of his envisioned communist destiny. Rendering two aesthetic features of the village - an intimate homeland and a revolutionized countryside-Mao characterized and proclaimed Shaoshan's rural identity. The public conception of Shaoshan could not help but follow Mao's. And neither, it would shortly transpire, could that of artists and architects seeking to commemorate Shaoshan. Among the memorial projects pursued there, Mao's ancient farmhouse was the first and most important. 


\section{CHAPTER II}

\section{MAO'S OLD HOUSE: THE MEMORIAL CORE OF SHAOSHAN}

After the founding of the PRC, revolutionary sites such as Jinggangshan, Ruijin, Zunyi, and Yanan joined to form a national memorial system and produced a new type of monument, henceforth referred to as the spatial memorial. The disparate regions of the PRC were thus united by these spatial memorials into a nation-spanning museum dedicated to an everlasting archaeology of the revolution. With this, the CPC managed to feed the fire of revolution in a time of peace.

One example of the spatial memorial lies with Mao's pre-revolutionary beginnings: his rural birthplace, Shaoshan. It was in Shaoshan that Mao was radicalized, and the ruralism that he saw as an inherent, vital part of Chinese Communist ideology had, under Mao, cohered into a political culture within the CPC. Ever since Mao's cult of personality blossomed in the 1940s, his proud rural character had become a consistent subject in the commemoration of Mao and the revolution. A natural extension of this was the artistic and architectural interest suddenly taken in articulating the significance of Shaoshan to Mao's legacy.

In the early $1950 \mathrm{~s}$, however, the fascination with Shaoshan faded somewhat. ${ }^{39}$ The CPC sought to foster a collectivist spirit and, concerned that Mao's cult of

\footnotetext{
39 My brief review of Mao's cult of personality in these chapters is borrowed from from Daniel Leese Mao Cult: Rhetoric and Ritual in China's Cultural Revolution (New York: Cambridge University Press, 2011), 1-67. Other related materials include Liu Ji, "mao zedong tan geren chongbai: haishi chongbai wo haoyidian" [Mao Zedong on cult of personality: it is better to worship me], gongshi wang (www.21ccom.net), January 14, 2012, accessed November 17, 2014, http://www.21ccom.net/articles/lsjd/lsij/article 2012011351975.html.
} 
personality had grown too swollen, took measures to curb it. ${ }^{40}$ Mao remained at the center of Chinese politics, of course, but was not treated as its only actor. Likewise, Shaoshan, as if following the subtle shift in Mao's political fortunes, was still seen as an integral part of the memorial network but did not enjoy any preeminence over other sites. It was but one of many.

Nevertheless, Shaoshan owned a distinction that no other site could claim: it hosted and nourished Mao in his youth. And at the very center of Mao's youth, and the public conception of Mao's youth, was his family's farmhouse, the preservation of which became the core of Shaoshan commemorative culture in the period. The house not only possessed an intimate physical connection with Mao, but also witnessed as the seeds for the peasant revolt were sown. It was the first and the most important monument in Mao's birthplace, and all later local memorials evolved from and referred to this fundamental, albeit modest, historical landmark.

This chapter focuses on the historic preservation and interpretation of Mao's house. I will examine the historic preservation of Mao's house in Shaoshan, its exhibition curriculum, and its connection with Shaoshan's rural identity in Maoist ideology. Based on the case of Mao's house, I will define the concept of the spatial memorial in the PRC's national system of patriotic sites. From this, I will analyze some distinct mechanisms in the post-revolutionary memorial culture. More broadly, I will consider Shaoshan's memorial standing in the specific context of the early 1950s and explore the connection between politics and historic preservation in China.

Mao's Old House in Shaoshan Before and Around 1950

\footnotetext{
${ }^{40}$ Khrushchev's criticism of Stalin in 1956 also had profound influence on the CPC, motivating the restraint on Mao's cult of personality in China.
} 
Seven years after Mao departed for school in 1910, his father, Mao Shunsheng, added another 12 rooms to their family house. Their residence now had a patio on the left, surrounded by cowsheds, storage space, and a back entrance ${ }^{41}$ (Figure 9). Mao still returned home sporadically in the 1920s, and he successfully convinced many of his relatives to join the Communist Revolution. However, as soon as the Nationalists started suppressing communism, Mao and his comrades were pushed into a restless exile. He left his hometown, as a wanted criminal, in 1927. The Maos' properties, including the house, were confiscated and occupied by different families. ${ }^{42}$ When the Liberation Army took over Shaoshan in 1949, Mao's old house had long been dilapidated. The local government immediately put the house under official custody, and one of Mao's relatives was designated to guard the property. A contemporary record recalls that the house was vacant, with no furniture or decoration at all. ${ }^{43}$

Probably dissatisfied with the house's poor condition, local officials began construction on a new residence in 1950 . This new pavilion, apparently much more appropriate for the leader than a deserted farmhouse, could "accommodate Chairman Mao whenever he came back." 44 Workers had been hired and a site had been leveled, when the directors received a letter directly from Mao demanding that the project be called off (Figure 10). The officials did not realize that the old house carried for Mao a crucial political significance. It—and, symbolically, Mao's early experience—was to be revered and preserved, however primitive it was. The rural identity of Shaoshan, Mao seemed to insist, had to be maintained.

\footnotetext{
${ }^{41}$ For information about this expansion, see Shaoshan Chorography, Shao Shan Zhi, 307-308.

42 For information about the house before 1949, see Shaoshan City Chorography, Shao Shan Shi Zhi, 149; and Shaoshan Chorography, Shao Shan Zhi, 308.

43 The record was referred to in Ma S., Shao Shan, 6.

44 "Guanyu shaoshan maozedong tongzhi jiuju weihu he baohu gongzuo de jidian tihui” [Some experience with the preservation and restoration of Comrade Mao Zedong's Old House], undated, HPA (Hunan Provincial Archive) 213-1-738.
} 


\section{The "Authentic" Restoration of Mao's House}

With the reconstruction proposal now abandoned, dismissed as an "incorrect thought," ${ }^{45}$ the officials turned to preservation and restoration of the old house, which proved no less difficult than a new construction. A painstaking effort was made to effect a genuine revival of Mao's living environment. For example, in order to reproduce the exact original texture, workers had to cover the house's front eave with old tiles gathered from the back roof, which was invisible to visitors and paved with new tiles. Broken doors and windows were not replaced with new materials but with used ones appropriated from the houses of neighbors. Wooden pieces of furniture, unless too rotten to stand, were kept in use. Those necessary additions, such as loadbearing brick walls, were painted with clay to obscure their existence. Local people were employed as consultants to help ensure the authenticity of the appearance. Professionals were assigned to repaint the face of walls, change broken tiles, wax furniture, and maintain precautions for fire and lightning periodically. ${ }^{46}$

Under such meticulous restoration, the house managed to reproduce the original living environment of Mao. The program withdrew Shaoshan from the contemporary context, reenacted a historical moment, and asserted that its manufactured time-space was the specific one that bred Mao. As a result, the claimed authenticity not only restored the house as the real birthplace of Mao, but even transformed the building into an everlasting commencement of his life. Mao's relationship with Shaoshan was reconstructed along with the restored structure. The place was now able to claim itself as an eternal representation of the leader.

\footnotetext{
45 Ibid.

46 Ibid.
} 
However, a revival of the authentic built-environment seemed still less than satisfactory according to the official agenda. The house was not only the place where Mao was born, but also the site of his early peasant movements. The preservation and exhibition of the house involved not only Mao but the history of the revolutionary as well. The latter, would prove persistently problematic. Shifts in the political current forced alterations to the house in conformity to whatever party line was then the prevailing one; typically, this meant romanticizing the peasant workers. The propagandistic image projected frequently compromised the site's historical authenticity. For instance, the literature about Mao and his family in Shaoshan had always aggrandized their revolutionary consciousness while understating their economic capital. The Maos' wealth—several times over that of common peasants and thus excessive in the eyes of land reformers - was intentionally neglected, and the family was referred to as simply a "revolutionary family" or even as an "unsophisticated peasant family." ${ }^{47}$ Courtesy of these discursive devices, Mao's early experience was gradually assimilated into a revisionist history of the communist movement.

The material renovation followed a similar pattern. For example, in order to "more highly emphasize the austere life in rural Hunan," the Hunan Provincial Party Committee ordered the pines and cypresses surrounding Mao's house to be replaced by more inexpensive plants, such as bamboo and wild roses. ${ }^{48}$ In August 1964, the Committee ordered an introductory plaque to be relocated from the front of the house to the central hall, citing as its reason to "renew the [discursive] content of the room,

\footnotetext{
${ }^{47}$ For an introduction to Mao's family, see The Exhibition Pavilion for Comrade Mao Zedong's Old House, 1978; and Hunan Renmin Publishing House, Shao Shan..

48 "Guanyu shaoshan maozedong.".
} 
divert focus from the religious baldachin to the revolution." ${ }^{49}$ Although the government claimed it to be the authentic building where Mao was born and raised, the house went through these and other subtle alterations under the veil of preservation. In fact, in these rounds of restoration, the CPC renovated and codified the house according to its revolutionary ideology. Its rural appearance has thus gained an extra signification as part of a materialized discourse of communist history. Its identity and representative imagery were reinvented to illustrate an imagined a revolutionized countryside.

As a consequence, the historic preservation of Mao's house in fact transformed the house into a political symbol. On the one hand, the seemingly authentic restoration reproduced Mao's original living environment and made the house a conduit to Mao's boyhood. Ironically, by reviving a single, concrete period in Mao's life, the restoration challenged the bounds of time on Mao's behalf, and an ageless icon was thus created. Moreover, by reenacting a connection to Mao that Shaoshan and only Shaoshan could claim, the restoration afforded Shaoshan a cultural capital it was unaccustomed to. On the other hand, the alterations dictated by party propaganda reinterpreted the house and the village according to the official historiography. In its efforts to promulgate the image of Mao and his family as crude peasants stirred to revolution, the party not only distorted Mao's early experience but also rendered his living environment inauthentic. Still, these two strands of meaning generated a bipartite meaning for Shaoshan's rural identity: as a pastoral homeland and as a community of revolutionaries. After rounds of restoration, Mao's house stood as the material agent of the concept of the rural identity in Maoist ideology.

49 "bayue sanri gaunyu xiugai zhuxi jiuju menqian shuoming pai de han he shuo ming de huizhi" [Response to the report on changing the introductory plaque in front of the Chairman's Old House on August 3), August 19, 1964 : HPA 213-1-738. 


\section{Building a Discourse: Tour Guide, Exhibition, and Museum}

Along with the material preservation of Mao's house, the local government also undertook to tailor the historical narrative of Shaoshan. When the house became public property in 1949, the officials managed to control the interpretation of Mao's youth through the custodians that guarded the house. These custodians worked as fulltime, on-site doorkeepers and tourist guides. They were often simultaneously Mao's relatives and the CPC's members, which guaranteed their emotional fidelity and political reliability. ${ }^{50}$ The script of their tour guidance borrowed from the official propaganda and was polished by rounds of inspections and modifications. ${ }^{51}$

In addition to the tour, another type of narrative was the exhibition of Mao's experience and local revolutionary history. The first objects on display were the old furniture once used in the house, which were collected as part of the authentic restoration of the house in the early $1950 \mathrm{~s} .{ }^{52}$ As the collections continued to expand, local revolutionary history was regarded as an equally valuable theme. Antiques of Shaoshan's peasant movement such as weapons, banners, and built-environments were integrated into the exhibition (Figure 11). These newcomers, nevertheless, were not suitable at all for Mao's house. They were packaged as an independent show transferring successively through the Mao Ancestral Temple, Shaoshan Guesthouse,

\footnotetext{
${ }^{50}$ For examples of these custodians, see Ma S., Shao Shan, 3-8.

51 "Shaoshan maozedong tongzhi jiuju wenti jieda" [Answers to the questions about Comrade Mao Zedong's Old House in Shaoshan], July 5, 1963: HPA 143-1-311; "Maozedong tongzhi jiuju fuzhu chenlieshi shuoming koutou jieshao" [An oral explanation of the complementary exhibition of Comrade Mao Zedong's Old House], undated, HPA 143-1-311; and "Mao Zedong tongzhi jiuju chenlieguan" [The Exhibition Pavilion of Comrade Mao Zedong's Old House], in Shaoshan Maozhuxi Jiuju Chenlieguan Jiangjieci, Di'er Gao [Interpretative text of Shaoshan Exhibition Pavilion of Chairman Mao's Old House, second edition](Exhibition Pavilion of Comrade Mao Zedong's Old House, 1969. Collection of Changsha Library).

52 Gao Jucun, "Shao shan mao ze dong jiu ju chen lie guan xiu jian shi mo" [History of the construction of the Shaoshan Exhibition Pavilion of Comrade Mao Dedong's Old House], Literature of the Chinese Communist Party 4 (2006): 37.
} 
and Shaoshan School. ${ }^{53}$ The local government called for a permanent exhibition in March 1959. In October of that year, a one-story house was finally constructed for the collection. The building was located beside Nan'an Sishu, or Nan'an Lobby, and was intended as a small resort for rest after the visit to Mao's house. It was built rather expensively, using grey bricks, to a size of 400 square meters and divided into two parts, one for the exhibition and one for guests' relaxation. The exhibition had three sections: Mao's youth, local revolutionary history, and presents and inscriptions from the tourists. ${ }^{54}$

Nan'an Lobby was the first memorial museum in Shaoshan. It was also the first museum dedicated to Mao in the entire country. The staging of the exhibition was crucial for Shaoshan, since the village was itself a prime exhibition of the communist leader and the communist movement. However, the dualistic connotation of rural identity—as Mao's birthplace and the as a community of peasant revolutionariesalso yielded a divergence in the curatorial curriculum. On the one hand, Mao's house was treated as the village's unparalleled material core; on the other hand, the swiftly amassing collections engendered another discursive identity that centered on the collective peasant movement. The rural identity of Shaoshan, at least in the mid1950s, was embodied in two, inextricably bound groups of people: Mao the leader and the revolutionized masses.

\section{$\underline{\text { Mao's House as a Spatial Memorial }}$}

\footnotetext{
${ }^{53}$ For information on the initial exhibition and items featured, see Shaoshan Mao Zedong Memorial Museum Chorography Committee, Shao Shan Mao Ze Dong Tong Zhi ji Nian Guan Zhi [Chronicle of the Shaoshan Mao Zedong Memorial Museum](Changsha: Hunan Renmin Publishing House, 1999), 68; Chen Mingyu, "Guang fan diao cha zheng ji, bu duan feng fu guan cang" [Continuous investigation and expansion of the exhibition], in Periodical of Shaoshan Mao Zedong Memorial Museum 2 (Shaoshan: Shaoshan Mao Zedong Memorial Museum, 1994): 66; and Gao, "Shao shan mao ze dong," 37.

54 Gao, "Shao shan mao ze dong," 37; and Gao,"Shao shan mao ze dong tong zhi ji nian guan de you lai" [The origins of the Shaoshan Mao Zedong Memorial Museum], XiangChao (August 2006): 48.
} 
By the end of the 1950s, Shaoshan had established its solid position in the memorial landscape of China. The restoration of Mao's farmhouse reconstructed the connection with Mao's revolutionary career and, as such, rebuilt the commemorative subject of the ritual. The exhibition and Nan'an Lobby provided a local discourse around that subject and elevated Mao's early experience to a subject of worship. In this way, Shaoshan created its own structure of ceremony and asserted its integralness in the commemoration of the Communist Revolution.

Said commemoration began just after the PRC was founded. The government established a schematic national system of patriotic memorials that covered many sites of the Communist Revolution, such as Wuchang, Jinggangshan, Ruijin, Zunyi, Yan'an, and Xibaipo. Each of these sites adopted the mechanism of spatial memorial and celebrated different aspect of the revolution. For example, Jinggangshan was the first successful militia established by Mao, and its memorial constructions reserved many rustic barracks and battlefield to represent the new type of military revolution. Ruijin, the capital of Chinese Soviet Republic, preserved many old governmental buildings along with outdoor meeting places to reproduce the contemporary political atmosphere. In Yan'an, the government exhibited those modest cave dwellings, once inhabited Mao Zedong, Zhou Enlai, and other leaders, in order to recreate CPC's movements during the Second Sino-Japanese War. The system delineated every phase of the revolution and spawned a prominent commemorative culture in the country.

Within this network, Shaoshan occupied an irreplaceable position. Mao was born there as a nondescript child in an ordinary farmhouse. In that house, he grew up as "a very Chinese kind of rebel in a very particular moment of historical change," 55 and emerged as a resolute, outstanding communist who chaired a state. In this way, the

\footnotetext{
55 Terrill, Mao, 14.
} 
humble village of Shaoshan defined both the subject — the mobilized masses — and the object — a hero, the leader — in communist historiography, and Mao's house manifested an eternal transformation from that subject to that object, between ordinary people and distinguished heroes. Mao's living environment nurtured his transformation, and to preserve and exhibit the environment was to preserve and share that transformative force. Mao's house, together with other built-environments once sheltering communist revolutionaries, was then venerated as a special type of monument: the spatial memorial.

Numerous contemporary studies of memorial culture have suggested that too often, we picture monuments with a grandiose stereotype, and we always forget that a monument can be of any form. ${ }^{56}$ This is especially true of the spatial memorial. Unable to cast traditional monuments, which have "distinctive and permanent" forms with solid materials ${ }^{57}$ the fledgling, penniless government cultivated a unique type of monument with a much cheaper material: space. They kept the ancient builtenvironments of their past — rural farmhouses, cave dwellings, wild fields, and even wooden bridges - and managed to reenact the original time-spaces that accommodated their activities. These spatial memorials functioned as a time machine that situated visitors in an experiential montage of the Communist Revolution. In this way, the national system of spatial memorial transformed the country into a nationwide museum dedicated to an abiding archaeology of revolution. The assumed authentic experience of revolution pervaded the land, fostering a cultural mapping

\footnotetext{
${ }^{56}$ For scholarship on this topic, see James E. Young,"Memory/Monument," in Critical Terms for Art History, ed. Robert S. Nelson and Richard Shiff (Chicago and London: University of Chicago Press, 2003), 234-250; Wu Hung, Monumentality in Early Chinese Art and Architecture (Stanford: Stanford University Press, 1995); and Erika Doss, Memorial Mania: Public Feeling in America (Chicago and London: University of Chicago Press, 2010).

${ }^{57}$ Kirk Savage, Monument Wars: Washington, D.C., the National Mall, and the Transformation of the Memorial Landscape (Berkeley, CA: University of California Press, 2009), 6.
} 
beyond scientific topography and creating an experiential justification for the newly imagined community of the PRC. ${ }^{58}$

Two publications vividly illustrate the operation of the spatial memorial. The aforementioned 1959 pamphlet Shaoshan and another homonymic album, published in 1978, were both intended for people who could not actually go to the village. As the substitute for on-site touring, they attempted to reproduce the experience of the Shaoshan pilgrimage through photography and narrative, and thus, in the official propaganda, they imitated the operation of a spatial memorial. For example, the pamphlet, after presenting a detailed survey of Mao's house, its furnishing, and its environment, goes on to expound how these built-environments witnessed and commemorated Mao's greatness: he learned about agricultural society in this field; he studied revolutionary documents on that desk; he shared his clothes with poor people here beside this rock; he fought for toiling peasants there in that temple. ${ }^{59}$

The album enacts a similar, while more organic, process with the aid of photography. It acts as a movie camera that transports readers into an alternate timespace. A photographic portrait of the teenage Mao greets readers as a prologue (Figure 12). The camera, switching to his house, begins from a birds-eye view, then descends and pauses in front of the facade, and then gazes at the entrance (Figure 13, 14, 15). Entering the central hall, it regards the room carefully, with an annotation explaining that "this is the family hall which Comrade Mao Zedong shared with his neighbor" (Figure 16). After the central hall, the album leads readers to other rooms of the house, then to the field and the pond, and then to other local sites of the revolution. The annotation continues with stories such as "here Mao helped his mother cooking,"

\footnotetext{
58 Benedict Anderson, Imagined Communities: Reflections on the Origin and Spread of Nationalism (London: Verso, 2006), 5-6.

${ }^{59}$ For the stories mentioned, see Hunan Renmin Publishing House, Shao Shan, 5-7.
} 
"there he conversed with brothers and persuaded them into revolution," and "he organized one of the earliest and strongest quads in the house's attic," et al. ${ }^{60}$ (Figure 17, 18). In the end, the album pictures hundreds of pilgrims on the passionate while orderly march to the house ${ }^{61}$ (Figure 19).

These two publications exemplified what was, for the government, the ideal visiting experience. The commemoration mechanism in Mao's old house employed a unique material, space, to motivate and coordinate people's affection. Space surpasses other types of visual commemorative media — texts, paintings, sculptures - by its multidimensional sensory apparatus. Mao's house was built into a systematically codified space that conducted both verbal and nonverbal communication with its visitors. It became a cognitive map orienting people's sensations and thoughts to inspire a preoccupied ideological, exegetical, and behavioral pattern (Figure 20).

Moreover, the spatial memorial's experiential nature produced a seemingly authentic understanding of historical events due to its privileging of specific context. Partaking of the environment that once nourished Mao, visitors found themselves sharing the same decisiveness and resolve, talent for inspiring others, and destined greatness. A section of their lives was substituted with Mao's life, and they were transposed into the hero that enacted the revolutionary history. Through a genuine spatial experience, the spatial memorial manufactures a simulacrum of Mao for visitors to project themselves onto. The occupation of Mao's house, or a symbolic occupation of Mao's personal time-space, would prove a key component in national commemoration and mass mobilization.

Since the early 1950 s, the CPC had built a national system of spatial memorial to

\footnotetext{
60 Exhibition Pavilion for Comrade Mao Zedong's Old House, Shao Shan, 10-11, 17.

61 Exhibition Pavilion for Comrade Mao Zedong's Old House. 1978, 84.
} 
hold mass commemoration and mobilization. Shaoshan was a consistent member within these patriotic sites at the time while this consistency did not last long. The political vibrancy in the Soviet Bloc in the late 1950s influenced China profoundly and gave rise to some marked changes to Mao's cult of personality. Mao's Great Leap Forward also produced a new type of urban form to reconstruct Chinese cities. All of these initiatives inspired notable development in Shaoshan's memorial construction, which I will analyze in the next chapter. 


\section{CHAPTER III}

\section{COSMOPOLITANISM VS RURAL IDENTITY: URBAN PLANNING DURING}

\section{THE GREAT LEAP FORWARD}

The radical transformation of Shaoshan's commemorative style may be attributed to the continued forward march of Mao Zedong's cult of personality. While in the early 1950s, Mao had seemed amenable to the CPC's push to curb the worship of individual leaders in China, he witnessed as the death of Stalin cast much of communist Eastern Europe into political upheaval and brought about the wholesale discrediting of Stalinist philosophy and defamation of Stalin personally. To prevent a similar circumstance from ever taking root in China, Mao deployed new movements on behalf of his own cult of personality. Beginning in 1957, Mao frequently asserted that the cult of personality was a helpful and even necessary phenomenon during the interim between the socialist and communist eras, a view not shared by other top leaders such as Liu Shaoqi and Deng Xiaoping. ${ }^{62}$ The Great Leap Forward movement, which Mao mobilized between 1958 and 1960, served to promote Mao's cult and extend his authority. Beneath the guise of economic policies, the movement was in fact highly political in its essence, a project aiming to reconstruct the nation according to Maoist revolutionary ideology. And the 1959 Lushan Conference, intended merely as an informal party discussion about the Great Leap Forward, only consolidated

\footnotetext{
62 In March 1958, Mao declared his support for his cult of personality in public in Chengdu Meeting. His attitude influenced other leaders, some of whom responded to Mao's comment and made compliments to Mao. This was the first time in official records that Mao openly backed his cult of personality after the PRC was founded. See Liu, "mao zedong tan geren chongbai."
} 
Mao's power: Mao suppressed opposition in the committee by forcing party leaders to identify their factional standing and arresting supposed dissenters. This, in turn, recast Mao's leadership on both national and regional levels. ${ }^{63}$

Mao's political campaign prompted many cities to adopt radical urban plans and building programs to represent the socialist development of the new nation. These designs indicate that a distinct architectural type was emerging in Chinese memorial landscape in the late 1950s. In 1959, the central government raised the Ten Great Buildings in Beijing, the most prominent examples of this architectural type.

Following the Ten Great Buildings, a considerable number of squares, museums, and urban expansions in a similar style were proposed across the country. At the pinnacle of the Great Leap Forward, these building types and styles birthed an influential cosmopolitan tradition in architecture.

This chapter explores Shaoshan and its urban plans against the backdrop of the Great Leap Forward. In the early phase of this political movement, the poor economy in rural Hunan strictly limited building activity; thus, Shaoshan remained secluded on the remote periphery of China and retained its rural identity. ${ }^{64}$ This suited the cult of personality Mao was promoting: the leader's old, rustic house was at the heart of the popular conception of Mao and seemed to discourage the grandiose expressions associated with the emerging cosmopolitan style. However, with the advent of the

\footnotetext{
63 The announced objective of the Lushan Conference, which began on July 2, 1959, was to review the early outcomes of the Great Leap Forward. Mao also intended to use the conference to restrain leftist tendencies and enforce a moderate course during the period. However, faced with criticism by the conservative Peng Dehuai, Mao fought back, imprisoning reactionaries and radicalizing the Great Leap Forward. Those jailed included Zhou Xiaozhou, the First Secretary of the Hunan Provincial Party Committee, who had governed Shaoshan. See Li Rui, Lu Shan Hui Yi Shi Lu [Record of the Lushan Conference](Zhengzhou: Henan Renmin Publishing House, 1993); and Zhou Xiaozhou Chorography Committee, Zhou Xiaozhou Zhuan [A biography of Zhou Xiaozhou](Changsha: Hunan Renmin Press, 1985), 58-70.

${ }^{64}$ Before the Lushan Conference, the governor of Hunan Province, Zhou Xiaozhou, seemed uneager to refurbish Shaoshan. From 1949 to 1959, new buildings were limited to some hotels and governmental and civil buildings instead of elaborate memorials. For Shaoshan's construction and economy during the Great Leap Forward, see Hunan Sheng Shaoshan Qu Guomin Jingji Tongji Ziliao: 1969-1979 [Statistics of the national economy in the Shaoshan District, Hunan Province: 1969-1979], 1980; and Statistical Bureau of Shaoshan District, Xiangtan City, Xiangtan Shi Shaoshan Qu Guomin Jingji Tongji Ziliao.
} 
Great Leap Forward, the local governors considered Shaoshan's urbanization a political investment and put forward building plans for the village. These plans not only reflected the national trend in memorial construction in China but also manifested the pursuit of a new monumental form to represent Mao in the new era. This chapter analyzes these urban plans, their political background, their exploration for monumental forms, and their relationship to Shaoshan's innate rural identity. My research reveals that despite the deep influence of the cosmopolitan style, evidenced in the Ten Great Buildings, Shaoshan's own urban plan was rooted in the district's inherent rural identity and aimed at a regional pattern. My major findings are twofold: First, the tension between the cosmopolitan style and Shaoshan's regional approach reflected the interaction between center and periphery in the PRC's power structure. Second, Shaoshan's search for anew monumental style provides a deeper understanding on its unique standing in Chinese memorial landscape.

\section{$\underline{\text { An Agreement between Zhang Pinghua and Tao Zhu }}$}

In the late 1950s, local officials sought to support the rise of Mao's cult by upgrading Shaoshan. For example, the local village landscape was dramatically renewed by the new provincial governor, Zhang Pinghua. ${ }^{65}$ At the Lushan Conference, Mao nominated Zhang, an activist who relentlessly backed him during the political turmoil, as the new First Secretary of the Hunan Provincial Party Committee. In October 1959, two months later, the first formal museum in Shaoshan, the Nan'an Lobby, was opened. When the central government closed the Nan'an

\footnotetext{
65 Zhang Pinghua (1908-2001) was born in Hunan and entered the CPC in 1927. Mao promoted him to governor of Hunan Province in September 1959. In 1977, he was nominated as the director of the Central Propaganda Department by Hua Guofeng. Zhang was an active member in a number of Mao's campaigns including the Great Leap Forward, the Lushan Conference, and the Socialist Educational Movement. For Zhang's activities during the Lushan Conference, see Zhang Pinghua, Zhang Pinghua Huiyilu [Memoir of Zhang Pinghua] (Changsha: Hunan Renimin Press, 1989), 101-108; and Li, Lu Shan, 176-177, 206, 226, 254-256.
} 
Lobby for economic reasons in April $1961^{66}$, Zhang ordered Shaoshan to "build a [new] exhibition hall, in which visitors would have something to see, for two or three hours. ${ }^{67}$ In response, the Hunan Provincial Party Committee established a new department, the Shaoshan Administration, to take charge of all memorial construction and commemorative rituals of the village. ${ }^{68}$ In October 1962, the second memorial museum, the Shaoshan Exhibition Hall, formally debuted (Figure 21). Revived from a cultural center adjacent to the Mao Ancestral Temple, the compound had two houses divided into four rooms. Two rooms held the exhibition Comrade Mao Zedong's Early Years and Revolution. Another housed the exhibition Comrade Mao Zedong Leading the CPC in the Chinese Democratic Revolution. The last room was left for visitors to rest, sign their names, and make comments. ${ }^{69}$

This new exhibition focused conspicuously on Mao himself. The local people's revolution, on the other hand, was either integrated into Mao's biography or briefly appended to the end, since it was "not appropriate to be independent or parallel [with Mao's story]."70 Moreover, besides Shaoshan, the narrative included stories in big cities and during the Democratic Revolution. The officials were obviously addressing the more-cosmopolitan achievements of Mao, such as cofounding the CPC in Shanghai and establishing militias in Jinggangshan. Shaoshan now tried to break through the circumscription of its rural identity and expand its representative

\footnotetext{
${ }^{66}$ Until 1961, the Chinese economy struggled under the Great Leap Forward. As a result, Mao ceded his position of National Chairman to Liu Shaoqi, who ordered widespread field surveys to investigate the economic and social situation. Liu himself went to Hunan, Shaoshan included and demanded that the Nan'an Lobby be rebuilt as a residence for farmers. Later, during the Cultural Revolution, this reconstruction was named a criminal act.

67 "Guanyu shaoshan chenlieshi de wenti xiang shengwei de qingshi baogao ji Qin Yuping pishi” [Report to the Provincial Party Committee about Shaoshan Exhibition Hall and the comment of Qin Yuping], January 1, 1962, HPA 143-1-252; and Gao, "Shao shan mao ze dong," 48.

68 See Wen Yaodong, "Chronicle," xianxia shaoshan wang (www.txssw.com), September 29, 2009, ccessed Sept. 17, 2014. http://www.txssw.com/newsssglj/dashiji/Index.html

69 "Guanyu shaoshan chenlieshi”; Gao, "Shao shan mao ze dong," 48; and Gao,"Shao shan mao ze dong tong," 37.

70 "Guanyu shaoshan chenlieshi."
} 
meaning. However, this proved to be a difficult task, since Shaoshan possessed one and only one memorial core: the old, rural farmhouse. This material construction and its inherent characteristic proscribed Shaoshan's rural identity. To elevate its representative standing would require new constructions, which, in fact, were soon put on the table.

In November 1962, Tao Zhu, an important advocate for Mao at the Lushan Conference and now the governor of the Central-South Bureau of the CPC (which included Zhang's Hunan Province) ${ }^{71}$, visited Shaoshan, escorted by Zhang. ${ }^{72}$ Over their trip, Tao and Zhang quickly agreed that Shaoshan needed fresh constructions to supplement, but not supplant, the old, rustic buildings. According to records, Tao emphasized a comprehensive development of regional tourism "to provide tourists something to see, to buy, and somewhere to eat, to live, and to play." Zhang, on the other hand, focused more on a new scale of construction, especially of the museum, which he criticized as "too small" and argued that "We need to build a bigger one. Of course not too big." 73

The material construction of Shaoshan was actually the symbolic representation

\footnotetext{
71 The Central-South Bureau of the CPC was the party administration that mediated central and provincial affairs in southern China. Its leader governed six provinces, namely, Henan, Hubei, Hunan, Jiangxi, Guangxi, and Guangdong, and had more power than provincial secretaries such as Zhang Pinghua. See "Da xingzheng qu" [Large administrative area], Wikipedia, last modified February 19, 2014, http://zh.wikipedia.org/wiki/\%E5\%A4\%A7\%E8\%A1\%8C \%E6\%94\%BF\%E5\%8C\%BA.; and "Zhong nan ju" [Central-South Bureau of the CPC], Baidu Wikipedia, last modified December 20, 2013, http://baike.baidu.com/view/4791893.htm.

72 Tao Zhu (1908-1969) was born in Hunan and entered the CPC in 1926. He was a commander in Lin Biao's Northeast Field Army, and Mao later appointed him to preside over Guangdong Province. During the Lushan Conference, he vocally backed Mao and was subsequently named the leader of the Central-South Bureau of the CPC. In 1966, Tao was promoted to director of the Central Propaganda Department, the vice premier of the State Council, and a member of the Standing Committee of the CPC's Political Bureau. Because of his conservative policy and his conflicts with Jiangqing (who was supported by Mao), Tao was put in prison and died soon thereafter. For Tao's experience at the Lushan Conference, see Zheng and Shu, Taozhu Zhuan, 279-287; Li, 1994, 308-321; and Li, Lu Shan, 19-20, 83-84, 154, 177-178, 199-207, 211. For Tao's trip to Shaoshan, see Zheng and Shu, Taozhu Zhuan, 42; and Gao, "Shao shan mao ze dong," 48.

73 Although my understanding of the materials points to a consensus of Tao and Zhang,There are contradictory records about which leader first proposed the new museum for Mao. For two accounts that credit Tao with proposing the museum, see Shaoshan Chorography, Shao Shan Zhi, 324; and Shaoshan Mao Zedong, Shao Shan Mao Ze Dong, 59. For an account that credits Zhang, see Gao, "Shao shan mao ze dong," 37-38; this source cites "Guanyu shaoshan chenlieshi.". For an account that credits Hua Guofeng, then the leader of Shaoshan, see Ma S., Shao Shan, 176-177.
} 
of Mao as a great leader. For Tao and Zhang, the project offered two important opportunities: one, to invest in Mao's cult of personality and thereby advance their standing; two, to claim authority over public artistic interpretations of Mao. To capitalize on these opportunities, however, necessitated a cosmopolitan makeover of Mao's humble birthplace or, at the very least, a modern repackaging of its rural identity.

After Tao and Zhang put forward their arguments for change, the local government soon responded with a detailed proposal. In May 1963, the Propaganda Department of the Hunan Provincial Party Committee reported:

As a revolutionary memorial site of importance to the country and also to the world, Shaoshan needs construction commensurate to its status. This calls for comprehensive, large-scale, and long-term planning[. . . . However, in consideration of the current economy, we should focus first on urban planning, beautifying the environment, and the exhibition project rather than expensive constructions[....] We propose to build a new museum this year or next year[.... .] We plan to ask the Central-South Bureau of the CPC and the central government to send professionals for more guidance. ${ }^{74}$

The proposal briefly mentioned an urban design that combined Tao's and Zhang's ideas but did not explicitly detail constructions, instead addressing the possibility of an upgraded exhibition in Shaoshan. It offered three potential themes for the exhibition: Mao's childhood and youth in Shaoshan; his entire early life, spread over several provinces; and his lifetime biography. The first theme, limited to a small period of Mao's evolution, would retain Shaoshan's rural identity. In contrast, the third one, spanning Mao's life, would encompass his full political meaning independent of time and space, diminishing the particular character of Shaoshan in the representation. For Shaoshan in 1963, the first plan appeared too conservative, and the

\footnotetext{
74 "Guanyu shaoshan maozedong tongzhi jiuju de jiben jianshe he chenlie gongzuo de qingshi baogao" [Report on the construction and exhibition of Comrade Mao Zedong's Old House in Shaoshan], May 11, 1963, HPA 143-1252.
} 
third one appeared too radical. The officials chose the second, eclectic program, the one that would cover several provinces and paradoxically "[respect] Shaoshan's regionality while not confined in the village." 75

\section{$\underline{\text { Two Urban Plans: Jin Zeguang and the Shaoshan Administration }}$}

At the end of its proposal, the Propaganda Department recommended that the memorial constructions be a collaboration between Zhang's Hunan Provincial Party Committee and Tao Zhu's Central-South Bureau of the CPC. ${ }^{76}$ In August 1963, Tao Zhu sent Jin Zeguang, one of the chief architects at the Landscape Design Institute of Guangzhou, to assist in Shaoshan's urban planning. ${ }^{77}$ Jin followed Tao's commitment to tourism and to providing "something to see, to buy, and somewhere to eat, to live, and to play," he proposed a master plan that culminated, respectively, in sightseeing, souvenirs, food, accommodation, and recreation.

At the end of the proposal, Jin offered two different construction plans. ${ }^{78}$ Plan A suggested turning the village into a huge garden adorned by memorials. Forests would be reformed according to horticultural study. Natural ponds would be turned into enjoyable resorts. Architectural projects would rely on restoration and expansion of extant buildings. A stele and a small park would be built beside Mao's old house to establish a circulating route for tourists. Other tourist sites, such as the Nan'an Sishu and the Shaoshan School, were also on the list of restorations. The current Shaoshan Guesthouse and a forthcoming museum would serve as the two main areas of

\footnotetext{
75 Ibid., 2. The Chinese texts reads, "ji tuchu le zhongdian, you bu xianyu shaoshan."

76 Ibid., 3.

77 See Gao, "Shao shan mao ze dong," 49; Hu Qingpo, "Shaoshan maozedong jiuju chenlieguan zenyang jiancheng de" [How the Exhibition Pavilion of Mao Zedong's Old House in Shaoshan was constructed], Across Time and Space (July 2001): 26.

78 "Guangzhoushi jiansheju zong gongchengshi Jin Zeguang tongzhi guanyu shaoshan guihua yijian de qicao" [Draft of the urban planning of Shaoshan by Jin Zeguang, chief engineer of the Guangzhou Construction Bureau], August 1963, HPA 213-1-651.
} 
hospitality. The Guesthouse, covered by greens, would have a fountain and an artificial hill upon its gate. In front of the guesthouse, a forest square would be built with a 1000-square-meter auditorium to the south. The museum would incorporate a photo studio, a gift shop, a restaurant, and a hotel. Of the museum's architectural style, Jin proposed that its layout and decorations be modeled on Chinese gardens, with seven decentralized exhibition rooms covering 1500 square meters and surrounded by trees. ${ }^{79}$

Plan A makes clear that Jin was trying to limit artificial constructions so as to preserve the natural environment. He showed deep respect for Shaoshan's rural identity by insisting on the centrality of Mao's house, restricting new memorial constructions, and creating a pastoral landscape. The modifications gesturing at cosmopolitanism were on a conservative scale, and the proposed square, auditorium, and museum shared a rural character. The tour of Shaoshan would be personally introspective rather than publicly didactic. The atmosphere would not be especially charged with politics but rather with history and nature. The reinterpretation of the rural identity in Jin's Plan A, in sum, would yield a pastoral and romantic landscape.

Plan B, on the other hand, was much more radical. It planned to raze the Shaoshan Guesthouse and all surrounding buildings and replace them with a long rectangular plaza, 100 meters long and 20 meters wide. At the center of the square, a bronze statue of Mao would be erected, flanked by a museum and an auditorium. The two buildings would be massive in size, with a similar, grandiose style and symmetric composition. Other public buildings, such as hotels, restaurants, and a photo studio, would unfold one after another beside the museum and the auditorium. The long

79 Ibid. 
square would thus present with a continuous facade centered on Mao's statue. In addition, there would be two large parterres, one at each end of the square. ${ }^{80}$ The composition of the square, the statue, and the buildings would radically change Shaoshan's environment, challenge its rural identity, and bring forth an urban center no less magnificent than that of any big city. Plan B thus actually anticipated a cosmopolitan memorial city beyond Mao's primitive farmhouse.

However, despite its grand scale, Plan B was in fact unsophisticated and even naive from a practical perspective. As conceived, its visual impact would come from an unabridged vision of the continuous facade along the square, an imagined front view in architectural drawing. When approached in reality, such a visual effect requires the viewer to stand far away from the facade, implausible for anyone walking along a narrow square. Jin himself seemed to be less fond of Plan B. His description of Plan B, compared with that of Plan A, was terse, and he even repeatedly hinted that Plan B would take much more labor and money while producing a cramped layout and a confusing function while demanding unnecessary commuting. ${ }^{81}$ In contrast, the proposal was laudatory of Plan A.

In fact, it is reasonable to conjecture that Plan A was the original plan that Jin Zeguang brought from Guangdong. Government documents disclose that when Jin accompanied local officers on site surveys, they "discussed several plans and had different ideas." 82 Plan A’s meticulous detail, professional landscape design, and consistent emphasis on tourism all speak to Jin's architectural education and to Tao Zhu's concept of a tourist city. Plan B, on the other hand, probably emerged from Zhang Pinghua's belief in large scale, which was taken up by local officials and

\footnotetext{
80 Ibid.

81 Ibid.

82 See Gao, "Shao shan mao ze dong," 49.
} 
interposed in Jin's writing. It was a matter of course that the native government was much more anxious about upgrading Shaoshan's material and discursive stature. Nevertheless, the contest between Tao's and Zhang's imaginings of a cosmopolitan Shaoshan deepened when expressed in professional designs. This disagreement would prove a persistent keynote in the later urban planning and architectural construction of the village.

Even though Jin answered local requirements by adding a Plan B, the native government still seemed unsatisfied with his proposal. The Shaoshan Administration submitted their own city plan to the Hunan Provincial Party Committee in October 1963. ${ }^{83}$ This “Report of the Ten-Year Plan on Shaoshan's Construction” went far beyond Tao's conception, committing to lifting Shaoshan to cosmopolitanism in every sense. Unlike with Jin's program, the plan offered a comprehensive scheme based on ambitious short-term economic development. Shaoshan's agricultural production, to increase three times in ten years, would involve grain, cash crops, fruit, and tea; other businesses implicated in this plan included animal husbandry, fishery, and forestry. New dams and reservoirs would be built, and an electrical grid would course through the village. Mechanization would be partially, if not wholly, achieved, and road networks would connect Shaoshan to surrounding towns. The entire plan would require governmental funding as high as 12 million yuan. ${ }^{84}$ Clearly, the local officials envisioned an urban center in the future. Shaoshan's move to cosmopolitanism was, to them, just a matter of time.

As to the architectural appearance for a cosmopolitan Shaoshan, the officials seemed neither prepared nor professional enough to answer that question. They

\footnotetext{
83 "Guanyu shaoshan jianshe shinian guihua de baogao" [Report of the Ten-Year Plan on Shaoshan's construction], October 15, 1963, HPA 213-1-651.

${ }^{84}$ Ibid., 8 .
} 
offered four different construction plans that, while united in envisioning a centralized or linear building arrangement, were severely lacking in detail. The first of these plans was nothing more than an abbreviated copy of Jin's Plan B. The second proposed to expand the Shaoshan Guesthouse and put the museum and the auditorium beside it to make "the buildings centralized." 85 The third one suggested juxtaposing the museum, the auditorium, and a hotel outside of the col as another tourist center apart from Mao's house. The fourth proposed raising the museum and the auditorium beside the Mao Ancestral Temple and the Mao Jian Temple to condense the space between these eminent structures. ${ }^{86}$

Of the architectural form, the Administration made no reference to any gardenlike layout, decentralized volumes, or preservation of the natural environment. Their only mention of artistic style was a vague reference to a "large-scale, pleasing form." 87 The persistent emphasis on size mirrored Zhang's comment on his prospective museum, cited earlier: "This [the Shaoshan Exhibition Hall] is too small. We need to build a bigger one." 88

Despite their unpracticality and insubstantiality, the construction plans did reveal a remarkable brazenness in their vision of how to publicly commemorate Mao. In the eyes of local officials, these designs suggest, Shaoshan's rural identity meant nothing. Its representative core would undergo "large-scale" modernization to enact massive mobilization. Regional architectural styles would be replaced by some "pleasing form,” one certainly much more imposing. Shaoshan's inherent rural identity was facing the challenge of cosmopolitan obliteration.

\footnotetext{
85 Ibid.

86 Ibid., 7-8.

87 Ibid., 7.

88 "Guanyu shaoshan chenlieshi."
} 


\section{Option A: Monumental Forms from the Cosmopolitan Style in Beijing}

A clear embodiment of this threat lay in the construction proposal for Zunyi, ${ }^{89}$ which, like, Shaoshan, was momentous within Mao's background and, therefore, partook of the ongoing Mao hagiography. ${ }^{90}$ The proposal, made in 1959, suggested rebuilding Zunyi into a city of monuments, with diverse architectural styles (Figure 22). Figurative sculptures of Red Army soldiers would be built in the outskirts. Homes cast in modernist styles would advertise socialist development. The most significant project of the memorial system, the Memorial Pavilion of the Zunyi Meeting, would occupy the city center (Figure 23, 24). The building would have a symmetrical layout with three juxtaposed, massive volumes in the center. At the ends of this composition, two far-reaching colonnades would unfold, bracketing a large square in front of the building. The style would be new and innovative, combining neoclassic principles, modernist austerity, and simplified traditional ornaments. Vertical lines would cover the central volumes with a big party emblem on the facade. A large statue of Mao would stand in the square in front of the building. The use of spacious square, figurative statues, and a symmetrical composition all spoke to the architectural proposal in the Ten-Year Plan of Shaoshan's Construction. The grand Memorial Pavilion of the Zunyi Meeting offered a potential prototype that met Shaoshan's vision of a memorial with a "large-scale, pleasing form."

In fact, the search for architectural monumental form in a "large-scale, pleasing form” was a universal quest for contemporary Chinese architects. Over this pursuit, architects had experimented with a variety of styles. The most remarkable examples

\footnotetext{
${ }^{89}$ Zunyi was the setting of a meeting that established Mao's leadership in the CPC at the beginning of the Long March.

${ }^{90}$ Regional Urban and Rural Planning Office in the Architectural Science Research Institute, "Zunyi shi de jinian tixi guihua" [Memorial system planning for the city of Zunyi], Architectural Journal 11 (1959): 10-12, 22.
} 
of these experiments stood in Beijing, from which Zunyi probably borrowed the concepts of the square and the colonnade. In 1958, which marked the pinnacle of the Great Leap Forward and the tenth anniversary of the PRC, the central government announced plans to reconstruct Tiananmen Square and build the Ten Great Buildings in Beijing. ${ }^{91}$ The whole project, concentrating money, materials, and professionals from across the country, was finished within one year.

Commenting on the Ten Great Buildings, Wu Hung remarks that they "can be considered political monuments and 'exhibition architecture' owing to their inherent symbolic and ceremonial tasks, their strategic locations in the capital and their expositional architectural style." $" 92$ In fact, this "exhibition architecture" exemplified a unique typology of memorial buildings in Communist China. Architectural business in China had undergone the same nationalization process as landscape painting. Architects, now functioning as cultural instruments, must provide a unanimous representative form in constructions that exhibited "the superiority of the socialist system. ${ }^{.93}$ A number of architectural styles were attempted with this aim in mind, but political activists invariably pronounced these attempts ideological failures. For the Ten Great Buildings in 1959, architects had to define an innovative monumental style

\footnotetext{
91 Tiananmen Square was built from one part of the Forbidden City with the Monument to the People's Hero in 1954. In 1958, the CPC's Central Committee decided during the Beidaihe Meeting to expand the square and build the Ten Great Buildings in Beijing, to celebrate the Great Leap Forward. From then on, Tiananmen Square was one of the biggest squares in the world, with a length of 880 meters and a width of 500 meters. The Ten Great Buildings include the Museum of Chinese History, the Museum of Agriculture, the Military Museum, the Cultural Palace of the Nationalities, the National Gallery of Art, the Great Hall of the People, the Beijing Train Station, and three guesthouses for foreign leaders, overseas Chinese, and minority Chinese. For an introduction to Tiananmen Square and the Ten Great Buildings, see Wu, 2005; "Tiananmen guangchang" [Tiananmen Square], Wikipedia, last modified June 14, 2014,

http://zh.wikipedia.org/wiki/\%E5\%A4\%A9\%E5\%AE\%89\%E9\%97\%A8\%E5\%B9\%BF\%E5\%9C\%BA\#.E5.8E.86 E5.8F.B2.E8.AE.8A.E9.81.B7.; "Beijing shida jianzhu" (Ten Great Buildings in Beijing), Wikipedia, last modified May 22, 2014,

http://zh.wikipedia.org/wiki/\%E5\%8C\%97\%E4\%BA\%AC\%E5\%8D\%81\%E5\%A4\%A7\%E5\%BB\%BA\%E7\%AD \%91; and Liu Kuo and Cao Zhiyu, "1958-1959: yinian jiancheng 'shida jianzhu” [1958-1959: Ten Great Buildings completed in one year], Ministry of National Defense of the PRC (www.mod.gov.cn), June 27, 2011, accessed September 5, 2014, http://www.mod.gov.cn/hist/2011-06/27/content 4248227.htm.

$92 \mathrm{Wu}, 2005,108$.

93 Zhao Dongri, “Tiananmen guangchang” [Tiananmen Square], Architectural Journal Z1 (1959): 18.
} 
on their own. ${ }^{94}$ A new artistic language had to be found to represent the unprecedented success of socialist development.

The answers to this quest proved varying, with architects of the Ten Great Buildings employing not one single form or lifting from one single influence but, for both, a multiplicity thereof. The buildings are not limited in time or space but "[adopt] essence from the past and the present, from the East and the West." In the makeup of the buildings, numerous stylistic sources--Chinese imperial traditions, Soviet neoclassicism, and modernism--were references for designs. ${ }^{95}$ They had no uniform or systematic order in common, whether with overall profiles or ornamental details.

One the other hand, the designs of the Ten Great Buildings were closely supervised by the central government, which managed one distinctive exhibition feature in all of the buildings. The design of the architecture integrates different traditions to create a new, eclectic monumental style. For example, each of the buildings adopts startlingly massive volumes and emphasizes spatial experience and the scale of the cityscape. Each of them employs a symmetrical composition while highlighting abstract geometry in visual effects. Each of them uses extensive wings or colonnades on the sides and a square in the front, while also adjusting the layout according to functionalist principles. Each of them includes ornaments on a moderate scale and in a simplified style. The two most significant buildings, the Great Hall of the People and the Museum of Chinese History, have colonnades as high as 30 meters

\footnotetext{
94 Zhu Jianfei, “Guojia, kongjian, geming: beijing, 1949-1959” [A spatial revolution: Beijing, 1949-1959], in Sixty Years of Chinese Architecture (1949-2009): History, Theory and Criticism, ed. Zhu Jianfei, (China Architecture and Building Press, 2009), 61.

95 A number of the Ten Great Buildings follow the Nationalist Form movement and adopt traditional elements. Examples include the Museum of Agriculture, the Beijing Train Station, the National Gallery of Art, and the Diaoyutai State Guesthouse. The Military Museum adopted the Soviet spire and other neoclassical elements. Other of the Buildings were modeled on simple modernism, including the Beijing Worker's Stadium, the National Hotel, and the Overseas Chinese Guesthouse.
} 
and as long as 300 meters to coordinate with Tiananmen Square ${ }^{96}$ (Figure 25, 26). The façade adheres to neoclassical principles and is divided into cornice, frieze, capital, shaft, and basement. Each part, however, is simplified into plain geometrical forms and employs only limited moldings. While there are some sculptural decorations in the façade, the overall impression is solemn while straightforward. The design is neither traditional nor modernist but implies the regional accent of the Art Deco architecture.

Therefore, although they employed different architectural decorations and drew from many forms and traditions, the Ten Great Buildings did share a univocal exhibitional feature: the "large-scale, pleasing forms" invoked in Shaoshan's Ten-Year Plan. Architects of the PRC had indeed found their innovative monumental style, one that simultaneously partakes of and differentiates itself from the architecture of "the past and the present, the East and the West." Their discovery, though rarely discussed in current scholarship, profoundly influenced the urban forms of China.

The CPC reconstructed Tiananmen Square and built the Ten Great Buildings as the culmination of the Great Leap Forward and the celebration of the tenth anniversary of the PRC. In a sense, the architectural program exemplified one important consequence of cultural production in Communist China. On the one hand, after the CPC determined to make Beijing its capital, the city was gradually built into the unparalleled political and cultural center of the country. On the other hand, in the new sociopolitical structure that the $\mathrm{CPC}$ reconstructed for China, the interaction between center and periphery, between worldly Beijing and provincial Shaoshan, was enforced, predisposed, and highly imbalanced. This unevenness in power structure

\footnotetext{
96 See Design Team for the Great Hall of the People, Design Institute of Beijing's Urban Planning Bureau, "Renmin dahuitang" [The Great Hall of the People], Architectural Journal Z1 (1959): 23-30; and Design Team for Museums, Design Institute of Beijing's Urban Planning Bureau, "Zhongguo geming he zhongguo lishi bowuguan" [The Museum of Chinese History and Revolution], Architectural Journal Z1 (1959): 33-39.
} 
was easily projected into the architectural field, evident in the case of the Ten Great Buildings. Under the supervision of the central government, the program concentrated personnel and resources from all parts of the country. After the project's completion, Beijing touted the buildings as the most outstanding representation of Communist China, and they received extensive exposure in publications. ${ }^{97}$ The monumental architectural character, dictated by the central government and materialized by the architects, soon became the classic, cosmopolitan fashion pursued throughout the nation. ${ }^{98}$ Squares were regarded as modern sanctuaries, meant to hold massive pilgrimages and symbolize socialist democracy. Exhibition architectures were treated as the physical manifesto of economic progress and political consciousness. Those eclectic monumental styles seen in the Ten Great Buildings were subsequently appropriated by many provincial capitals and peripheral towns. ${ }^{99}$ Principal proof of this lies in the planned square and the Memorial Pavilion in Zunyi. In Shaoshan, when the local officials proposed a long square or buildings in "large-scale, pleasing form," they probably had a similar picture in mind.

\section{Option B: The Rural Identity, the Local Memorial Core in Shaoshan}

However, Shaoshan had a memorial core absolutely different from that of Zunyi or Beijing. In the latter cities, it was the abstract, collective society of all

\footnotetext{
97 For example, Architectural Journal, one of Chinese largest architectural publications, published a special issue in 1959 (Z1, 1959) to introduce the memorial projects in Beijing, including Tiananmen Square and the Ten Great Buildings.

98 After the construction of the Ten Great Buildings, many regional governments also promoted their own ten great buildings, in their region, to celebrate National Day and the Great Leap Forward. See Zhang Haidong, "Research on the Organizational Development and Architectural Creation Process of the Guangzhou Design Institute (1952-1983)" (master's thesis, South China University of Technology, 2009); and Zhou Puyi, "Cong beijing jizuo xin jianzhu de fenxi tan woguo jianzhu chuangzuo" [Discussion of the architectural creation in our country based on the analysis of several new buildings in Beijing), Architectural Journal 3 (1957): 41.

99 See Mao Zirao, "Shenyang shi renmin dahuitang sheji" [The design of the Great Hall of the People in Shenyang], Architectural Journal 12 (1959): 2-5; Southwest Industrial Architectural Design Institute, "Sichuan sheng nongye zhanlan guan" [The Agricultural Exhibition Pavilion in Sichuan Province], Architectural Journal 2 (1960): 33-35; and Zhou, "Cong beijing," 41.
} 
revolutionaries that those memorials aimed to commemorate. ${ }^{100}$ The square and the exhibition architecture emerged naturally, following this logic, with their immensity, simplicity, and abstract architectural forms. In these memorials, Mao was represented as one with the masses. Shaoshan, though, had a unique claim on Mao: it was his birthplace. Its contribution to the chronicle of the revolution was notable but smallscale, ill-suited to the grandiosity of the commemoratives in Beijing and even Zunyi. Thus, its memorial core focused on the personality of Mao, and local memorial constructions had to seek more intimate, personal forms rather than squares and the exhibition architecture.

Only a few personal memorials were built before the 1960s in China due to the CPC's tenet on atheism and collectivism. The memorial museums of Lu Xun offered the most applicable model for Shaoshan. ${ }^{101}$ In 1956, the local government in Beijing planned to build a memorial museum for Lu Xun beside his old home, where he lived from 1924 to 1926 . The architects in charge recalled that, in the beginning, they submitted a series of museum designs based on two opposite prototypes: a courtyard separate from Lu's house (Figure 27) and one that completely enclosed the house (Figure 28). The architects reported: "The sponsors did not agree with the No. 1 and No. 4 [the two prototypes] plans which centered on the old residence. The reason was that the museum was not built for the house. Rather, it should educate and inspire people to emulate Lu Xun through the exhibition. In addition, the house was crude

\footnotetext{
100 This commemorative subject in Chinese socialist memorials is most remarkable in the Monument to the People's Heroes. This monument, whose inscriptions and sculptures are dedicated to the "people," represents how the CPC exploits and projects the masses in propaganda. See $\mathrm{Wu}, 2005,24-26$.

${ }^{101} \mathrm{Lu}$ Xun (1881-1936), or Lu Hsün, was a leading figure in modern Chinese literature. A novelist, editor, translator, literary critic, essayist, and poet and the titular head of the League of Left-Wing Writers, Lu was primarily a liberal and never joined the CPC. Mao later acclaimed him as "the most correct, brave, loyal, and enthusiastic national hero" and "a saint in modern China." See Mao Zedong, 1991, 698; and Kong Jian and Jing Xun, "Mao Zedong yu Lu Xun de gongtong yuyan" [The common language between Mao Zedong and Lu Xun], News of the Communist Party of China (www.cpcnews.cn), February 22, 2011, accessed September 14, 2014, http://dangshi.people.com.cn/n/2013/0222/c85037-20564300-5.html.
} 
and thus inappropriate to display in notable places. The architectural styles [of the prototypes] were either too traditional or too Western[... .]"102 The government selected a plan that combined the two prototypes. The plan outlined an independent compound beside Lu's house (Figure 29). Its design sustained a symmetrical layout, a square in the front, two flanking colonnades, and a simplified grandiose facade ${ }^{103}$ (Figure 30, 31).

Also in 1956, the government of Shanghai, where Lu Xun had lived from 1927 until his death in 1936, built its own museum for Lu Xun using a dramatically different approach. The museum in 1956 was one part of a larger plan to move Lu's coffin into a public park ${ }^{104}$ (Figure 32). A new tomb was constructed and situated in a "bright and delightful" atmosphere, with a figurative statue in the front, a terrace in the middle, and two floral verandas beside. ${ }^{105}$ The museum sat in woods distant from the tomb. Its design, according to the architects' introduction, sought to render a "modest while cheerful, brisk while tasteful" air, in a southern Chinese style. ${ }^{106}$ Its plan and facade thus deviated from those of the monuments in Beijing and took a more regional path. The architects borrowed the local architectural language from Lu's birthplace--white walls, grey tiles, and tall gables--to make the building more similar to a local school rather than some exhibition architecture. (Figure 33, 34, 35)

The different representations of Lu Xun in Beijing and Shanghai stemmed from Lu's varied identifications. Lu had been promoted in communist propaganda as an exemplar of the leftist revolutionary. For Beijing, the source of the propaganda, the

\footnotetext{
102 Zhang Zhaoping, "Luxun jinian guan zongti sheji fangan de jieshao" [An introduction to the overall design of Lu Xun's Memorial Pavilion], Architectural Journal 4 (1956): 59.

103 Ibid., 57-58.

${ }^{104}$ Chen Zhi and Wang Dingzeng, "Shanghai hongkou gongyuan gaijian ji: luxun jinian mu he chenlieguan de sheji” [The renovation of Shanghai Hongkou Park: The design of Lu Xun's Tomb and Memorial Pavilion], Architectural Journal 9 (1956): 1-3.

105 Ibid., 4-5.

106 Ibid., 5-6.
} 
discursive posture was preferred to a genuine preservation of Lu's house. Its architectural form thus followed the exhibition architecture tradition and its monumental styles. For Shanghai, less connected to the central government or affected by its propaganda, a faithful expression of Lu's persona was paramount. Its program was directly involved with housing Lu's remains, and its architects found a style appropriate to his biography.

Lu Xun's museums in Shanghai and Beijing foreshadowed the different proposals for Shaoshan's memorial buildings. Like the architects of the Lu Xun memorial in Shanghai, Tao Zhu and Jin Zeguang outlined a tourist site for Shaoshan with a regional accent and an intimate atmosphere. Zhang Pinghua and Shaoshan's local officials, on the other hand, imagined a metropolitan city with the monument style popular in Beijing. Both sets wanted to achieve a cosmopolitan transformation of Shaoshan, but they conflicted in their basic identifications of the village. Tao was faithful to Shaoshan's rural identity, and his plan tried to preserve the pastoral landscape as the background of Mao's house. Zhang conformed to the cosmopolitan movement and tried to copy Beijing's favorite style, while his specific proposal appeared discursive or even unrealistic. The Shaoshan memorial project thus stood at a divide.

The different plans for urbanizing Shaoshan were a microcosm of the larger debate over how best to commemorate Mao amid the swirl of new political movements. With the resurgence of Mao's cult during the Great Leap Forward, a new monumental form was sought to reflect Mao's preeminence. One potential solution was to borrow the metropolitan fashion of memorial design, embodied in the proposal of Zhang Pinghua. But despite offering the safety of an established and popularly approved architectural form, Zhang's approach was predicated on the unequal 
relationship between cultural center and periphery, and may perhaps misinterpret the unique political meaning of Shaoshan. Another solution was to respect Shaoshan's distinct identity and create an accordant memorial form, expressed in the proposal of Tao Zhu. The challenge here lay in drafting an exclusive artistic language to codify Mao's cult, and one that would earn the approval of hypervigilant party critics. The disagreement between Zhang and Tao articulated the dynamic interaction between the cosmopolitan culture and the local tradition in China.

Nonetheless, the contest between Tao and Zhang withered before a winner emerged. With neither plan yet adopted, the whole construction program faced unexpected adversity that almost destroyed it. On March 21, 1964, the Hunan Provincial Bureau of City Construction reported that the newly proposed constructions in Shaoshan would cost 1.8 million yuan. The budget covered the firstphase projects, such as the museum, a staff dormitory, and the Guesthouse expansion. This expenditure was to be paid by the Provincial Cultural Bureau, which, on March 28, submitted a more detailed budget confessing that the department had run out of money. ${ }^{107}$ Faced with the potential collapse of the redesign, Zhang ordered his fellowmen to go to Beijing to request funding.

Although the project carried significant political meaning, Zhang and Tao had tried not to let word of their project reach Mao or the central government. Because Mao had opposed building a new house for himself in Shaoshan in 1950, they feared that he would turn down their project in 1963 as well. ${ }^{108}$ Zhang tried to maintain

\footnotetext{
107 Gao, "Shao shan mao ze dong," 49-50. In the Changsha archive, I found the budget issued by the Cultural Bureau on March 28. See "Shaoshan chenlieguan jianshe jihua he jingfei wenti de shenqing" [The construction plan and application for funds concerning Shaoshan's museum], March 23, 1964, HPA 213-1-738.

108 The fact that Tao and Zhang did not report to the central government is common in introductions to the memorial buildings in Shaoshan. See Gao, "Shao shan mao ze dong," 50; Ma Yuqing, "Can jia chou jian mao ze dong shao shan jiu ju chen lie guan de hui yi" [Memory of participating in the preparation of Mao Zedong's Shaoshan Exhibition Pavilion], in Zai shao shan, 46-47; and Hu, "Shaoshan maozedong jiuju," 30.
} 
secrecy even when asking for the additional funds. His couriers avoided the official bureaucratic procedure but communicated directly with officials in Beijing, including the ones in the Ministry of Culture and the Ministry of Propaganda. While all declared their support, none was willing to formally endorse the project without Mao's sanction. In March 1964, the Ministry of Culture delivered the final answer: no accreditation and funding could be released unless Mao approved the constructions. ${ }^{109}$ However grand and stately--as Zhang hoped--or however modest and tasteful--as Tao urged-- Shaoshan's cosmopolitan transformation seemed wasted.

109 Gao, "Shao shan mao ze dong," 50; and "chengji Xu Guangxiao fu buzhang suotan shaoshan chenlieguan wenti jilu ji Hu Qingpo de tanhua jilu" [Record of Vice Minister Xu Guangxiao's comment on the Shaoshan Museum and his conversation with Hu Qingpo], June 29, 1964, HPA 213-1-738. Ma Yuqing also recalled how he and another colleague went to the central government requesting money and were later turned down. See Ma Y., "Can jia chou jian," 46-47. 


\section{CHAPTER IV}

THE COSMOPOLITAN TRANSFORMATION OF SHAOSHAN: BUILDING THE EXHIBITION PAVILION IN 1964

The predicament that Tao Zhu and Zhang Pinghua confronted in Shaoshan in 1963--the budgetary constraints, the fear of offending Mao--was slight relative to the larger socioeconomic and political problems engulfing early 1960s China. The Great Leap Forward, which had promised economic salvation, resulted in the deaths of millions from starvation. Mao's authority was threatened and his cult of personality stained. In 1962, he was forced to publicly affirm his failing and consent to the economic repairs led by Liu Shaoqi, who denounced the ideological dogma that had propelled the humanitarian disaster. ${ }^{110}$ Other social programs that tried to reinforce the PRC's philosophical commitment to Maoism, such as the Four Purifications and the Socialist Education Movement ${ }^{111}$, were also mostly curtailed by Liu's bureaucratic system. In Mao's eyes, the PRC was abandoning Marxist orthodoxy and drifting toward the capitalist bloc. His alliance with Liu was strained, his control of the CPC falling apart.

\footnotetext{
110 The occasion on which Mao had to publicly admit his fault was the central working conference from January 11 to February 7, 1962, attended by more than 7,000 people from across the country. See "qiqianren dahui" [Seven-thousand-people conference], Baidu Wikipedia, last modified October 22, 2014, http://baike.baidu.com/view/111392.htm.

${ }^{111}$ The Socialist Education Movement was launched by Mao Zedong in 1963. After the Great Leap Forward, the government returned to a conservative policy, which was seen by Mao as rightist and thus reactionary. Mao sought to remove what he believed to be reactionary elements in the bureaucracy of the CPC, saying that "governance is also a process of socialist education." This movement is a purely political struggle that disturbed production, and directly led to the the Cultural Revolution. The "Four Purifications" from 1962 was the premier and an important part in the "Socialist Education Movement." See "Socialist Education Movement," Wikipedia, last modified June 13, 2014, http://en.wikipedia.org/wiki/Socialist Education Movement.
} 
The redevelopment of Shaoshan was jeopardized by the leader's increasing disrepute. Although Shaoshan had been growing persistently since 1949, the number of visitors declined considerably during 1961 to $1963 .{ }^{112}$ (Figure 36) In 1961, after Liu visited Shaoshan, the government ordered the closure of the first memorial museum in the village, the Nan'an Lobby, for economic reasons. Unsurprisingly, when Tao and Zhang proposed new constructions and solicited supporters from the central government, no one was enthusiastic enough to aid the venture.

Faced with these challenges, Mao fought to recover his reputation and reclaim his power through a skilled, strategic mass mobilization. He and his fellowmen saturated the public with Mao advertisements. The Selected Works of Mao Zedong was published to canonize Mao Zedong Thought as the ultimate theory of communist revolution. ${ }^{113}$ An anthology of Mao's poetry was published to proclaim his literary talent. In the military system, Lin Biao waged a campaign that practiced "exegetical bonding" as the "Lively Study and Application of Mao Zedong Thought" and engineered the distribution of the Little Red Book, a compendium of Maoisms. ${ }^{114}$ Under the guise of official propaganda and socialist culture, Mao was reinforcing his authority and preparing for an unexpected strike.

Tao's and Zhang's respective construction plans for Shaoshan were formed in this

\footnotetext{
112 Shaoshan Chorography, "Shao Shan Zhi, 331.

113 For information about the Selected Works of Mao Zedong and Mao Zedong thought, see http://baike.baidu.com/view/138481.htm; and Xiong Kunjing, "Mao zedong xuanji>bianji chuban shimo" [The editorial history of Mao Zedong's Selected Works], News of the Communist Party of China (www.cpcnews.cn), December 5, 2013, accessed September 17, 2014. http://dangshi.people.com.cn/n/2013/1205/c8503723756594.html;

"Mao Zedong xuanji" [Mao Zedong Selected Works], Baidu Wikipedia, last modified August 25, 2014, http://baike.baidu.com/view/138481.htm.; "Mao Zedong sixiang" [Mao Zedong thought], Wikipedia, last modified September 14, 2014, http://zh.wikipedia.org/wiki/\%E6\%AF\%9B\%E6\%B3\%BD\%E4\%B8\%9C\%E6\%80\%9D\%E6\%83\%B3\#.E5.8F.82. E8.80.83.E6.96.87.E7.8C.AE. For period commentary, see David E, Apter and Saich Tony Saich, Revolutionary Discourse in Mao's Republic. Cambridge, (Cambridge, MAMass: Harvard University Press, 1994); and Leese, Mao Cult.

114 The "exegetical bonding" referred to various discursive practices aimed at promoting ideological disciplines in the cult of Mao. It was first launched in the PLA (People's Liberation Army) and later promulgated throughout the nation. See Apter and Saich, Revolutionary Discourse. .
} 
complex political environment. This chapter analyzes the unfolding of this memorial construction and its final result, the Exhibition Pavilion of Comrade Mao Zedong's Old House, an important memorial dedicated to Mao before the Cultural Revolution. My research connects the design and construction of the Exhibition Pavilion with its specific political environment and illuminates the speculative initiatives in the memorial project. In particular, this chapter focuses especially on two questions: how political actors chose specific architectural styles to convey their ideology; and how architectural style and space became a materialized piece of political meaning. In exploring these, this chapter reveals the interaction between politics and architecture in the context of Communist China.

Circumstance and Perseverance: A Reconsideration of the Memorial Offering in 1963

In 1950, the government of Shaoshan had proposed building a new house for Mao. A comparison of this plan with those later hatched by Tao and Zhang exposes interesting similarities and differences. Both programs were initiated by local officials and met with disapproval from the central government. In both cases, the proposers were afraid of reporting their plans to Mao. But in fact, the circumstances surrounding the plans were vastly unalike. In the early 1950s, Mao and other leaders had strictly prohibited personality cults, while in 1963, public veneration of Mao was a public trend and quite nearly a national movement. Mao's attitude toward this secular religion had shifted from unequivocal opposition to a more ambiguous standing.

That was probably the reason that Tao, although faced with the disapproval from the central government, still insisted that Shaoshan build its memorials for Mao whatever the cost. At last, both Tao's Central-South Bureau of the CPC and Zhang's Hunan Provincial Party Committee allocated a half million yuan for the project. This 
amount was far less than in the proposed budget. ${ }^{115}$ As a result, the program shrank considerably, with the auditorium, the square, and the large-scale planning entirely abandoned. The surviving constructions included the museum itself, a restaurant, a dormitory, and some modern municipal facilities. The grand project of comprehensively transforming the community was tabled. ${ }^{116}$

However, even on a diminished scale, building a new museum in Mao's birthplace still had a profound political meaning. More significantly, the lack of official accreditation turned the memorial into a private offering from Tao and Zhang. This secrecy suggested a personal motive in building the museum. It demonstrated for the sponsors a distinct, intimate relationship with Mao, a relationship between believers and their god, between servants and their lord. To build the material memorial was to build a unbreakable symbolic connection with Mao. In doing so, the architects may have been anticipating that his investment would one day pay off and bring him more political power. For Tao, this would turn out to be true. ${ }^{117}$

\section{$\underline{\text { Tao's "Three Ought To" Principles }}$}

To review, the material construction of the Shaoshan memorial was actually the discursive construction of Mao, and the architect of the buildings was the architect of Maoist ideology. With the budget and a smaller scale entailed, Tao Zhu, drafter of the more modest plan, seized direction of the construction and interpretation of the Shaoshan memorial. Tao assembled a group of professional architects in Guangdong

\footnotetext{
115 See Gao, "Shao shan mao ze dong tong zhi," 50; and Hu, "Shaoshan maozedong jiuju," 30.

116 The final constructions appear in the list found in "Shaoshan yiqi gongcheng jiaojungong yanshou zhengmingshu" [Certificate on the examination of the first period of construction in Shaoshan], September 28, 1964, HPA 213-1-738.

117 At the time of the museum's construction, Tao was the first secretary of the Central-South Bureau of the CPC. In December 1966, upon the advent of the Cultural Revolution, he was promoted by Mao to minister of the Propaganda Department and a member of the Standing Committee of the CPC's Political Bureau.
} 
Province, including Xia Changshi, Mo Bozhi, Chen Boqi, She Junnan, Jin Zeguang, and Huang Yuanqiang, to make up the design team. ${ }^{118}$ He even put forward his own prescription for the design of the museum, known as the "three ought to" principles:

Ought to conform to Hunan vernacular style and keep accordance with its rural environment, while the interior can be more comfortable.

Ought to be solemn and simple, functional while natural, with grey bricks, raw tiles, and white walls.

Ought to present a cultivated atmosphere, where a Chinese garden arrangement may be considered. ${ }^{119}$

As enunciated here, Tao did not subscribe to the popular trend in contemporary memorial buildings, manifest in the exhibition architecture in Beijing, but favored a regional path.

Interestingly, this taste for the rural identity converged with the necessary secrecy of the project. Since it was an unsanctioned, underground program, the participants had to make every effort to conceal the constructions from Mao and his informants. One important measure was to achieve a relatively small scale of refurbishment and to obscure it with their rural background, so that no unwanted government attention would be drawn, aided the secrecy.

For example, the local officials tried to manufacture a misleading concept in official records by referring to the new construction as only an expansion of the

\footnotetext{
118 The architectural team enlisted to draft and build Shaoshan's museum was multifarious and difficult to scholars to definitively compile. Hu Qingpo mentions Director of Guangdong Infrastructure Bureau Liao Wai, Jin Zeguang, and some professors; see Hu, "Shaoshan maozedong jiuju." .Cui Zixia names Xia Shichang, Chen Boqi, Du Rujian, and Huang Yuanqiang; see Cui Zixia, Research on the Organizational Development and Architectural Creation Process of the Architectural Design \& Research Institute of Guangdong Province (master's thesis, South China University of Technology, 2012). Denong Zou names Huang Yuanqiang; see Zou Denong, Chinese Modern Architectural History (Tianjin: Tianjin Science and Technology Press, 2001), 275-276. Cai Dedao in my interview cites Xia Shichang, Mo Bozhi, He Jingtang, and Huang Yuanqiang; see Cai Dedao (master of architecture candidate) in discussion with the author, June 21, 2013. It was once customary to treat designs as collective work and therefore leave no individual signature. Moreover, according to Cai, Tao especially directed the architects from Guangdong to leave authorship of the museum to people in Hunan Province, all of which makes it difficult to find the exact names of the designers. After an analysis of the blueprint documents and the architectural style(s) that mark the building, I posit that Xia Changshi, Mo Bozhi, Chen Boqi, She Junnan, Huang Yuanqiang, and Jin Zeguang all contributed to the design.

119 There have been different versions of Tao's instruction on the architectural style. See "chengji Xu Guangxiao"; Gao, "Shao shan mao ze dong," 49; and Ma Y., "Can jia chou jian," 59. Many elements in these versions overlap with each other, and those parts have these three principles in common.
} 
former building. When Zhang ordered an individual building for exhibition in December 1961, the official documents denoted the project with the phrase zhanlan shi (exhibition room). ${ }^{120}$ In November 1963, when Tao and Zhang proposed a new museum, the recorder named the museum as xin de chenlie guan (a new exhibition pavilion), indicating a radically heightened scale. ${ }^{121}$ However, when the central government turned down the accreditation and Tao nevertheless decided to continue on his own, the project was referred to as merely a "renovation and expansion" of the extant Shaoshan Exhibition Room. ${ }^{122}$ In the name of expansion, the officers and architects demolished the Exhibition Hall to make way for a brand new museum. By ordering a "vernacular style [in] accordance with its rural environment," Tao was probably anticipating an outlook that went along with the expansion theory.

It was also probable that, by demanding a local style, Tao was trying to preserve Shaoshan's representative value. Tao seemed to fully understand Shaoshan's symbolic meaning for Mao, and his planning of the village had always harmonized with, and highlighted, its rural identity. In choosing the vernacular forms, Tao tried to honor Mao's vision of "incessant waves of the endless paddy" and hew to the memorial core established by the works of party-approved landscape painters: Mao's old farmhouse in a pastoral background.

Embracing the regional style was unconventional enough, but Tao's third principle, "where a Chinese garden arrangement may be considered," also was remarkable. Here, Tao may have been aiming for an architectural style that would materialize Mao's literary talent. The Chinese traditional garden has always been

\footnotetext{
120 "Guanyu shaoshan chenlieshi”; and Gao, "Shao shan mao ze dong," 48.

121 "Guanyu chengli choubei xiaozu, chouban shaoshan chenlieguan de qingshi" [Report on the organization of a preparation team to build the Shaoshan Exhibition Pavilion), November 11, 1963, HPA 213-1-651.

122 "Shaoshan chenlieguan jianshe."
} 
associated with artists and scholars ${ }^{123}$ and had recently been incorporated into $\mathrm{Lu}$ Xun's Shanghai memorial to foster an intimate, solemn mood. The "cultivated atmosphere" was thought appropriate for Mao, himself a poet and calligrapher. The use of a garden-like layout in Shaoshan's museum was thus possible and practical.

However, traditional gardens still lacked the monumental style--the impressiveness, immensity, or intensity-- befitting a memorial, let alone one honoring so eminent a figure as Mao. With memorials on the national stage, garden elements were invariably overwhelmed by the "large-scale, pleasing form" surrounding them, and little traditional landscape could be seen in their built-environments. ${ }^{124}$ Moreover, the Chinese garden is a building type culturally foreign to Hunan Province, seemingly rendering a garden-like layout inappropriate for Shaoshan. ${ }^{125}$ All these artistic and geographical incompatibilities invite an obvious question: Why did Tao commit to a garden arrangement for the Shaoshan memorial? The answer lay far from Shaoshan, bound up in Tao's own experience.

\section{Explaining Tao's Garden Layout}

Since 1949, Tao had been serving as governor of southern China. Deeply rooted there, literally and metaphorically, are the Lingnan gardens, one of four types of traditional gardens in China and undoubtedly the type Tao spoke of in his building proposal $^{126}$ (Figure 37). Tao had fully absorbed the great symbolic meaning carried by

\footnotetext{
${ }^{123}$ For Chinese garden and its literati tradition, see Maggie Keswick, and Charles Jencks, The Chinese Garden: History, Art \& Architecture (New York: Rizzoli, 1978).

124 This was seen in the Museum of Chinese History and Revolution and in Lu Xun's memorial museum in Beijing.

${ }^{125}$ Given the poor economy in contemporary Hunan Province, a garden layout is neither economical for Shaoshan.

${ }^{126}$ Generally speaking, there are four types of traditional gardens in China: the northern imperial gardens, the literati gardens near the Yangtze River, the Lingnan gardens in such southern Chinese provinces as Guangdong and Fujian, and the gardens in southwestern China. The Lingnan gardens are distinguished by their economy and utility. Greens and waters, usually small in size, are conceived not only as aesthetic sceneries but also as salutary
} 
the Lingnan garden, to be addressed shortly, and resolved to bring it to Hunan.

Tao's other descriptive terms, "solemn and simple, functional while natural,"

point to a modernist variant of the Lingnan garden found in the mid- $20^{\text {th }}$ century. His desire for this variant of the Lingnan garden was evident in his choice of architects to realize his vision: Xia Changshi, Mo Bozhi, and She Junnan. ${ }^{127}$ Xia Changshi (19051996) received his professional education in Germany, obtaining a master's in architecture from the Karlsruhe Institute of Technology in 1928 and a $\mathrm{PhD}$ in art history from the University of Tübingen in 1932. Later that year, he returned to China bearing with him the German scientific, functionalist analysis in architectural design, the meticulous emphasis on tectonic details, and the modernist belief in industrial simplicity (Figure 38). Xia had a consistent interest in traditional Chinese architecture, especially that of southern China, and applied to this interest the scientific, technological perspective in which he had been educated. He would later set the foundation for the modernization of Lingnan gardens. ${ }^{128}$

If Xia was the pioneer in modernist interpretation of Lingnan gardens, Mo Bozhi

habitats. The garden elements are subtly integrated into the architecture to offer a pleasant built-environment against a subtropical climate.

${ }^{127}$ Because of the more relaxed political environment in Guangdong, the architects in the area, such as Xia Changshi, Mo Bozhi, and She Junnan, were able to develop their distinct styles without the imposition of the mainstream architectural culture. While all differed in emphasis and solution in their designs, their works all responded to the subtropical climate and exhibited functionalist principles. Because of these commonalities, contemporary scholarship gathers their work under the singular label Lingnan Style. While Lingnan Style architectural works do share some characteristics, what "Lingnan Style" precisely means is a question not yet sufficiently understood. Here, Lingnan Style indicates the works created by specific architects - especially Mo Bozhi and She Junnan - in specific times and in a style that combines Lingnan garden and functionalist layouts. ${ }^{128}$ My introduction of Xia Changshi gathers information from Xia Changshi and Mo Bozhi, "Mantan lingnan tingyuan" [Discussion of Lingnan gardens], Architectural Journal 3 (1963): 11-14; Shi Liang, "Research on the Life and Works of Xia Changshi" (master's thesis, South China University of Technology, 2007); Xiao Yiqiang, "Reasoning on the Modernity of Lingnan Modern Architecture Design." New Architecture (May 2008): 8-11; Peng Changxin, "Regionalism and Realism: Xia Changshi's Ideas on Modern Architecture in China," South Architecture (February 2010): 36-41; Dou Yide, "Lingnan Style and Architecture with Chinese Characters," South Architecture (2009): 4-6; Xiao Yiqiang and Yang Yanwen, “An Essay on Mr. Xia Changshi," South Architecture (February 2010): 14-15; Zou Denong, Zhang Xiangwei, and Dai Lu, A History of Chinese Modern Architecture (Beijing: Chinese Architecture \& Building Press, 2010); "Seeking Modernity of Chinese Architecture in 1950-1980s," Time+Architecture (May 2007): 6-15; and Li Rui and Feng Jiang, "Timeline of Hsia Changshi's Life and a Bibliography of Hsia Changshi," South Architecture (February 2010): 46-48. 
(1914-2003) was his foremost contemporary. ${ }^{129}$ In the 1950s, Mo, who had graduated as a civil engineer from Sun Yat-sen University, was commissioned to design the restorative projects of several traditional restaurants in Guangzhou, and demonstrated an acute understanding of and skillful craftsmanship in Lingnan gardens. In 1961, Mo accompanied Xia to conduct field surveys of over thirty Lingnan gardens; two years thereafter, he designed the Shuangxi Villa for the Guangzhou Municipal Government. The Villa, along with Mo's later projects, integrated the natural landscape with modern constructions. Architectural volumes were downsized and sheltered in the pastoral terrain. Artificial buildings were masterly assimilated into nature, with frequent and smooth transitions between interiors and exteriors (Figure 39, 40). Mo used reinforced concrete, a beams system, and modern structural joints, while also incorporating some local formal elements such as sloping roofs, masonry textures, and latticed windows ${ }^{130}$ (Figure 41). These works constituted a distinct architectural aesthetic — one originating in southern China while conforming to modernist constructive principles.

She Junnan (1916-1998) was, with Mo, the second of "two peaks in the development of Lingnan architecture." ${ }^{\prime 131} \mathrm{He}$ was famed for his functional deployments, economical use of materials, and the adoption of garden elements. In 1959, a time that the nation as a whole was obsessed with expensive and extravagant exhibition architecture, She observed, "[b]uildings at low cost can be of good quality as well[ ... . ] [n times of need, lower]-class materials can be used comprehensively,

\footnotetext{
${ }^{129}$ My introduction of Mo Bozhi gathers information from Zeng Zhaofen, "Yungui liangnan: mo bozhi yu lingnan jiagou" [Returning to Lingnan: Mo Bozhi and architecture in Lingnan], Architectural Journal 9 (1993): 42-47; Liu Yubo, "Huiguibenyuan: huigu zaoqi lingnan jianzhu xuepai de lilun yu shijian" [Review of the early practice and theory of Lingnan architecture], Architectural Journal 10, (2009): 29-32; and Zhuang Shaopang, "Research on the Architectural Creation and Thought of Mo Bozhi," (PhD diss., South China University of Technology, 2011).

130 Zhuang, "Mo Bozhi," 79-82.

131 Zeng, "Yungui liangnan," 42.
} 
middle-class ones can be upscaled, and upper-class ones can be delicate ornaments. We can reuse scrap materials and local, economical makings." ${ }^{" 132}$ One of his works in 1964, the Guangzhou Friendship Theater, was regarded as a great success despite a limited budget. More to the point, it managed to integrate a garden. ${ }^{133}$

Along with Xia, Mo, and She, other members of Tao Zhu's team were among the most esteemed architects in southern China. Chen Boqi (1903-1973) was the dean of the Architectural School at the Southern China Polytechnic University, where Xia and Mo worked as professors. Huang Yuanqiang (1923-?), a student of Xia during the 1930s, ${ }^{134}$ was the chief architect at the Architectural Design Institute of Guangdong Province. And Jin Zeguang, introduced in Chapter Three, was the deputy chief engineer at the Guangzhou Municipal Institute of Landscape Design. These professionals had intimate working and personal relationships with each other ${ }^{135}$ and were united in their practical and philosophical devotion to modernist spareness. Deploying this team with the directive of a "garden arrangement," Tao clearly envisioned a modernist, Lingnan landscape commemorative in Mao's birthplace.

This vision surely was an aesthetic one, but in the atmosphere of Maoist China, politics and art were inseparable, and Tao and his team were not immune. As noted earlier, the nationalization of architecture guaranteed for the officials a significant influence on architectural designs. The situation in south China, despite its remove

\footnotetext{
132 He Jingtang, "Yi jianzhu dashi she junnan" [Recollection on the master She Junnan], Architectural Journal 3 (1999): 58.

133 She Junnan, “Di zaojia nengfou zuochu gao zhiliang de sheji: tan guangzhou youyi juyuan sheji” [Can highquality design be created under financial constraints: Discussion of the design of Guangzhou Friendship Theatre], Architectural Journal 3 (1980): 16-19. My introduction of She Junnan also gathers information from Zhong Xinquan, "Renmin de jianzhushi: ji jianzhu lao zhuanjia she junnan" [People's architect: Recollections on the architecture expert She Junnan], Architectural Journal 3 (1999): 54-55; and She Junnan, "Wo de zishu" [My autobiography], Architectural Journal 3 (1998): 74-75.

${ }^{134}$ Huang Yuanqiang studied architecture in and graduated from Chongqing University in 1946. Xia taught in Chongqing University from 1942-1945.

${ }^{135}$ From the biography of these architects, it is evident that most of them have taught in the same university and worked in institutions that had a close relationship. See Li and Feng, "Hsia Changshi's Life"; Zhuang, "Mo Bozhi"; and She, "Wo de zishu."
} 
from national culture hubs, was no different. Even here, architectural designs were more or less another representative media governed by the officials. All of the architects on Tao's team worked in government administrative bureaus or at national universities, and their building projects were unexceptionally approved and sponsored by the local government. It was through the political forces in southern China that Xia, Mo, and She were able to take the artistic risk of venturing a regional Lingnan style at a time of national fascination with metropolitan forms such as the "largescale, pleasing form" in the Ten Great Buildings or the "nationalist form." 136

The close connection between regional political wills and Lingnan architecture was not new. For example, beginning in the early 1950s, Mao launched a campaign to reinforce national authority and weaken regional power. Officials in southern China were rebuked in the name of "territorialism"” or "localism."137 In the meantime, buildings in the area were either denounced as "capitalist flowers of evil" or denigrated as outdated traditionalism. ${ }^{138}$ Because of their intimate ties with the regional authorities, the architecture combining Lingnan gardens and modernist aesthetics had long been expelled from mainstream publications and competitions. ${ }^{139}$ In fact, Tao had been sent by Mao to southern China precisely to help suppress regionalism. Nevertheless, Tao's attitude toward the local architecture was subtle and

\footnotetext{
136 The "nationalist form" was an architectural movement from 1952 to 1956 that tried to use Chinese traditional elements, such as brackets and sloping roofs, in modern buildings. It began as a response to the CPC's call for a Socialist Realist style in architecture. In 1956, the Soviet Union criticized lavish styles in building; in the same year, the CPC also set a restraint on the "nationalist form." See Zou, Chinese Modern Architectural History.

${ }^{137}$ For more about the anti-regionalist movement, see Chen Hua-sheng, "Guangdong's 'Anti-localism' Campaigns and Factional Conflict (1949-1975)," Research on Mainland China 2 (2008); Editorial Committee of the Biography of Ye Jianying, "Zai 'fan difang zhuyi' de xuanwo zhong" [In the circumstance of "antiregionalism"], in Ye Jianying zhuan [The biography of Ye Jianying](Beijing: Contemporary China Series Editorial Department, 2006); and Wang, "Difang zhuyi zhongchuang xia de guangdong ganbu" [The officials in Guangdong who suffered under "regionalism"], Yanhuang shijie 10 (2013).

${ }^{138}$ Lin Fan, "Renmin yaoqiu jianzhushi zhankai piping he ziwo piping" [The people ask architects to engage in criticism and self-criticism], Architectural Journal 2 (1954): 122-124.

${ }^{139}$ Cai Dedao noted that Lingnan architecture had long been peripheral to the field before some designs bearing the style were praised by the Society of Chinese Architects in 1983. Quoted from Cai, 2013.
} 
sophisticated. Although he demoted many local officers, Tao reinstated those who had once chaired the construction bureau. In addition, he devoted remarkable effort to constructing and landscaping Guangzhou, ${ }^{140}$ even recruiting a specific group of architects from various design institutes to take charge of his building programs. Many important projects in southern China, such as upper-class sanitarians for official leaders, famous resorts, and prominent public buildings, were frequently assigned to this team, despite the fact that such practices cost more and were in fact outside the bureaucratic system ${ }^{141}$ (Figure 42, 43). With Tao's efforts, southern Chinese architecture retained earlier styles modeled on traditional or modernist prototypes. This would blossom into the exceptional style that combined modern construction with traditional elements, such as Lingnan gardens. In a sense, Tao Zhu, the antiregionalist warrior of Mao, produced his own regional style by encouraging the blending of traditional and modernist perspectives.

Tao's audacity in feeding his own architectural style was indeed deliberate and exempt from the accusation of regionalism. Tao was an overt loyalist toward Mao, and the architectural style he sponsored was one that had been favored by Mao, Zhou Enlai, and other central leaders. ${ }^{142}$ To build in this architectural style, rather than claiming any regionalist tendency, was to construct, for Tao, a distinguished, cultivated fame and identity in Mao's circle. Politics aside, the stylistic language

\footnotetext{
140 One of the officials reinstated by Tao was Lin Xi, a significant figure in the development of Lingnan architecture. See She Junnan, "Linxi: lingnan jianzhu de juren" [Lin Xi, a giant in the development of Lingnan architecture], South Architecture 1 (1996): 58-59; Tan Guangwen and Ding Lijun, "Linxi" [Lin Xi], Guangdong yuanlin [Guangdong garden] 2 (2009): 73-74; and Zhuang, "Mo Bozhi," 22-24.

${ }^{141}$ Such projects included the Hexi Official Sanitarian in Conghua, Guangdong Province; the Workers' Cultural Palace in Haikou, Hainan Province; the Teaching Buildings in Guangxi University, Guangxo Province, and the Fubo Pavilion and Baiyun Pavilion in Guilin, Guangxi Province.

142 In 1956, Mao lived in the Donghu Guesthouse in Wuhan, which was a modern construction made in gardenlike style. Zhou Enlai had lived in the Shuangxi Guesthouse and the Baiyun Shanzhuang, which was designed by Tao's team of architects. In addition, many of Xia Changshi's works were praised by Zhou Enlai, Zhu De, and Wang Zhen. See Li and Feng, "Hsia Changshi’s Life."
} 
articulated here implied certain cultural significations as well. It was a domestic style found only in China, catering to the nationalist sentiments of the new regime. The garden features had their roots in the literati tradition, bespeaking a high taste in knowledge and aesthetics. The modern materials such as concrete and glass, on the other hand, remolded the "dark and feudal spirit" of the literati tradition ${ }^{143}$ and responded to the pursuit of scientific and economic development. The failure of the "nationalist form" in the late 1950s declared the bankruptcy of any nationally monopolized styles. ${ }^{144}$ Tao, with his fellow architects in Southern China, seized this opportunity to propagate their own architectural brand and to connect it directly with Mao.

The Exhibition Pavilion of Comrade Mao Zedong's Old House

Between January and March, Tao twice sent his design team to Shaoshan. ${ }^{145}$ Early in April, preparations for building, including the earth excavation, material collection, and organization of labors, were ready, and construction began on May 7 . By August 20, 1964, a new museum, a dormitory, and a restaurant were completed. ${ }^{146}$ The new museum was situated between the Mao Ancestral Temple and the col, facing west and resting on a mountain slope. The whole compound was one-story high, covered about 2700 square meters, and gradually elevated according to the

\footnotetext{
${ }^{143}$ A distinct culture in imperial China, the literati tradition was, according to the CCP's propaganda, a symbol of feudalist-era corruption and decadence. Subsequent academic study has exposed this stigma as biased and erroneous.

${ }^{144}$ In 1955, the central government declared that past guidelines in architectural design were wasteful and criticized a number of architects associated with the nationalist form. Later on, some architects would claim that the varied political movements had confused them. As it turned out, few formal languages would dominate Chinese architectural design. See Zou, Chinese Modern Architectural History.

145 Gao, "Shao shan mao ze dong," 48-50; Gao, "Shao shan mao ze dong tong zhi," 38-39; Shaoshan Mao Zedong, Shao Shan Mao Ze Dong, 59; Hu, "Shaoshan maozedong jiuju," 22-29; and "Shaoshan chenlieguan." 146 See "Shaoshan yiqi gongcheng."
} 
terrain. ${ }^{147}$ The building had an entrance lobby and two yards, surrounded by seven exhibition rooms and service quarters (Figure 44, 45, 46, 47). The yards were occupied with different natural scenes. The left one had a square pool with little islands and a bridge, while the right one was much larger, with trees and grass (Figure $48,49)$. The exhibition rooms were connected by a corridor circling the yards. Walls facing the yards were made up of large areas of windows, which, along with the corridor, made the transition between exterior and interior smooth and natural (Figure $50)$.

Tao's garden arrangement was fully realized in the building. The fluid space in the corridor, the transparent partition, the interaction between man and nature, and the highly varied floor heights all were indebted to southern Chinese traditional gardens. The frequent transition between indoor space and natural environment was considered the signature of Mo Bozhi's design, as found in the Shuangxi Villa. The simplified traditional details of the garden were also common in Mo's works ${ }^{148}$ : not only were corridors paved with green and white quadrilles and decorated with exquisite moldings (Figure 51) but the design of doors, windows, and struts followed Mo's landscape architecture as well (Figure 52, 53). Although some details--the flame, the sunflower, and the spear of rice ${ }^{149}$--were borrowed from the revolution iconography, the compound indeed rendered a cultivated and natural environment. The features of Lingnan gardens, which were local and iconic to southern China, were now implanted in Mao's birthplace.

On the other hand, the exterior of the museum closely resembled those of rural

\footnotetext{
147 The museum statistics come from the Shaoshan Mao Zedong, Shao Shan Mao Ze Dong, 59-60; Hunan Shaoshan Revolutionary Committee, Hunan Institute of Architectural Design, "Shaoshan in Construction," Architecture Journal (January 1977): 1-11; and Gao, "Shao shan mao ze dong," 50.

148 As seen in the Shuangxi Villa (1963), Fubo Pavilion (1964), Shanzhuang Guesthouse (1964).

149 The flame symbolizes the hope and compassion of revolution. The sunflower symbolizes eternal loyalty toward Mao. The rice spear symbolizes the abundance of food and power.
} 
traditional buildings. With limited openings on the external walls, few garden features could be recognized from the outside. Instead, the museum looked like a modernized local temple in Hunan, with highlights such as white walls, grey tiles, and rural material and techniques. The facade followed the custom of yi ming liang an, a composition common in local public buildings (Figure 54, 55). The use of a gabled roof over the entrance deviated from the regular building topology for emperors, which preferred hip roofs, but conformed to the design of the adjacent Mao Ancestral Temple. ${ }^{150}$ F-shaped brackets were added under flying eaves to imitate the regional structures, even though such details were unnecessary for reinforced concrete buildings ${ }^{151}$ (Figure 56). As with the Mao Ancestral Temple, the entrance had four columns, the outer ones painted red. As with the Nan'an Sishu, two layers of beams linked the columns. The plinth of the wall was modeled on local residences and made of ashlars. And the architects from Guangdong Province brought their respect for the natural environment to Shaoshan. The new construction, with its one-story height and decentralized volumes, was largely sheltered in native woods and bushes.

The new museum in Shaoshan thus followed the regional approach and maintained its rural identity, a consequence of Tao's insight into and appreciation for the representative identity of Mao's birthplace. In the new constructions, Tao assumed Shaoshan's distinctness and, through the Lingnan garden designs, affixed his own identity rather than renting a generic one from Beijing. By this, he simultaneously revealed and accomplished his ultimate mission with the Shaoshan project: to honor

\footnotetext{
${ }^{150}$ In Chinese traditional architecture, the type of roof correlates to the status of the owner. The hip roof is the highest grade and reserved for emperors, and the gabled roof is used for officials and in temples. The Shaoshan museum's use of the gabled roof may be motivated by two factors: to conform to the local environment, as was done with the Mao Ancestral Temple, or to highlight the contrast between rural Shaoshan and the Forbidden City, which used a hip roof and accommodated Mao.

151 The F-shaped structure under roofs is a common tectonic joint in farmhouses in rural Hunan. It is also used in Mao's house and Nan'an Sishu.
} 
Mao in a distinctive, personal, and pragmatic way — that is, in a way most befitting Shaoshan, Tao and Mao themselves, and the spirit of Maoist communism.

Yet even with a constrained budget and a rural appearance, the building still managed an elegant impression. The museum employed She Junnan's concept of using "lower-class materials comprehensively, middle-class materials as upper-class ones, and upper-class ones as delicate ornaments." was made with expensive materials including marble, steel, and concrete (Figure 57). The upper structures, however, were built with cheap materials, such as wooden timbers, and were either hidden by the ceiling or covered by bright paintings (Figure 58). The stairs, columns, corridors, and wall plinths were all tiled with manuallyworked terrazzo to simulate the effect of expensive marble. Window frames and doors were made of steel rather than wood, with a combination of alternating frosted and clear glass. The architects successfully manufactured a perception of modern, luxurious construction, in spite of - and, owing to their ingenuity, because of - their humble materials and thereby magnifying the representation of Mao.

Besides formal and structural design, the spatial arrangement of the museum was tailored toward its propagandistic function. The layout followed the tradition of circular arrangement in the exhibition architecture. This circulation of visitors, facilitated by the transparency between walls and gardens, created an experience that was to be a keystone in the pilgrimage to Shaoshan. Describing the nature of museums, Tony Bennett states:

[Museum, international exhibitions and modern fairs] are also institutions which, in being open to all-comers, have shown a similar concern to devise ways of regulating the conduct of their visitors, and to do so, ideally, in ways that are both unobtrusive and self-perpetuating[... .] All three institutions have shared a concern to regulate the performative aspects of their visitors' conduct. Overcoming mind/body dualities in treating their visitors as, essentially, 'minds

152 He, "Yi jianzhu," 58. 
on legs,' each, in its different way, is a place for 'organized walking' in which an intended message is communicated in the form of a (more or less) directed itinerary. ${ }^{153}$

This 'organized walking' is pivotal to the curatorial program of Shaoshan's museum. Visitors in the museum would find themselves not only watching the collections but also meeting, constantly, with other pilgrims through windows and corridors (Figure 59). The intention was for each visitor to take in not only the antiques on the wall but also the movement of the large, devoted troop of fellow comrades. The visitor was both audience for the museum and actor in a commemorative ritual. By offering this specific motive and interactive pattern, the museum space put forth highly attuned regulations for controlling its visitors' behaviors and interactions. The museum proved to be a modern panopticon ${ }^{154}$ modulating people's behavior and beliefs automatically. The Chinese Communist duality separating General Mao from his massing followers was thus visualized and intensified at this collective devotional. The troops of faithful pilgrims were once both the subject and palpable objective of socialist aesthetics, the "reality on a higher plane," in Socialist Realist paintings. Now, in the eyes of the visitors, this aesthetic jumped out of the frames and became the truth.

The Title and the Exhibition of the Exhibition Pavilion

When the architectural design and construction were carried out swiftly, a

\footnotetext{
153 Tony Bennett, The Birth of the Museum: History, Theory, Politics (London and New York: Routledge, 1995).

154 The concept behind the panopticon is for a single watchman to observe (-opticon) all (pan-) inmates of an institution without the inmates being able to tell whether or not they are being watched. Although it is physically impossible for the single watchman to observe all cells at once, the fact that the inmates cannot know when they are being watched means that all inmates must act as though they are watched at all times, effectively compelling them to constantly control their own behavior constantly. The design consists of a circular structure with an inspection house at its center, from which the manager or staff of the institution is able to watch the inmates, who are stationed around the perimeter. The panopticon was designed by the philosopher Jeremy Bentham, who imagined his invention as "a mill for grinding rogues honest." See "Panopticon," Wikipedia, last modified September 9, 2014, http://en.wikipedia.org/wiki/Panopticon.
} 
professional team was assembled to prepare the exhibition in the museum. ${ }^{155}$ The aim of the exhibition, as conceived by Tao and Zhang at the time, was to serve as a supplementary display of Mao's house and to reflect Mao's early years and revolutionary activities in Hunan. This modest program was a continuation of the previous curatorial theme of the Shaoshan Exhibition Hall, and was deemed feasible by both local and central officers. ${ }^{156}$ The lobby exhibited a photograph of Mao in the center portraying the leader in the Beidaihe Meeting. ${ }^{157}$ Underneath was Liu Shaoqi's pronouncement that Mao Zedong Thought was the canon for all party members. Four interrelated exhibitions described Mao in four different periods of his life: his youth, the establishment of the CPC, the First Revolutionary Civil War, and the Autumn Harvest Uprising. Shaoshan's local revolutionary history was fully assimilated in Mao's biography.

The exhibition illustrated how CPC authorities remolded historical discourse. According to a contemporary document, the curators intentionally substituted Mao for Chen Duxiu as the founder of the CPC and altogether omitted those founders who held "an ambivalent factional stance such as Qu Qiubai."158 Zhang also ordered the curators to highlight Liu Shaoqi, newly ascendant, in the development of the Party, while Liu in fact had only a limited connection with Mao before the 1940 s. ${ }^{159}$ In

\footnotetext{
$155 \mathrm{Hu}$,"Shaoshan maozedong jiuju," 28-30; and Ma Y., "Can jia chou jian," 29-31.

${ }^{156}$ For the orientation and the content of the exhibition, see "Guanyu shaoshan maozedong"; "Shaoshan maozedong tongzhi jiuju fuzhu chenlie jihua" [The plan for the complementary exhibition of Comrade Mao Zedong's Old House in Shaoshan], July 30, 1964, HPA 143-1-252; and "Shaoshan maozedong tongzhi jiuju chenlieguan chenlie gongzuo jianbao" [Brief report on the curatorial work of the Exhibition Pavilion of Comrade Mao Zedong's Old House in Shaoshan], November 3, 1964, HPA 143-1-386. For Tao and Zhang's opinion, also see the Brief Report. For comments from central officers, see "chengji Xu Guangxiao."

157 In this meeting, Mao ignored the suggestion that the radical economic movement should turn realistic. Instead, he claimed there were poisonous revisionists in the party and accommodated further political campaigns. See "Beidaihe huiyi (Beihaihe Meeting)," Baidu Wikipedia, last modified August 8, 2014, http://baike.baidu.com/view/424284.htm.

158 "Shaoshan maozedong tongzhi."

159 "Shengwei Zhang Pinghua shuji dui shaoshan chenlieguan de zhishi” [Secretary of the Provincial Party Committee Zhang Pinghua's instruction on Shaoshan's museum], September 23, 1964, HPA 213-1-738.
} 
addition to the exhibition, another discursive transformation involved the tour guide of the museum. The government now hired its professional and exclusive team to monopolize the interpretation of the collections. When the museum was overcrowded with visitors, public speeches would be held in the early morning, usually to thousands of people. ${ }^{160}$

After the construction and exhibition were ready, Tao and Zhang came to examine the buildings in September. After their examination, a formal name was assigned to the museum: the Exhibition Pavilion for the Old House of Comrade Mao Zedong. ${ }^{161}$ The museum was officially opened on October 1, National Day, in 1964. No celebration or media coverage was allowed, in order to continue to keep the project a secret from Mao. ${ }^{162}$

The title of the museum proved to be another deliberate scheme to soften the political impact of the building. As Ma Yuqing, then the director of the museum, recalled, the common title for similar projects, jinian guan (memorial building), was inappropriate for connoting that those to be commemorated were either historical or deceased, neither of which applied to Mao. Terms such as zhanlan guan (exhibition hall) and bowu guan (museum) implied a large authoritative institution that monopolized the authorship, possession, or interpretation of its display. ${ }^{163} \mathrm{In}$ fact, neither Mao's house nor the collections were exclusive properties, and any pretentious labeling might cause serious political problems. The final decision, jiuju chenlie guan

\footnotetext{
160 Shaoshan Mao Zedong, Shao Shan Mao Ze Dong,112, 118.

161 The name may be the result of Tao and Zhang's discussion. See "Shengwei Zhang Pinghua"; and Gao, "Shao shan mao ze dong," 39-40. Hu Qingpo recorded that the name was put forward by Tao Zhu, see Hu, "Shaoshan maozedong jiuju," 31 .

162 For information about the construction and the opening of the museum, see Gao, "Shao shan mao ze dong tong zhi," 49-50; and "Guanyu gaijian shaoshan chenlieguan gongcheng sudu qingkuang de huibao" [Report on the current construction of Shaoshan's Museum], May 12, 1964, HPA 213-1-738; and Shaoshan Mao Zedong, Shao Shan Mao Ze Dong, 59. See also Ma S., Shao Shan, 177.

163 Ma Y., "Can jia chou jian," 49.
} 
(exhibition pavilion for the old house), sought to downplay any suspicion of arbitrary authority by disguising the museum as a subordinate pavilion of Mao's house, from which it borrowed all its authorship and collections. However, the exhibition incorporated a much larger content, and the building was far more expensive than the farmhouse. The title sounded as if the costly project were only a functionalist answer to the growing number of Mao collections across China. Tao and Zhang's sincere devotion was thus insulated from of any individual political speculation.

\section{A Milestone in Mao's Cult of Personality}

The establishment of this museum and its exhibition manifestly signaled a new era of Mao's commemoration in Shaoshan. It was a telling reading of the current state of Mao's cult of personality: still brewing but about to boil. The upgrading of Mao's birthplace may be inadequate according to the communist collective tradition or Mao's will, but it was highly profitable in the eyes of local politicians. In these complex circumstances and with Tao's guidance, Shaoshan undertook a distinct path toward cosmopolitan transformation, rejecting the prevalent monumental styles in Beijing, the exhibition architecture, and reclaiming the native rural identity as its representative core. This may have been a satisfactory solution in the eyes of Mao's followers, given that there were no exceptional architectural icons in the cult of Mao. On the other hand, the accentuation of Shaoshan's rural identity only reinforced its regionality and thus its peripherality. Facing the rise of Mao's cult, Shaoshan's transformation to a cosmopolitan site was only partially realized.

Nevertheless, the museum was still a milestone in Mao tributes. This was the first architectural program dedicated solely to Mao, and this breakthrough meant a lot in itself. In previous dedications, Mao's representation was impaired by function and 
form: articles and paintings, with signifiers such as texts, images, and frames. In builtenvironments, however, the signifier was landscape and architectural space which can be viewed and experienced. With architectural media, audiences skipped any course of symbolic representative systems but were directly absorbed into the system of representations. During the "authentic" spatial experience in Mao's house, the leader was not represented but was actually "present" before the viewer. And through experiencing the curatorial space, the viewers entered the signifier and became one part of the signified, or the represented, in the commemoration of Mao. In this way, the memorial museum allowed for physical bodies to be iconized as a part of the symbolic rituals in the larger commemorative program. In a sense, the museum was a modernized familial temple in Mao's cult, offering both an interpretative and an experiential structure for the secular religion of Mao.

Although the museum was a prominent offering to Mao, the surge of Mao's cult proved so powerful and so quick that Tao and Zhang soon grew unsatisfied with the museum's regional, marginal status. After their examination of the museum in September 1964, Tao recommended adding two independent exhibitions, a wenyi shi (art and literature room) and a junshi shi (military room) after the biographical introduction of Mao. These two rooms, according to Tao, would act as an independent, comprehensive celebration of Mao's military talents and literary gifts. ${ }^{164}$ Zhang, meanwhile, directly opposed the opinion of a central officer who argued that the museum should be small, declaring: "Some people said the museum in Shaoshan shouldn't be too large. This is wrong. It shall try as hard as possible to be a museum accommodating the most abundant material about our revolution in this country. This

164 "Shaoshan maozedong tongzhi”; "Shengwei Zhang Pinghua"; and Ma Y., "Can jia chou jian," 49-51. 
shall be realized step by step." 165 In 1965, the museum added three more exhibition sections chronicling Mao's activities during the Second Sino-Japanese War and the Third Revolutionary Civil War and after the PRC was founded. ${ }^{166}$ In this way, the exhibition transcended any specific locality, any commitment to Shaoshan alone, and instead strove to encompass the whole of Mao and, by extension, the whole of China. The interpretative programs in Shaoshan abandoned their foundation in rural identity and embraced the cosmopolitan transformation.

The transformation of memorial constructions was much more difficult. The biggest challenge lay in Mao's seeming ineradicable identification with rural Shaoshan. Because of Mao's origin story, Shaoshan was fixed in the wider Chinese imagination: a pastoral homeland, a peripheral agricultural community, and a revolutionized society. Mao returned to Shaoshan in June 1966, shortly before launching the Cultural Revolution. Hearing of the new constructions, he was somewhat affronted and refused to visit the museum. ${ }^{167}$ However, despite his desire to preserve Shaoshan's rural identity, Mao acquiesced to the new memorials, yielding to the need to magnify his cult as he stood to wage the Cultural Revolution. Tao and Zhang's offering, undercover for years, was finally sanctioned. With the chaos of the Cultural Revolution on the horizon, Mao's birthplace, Shaoshan, gained its last moment of peace. The construction of the Exhibition Pavilion was the last memorialbuilding activity in Shaoshan between 1949 and 1966.

\footnotetext{
165 For Tao and Zhang's comments, see "Shengwei Zhang Pinghua." This document paraphrased Tao and Zhang's comments after they examined the museum in September. Ma Yuqing records that Tao wanted two exhibitions for Mao's military and literary talents, respectively. See Ma Y., "Can jia chou jian," 50.

166 Shaoshan Mao Zedong, Shao Shan Mao Ze Dong, 92.

167 When Mao returned to Shaoshan in 1966, he was preparing the Cultural Revolution and was in a downcast mood. Upon being invited to the museum, he snapped, "I'm a stand guard there every day [referring to a statue in the museum]. Why do you need me to go there?" It is also recorded that Mao declared that there were many revolutionaries in Shaoshan and that they, rather than his family alone, should be exhibited. See Ma S., Shao Shan, 179; Gao, "Shao shan mao ze dong," 39; and Liu Wentao, Wu Mingfan, and Wu Jianguo, "Cong maolu dao shengdi: ji shaoshan maozedong tongzhi jinianguan" [From farmhouse to sacred land: On the Shaoshan Memorial Museum of Comrade Mao Zedong), Wenshi jinghua [Gems of culture and history] 2 (1999): 47.
} 
In the last three chapters, we have reviewed the restoration of Mao's old house, the manufacture of a spatial memorial, the urban planning during the Great Leap Forward, and the conception and execution of Tao's Exhibition Pavilion. Over the years, Mao's birthplace had been eagerly seeking a memorial language that would assimilate both its cherished rural identity, a critical ingredient in the public estimation of Mao, and prevailing metropolitan traditions. Nevertheless, Shaoshan was such a significant memorial in the PRC that the artistic representation of its meaning far trancended architectural design. The next and final chapter will survey a number of characteristic landscape paintings of Shaoshan and thereby offer a deeper understanding of the representative nature of the village. 


\section{CHAPTER V}

\section{THE VISUALIZATION OF THE RURAL IDENTITY: THE LANDSCAPE PAINTINGS OF SHAOSHAN}

It was only after the founding of the PRC, and the resulting national hunger for honoring Mao's roots, that Shaoshan became a popular theme for landscape painters. When the government reinforced ideological controls in the late 1950s, artistic production was put under rigorous supervision. A set of official iconography was contrived to systematize pictorial interpretation of Shaoshan. This iconographic language bore a significant political mission: to visualize the rural identity of Shaoshan and, as such, to interpret Maoist historiography and mobilize the masses. In this chapter, I will investigate CPC's gradual political exploitation of landscape paintings of Mao's birthplace for ideological inculcation and political propaganda. By reviewing some indicative works produced between 1959 and 1976, I will analyze the underlying tenets of Socialist Realism and the function of propagandistic paintings birthed by the movement.

\section{$\underline{\text { Li Xiongcai's Naturalism }}$}

Beginning in May 1959, the Hunan provincial government invited several artists from outside Hunan to paint for the Shaoshan Landscape Album to recognize the tenth anniversary of the Republic. The first artist to report was Li Xiongcai, who had visited Shaoshan in 1955 and produced the first paintings of the village in China. In 
these, made in 1955 and 1959, Li took a realist approach in offering individual portraits of all renowned local sites, including Mao's Old House, the pond Mao regularly swam in, Shao Mountain, and the Mao Ancestral Temple, along with other public buildings (Figure 60, 61, 62). Li's illustration of Shaoshan resembled a scientific ethnographic survey that lacked artistic reproduction. Li acted as a stenographer who immediately and faithfully recorded the landscape he encountered, applying a natural perspective, a simple composition, and a loose atmosphere with most details blurred as if in mist. The drawings employed a lot of light brushes and swift lines recalling the style of sketching.

In fact, Li's unsophisticated scheme probably stemmed from the CPC's Socialist Realist guideline that asked painters "to sketch from nature." 168 It is likely, then, that the chief purpose of Li's casual style was to provide a simple realist representation of the village. Furthermore, his individual portraits also offered a convenient template for album production. Nevertheless, Li, with his ethnographic strategy, established a tradition for later depictions of Shaoshan. Individual portraits became a regular mode for representing of the village, and local officers, as if to encourage similar productions, would routinely lead future artists around on a complete survey tour of the village.

\section{Fu Baoshi’s Shaoshan Scroll: A Pastoral Homeland}

\footnotetext{
168 According to Wikipedia, "Socialist Realism is a style of realistic art that was developed in the Soviet Union and became a dominant style in other socialist countries[. . . . Socialist Realism often glorifies the roles of the meek and working class and the struggle for its emancipation. "Socialist Realism," Wikipedia. Last modified Sept. 2, 2014. http://en.wikipedia.org/wiki/Socialist realism. During 1950s in China, there was an influential movement in the field of landscape painting. In the name of Socialist Realism, the government encouraged painters to abandon the imperial tradition, which adhered to ancient styles and compositions. Artists were called upon to capture concept and style from nature and to depict the real landscape of their motherland. Later on, more strict political reins were put forth and only a few motifs were approved, such as the portrayals of Mao's poems, activist figures, and production scenes. This history of Chinese landscape painting comes from Chen Lvsheng, Xin Zhongguo Meishu Shi: 1949-1966 [A pictorial art history of the PRC: 1949-1966](China Youth Press, 2000). For the concept of sketching from nature, see Ai Qing, "Chinese transliteration" [On Chinese landscape painting], Art and Literature (June 1953).
} 
The next artist summoned to Shaoshan was Fu Baoshi, who arrived on June 6, 1959, just weeks before Mao's visit in 1959. Local officials offered Fu a Li-styled ethnographic tour, but the outcome went beyond their expectations. Fu disagreed with Li about ethnographically portraying landmarks, asserting that "pure naturalist presentation fails to emphasize Shaoshan's 'key point' as merely numbering the spots." ${ }^{169}$ With a taste more selective and mature than Li's plain realism, Fu conceived a different, panoramic representation of Shaoshan. This allowed him to synthesize the various types of scenery and distill the real representative value of the village, which he enumerated as his "key points": "Chairman Mao's Old House and the Shao Mountain — with all else coming next to them." ${ }^{, 170}$ Moreover, Fu employed a traditional genre, the scroll painting, in concert with his panoramic scheme. The elongating proportions of a scroll enabled him to include a full-scale representation of the village, while its unique reading process ensured a segmented while complete narrative. ${ }^{171}$ In his Shaoshan Scroll, Fu arranged a staged, hierarchical narrative with manifold scenes and bound up with his key points (Figure 63).

For Fu to effectively convey his key points, especially Mao’s Old House, required deliberate design. In searching out the best viewpoint to sketch the house, $\mathrm{Fu}$ found that "circling around the pond where Chairman Mao used to swim proved to be

\footnotetext{
${ }^{169}$ Fu Baoshi, “Zai mao zhuxi de guxiang--shaoshan zuohua xiaoji” [Notes on painting in Chiarman Mao's hometown, Shaoshan], in Fubaoshi meishu wenji [An art anthology, by Fu Baoshi](Shanghai: Ancient Books Publishing House, 2003): 466-467.

${ }^{170} \mathrm{Fu}$, “Zai mao zhuxi," 466-467.

171 Jerome Silbergeld has observed some distinct features of handscroll paintings: "The painting is viewed from right to left, as one reads in Chinese, unrolling a bit at a time from the roller and transferring the excess to a loose roll temporarily maintained around the stretcher on the right. About one arm's length is exposed at a time for viewing." Jerome Silbergeld, Chinese Painting Style: Media, Methods, and Principles of Form (Seattle and London, 1982), 12-13. Wu Hung notes four features: a horizontal composition, a limited height and far greater length, the "scroll" form, and the "unrolling" process in executing and viewing a painting. Wu concludes that, "In terms of both painting and viewing, a handscroll is literally a moving picture, with shifting moments and loci. A handscroll, when handled and viewed properly, is a series of consecutive sub-frame, not a monolith in s single frame." Wu Hung, The Double Screen: Medium and Representation in Chinese Painting (Chicago: University of Chicago Press, 1996): .
} 
of great importance in properly viewing and composing the picture."172 The proper composition, as it turned out, was to put the house in the vanishing point of linear perspective, an innovation breaking from his previous draft and Li's works (Figure $64,65)$. Moreover, Fu set the house at the end of the scroll as the final, dominant figure of the panorama. In order to heighten anticipation for the house, he highlighted a number of referential features as heralds: the red flags, the welcoming archway, the plaque with a red arrow, and the endless woods bridging the canvas. Therefore, while viewers unrolled the scroll, the continuous introduction of features would incrementally immerse viewers in a realist but well-plotted, evolving pastoral landscape that culminates at the facade of Mao's House.

Fu's deliberate composition was well rewarded. Official approval together with Fu's own advertisement brought his paintings extensive exposure, ${ }^{173}$ and the works became a classic reference for future representations of Shaoshan. The reasons for this lay in their sophistication and subtlety. Unlike Li's plain realism, Fu's embedded a political message that only enhanced the veneration of Mao present in the works. In advocating realist landscape painting, the government was in fact anticipating the naturalization of an artificial cultural construction. Fu's works, with their imputed natural and unbiased eyes, answered the demand to depict "not simply as 'objective reality' but reality in its revolutionary development," ${ }^{174}$ reality "on a higher plane,

\footnotetext{
172 Fu, "Zai mao zhuxi," 464.

173 After Fu finished his paintings in July 1959, he was assigned to work for the Great Hall of the People. On July 8, 1959, Fu's Shaoshan Scroll was published in the People's Daily. On July 24, 1959, Fu's Chairman Mao 's Old House was published in the People's Daily. From 1959 to 1960, Fu's paintings of Shaoshan and his article "Zai mao zhuxi de guxiang -- shaoshan zuohua xiaoji” [Notes on painting in Chairman Mao's hometown, Shaoshan] were published in a number of newspapers, including the New Yangon Newspaper (August 8, 1959), Tianjin Pictorial (August 10, 1959), Yuhua [Rain flower](September 1, 1959), Dongfeng Pictorial (Apr. 16, 1960), and Jiangsu Pictorial (July 1960). The Shaoshan Scroll was also exhibited in the $3^{\text {rd }}$ National Exhibition of Works of Art in Beijing on June, 17, 1959. For publication and exhibition information, see Xinhua, Sheng Di Shao Guang: 20 Shi Ji Zhong Qi Zhong Gguo Hua Zhi Shao Shan Tu Xiang [The sacred place Shaoshan: Shaoshan iconography in Chinese traditional painting in the mid-20th century](Beijing: Cultural and Art Publishing House, 2011): 43-44. 174 A. A. Zhdanov, "Soviet Literature - the Richest in Ideas, the Most Advanced Literature" (Speech to the Soviet Writers Congress, August 1934), Marxists Internet Archive (marxists.org), 2004. accessed September 17, 2014,
} 
more intense, more concentrated, more typical, near the ideal, and therefore more universal than actual everyday life." ${ }^{175}$ Fu's use linear perspective stresses the centrality of Mao's house "as a universal reality[... . ] [the] only one, external subject for the object it represents." ${ }^{" 176}$ His panoramic composition and sensitive highlighting of the referential features, which were in reality too tiny and dispersed to be captured at one time, furnished an omnipresent reminder of the political significance of the village. $\mathrm{Fu}$, with his realist painting, indeed offered a pictorial interpretation of ideological tenets. And he himself recognized that, later reflecting on painting the scroll: "Comrades have told me stories and offered ideas to improve my painting. In fact I'm just visualizing everyone's thoughts."177

The "thoughts" Fu had in mind clearly bent toward Mao. The central position and the frontal view of the house affirm a constant gaze as a declaration of authority. The systematic referential features segregate while mediating between that greatness and the rural wilderness. Fu was claiming that, though in the remote periphery, Mao's house had always been literally the unforgotten and unmistakable center, distinguished from other houses, sanctified and memorialized. The presence and presentation of the house spelled righteousness and reverence. Of course, the house was only a symbolic icon. Fu was referring to Mao.

\footnotetext{
https://www.marxists.org/subject/art/lit_crit/sovietwritercongress/zdhanov.htm.

${ }^{175}$ Mao Zedong, "Talks at the Yan'an Forum on Literature and Art" (May 1942), Marxists Internet Archive (marxists.org), 2004, accessed September 17, 2014, https://www.marxists.org/reference/archive/mao/selectedworks/volume-3/mswv3 08.htm.

${ }^{176}$ Commenting on perspective, Denis E. Cosgrove writes that "an important effect of linear perspective is to arrest the flow of history at a specific moment, freezing that moment as a universal reality[. . . ... Perspective, in structuring and directing universal reality at a single spectator, acknowledges only one, external subject for the object it represents[... . ]... The claim of realism is in fact ideological." Denis E. Cosgrove, Social Formation and Symbolic Landscape (London: University of Wisconsin Press, 1998), 26. On this page, commenting on perspective, Cosgrove suggests that "an important effect of linear perspective is to arrest the flow of history at a specific moment, freezing that moment as a universal reality[... .] Perspective, in structuring and directing universal reality at a single spectator, acknowledges only one, external subject for the object it represents[....] The claim of realism is in fact ideological."

${ }^{177} \mathrm{Fu}$, "Zai mao zhuxi," 466-467.
} 
After the establishment of PRC (People's Republic of China), Mao and other party leaders were looked to as the salvation of the country and received unmatched esteem. Huge affection was heaped upon them, and the masses passionately joined in the cult of personality, glorified the revolution, and commemorated their links with the leaders. Mao's house in Shaoshan partook of that veneration. ${ }^{178}$ In his painting, Fu was following the identification that exclusively acknowledged the house as Mao and the village as Mao's birthplace.

In addition to this affirmation of respect, Fu was also creating his pictorial interpretation of Shaoshan's rural identity. Centering on the house, his painting managed to convert the rural landscape into a coherent narrative about Mao's house. It planted a system of referential gestures into its rural environment and continuously reinforced the connection between the house's centrality and the surrounding landscape. In doing so, the painting successfully transformed the pastoral landscape into a permanent, symbolic image of Mao and his rural birth. And thus one connotation of Shaoshan's rural identity, that of Mao's intimate homeland, acquired a specific visual expression, an artistic language to be used in all later representations of Shaoshan.

\section{$\underline{\text { Socialist Realist Guidelines in Mid-20th Century China }}$}

A brief background survey of contemporary artistic trends in post-revolution China is needed to fully grasp Fu's aesthetic contribution. After the establishment of the PRC, the government nationalized all artistic and literary production. A peremptory principle, the so-called Socialist Realism, was put forward for writers,

\footnotetext{
178 In Shaoshan, such spontaneous affection can be detected in the naming of Mao's house. Soon after the village was taken over by communist powers, the locals branded Mao's house with the sign "zhongguo renmin weida de lingxiu mao zhuxi de jia" (Home of Chairman Mao, the Great Leader of the Chinese People). Ma S., Shao Shan, 8, 18.
} 
artists, and architects. At the 1934 Soviet Writers Congress, the Soviet politician A. A.

Zhdanov advanced a definition Socialist Realism:

In the first place, it means knowing life so as to be able to depict it truthfully in works of art, not to depict it in a dead, scholastic way, not simply as "objective reality," but to depict reality in its revolutionary development[....] In addition to this, the truthfulness and historical concreteness of the artistic portrayal should be combined with the ideological remolding and education of the toiling people in the spirit of socialism. ${ }^{179}$

In 1942, Mao also announced Socialist Realism as the CPC's guideline of delivering art and literature:

Our art and literature is for our proletariat, our peasantry and our soldiers, to whom the popularization and professionalization of art shall orient[....] Life as reflected in works of literature and art can and ought to be on a higher plane, more intense, more concentrated, more typical, near the ideal, and therefore more universal than actual everyday life. ${ }^{180}$

In fact, it was a matter of course for Communist parties, who distinguish themselves by ideological self-surrender, to embrace realist art. One mechanism of ideology operates as a system of imagery with which to interpret the world and, ultimately, to remake it with that interpretation. It is on such a reimagining of reality that communist parties live and rely. Realist painting, by following an exclusively "correct" system of presentation, claims like ideology that its reflection of the world is so congruent with reality that the two become interchangeable and even consubstantial. Realist art is therefore favored by Communists as a medium through which to revive and expose the forsaken and oppressed burdened under the preMarxist reality.

In Socialist Realist art, as a result, the depicted reality acted as the conduit between art and the dominant ideology. Artists functioned as mapmakers picturing the

179 A. A. Zhdanov. "Soviet Literature."

${ }^{180}$ Mao, "Talks at the Yan'an Forum." 
topography of the party-sanctioned reality, and as miners excavating visual materials to feed party hegemony. Their production was then filtered through nationalized valuation systems that governed publication and exhibition. Only those pieces that were pronounced ideologically compliant and likely to further the union between art and politics were sanctioned. In sum, Socialist Realism was in fact a continuous distortion of and alienation from lived reality in the name of doctrinal reality. It was a dynamic dialogue between art and politics where an "authentic" national landscape was invented and publicized. A spectacle society was thus constructed from semiotic icons and visual codes, an imaginary totality dictated by party leaders and visualized by cultural workers.

This nationalized system of cultural production had a profound influence on artists. One impact involved in iconography was that the reproduction of icons appeared necessary to achieve a "more intense, more concentrated, more typical" representation. ${ }^{181}$ In the case of Shaoshan, Fu proved to be a major actor in this reproduction. His representation readdressed the natural presentation of Shaoshan's landscape and manufactured an ideology-oriented image. His conscious recreation of the natural landscape earned him a prominent position in the cultural industry. It became a classic visual interpretation of Mao's birthplace, a "correct" presentation of the landscape. Fu's innovative iconography gained widespread attention in national publications and exhibitions, which only informed the official approval. His specific patterns were thus regarded as the ideal visual codes of Mao's birthplace according to party ideology.

In fact, most depictions of Shaoshan would follow Fu's path. Two extreme examples are the paintings Song Wenzhi and Li Xiongcai prepared for exhibition at

181 Ibid. 
the Chairman Mao Memorial Hall, the mausoleum of Mao Zedong, after Mao's death in 1977 (Figure 66, 67). Song's and Li's paintings were the ultimate pictorial eulogy of Mao. Both of their works, entitled Dawn of Shaoshan, included Mao's house, large areas of misty pinewoods, and endless peaks in the distance. The agricultural village was now acknowledged only as a mystifying pastoral host of the house, with no additional details. This iconography, once the innovation of Fu Baoshi as a signifier of Mao's rural descent, reached its pinnacle in this final memorialization of Mao.

\section{The Poetic Paintings of 'To Shaoshan': A Revolutionized Community}

Days after Fu Baoshi finished his scroll, Mao returned to Shaoshan and recorded his own interpretation of the rural landscape. His poem 'To Shaoshan' began circulating among officials and intellectuals right after its completion. Mao had it revised by several literati and published the piece in the People's Daily and in his poetry anthology in $1964 .{ }^{182}$ Mao's poems had won such great fame that "almost everybody had one anthology[.... ] [and] there was a pervasive fervor to study Chairman Mao's poems." 183

Fu Baoshi, too, soon joined the "fervor" for Mao's writings by dedicating other paintings of Shaoshan to Mao, in May 1960, February 1964, and September 1964 (Figure 68, 69, 70). In several respects, these subsequent pieces and the Shaoshan Scroll differed dramatically. The paintings, now normally scaled, deployed a onefold, compact theme rather than a manifold narrative. The awkward perspective in the

\footnotetext{
182 The poem in the first chapter was its original version. Mao consulted with other intellectuals about the poem during the Lushan Conference and altered parts. The piece published in the People's Daily and Mao's anthology was the final edition. For the first edition and the changes made to the poem, see Ma S., Shao Shan, 88.

${ }^{183} \mathrm{Hu}$ Shouren, "Du maozhuxi xin fabiao de shici shishou" [Studying the Ten Poems newly published by Chairman Mao],. Journal of Jiangxi Normal University (Philosophy and Social Sciences Edition) (January 1964): 1. For the popularity of Mao's poems, also see Xiao Difei, Jiang Weisong, Gao Heng, Huang Yunmei, Yin Menglun, Xu Wendou, Meng Guanglai, Sun Sibai, and Gao Lan, "Bitan xuexi maozhuxi shici shishou" [Writing on the study of the Ten Poems by Chairman Mao], Journal of Literature, History, and Philosophy (January 1964): 7-19.
} 
scroll regained its objectivity. The "key point," Mao's house, enjoyed neither a frontal nor a central depiction. Instead, large areas of agricultural fields occupied the canvas. No peasants or animals were present, only repeated patches of field. It appeared that the paintings had abandoned previous plotted schema or referential iconography. The landscape seemed to have regressed to the unmysterious works of $\mathrm{Li}$, to the "incessant waves of the endless paddy," to an unadorned presentation of the countryside.

The paintings would be indeed naturalistic except that Fu Baoshi repeatedly inscribed the poem 'To Shaoshan' on the top of the canvases and titled all the works after Mao's poetry. In fact, the pictorialization of Mao's poems was one principle genre of Socialist Realist art. At a time when artists faced increasing censorship and images were assessed as visual ideology, a plain pictorialization of Mao's poems indeed embodied the most politically correct theme. Painters of the genre, however, had to forego any individual interpretation of the object and fixate instead on the single subject—or, as the party would have it, the only subject. Likewise, Fu simplified his art and thereby expunged even the possibility of ideological discord between his work and Mao's "incessant waves of the endless paddy." The elimination of Fu's referential icons reduced the work to a realist image, while the imposition of Mao's poem iconized the image. The identity that Mao's figure had cast for Shaoshan, that of a peasant society massing for revolution, thereby achieved a visual embodiment within these landscape paintings.

This new embodiment of Shaoshan relied on the reproduction of a new iconography. In these works, Mao's house lost its autonomy. The green field, on the other hand, was the only outstanding character, the exclusive symbol in the countryside. Here, Fu was indeed departing from his old style and adopting a different iconography. Like Mao, Fu was using the "incessant waves of the endless paddies" to 
signify the revolutionized community, which, as I argued earlier, constituted the second connotation of Shaoshan's rural identity.

Owing to Mao's poem, such an emphasis on agricultural fields was common in contemporary representations of Shaoshan. Peng Zhaomin's oil painting Chairman Mao Returning to Shaoshan in 1959, for example, ignored Mao's house completely (Figure 71) and, further, neglected any visual icons specific to Shaoshan. Instead, it included anonymous, salutatory people marching in the field, images lifted directly from Mao's poem. In addition, a plaque with text was added, noting that the field was the property of the People's Commune, to highlight the revolutionary subject. ${ }^{184}$ Shaoshan was now represented exclusively through the revolutionized peasants.

The Integration of the Revolutionized Community and the Pastoral Homeland

After the PRC was founded, the identification of Shaoshan as the countryside alight with revolution had spread across the country. Suddenly, the peripheral locals in Shaoshan were awash in cultural and political value for the very quality, their rural identity in Maoist ideology. The central government spearheaded this effort, propagandizing the village as an "advanced representative" of socialist development in order to mobilize the masses. Since the early 1940s, the People's Daily had kept the peripheral village in constant exposure. ${ }^{185}$ More than one third of those Shaoshanrelated pieces spotlighted Mao's house as a site of worship, to be visited, renovated,

\footnotetext{
184 The People's Communes, which were born during the Great Leap Forward and lasted until 1983, became official state policy in 1958 after Mao visited an unofficial commune in Henan Province. The communes had governmental, political, and economic functions. In the communes, everything was shared, and production and distribution were assigned by the leaders according to governmental budgets. In 1983, the People's Communes were replaced by townships.

185 According to my account, there were 2 news pieces related to Shaoshan in the People's Daily in 1950. The number was 4 in 1951, 3 in 1952, 3 in 1953, 2 in 1954, 4 in 1955, 7 in 1956, 0 in 1957, 5 in 1958, 3 in 1959, 12 in 1960, 13 in 1961, 3 in 1962, 8 in 1963, 14 in 1964, and 10 in 1965. The frequency of Shaoshan-related pieces closely correlated with fluctuations in Mao's national standing. The news pieces were accessed through the full text database of People's Daily, from the National Library of China.
} 
decorated, and admired. More than half hailed the village as a pioneer in military struggle, economic production, political movement, and socialist culture. Also trumpeted, of course, was Shaoshan's distinction as the birthplace of a great leader and, therefore, as the fountain of Chinese communist revolution. Exploiting these two identities, the outlying village entered the very center in China's ideological mapping.

Fu's ambivalence notwithstanding, Mao's house and the peasantized revolution were tightly bound in the official discourse, as this survey of the People's Daily features about Shaoshan reveals. Per the CPC's propaganda, Mao with his rural descent was an ideal representative of the peasant community in China. In the oil painting Chairman Mao Returning to Shaoshan in 1959, the grouping of Mao, farmers, and the field bespeak a symbolic partnership and overlapping identification of this pair. The unification of Mao and Shaoshan farmers, along with the artistic merging of Mao and peasant society as a whole, provided a symbolic constellation through which the party leaders, and especially Mao, achieved legitimization and repute among the peasants. This constituted one critical process in the communists' migration to the central stratum of the country. Commenting on Stalin, Mao, and this new type of charismatic leader professing to represent the masses, Alfred Rieber observes a common path:

In the old regimes, the primary ethnic and regional identities of these future leaders were peripheral to the traditional power centers. Their political goals were to build or rebuild the state in order to legitimize their role as leaders of a new type. The nature of their origins also disposed them to suspect conventional forms of nationalism. In a period of political and social uncertainty, they sought to reconstruct in radical ways both state and society in order to locate themselves at the symbolic and real centers of power. ${ }^{186}$

The representative unification of Mao and the peasants illustrated his, and the party's,

186 Alfred J. Rieber, "Stalin, Man of the Borderlands," The American Historical Review 106. 5 (December 2001): 1654-1655. 
and subsequently Shaoshan's transition toward the symbolic center of the reconstructed state of China.

The Hunan government was also anxiously pursuing this symbolic integration with the leader. Upon the tenth anniversary of the National Day, the government issued two self-advertising publications: the aforementioned Shaoshan Landscape Album and an introductory pamphlet simply titled Shaoshan. Both publications begin with an homage to Mao, his rural birth, and his leadership. Both describe the local participation in the communist revolution and new achievements in socialist construction — which, of course, were led by and credited to Mao. Far from its humble agrarian persona, Shaoshan now proudly branded itself as a revolutionized community connected with and embodied by its favorite son.

The identification between Mao and his local community was explicitly manifest in the 'Shaoshan' pamphlet's illustrations. In the section about Mao's early revolutionary background, the pamphlet used Fu Shizhu's painting Comrade Mao Zedong Organized xue chi hui in Shaoshan ${ }^{187}$ to represent Mao's leadership in local peasant movements (Figure 72). Although the piece follows the popular subject of Mao lecturing to anonymous revolutionaries, it deviates from traditional patterns that picture the leader as the absolute core of the composition. The painting instead places Mao next to a more prominent, symbolic icon — the flame — and transforms Mao into a figurative embodiment of collective leadership. Wearing a distinctive long gown and attracting the gaze of his comrades, surrogates of the painting's viewers, Mao points to and thereby shifts our focus onto the document in his hand, at which point the purlins at the top converge and vanish as projections. Viewers will then find their eyes wandering between the document and the open book on the right, and finally settle on

${ }^{187}$ Hunan Renmin Publishing House, Shao Shan, 12-13. 
the flame towering between them. The flame, as it turns out, is the real center of the composition. It is the core of the visual pyramid anchored on the document, the book, and the oil lamp. It is also the core of a larger pyramid shaped by Mao and his closest companions. It is the physical center of the canvas where diagonals intersect, and it performs as the only illuminant of the scene.

In the iconography of the $\mathrm{CPC}$, the flame is a significant symbol of passion, hope, and remolding. Documents and maps also appear frequently, signifying the correct, salient collective leadership. ${ }^{188}$ In Fu Shizhu's painting, Mao indeed serves as an emissary bringing sparks of hope to the mobilized masses, and his mission and identity are closely associated with the local revolutionary community. It is the abstract symbolic icons, the document and the flame, that signify the established center, while it is the peripheral figures, including and mediated by Mao himself, that strive for that center as a group. This collaborative camaraderie between Mao and local revolutionaries is also found in the pamphlet's other illustrations, such as Guide the Way and Welcome Back to Shaoshan, Comrade Mao (Figure 73, 74).

Along with the symbolic unifying of Mao and the local community, the two connotations of Shaoshan's rural identity—as Mao's pastoral homeland and as an exemplary revolutionized community—also successfully merged with each other. The visual representations of those two connotations, rendered successively by Fu Baoshi in his Shaoshan Scroll and his later paintings, were finally integrated by Li Keran. Li had been painting Shaoshan since 1956. His earliest work followed the pastoral homeland tradition and had an analogous composition to Fu's Shaoshan Scroll (Figure 75). In 1969, Li offered another portrait of the village, adding parades of

${ }^{188}$ For the motif of Mao lecturing to the masses with the iconography of the flame and the document, see hunan gongchan zhuyi xiaozu, by Zhou Shuqiao (1971); wenwu zhidao yichi yizhang, by Yang Lizhou, Wang Yingchun, and Su Guang (1977); and maozedong zai liandui zhong jiandang, by Gao Quan (1977). 
pilgrims — soldiers, peasants, and others — and a small patch of field at the edge (Figure 76). In 1974, Li dedicated a renewed version of the 1969 piece as his most ambitious painting of Shaoshan (Figure 77). This time, he enlisted a more diverse crowd of pilgrims such as students, workers, and ethnic minorities to encompass the whole country. He also enlarged the scope of activities - marches, lectures, photographs, and even meditation - to make the piece an illustrated manual of pilgrimage behavior. The most significant change, however, was the greatly expanded agricultural field. Together with the field, Li highlighted multistory constructions, electrical towers, and a red archway_all icons symbolic of socialist progress in a revolutionized countryside. In Li's three paintings, the imagery of the "incessant waves" evolved over time and gradually gained acknowledgment as an established iconography fit to lie alongside Mao's house as signifiers of Shaoshan. His last painting provides an integral representation of the multilayered meaning of the rural identity, definitively twinning the two connotations Shaoshan artwork had come to acquire.

From Li Xiongcai's unvarnished naturalistic portraits, to Fu Baoshi's Shaoshan Scroll, to Peng Zhaomin's Chairman Mao Returning to Shaoshan in 1959, and finally to Li Keran's comprehensive illustrations, the post-revolutionary depictions of Shaoshan offered two different iconographies deriving from two different but interrelated connotations of Shaoshan's distinct rural identity. As Mao's birthplace, Shaoshan was inseparable from the charismatic leader in the popular imagination, and its pastoral landscape was thought to be an ideal background for his greatness. As a frontline in communist revolution, Shaoshan represented the mobilized masses, and its agricultural scenery, their place of fieldwork, was a pictorial metaphor for the revolutionary community writ large. 
Shaoshan thus distinguished itself from all other communist-memorial sites. As it apprehended and melded these two discursive and visual identities, Shaoshan transcended mere association with Mao and the masses to become directly equated to them-indeed, to become them. Shaoshan's unity with the masses elevates itself to the subject of communist revolutionary historiography, in which an eternal liberation was to be attained for everyone, everywhere. Shaoshan's oneness with Mao, on the other hand, exalts itself to the object of that historiography and the destination of that movement. Moreover, by unifying these two identities in the official discourse and artistic depictions of Shaoshan, an unbroken circulation of Maoist philosophy was enacted. Artists would use these works to venerate Mao and lionize the movement, earning the approval of official propagandists and thereby encouraging future artists to only expand or deepen these sentiments. The media was saturated with this content, and a uniform public identity was thus manufactured. These pictorial representations, along with the restoration of Mao's house and the architectural designs of the Exhibition Pavilion, share a political representative nature and constitute the central chapter of the art history of Shaoshan, a revealing microcosm of cultural production in the PRC. 


\section{CONCLUSION}

During the Cultural Revolution from 1966 to 1976, Mao's cult had entered its heyday and overwhelmed the entire country. Shaoshan in turn rose to become the most important Mao memorial site after Beijing. Accompanying this explosion in popularity, a multiplicity of political ritual practices were introduced in the village and dramatically transformed its commemoration culture. In this conclusion, I will briefly review some prominent characteristics of Shaoshan's memorial practice during the Cultural Revolution that reflect larger phenomena in Shaoshan's development in that period.

The most important one of these characteristics Shaoshan involved the fetishism tradition associated with ancient rituals across nations and cultures. Commenting on George Washington's birthplace, Bruggeman writes that "relics did not simply symbolize saints, they were saints[. . . .] Wrapped within this sentiment is a subtle hint of the sublime. To share, literally through land ownership or some other direct involvement, in Washington's birthplace is to share in his greatness." ${ }^{189}$ With the aforementioned features as a spatial memorial, Mao's house in Shaoshan, like Washington's in Virginia, allowed pilgrims to approach "the sublime." This sentiment was only intensified by Mao's near-apotheosis during the Cultural Revolution. Applying Bruggeman's analysis, Mao's house, a relic in his secular religion, became Mao himself in the eyes of his worshipers.

${ }^{189}$ Seth, George Washington, 17, 36. 
While his human body remained secluded in the Forbidden City, for pilgrims longing for access, Mao's house served as a substitute character. In 1966, nearly three million pilgrims went to Shaoshan, a number thirteen times greater than did so in 1965 and 39 times greater than in $1964 .{ }^{190}$ Then, at the pinnacle of Mao's cult of personality, their visiting experience was different from that of the 1950s. Wang Yijie, a local officer in Shaoshan in the 1960s, recalled people visiting Mao's house in 1966 as follows:

In front of Chairman Mao's Old House, the Red Guards learned that Chairman Mao used to swim in the front pond. Some people, as a result, took off their clothes and jumped in the pond to swim, even though it was freezing in winter[....] In the beginning they picked up little stones and tiles in front of the house. Then they picked off leaves and broke off branches. There was a loquat tree behind the house, and it was said that Chairman planted it, and the tree died, with all its branches stripped. Some people collected dirt under the walls, wrapped it in handkerchiefs, and took it away[... .] Some people leaned against the wall, folded their hands on their back, and [furtively] scratched the dirt wall, with tiles or knives, to get the dirt. Gradually, there appeared several holes in the wall and the house became a dangerous, substandard building $[\ldots]^{191}$

As described here, the worshipful treatment accorded Mao's house reveals a prominent mark of the fetishist tradition. With the house and Mao identified as one, the worshipers personified the building, trying to to physically interact with it as if they were interacting with Mao himself.

The suddenly prevalent fetishist tradition soon gave rise to a new pop culture phenomenon. Feeding Mao's cult of personality, the government minted a kind of virtual relic, the Souvenir Badge to Shaoshan, to disseminate the sacred gospel of Mao's house. ${ }^{192}$ (Figure 78) For the pilgrims to Shaoshan, the Souvenir Badge materialized and encapsulated their personal connection with the house and, as such,

\footnotetext{
190 Shaoshan Chorography, Shao Shan Zhi, 331.

191 Wang Yijie, "Zai shaoshan gongzuo de huiyi pianduan" [Some pieces of memory of working in Shaoshan], in Zai shao shan, 287-288.

192 Wang, "Zai shaoshan gongzuo," 287-288.
} 
with Mao himself. Wang recalls that "for the Red Guards who came to Shaoshan, there were three hot spots: Chairman Mao's Old House, the Exhibition Pavilion, and the Station for Souvenir Badge, all of which are open 24 hours and crowded with long lines every day." 193 The iconography of these Souvenir Badges contained a hint of idolatry. Mao's house occupied the center and was itself sanctified, exhibiting the typical characteristics of a saint: a front view, a constant gaze, a ceremonial costume, and a crowning halo. ${ }^{194}$

The fetishism and objectified sainthood culminated in an almost-literal idolatry, one that resurrected the ancient commemorative practice of building and offering sacred statues for modern China. Shaoshan, as a hub of Mao worship, embraced this phenomenon, absorbing it into its extant memorial landscape. In 1967, a railway station and a statue of Mao were built near Shaoshan. ${ }^{195}$ (Figure 79, 80) In the statue, Mao's right arm is raised in the air, his left held akimbo, as if giving a lecture to the public. In this way, when pilgrims flocking to Shaoshan emerged from the station, "Mao" would welcome them in a pose evocative of how he had first inspired them and instigated their rise. The statue was venerated as if it were Mao himself in the flesh. For example, there would be volunteers to build a shed to provide shelter for the statue, expressing that "it makes us uncomfortable to watch the senior Chairman [the statue] suffering in wind and rain." 196

\footnotetext{
193 Ibid., 286.

${ }^{194}$ For contemporary scholarship on popular art during the Cultural Revolution, see San Mu, "wenge zhong de 'Shengxiang' meishu yundong he guangshang shang de hongse bopu" [The icon arts of the Cultural Revolution and Pop Art in the squares], Tribune of Social Sciences (June 2006): 72-83; and Mingxian, Xin Zhongguo Meishu Tushi: 1966-1976 [A pictorial art history of the PRC: 1966-1976](China Youth Press, 2000).

195 For the construction of the railway station and Mao's statue, see "relie huanhu mao zhuxi juxing suxiang luocheng he shaoshan tielu shengli tongche" [Warmly hail the completion of Chairman Mao's statue and the opening of Shaoshan railway station], December 1967, HPA 159-3-3; "mao zhuxi juxing suxiang zai shaoshan weiran yili, shaoshan tielu quanmian jungong jintian zhengshi tongche" [The grand statue of Chairman Mao is constructed; Shaoshan's railway station is opening today], Changsha Evening, December 28, 1967; and Shaoshan Chorography, Shao Shan Zhi, 326.

196 Hou Yibing, "suiyue bianqian, mao zhuxi xiang jin an zai” [Time passes, how are Chairman Mao's statues now], renmin wang (www.people.com.cn), December 4, 2003, accessed November 18, 2014, http://www.people.com.cn/GB/wenhua/1088/2227972.html.
} 
The adoration heaped upon these statues, and Shaoshan's exuberant practice of these ancient rituals, cemented the village's position in Chinese commemorative culture. To further grow its stature, Shaoshan resolved to augment its modernity by adopting certain urban forms. As with Tao Zhu's museum, however, this adoption was only partial. The design of Mao's statue exemplified the continuing tension between and ultimate reconciliation of alien cosmopolitan and regional rural styles. During the Cultural Revolution, Mao-statue building was launched in Beijing and later spread across the country. These statues represented the older Mao, usually in a Red Army uniform and in a gesture of greeting. ${ }^{197}$ In Shaoshan, however, the artist designed a special presence for Mao. The 1967 statue portrayed Mao in his youth, wearing a long gown and lecturing like a prophet. The connection to Mao's upbringing was unmistakable. The gown reflects Shaoshan's humility, the prophesying the inspirational drafts of air that incited Mao and actuated the revolution. The youthful Mao, of course, reminded the statue's audience that his formative years, when he was stirred to revolution, were lived here, in Shaoshan. The urban and rural conceptions of Mao were thus distinguished; smoggy, warlike Beijing did not contaminate the pure Shaoshan air. The rural identity of the village, the statue design proclaims, stood strong.

The desire to uphold Shaoshan's unique character and special political meaning was likewise evident in the expansion of the Exhibition Pavilion. During the Cultural Revolution, a new type of memorial museum overwhelmingly became the metropolitan fashion in the architectural field. These museums, borrowing styles from

\footnotetext{
197 This representation of Mao replicated his appearance during the Red Guard parade in the Cultural Revolution. The first statue in this kind was constructed in Qinghua University on September 15, 1967. Since then, this type had spread China, only to disappearing in the late 1980s. See "mao zedong suxiang," [Mao Zedong statue] Wikipedia, last modified August 1, 2014, http://zh.wikipedia.org/wiki/\%E6\%AF\%9B\%E4\%B8\%BB\%E5\%B8\%AD\%E5\%A1\%91\%E5\%83\%8F.
} 
exhibition architecture and other revolutionary icons, were dedicated solely to Mao, as opposed to the Revolution as a whole, and were called "Long Live Palace."198 In 1969, after Mao imprisoned Tao Zhu over political disagreements, some officials declared that Tao's Exhibition Pavilion in Shaoshan was "a malicious misinterpretation of Mao" and suggested that it be replaced by a Long Live Palace, even selecting a site for the prospective building. ${ }^{199}$ However, the universal conception of Mao's birthplace was fixed in its rural identity, opposing any radical remaking of Shaoshan. Hua Guofeng, a local officer in Hunan Province, exemplified the will to protect Shaoshan from unwanted cosmopolitan influence. Hua communicated with various leaders in the central government, including Premier Zhou Enlai, to argue against the proposal. Under Hua's supervision, the "radical redesign" was appropriately downsized to a conservative expansion of the Exhibition Pavilion in a consistent style. ${ }^{200}$ And this reconciliation between modernity and tradition in Shaoshan penetrated even the most necessary technological compromises, with the aforementioned railway station deliberately kept distant from Mao's house. ${ }^{201}$ So great was the commitment to preserving Shaoshan's rural identity that step was made as a matter of official government policy.

After Mao died in 1976, the government inhibited Mao's cult of personality and the commemoration in Shaoshan. After the Tiananmen Square protest in 1989, however, the CPC reinforced ideological control and resumed the worship of the Communist revolution. Since the early 1990s, a multiplicity of memorials have been

\footnotetext{
198 For examples of these buildings, see Sichuan Mao Zedong Thought Long Live Palace in Chengdu in 1969, Guangdong Exhibition Museum in Guangzhou in 1969, and Changsha Exhibition Museum. Zhou Denong, Dai Lu, and Zhang Xiangwei, "zhongguo xiandai jianzhushi," 80-82.

199 Ma S., Shao Shan, 180-181.

200 For Hua Guofeng's supervision in expanding the Exhibition Pavilion, see Ma S., Shao Shan Dang An, 181182.

201 This is directly ordered by the central government. See "guanyu shaoshan tielu zhongdianzhan weizhi de tongzhi" [Advice for locating the terminal of Shaoshan's railway station], May 22, 1967, HPA 159-3-3.
} 
built to establish Shaoshan's leading role in the commemorations of Mao across the nation. Today, Shaoshan's commemorative culture has acquired yet a third dimension. Not only does Shaoshan remain the dominant center of Mao honoraria and a historical symbol of Maoist revolution, but it has also become a kind of litmus test through which each new generation of Chinese leaders demonstrates its revolutionary credentials and gains popular legitimacy. Every Chinese president since Mao's passing, from Deng in the 1970 s to $\mathrm{Xi}$ in the current decade, has made a pilgrimage to the once-tiny village in Hunan and paid public homage to its favorite son. ${ }^{202}$

The local memorials offer a revealing perspective through which to observe, and are themselves an embodied record of, socialist ideology, political ritual, and aesthetic dynamism in $20^{\text {th- }}$ century China. This study advances our understanding of and appreciation for these memorials. When I arrived at the village in July of 2014, I got the chance to witness the demolition of the old Exhibition Pavilion of Comrade Mao Zedong's Old House and the construction of a new memorial museum (Figure 81). It was impressive to compare the public's enthusiasm for constructing new memorials and their indifference in witnessing the demolition of the older ones. In contemporary China, the commemorative ritual of Mao and the CPC, along with its art and architecture, has not faded and feels as though it never will.

\section{$\underline{\text { Future Research Directions }}$}

Although it is an important case in Chinese art history in the $20^{\text {th }}$ century,

\footnotetext{
202 Deng Xiaoping visited Shaoshan on Oct. 19, 1973; Jiang Zeming visited Shaoshan on Mar. 11, 1991, and Dec. 20, 1993; Hu Jintao visited Shaoshan on Jun. 30, 1993, and Oct. 1, 2003; and Xi Jinping visited Shaoshan in 1966 and 1997 and on Mar. 20, 2011. See Song Dailun, "zhonggong liren lingdaoren mianhuai mao zedong hanjian jiuzhao" [Rare old photographs show the CPC's leaders commemorating Mao Zedong], Takungpao (www.takungpao.com), December 26, 2012, accessed September 14, 2014. http://photo.takungpao.com/politics/2013-12/1363983.html; and Li Fengfa, "siren zhongyang lingdaoren de shaoshan xing" [Four generations of the CPC's top leaders and their trips to Shaoshan], Mao Zedong Digital Library (www.mzdlib.com), accessed September 14, 2014. http://www.mzdlib.com/libszzy/MaoZeDongXingJiuShuJuKu/4826.html.
} 
Shaoshan, along with its commemorative culture, is actually severely understudied. Most research on the subject comes from China, which poses complications: in Chinese academia, exploration of Shaoshan has been confined to the field of history and bound, and possibly distorted, by the official ideology, where the authoritarian climate has discouraged deep examination of politically contentious memorial sites and commemorative rituals. This official background further restrains development in research methodologies. For example, Wan Xinhua's shengdi shaoguang, an eloquent work on Shaoshan's landscape paintings, conforms to the official historiography and adheres to traditional analytic frames and, as such, ignores more-theoretical constructions in discussing art production. The same problems exist largely in the research of architectural history.

Against this background, the contribution of my thesis is twofold: first, it unveils, for the West, the complex interplay between art/architecture and politics in postRevolutionary Communist China and particularizes its manifestations in rural and urban settings; second, it applies Western scholarly disciplines, including art history and memorial study, to the study of this interplay. Moreover, my research coins and introduces some new key words and novel perspectives, such as space politics, political rituals, and the tension between "center" and "periphery," in the study of Chinese modern architectural history. These keywords and perspectives would provide new angles in observing the memorial built-environments in China, such as the Ten Great Buildings in 1959, the Chairman Mao Zedong Mausoleum in 1977, and even the Chinese Pavilion in the World Exposition in 2010. In the contemporary authoritarian environment of China, the political rituals in art and architecture will endure and begs for persistent academic research. It is my hope that this study may contribute to this enterprise. 


\section{ILLUSTRATION}

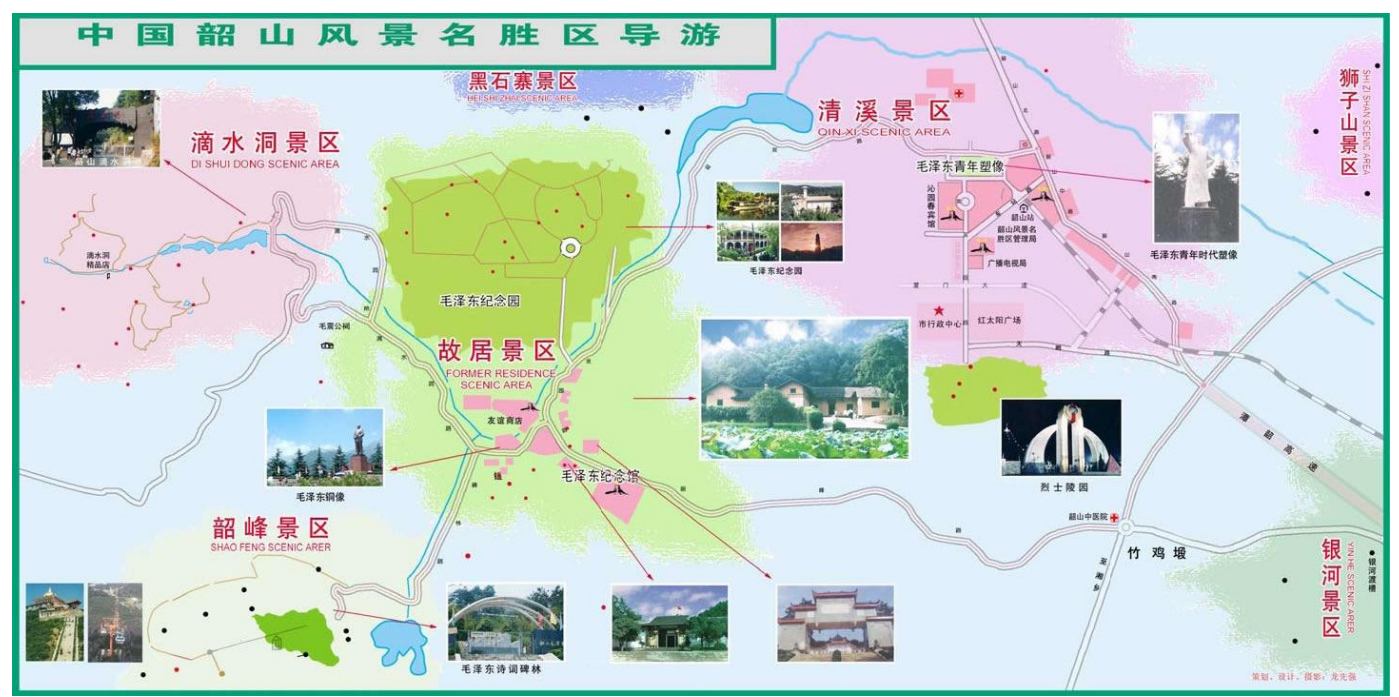

Figure 1. Tourist map of Shaoshan village. The Provincial capital, Changsha, is to the northeast. Image from "Shaoshan fengjing mingsheng qu lvyou shitu" [Map of Shaoshan's Scenic Areas], zhongguo shaoshan (www.shaoshan.gov.cn), accessed March 11, 2014,

http://www.shaoshan.gov.cn/Photo/ShowPhoto.asp?PhotoID=20\#Title.

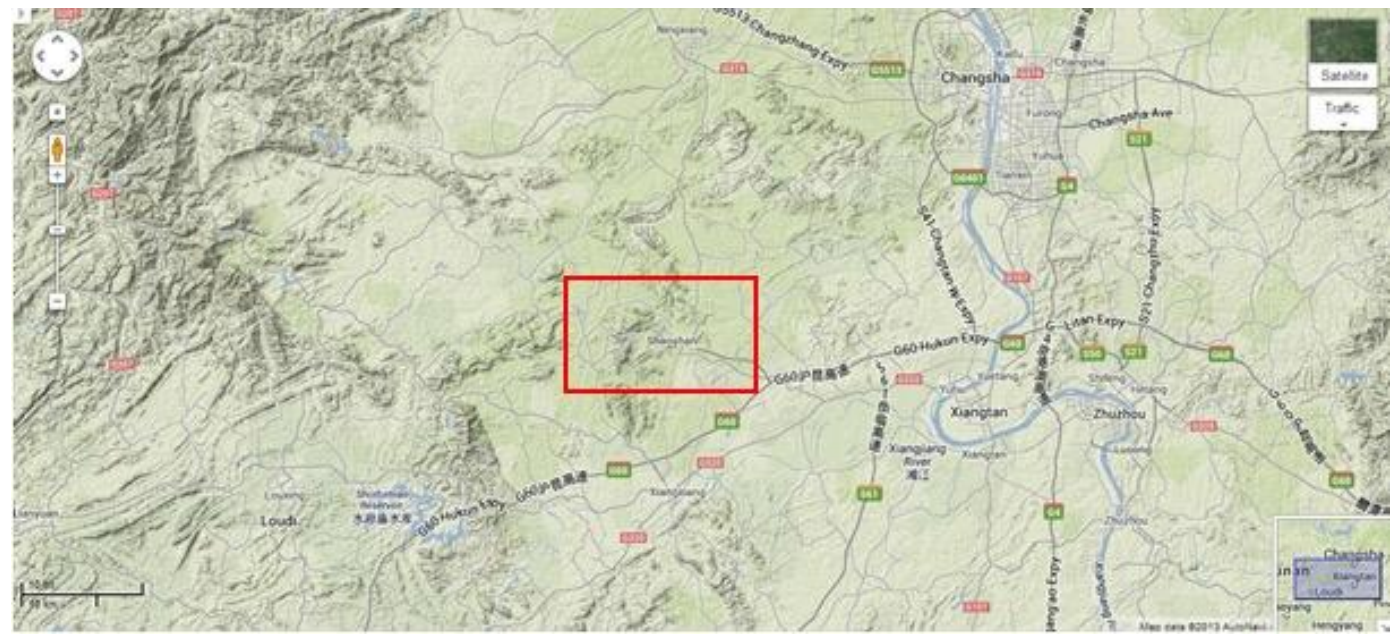


Figure 2. Location of Shaoshan village. Image captured from Google Maps.

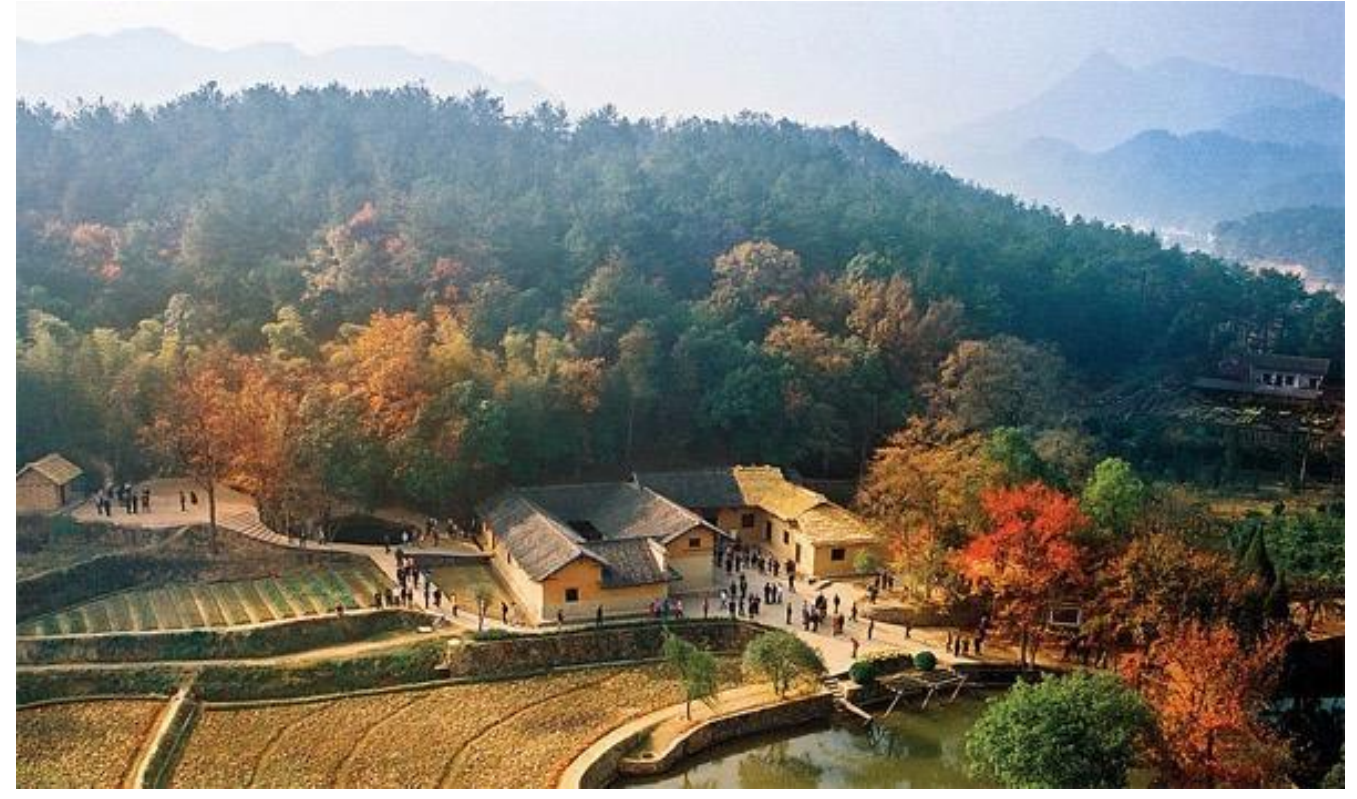

Figure 3. Overview of Mao's house. "Mao Zedong guju” [Mao Zedong's Old House], Zhangjiajie Guoji Lvxing She [Zhangjiajie International Travel Agency], www.zjjtm.com. http://www.zjjtm.com/jingdian/jingdian_53.html.

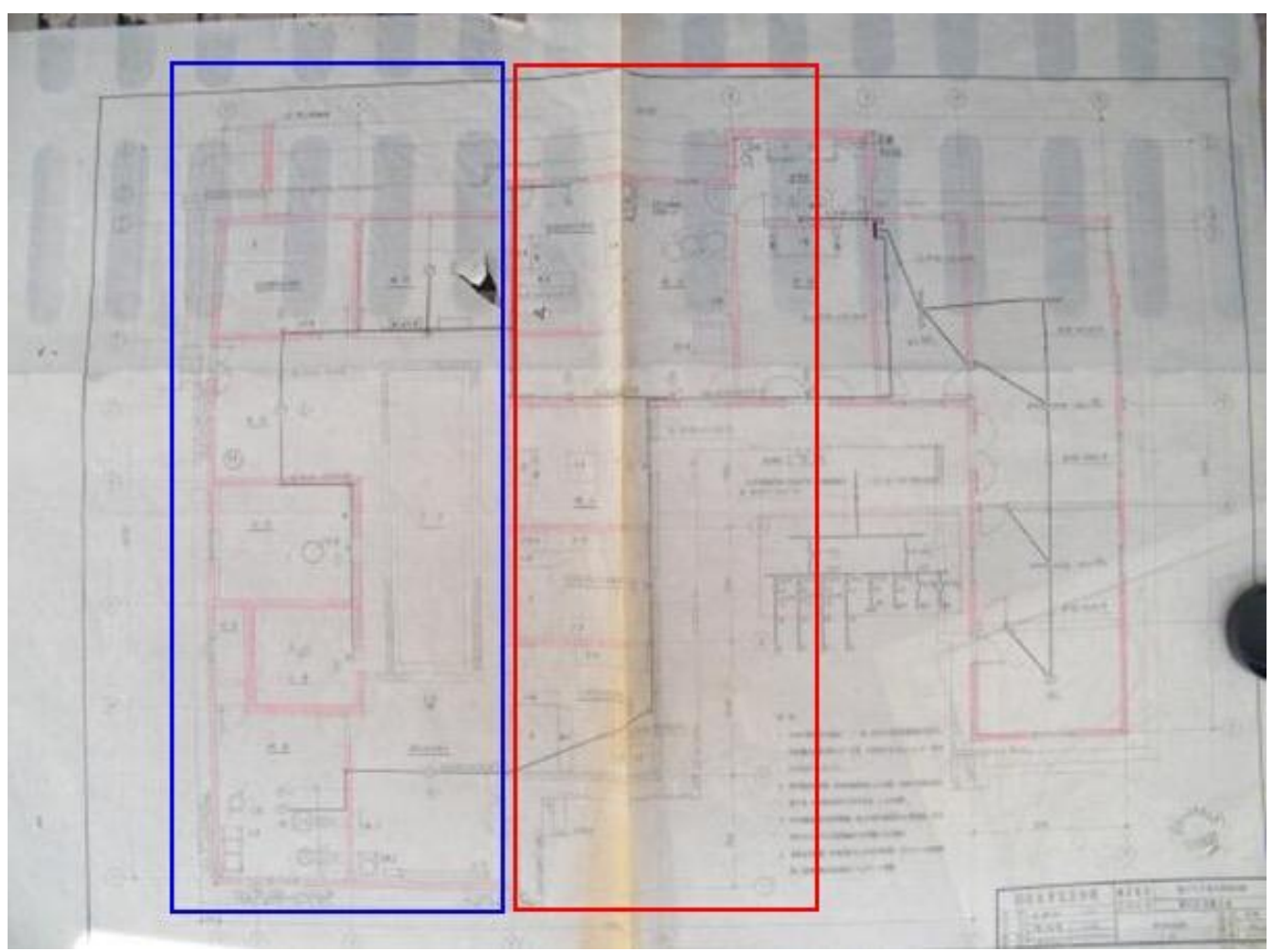


Figure 4. Plan of Mao's farmhouse. The red circled area is Mao's Old House. Mao lived in the lowest room. In 1917 Mao's father expanded the rooms that appear in the blue rectangular. Architectural drawing from the archives of the Hunan Provincial Architectural Institute. Photo by the author.

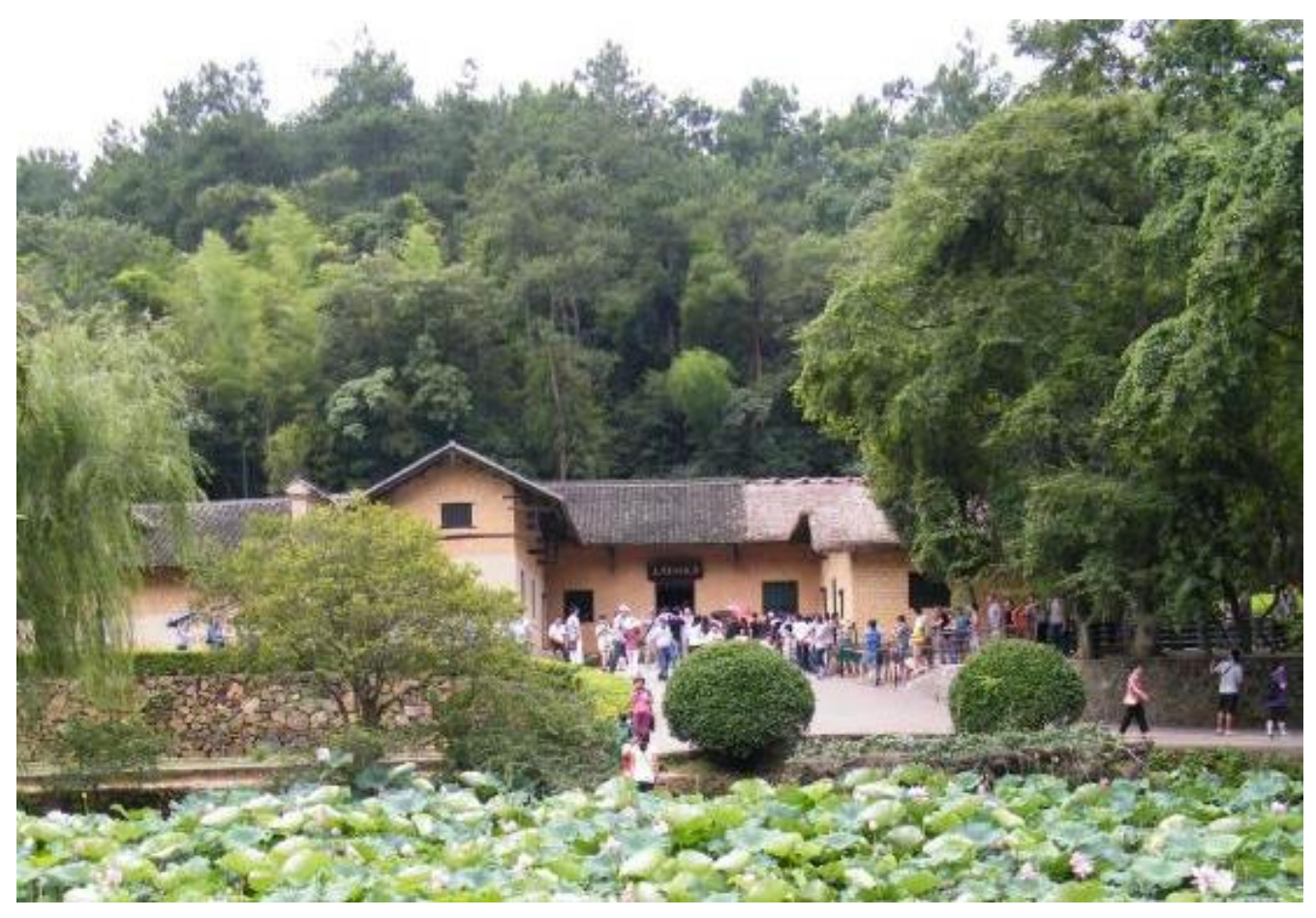

Figure 5. Facade of Mao's house. Photo by the author. 


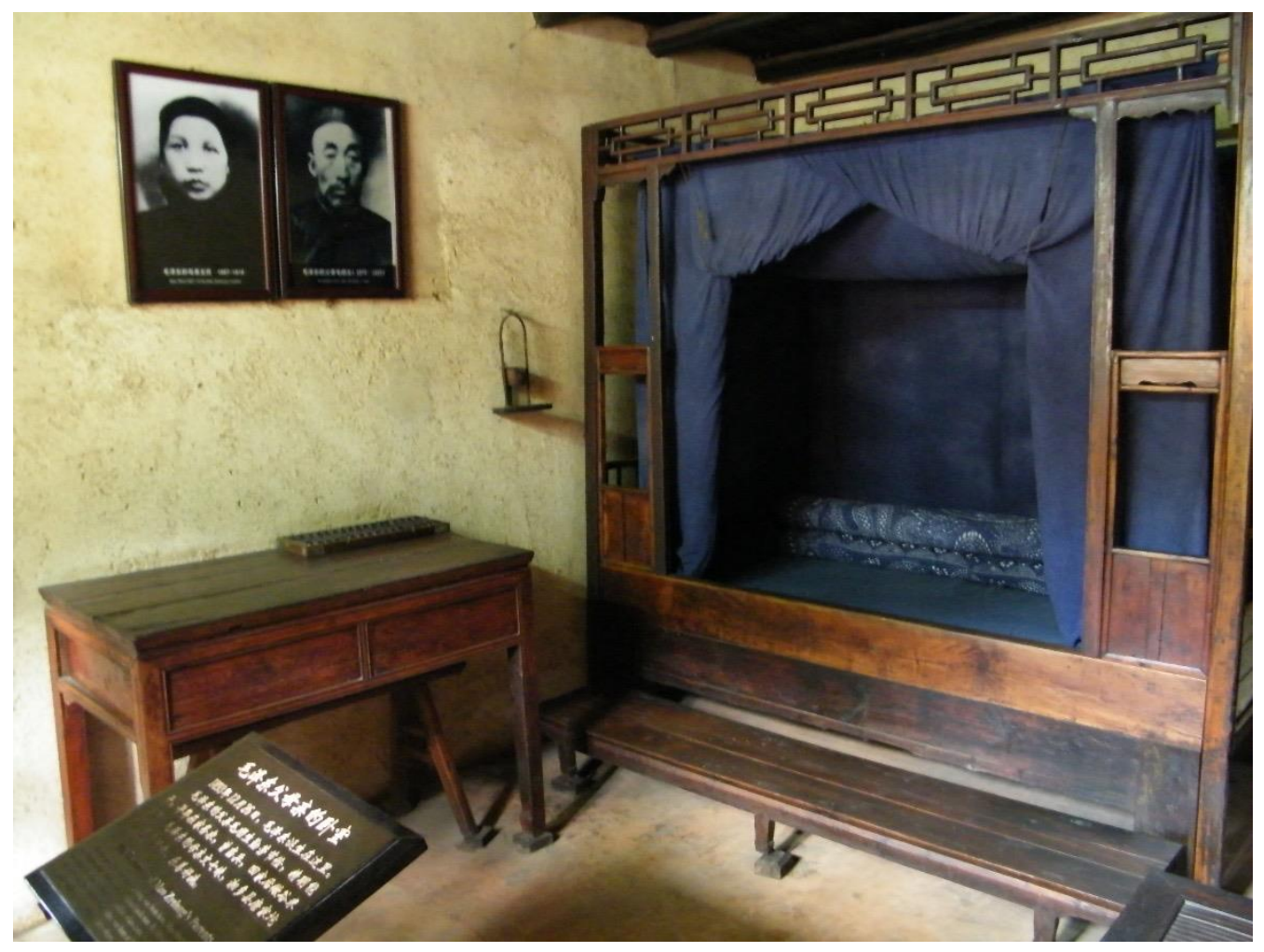

Figure 6. Interior of Mao's parents' room. Photo by the author.

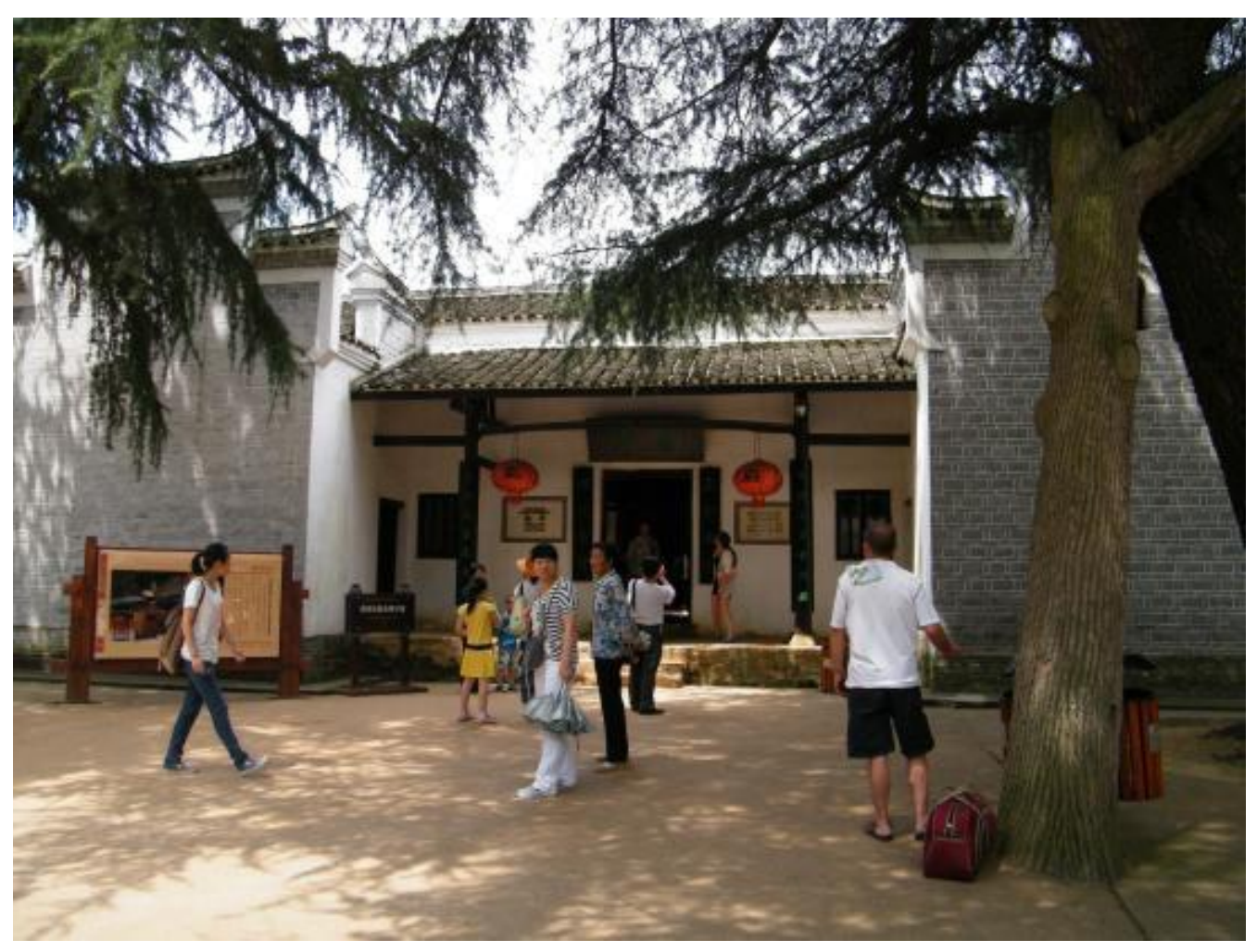

Figure 7. Nan'an Sishu. Photo by the author. 


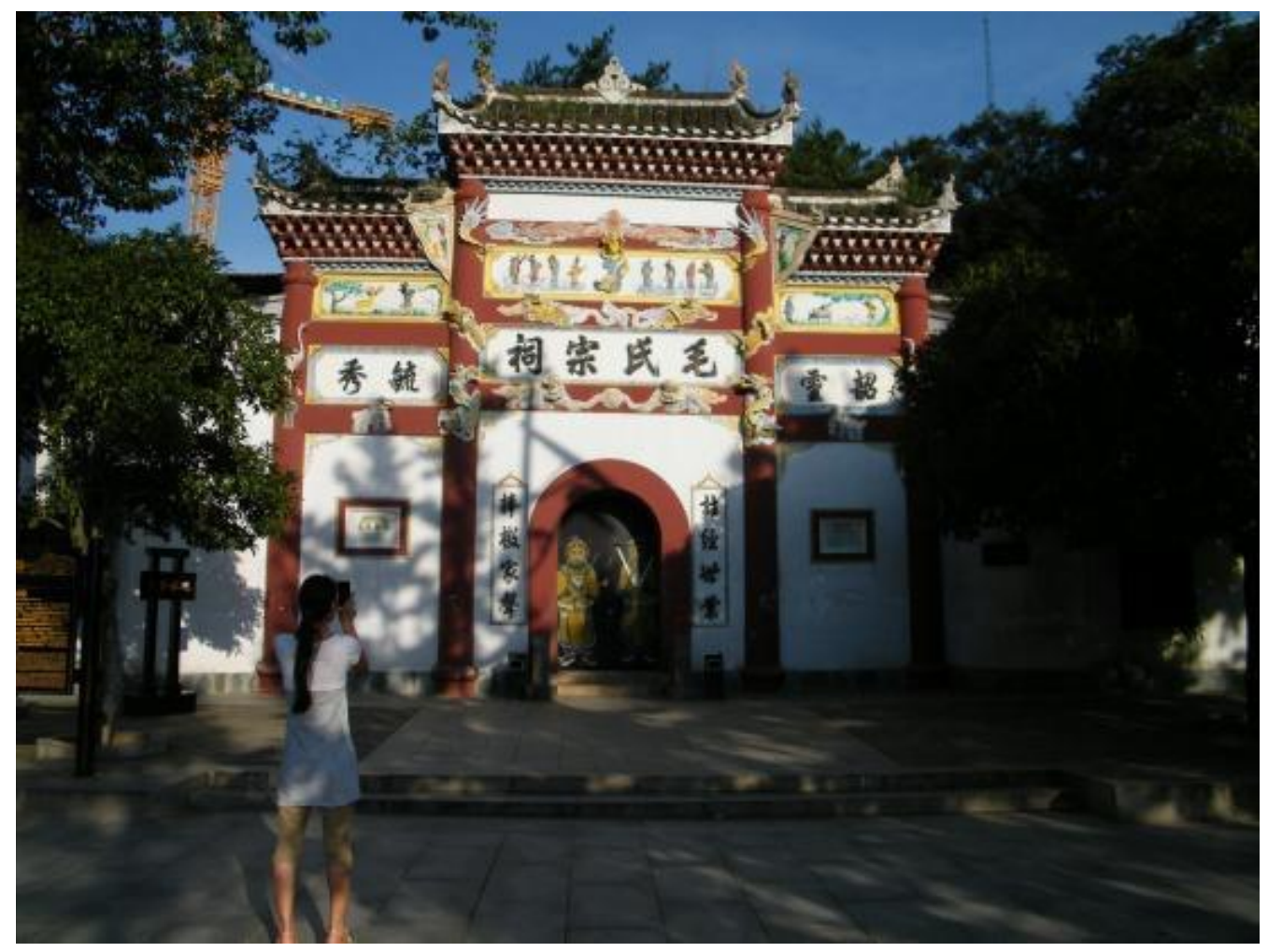

Figure 8. Mao's Ancestral Temple. Photo by the author.

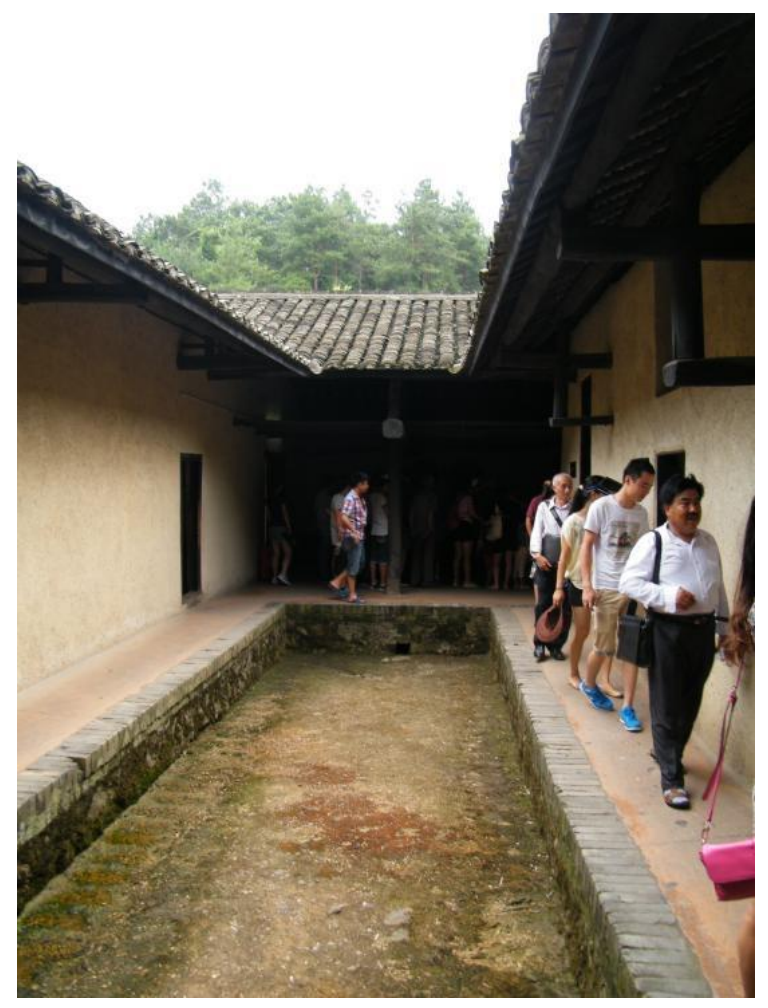

Figure 9. Expansion of Mao's house in 1910. Photo by the author. 


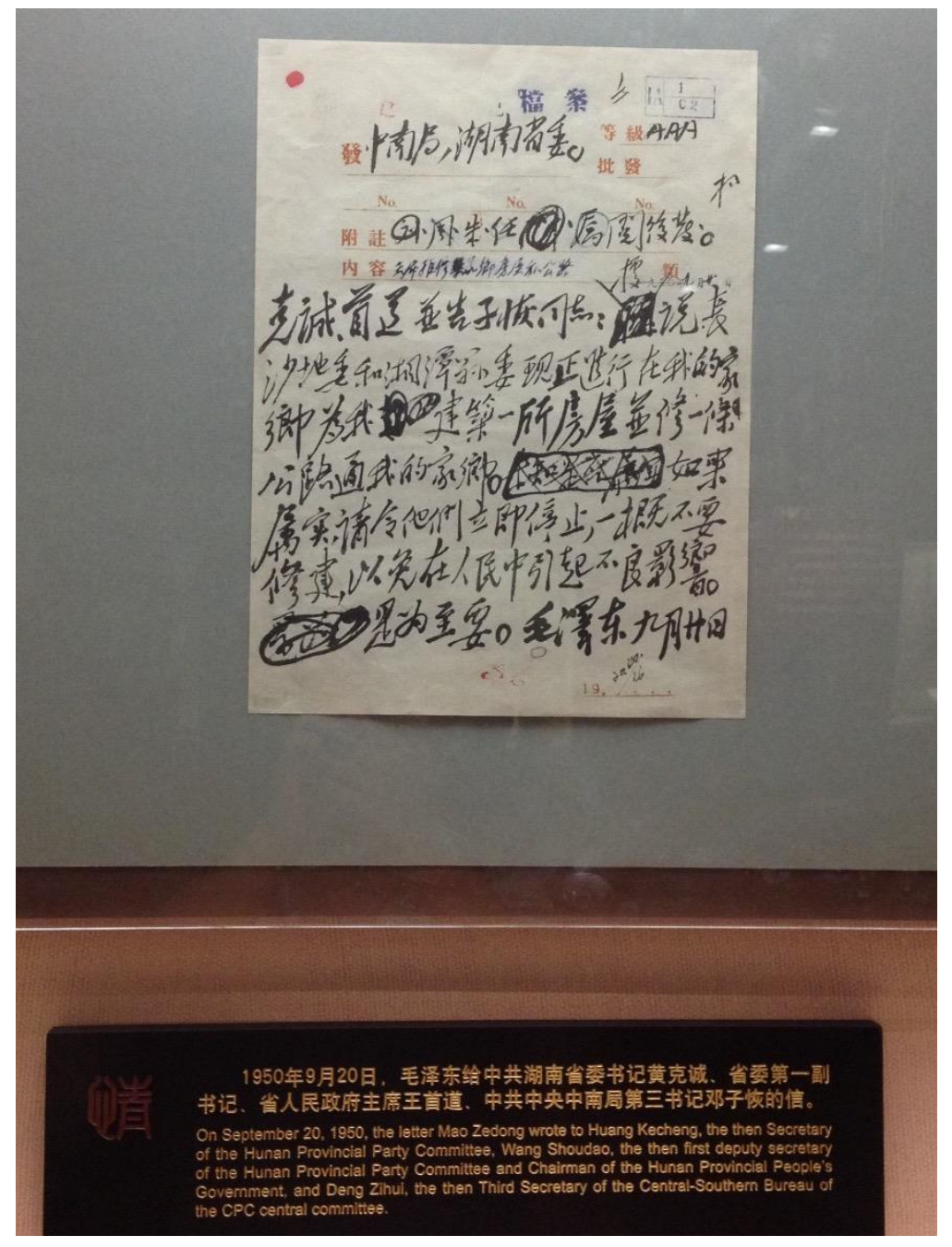

Figure 10. Mao Zedong, "Guanyu liji tingzhi zai shaoshan wei maozedong jianfang gei huangkecheng deng de xin" [Letter to Huang Kecheng to stop building a house for Mao Zedong in Shaoshan], September 20, 1950; and Jianguo yilai maozedong wengao [Mao Zedong's manuscript after the PRC was founded](Beijing: Central Literature Press,1996). Photo by the author. 


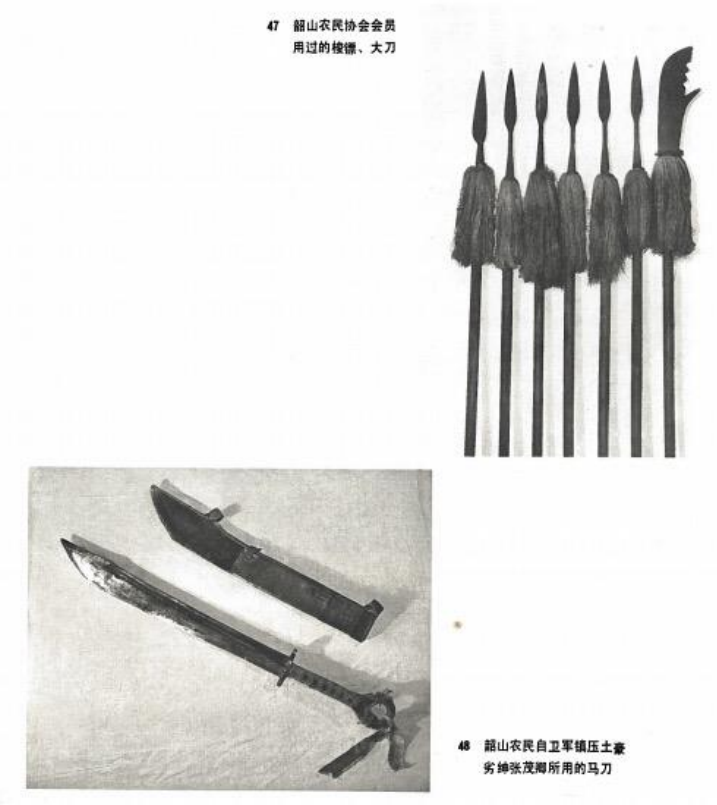

Figure 11. Some of the revolutionary relics collected in Shaoshan. Scanned from The Exhibition Pavilion for Comrade Mao Zedong's Old House, Shao Shan (Beijing: Cultural Relics Publishing House, 1978).

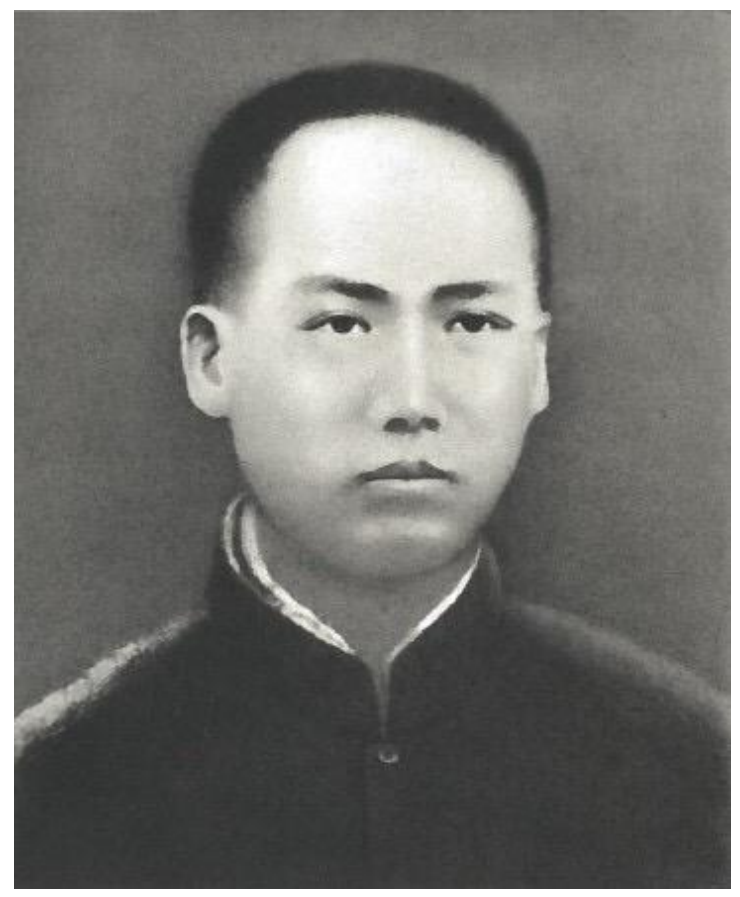

Figure 12. Young Mao's portrait in the Shaoshan album. Scanned from Exhibition Pavilion for Comrade Mao Zedong's Old House, Shao Shan. 

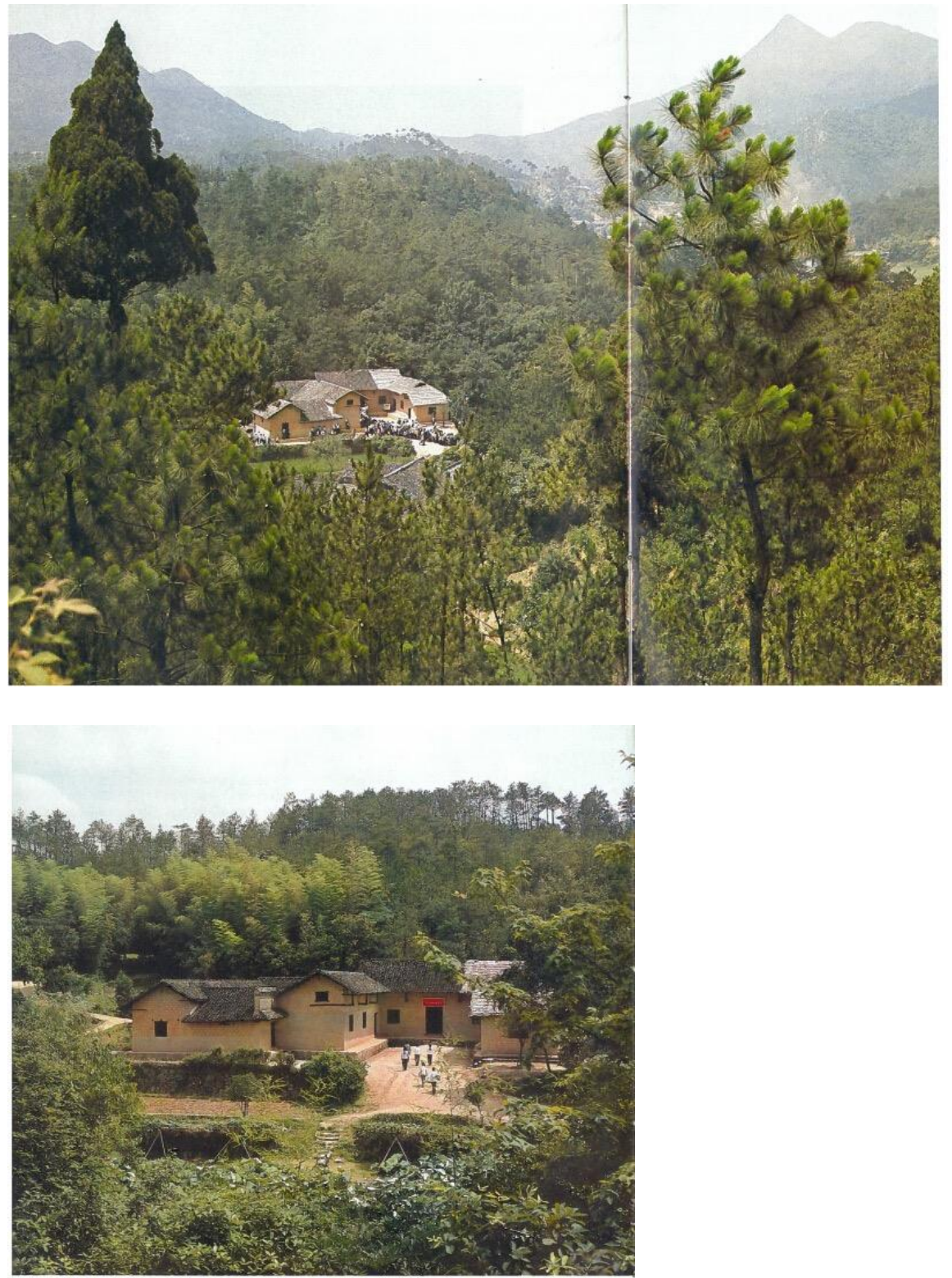

- 毛深东同志旧展

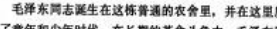

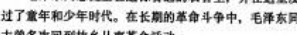




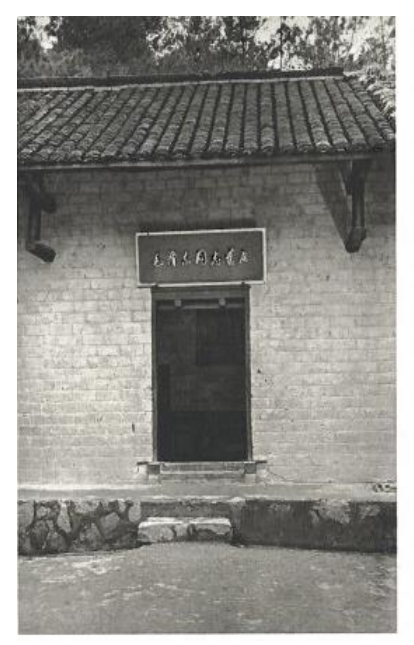

Figure 13, 14, 15. Next plate in Shaoshan: Ariel view of Mao's old house.

Next plate: A closer photograph of Mao's house.

Next plate: The front door of the house. Images scanned from Exhibition Pavilion for Comrade Mao Zedong's Old House, Shao Shan.
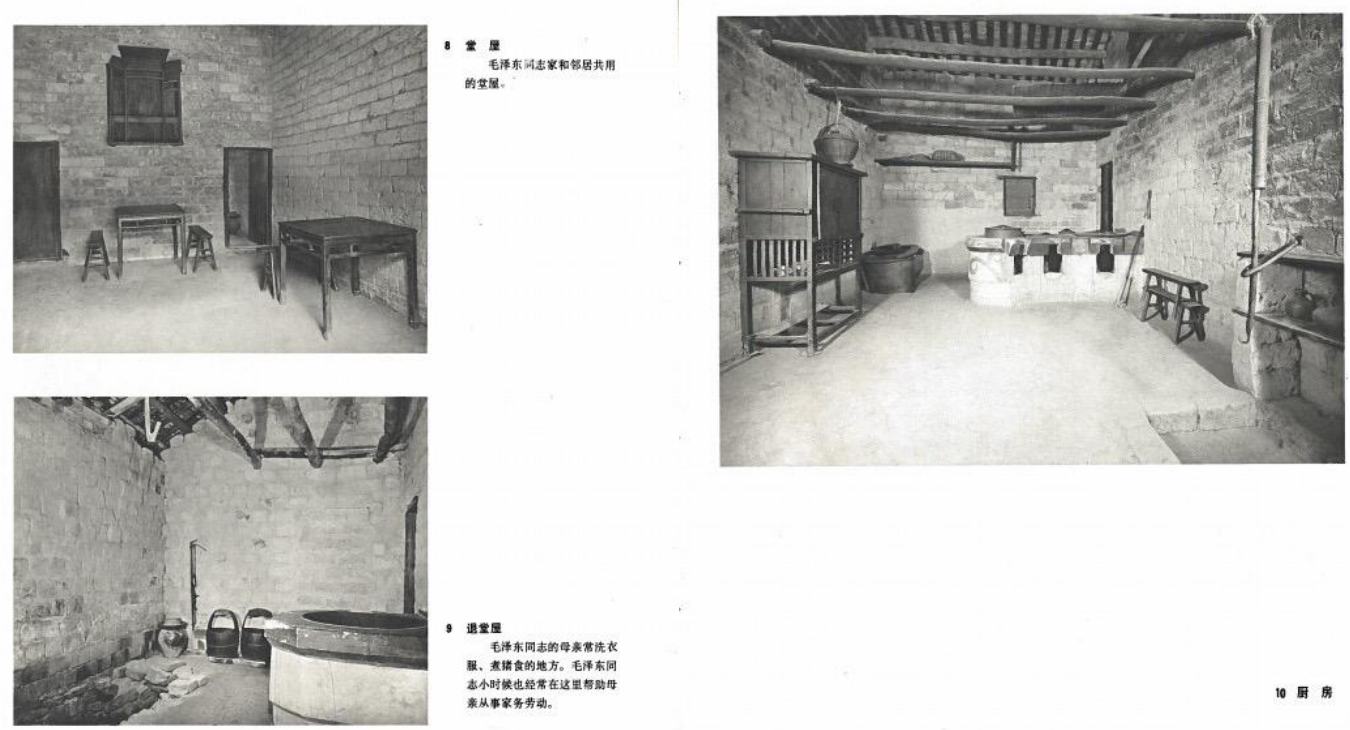

Figure 16. Following plates: the central hall and other rooms of the house. Scanned from Exhibition Pavilion for Comrade Mao Zedong's Old House, Shao Shan. 

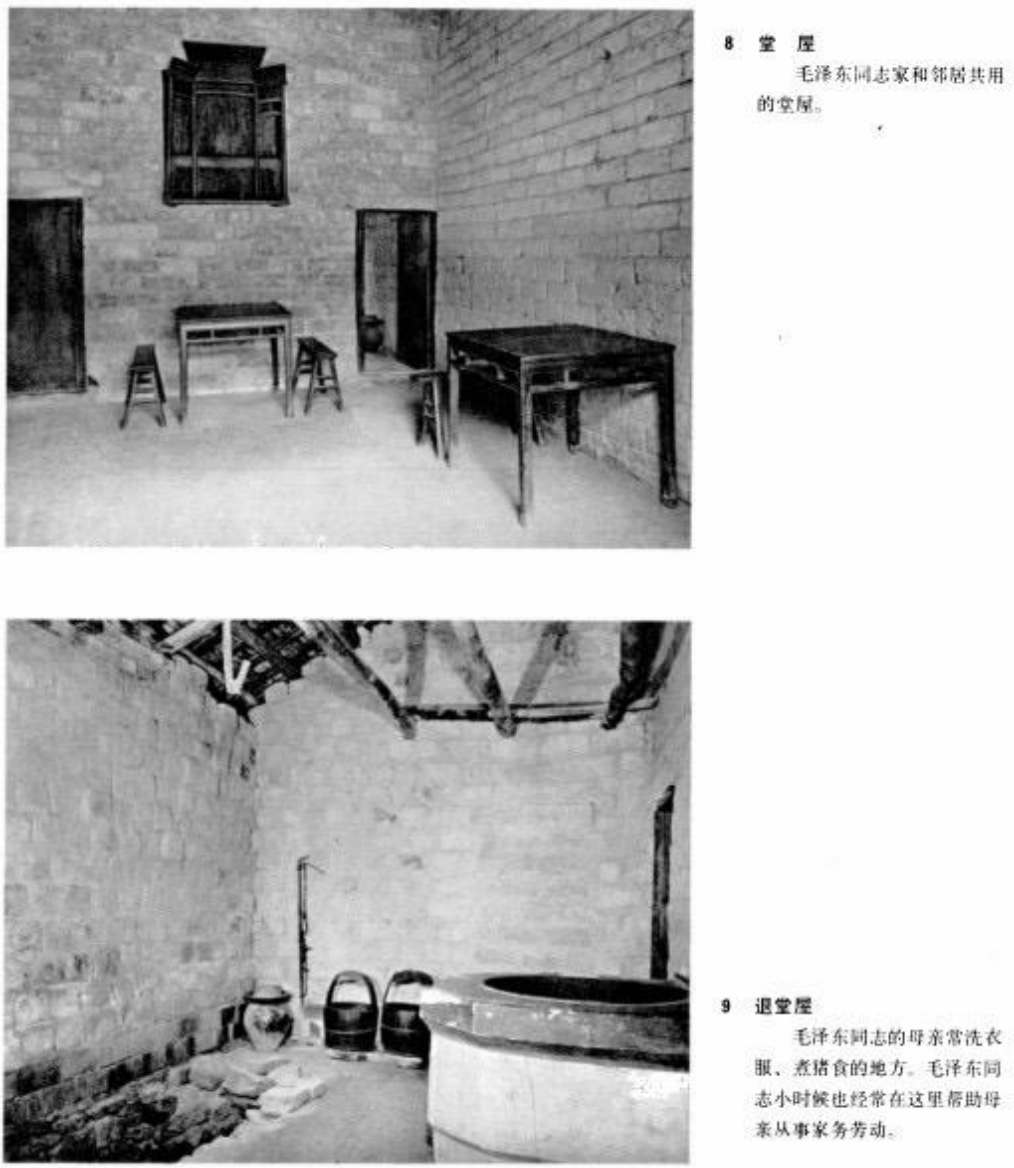

9 退空屋

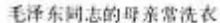

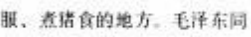

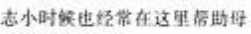
亲丛事家务黄动。

Figure 17. The Shaoshan album introduces the village like the pamphlet. This section illustrates the kitchen of Mao's house. The text reads: “In 1920, when Mao returned to Shaoshan, he sat here with his brothers and sisters and had an intimate conversation with them. Mao explained the communist movement and led his relatives to the road of revolution.” Scanned from Exhibition Pavilion for Comrade Mao Zedong's Old House, Shao Shan. 
25 禾场

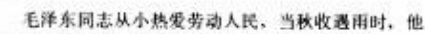

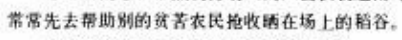

这是毛泽东同志少年时代晊过谷的禾场。

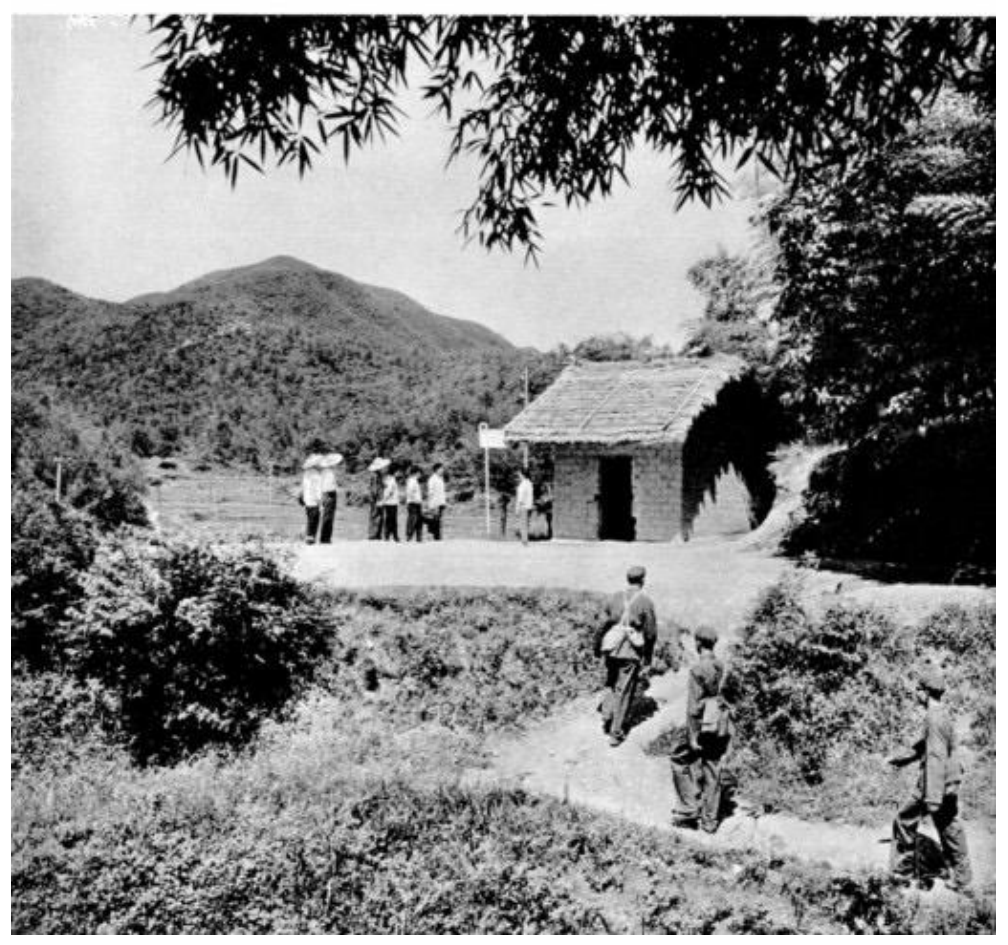

Figure 18. This section of the Shaoshan album introduces the place where Mao dried his rice. The text reads: "Comrade Mao Zedong loved working people since he was a kid. When it rained, he always helped other poor peasants to collect their dried rice rather than his own." Scanned from Exhibition Pavilion for Comrade Mao Zedong's Old House, Shao Shan. 

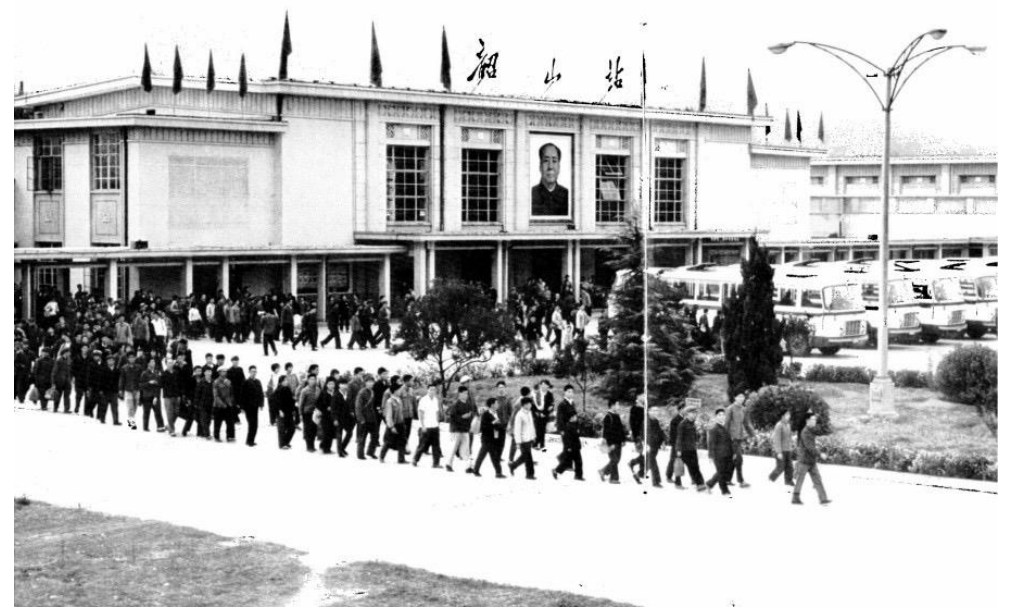

Figure 19. People arriving at Shaoshan Railway Station and marching to Mao's house. Scanned from Exhibition Pavilion for Comrade Mao Zedong's Old House, Shao Shan. 


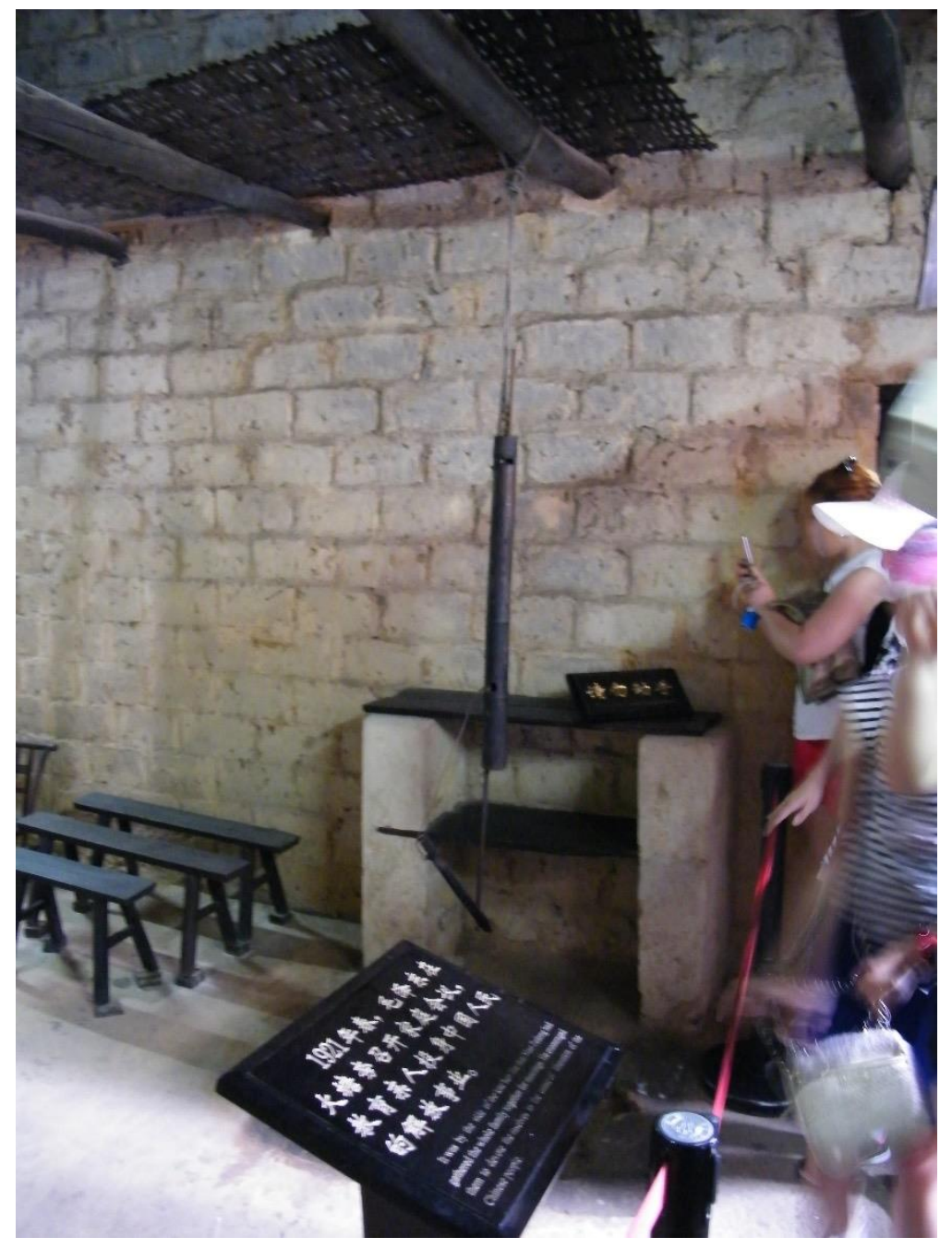

Figure 20. Kitchen in Mao's house. Photo by the author.

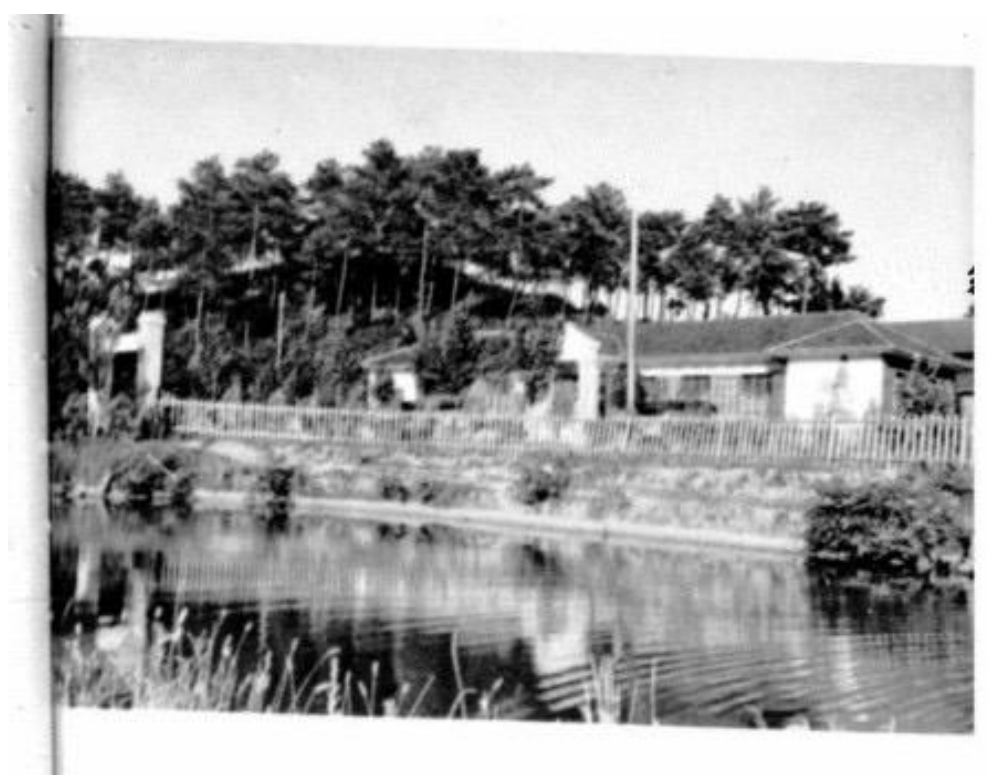


Figure 21. Old Shaoshan Cultural Center. It was later converted into the Shaoshan Exhibition Hall. Photo by Zhao Li. In Li, "Shaoshan wenhua guan” [Shaoshan cultural center], Shao Shan (Changsha: Hunan Renmin Publishing House, 1959), 31.

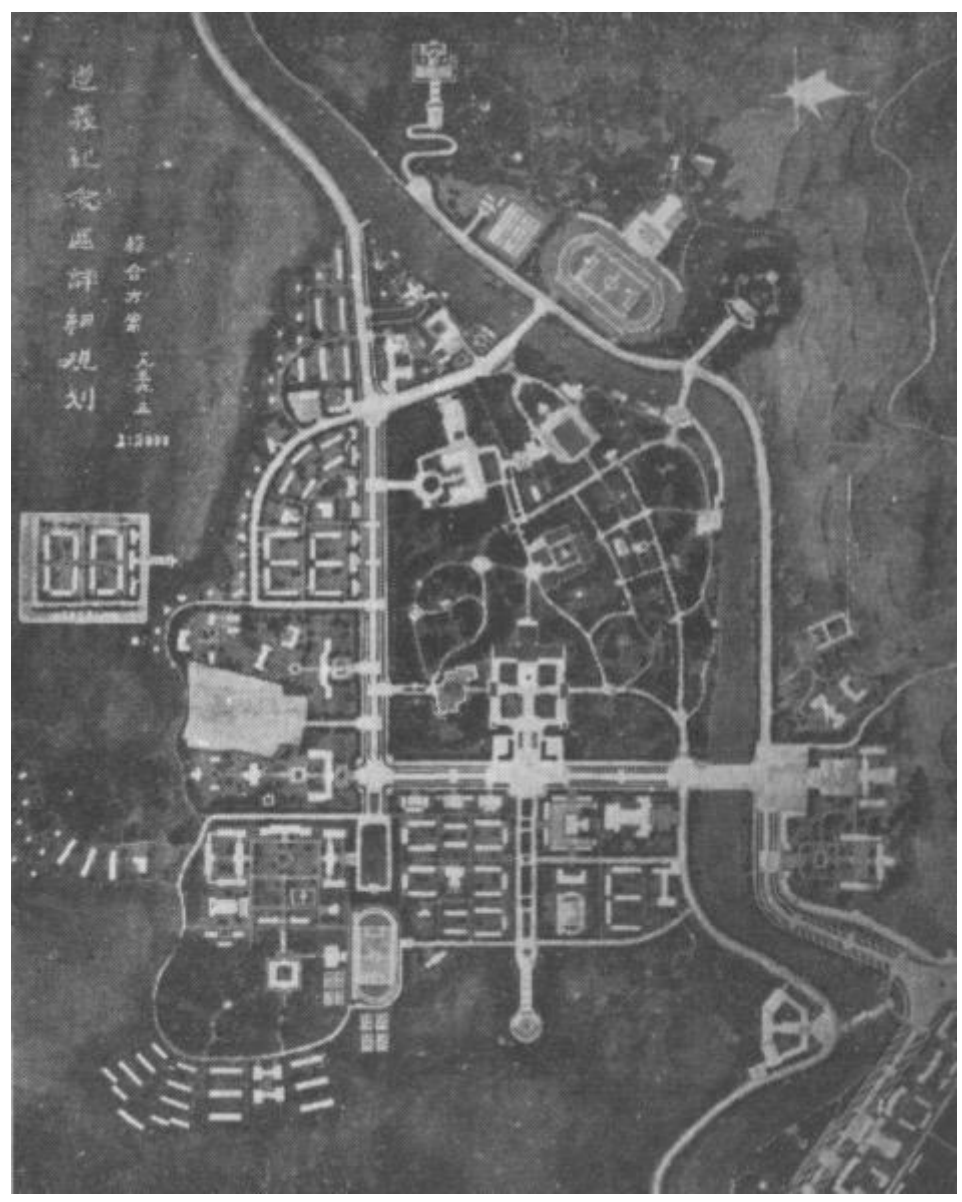

Figure 22. Urban planning of Zunyi's memorial center in 1959. Regional Urban and Rural Planning Office in the Architectural Science Research Institute, "Zunyi shi de jinian tixi guihua." [Memorial System Planning for the City of Zunyi], Architectural Journal 11 (1959): 10-12, 22.

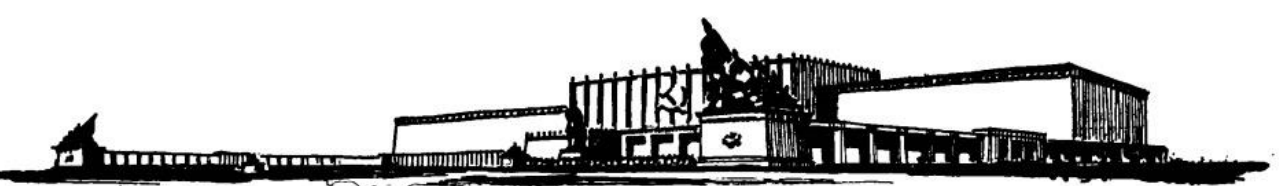

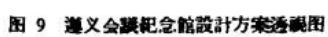




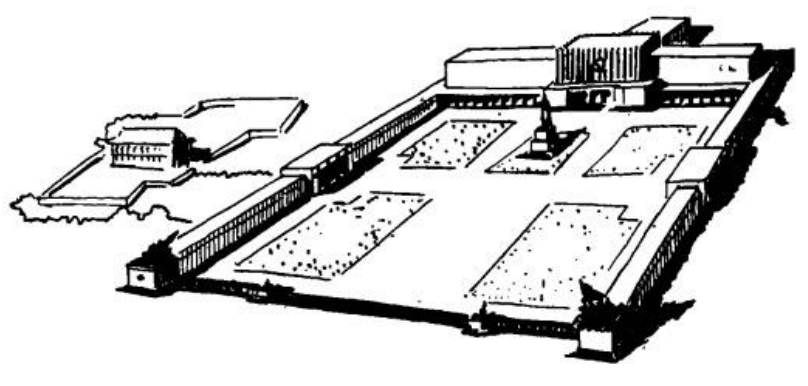

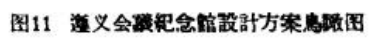

Figure 23, 24. Different perspectives of the proposed Memorial Pavilion in Zunyi.

Regional Urban and Rural Planning Office in the Architectural Science Research

Institute, "Zunyi shi de jinian tixi guihua" [Memorial System Planning for the City of Zunyi] Architectural Journal 11 (1959): 10-12, 22.

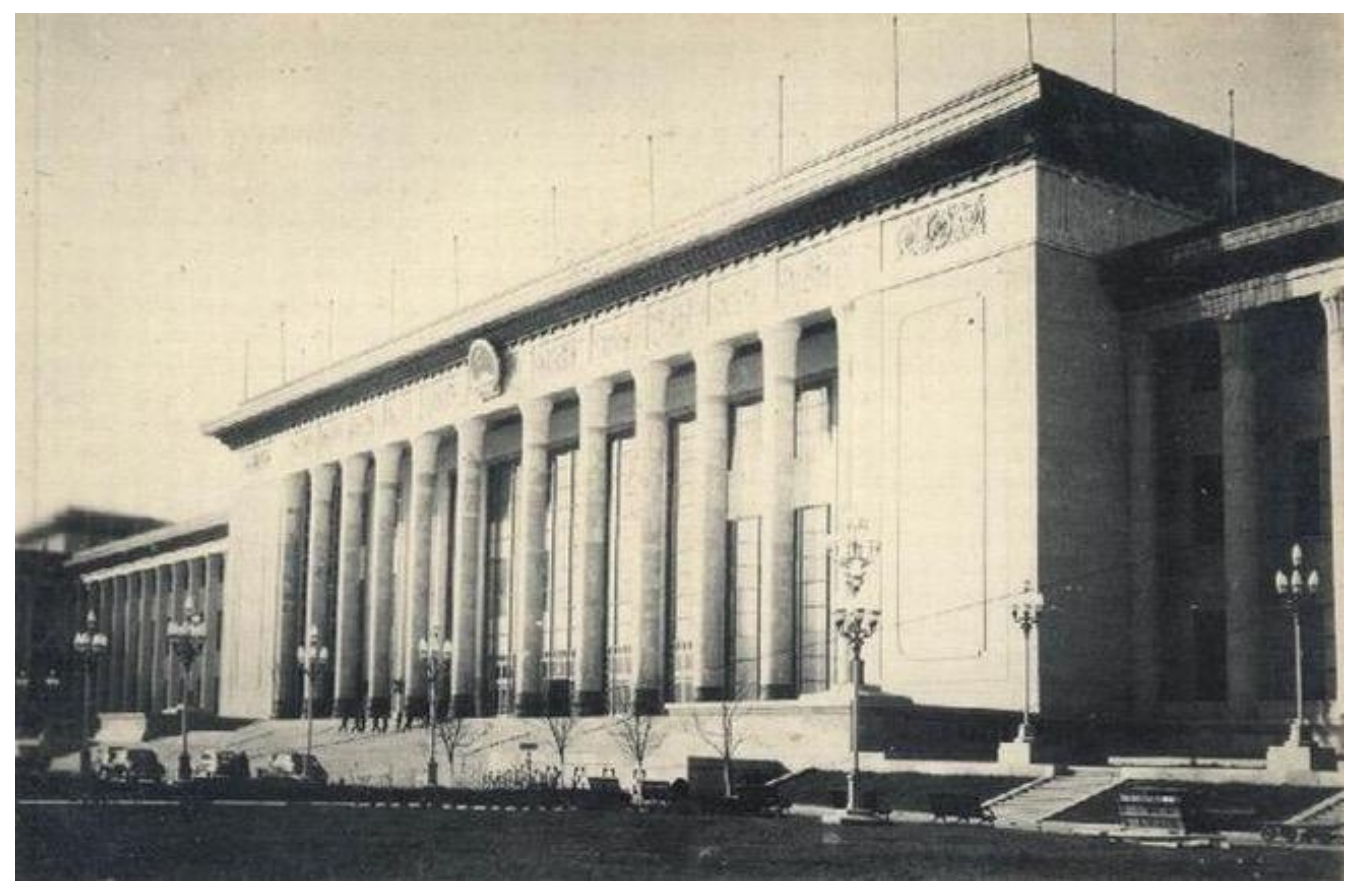

Figure 25. Great Hall of the People. Image from "Beijing shida jianzhu" [The Ten Great Buildings in Beijing], Wikipedia, last modified May 22, 2014, http://zh.wikipedia.org/wiki/\%E5\%8C $\% 97 \% \mathrm{E} 4 \% \mathrm{BA} \% \mathrm{AC} \% \mathrm{E} 5 \% 8 \mathrm{D} \% 81 \% \mathrm{E} 5 \% \mathrm{~A} 4 \%$ A7\%E5\%BB\%BA\%E7\%AD\%91. 


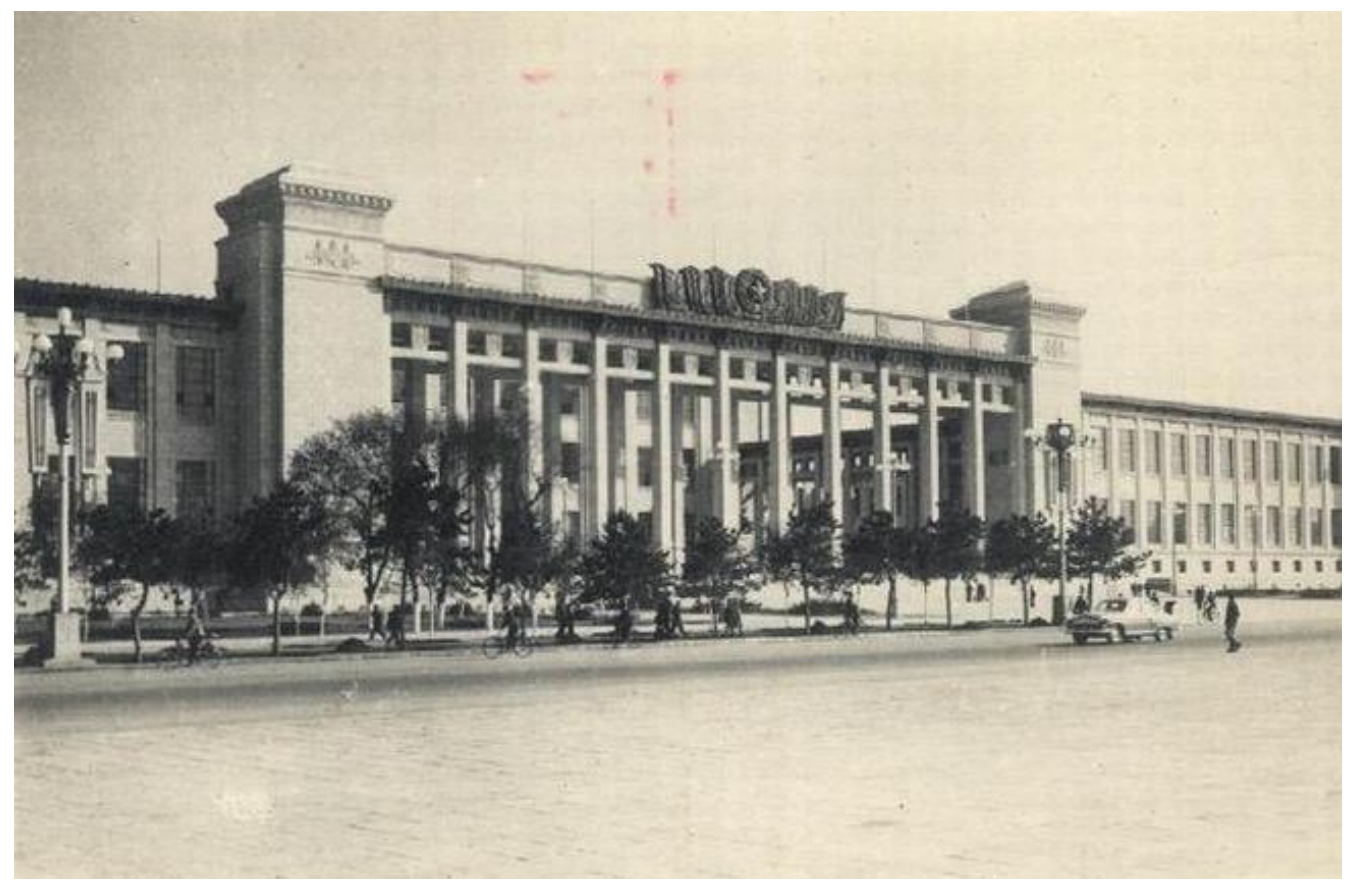

Figure 26. Museum of Chinese History. Image from "Beijing shida jianzhu."

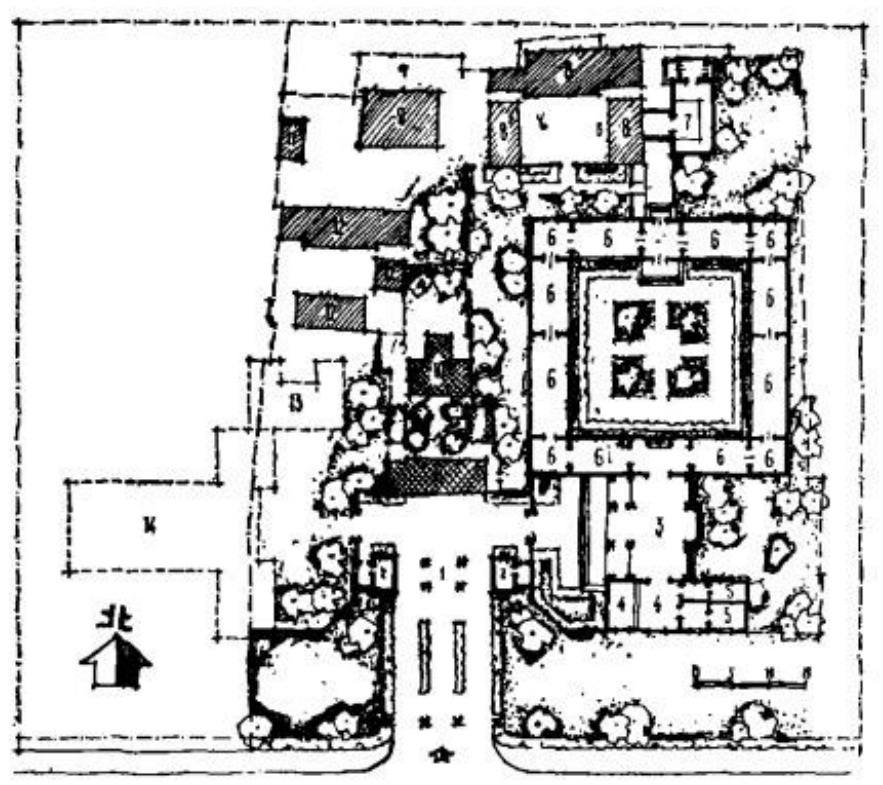

Figure 27. Plan of the No. 1 Proposal for the Beijing Lu Xun's Memorial. The black rectangular in the upper left is Lu Xun's old house in Beijing. The blank rectangular with numbers on the right is the proposed memorial. Image from Zhang Zhaoping, "Luxun jinian guan zongti sheji fangan de jieshao" [Introduction to the overall design of Lu Xun's memorial pavilion], Architectural Journal 4 (1956): 54-59. 


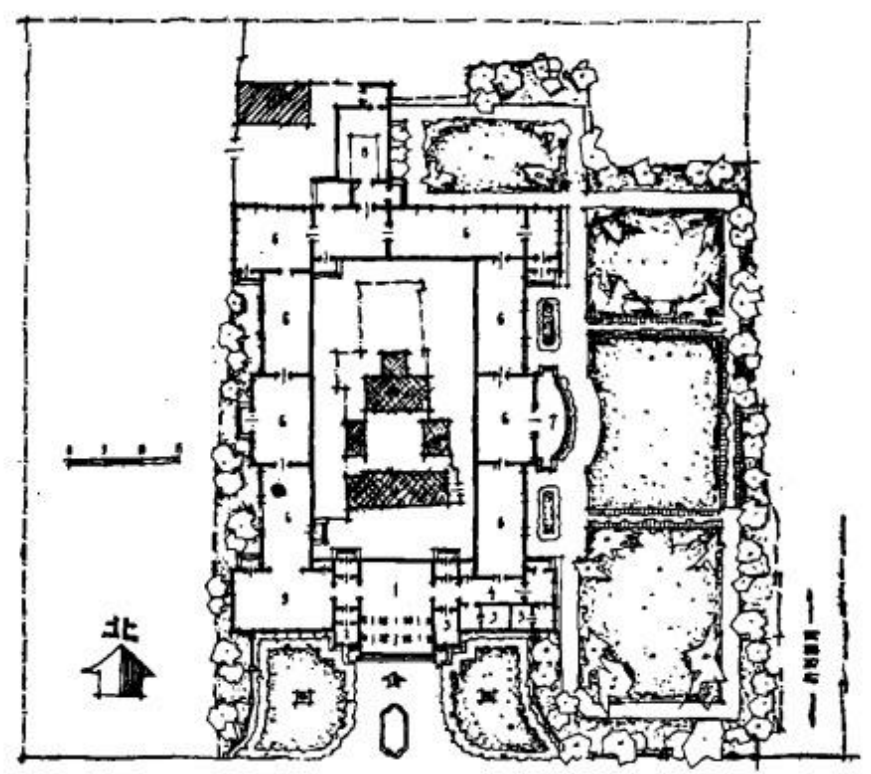

Figure 28. Plan of the No. 4 Proposal. Now the old house is arranged inside the memorial. Image from Zhang, "Luxun jinian."

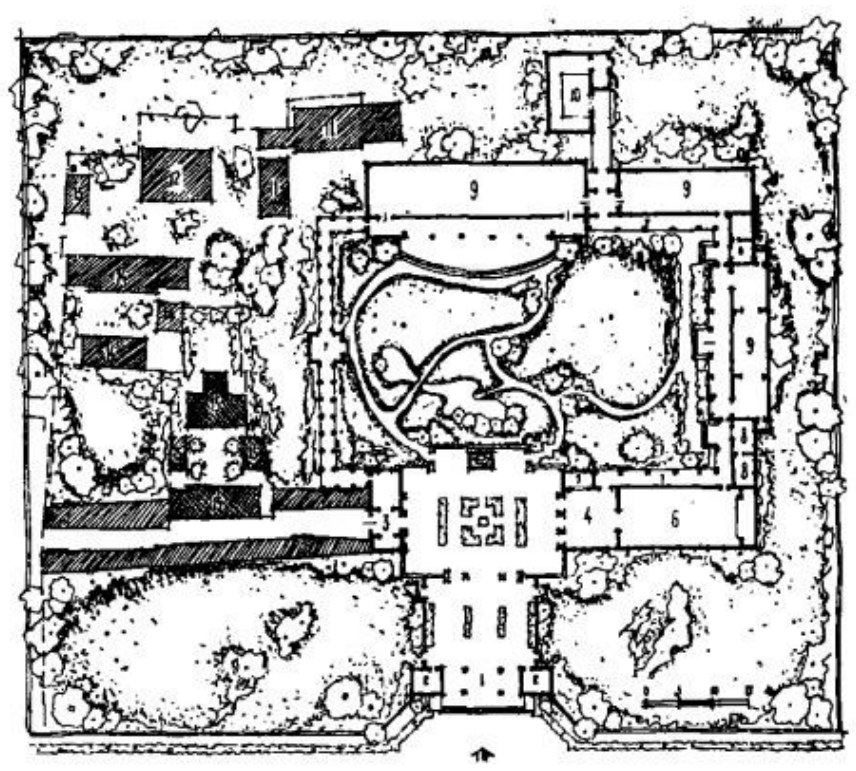

Figure 29. Plan of the selected proposal. Image from Zhang, "Luxun jinian." 

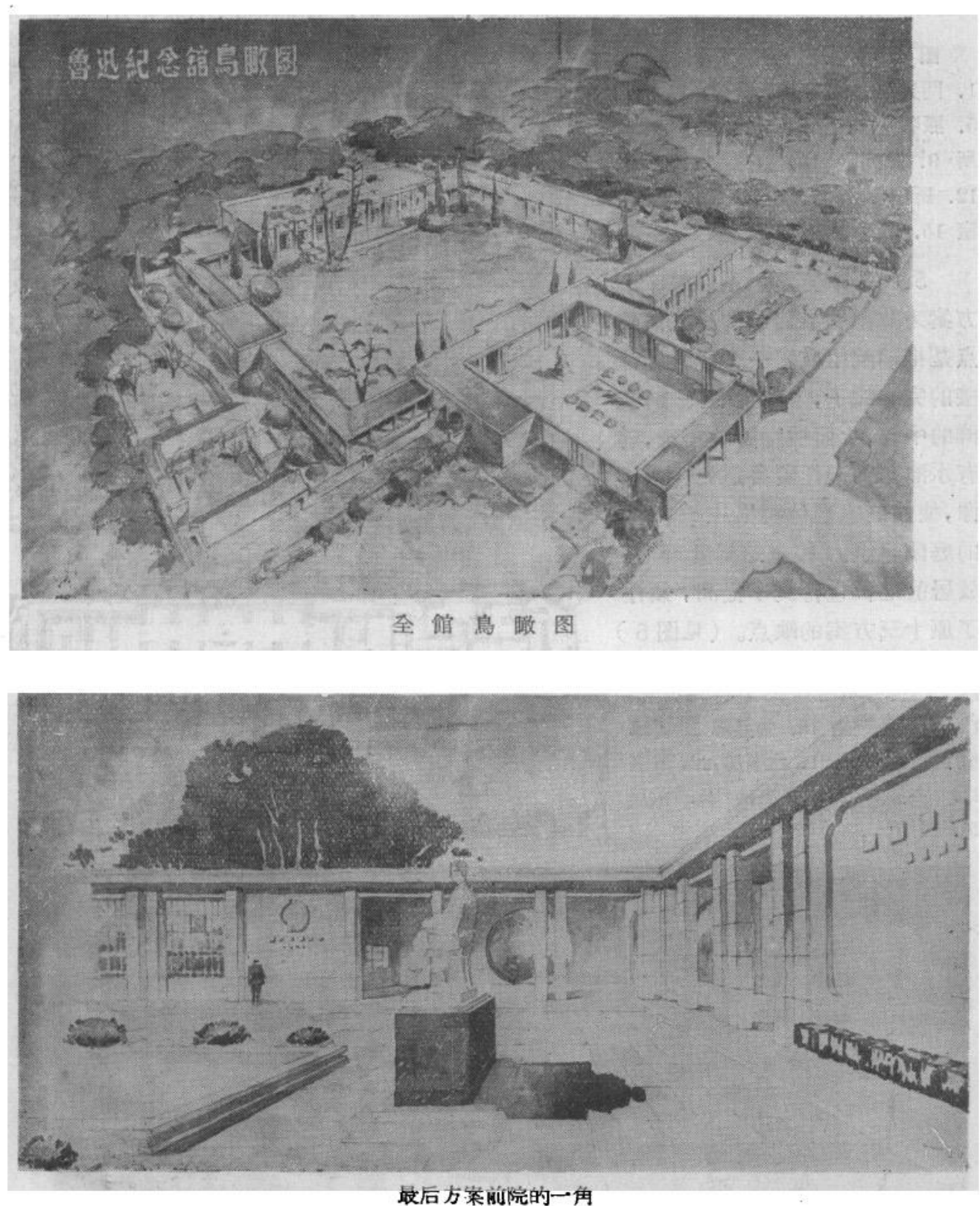

Figure 30, 31. Renderings of Beijing Lu Xun's Memorial. Image from Zhang, "Luxun jinian." 


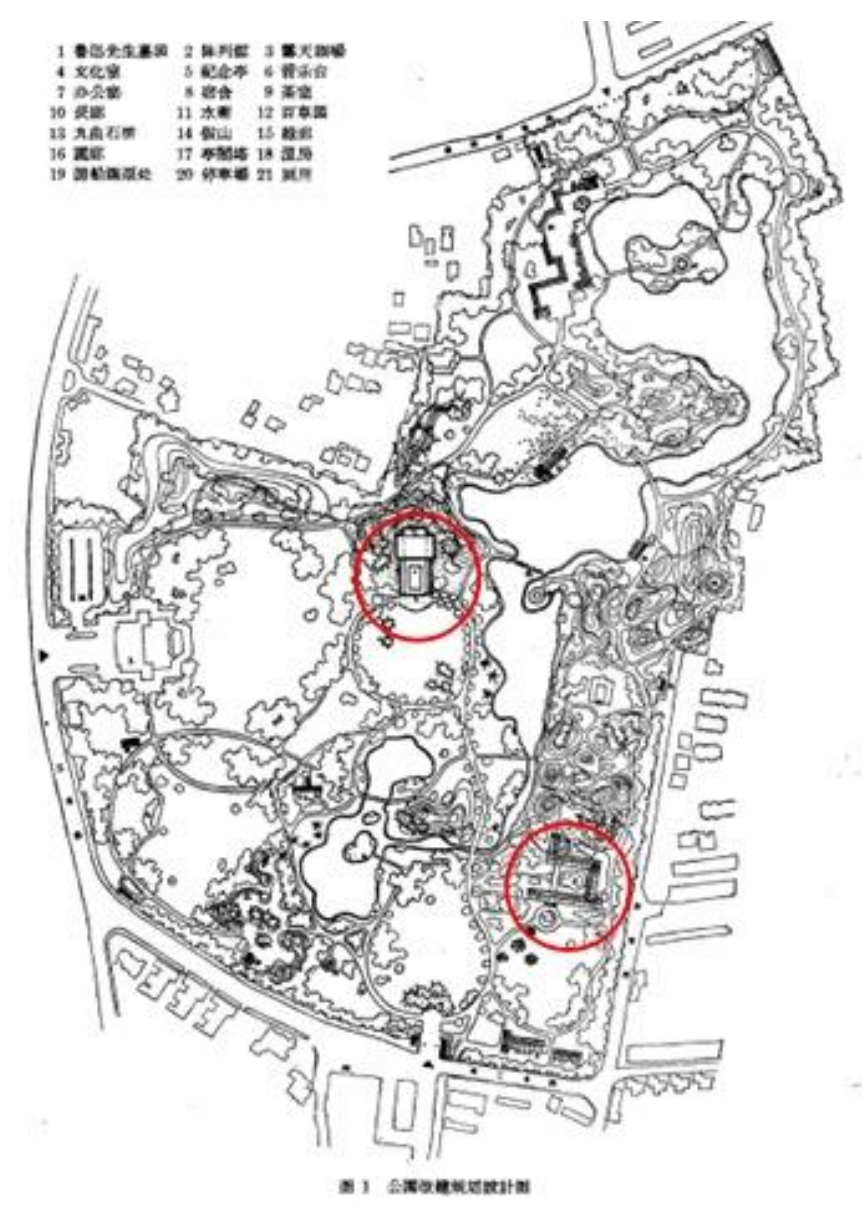

Figure 32. Plan of the garden that surrounded Lu Xun's Memorial in Shanghai. The circle in the middle marks Lu Xun's tomb. The circle below marks the memorial. Image from Chen Zhi and Wang Dingzeng, "Shanghai hongkou gongyuan gaijian ji: luxun jinian mu he chenlieguan de sheji” [The renovation of Shanghai’s Hongkou Park: The design of Lu Xun's tomb and memorial pavilion], Architectural Journal 9 (1956): 1-10. 


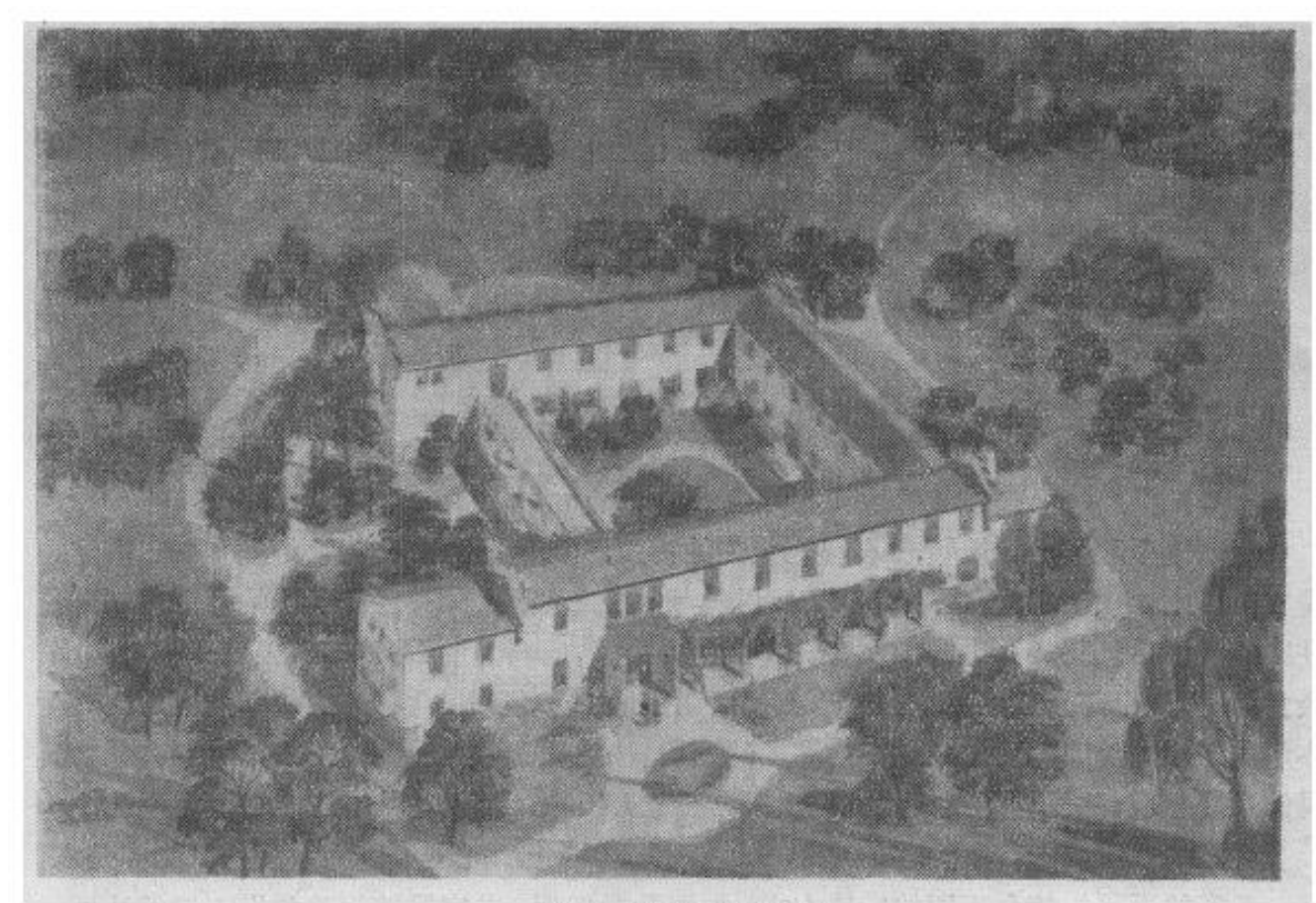

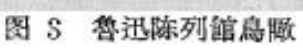

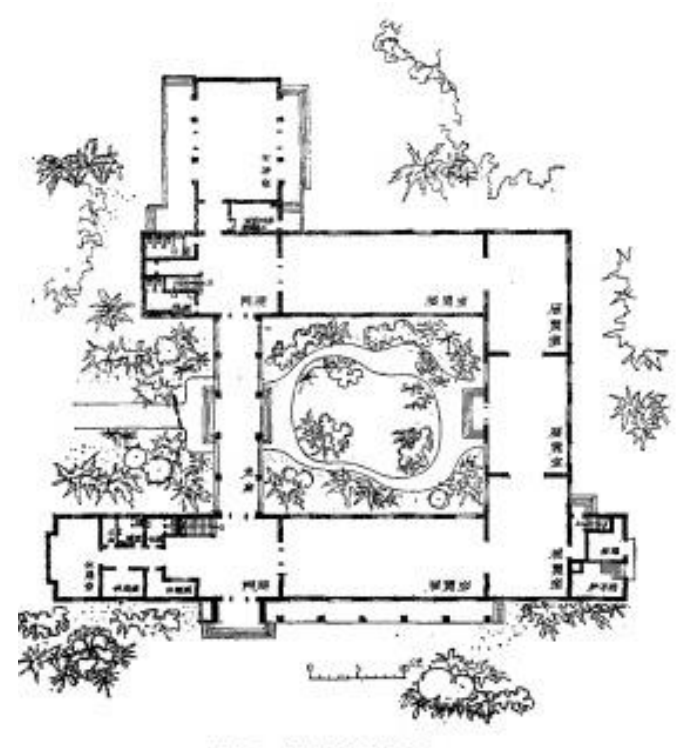

图 8 榢列解卧展平面

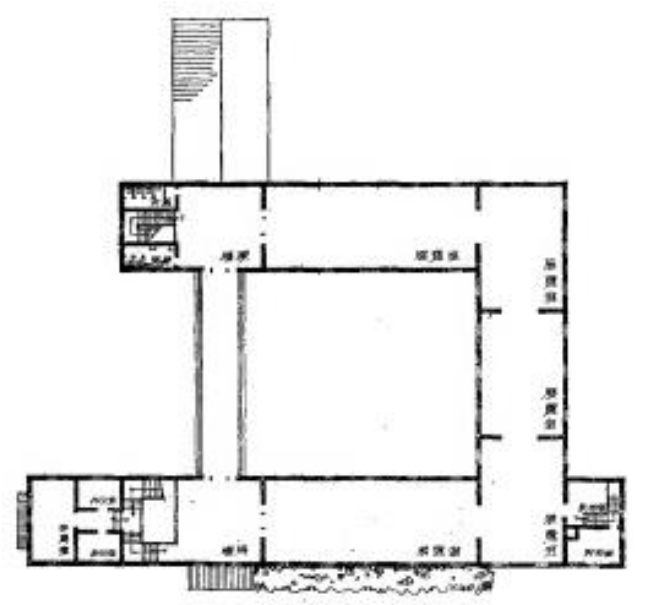




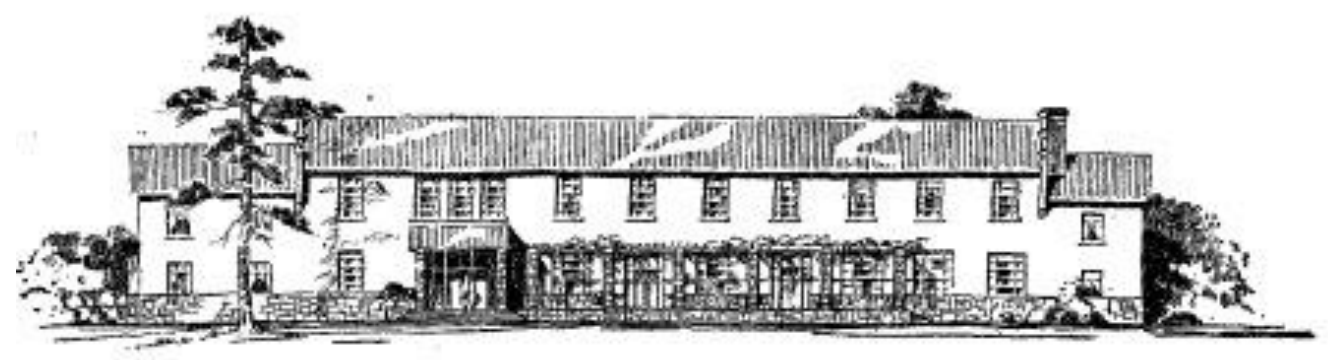

图 11 的列解南立面

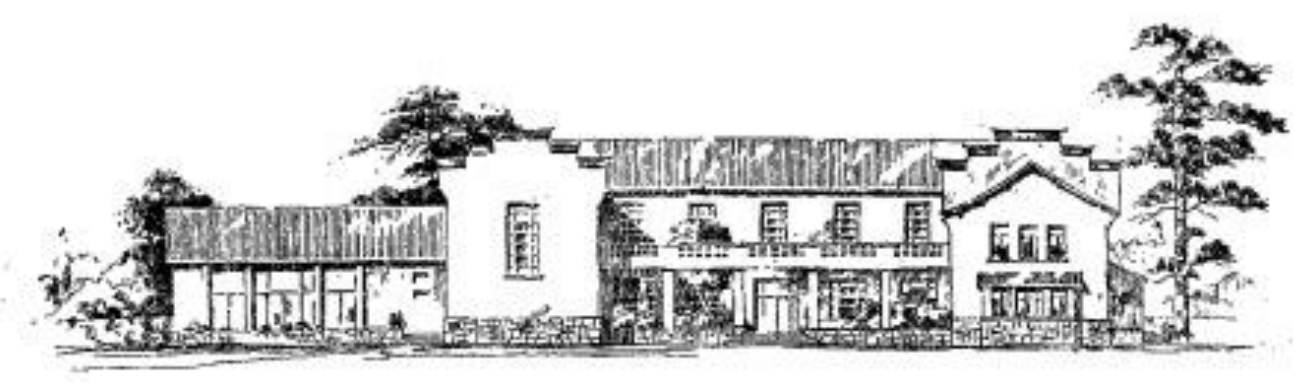

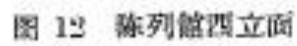

Figure 33, 34, 35. Rendering of Lu Xun's memorial in Shanghai.

Plan and facade of Lu Xun's memorial in Shanghai. Images from Chen and Wang, "Shanghai hongkou." 
1953 - 1990 年韶山接待观众统计表

\begin{tabular}{|c|c|c|c|c|c|}
\hline \multirow{2}{*}{ 年 份 } & \multirow{2}{*}{$\begin{array}{l}\text { 国 内 } \\
\text { (万人) }\end{array}$} & \multicolumn{2}{|l|}{ 外 } & 安 & \multirow{2}{*}{$\begin{array}{c}\text { 港、澳、台同胞、 } \\
\text { 华 㳢 }\end{array}$} \\
\hline & & 国家、地区 (个) & 批 数 & 人 & \\
\hline 1953 & 1. 48 & 12 & 23 & 166 & \\
\hline 1954 & 1.69 & 10 & 29 & 616 & \\
\hline 1955 & 2.70 & 19 & 129 & 1089 & \\
\hline 1956 & 3. 67 & 21 & 120 & 528 & \\
\hline 1957 & 3. 40 & 24 & 88 & 456 & \\
\hline 1958 & 2. 76 & 14 & 102 & 461 & \\
\hline 1959 & 4. 77 & 21 & 137 & 527 & \\
\hline 1960 & 5. 60 & 56 & 172 & 511 & \\
\hline 1961 & 4. 73 & 41 & 68 & 266 & \\
\hline 1962 & 5. 09 & 44 & 87 & 325 & \\
\hline 1963 & 4. 15 & 43 & 108 & 517 & \\
\hline 1964 & 7. 46 & 62 & 144 & 741 & \\
\hline 1965 & 20.1 & 60 & 144 & 712 & \\
\hline 1966 & 290 & 39 & 350 & 3476 & \\
\hline 1967 & 200 & 72 & 234 & 1957 & . \\
\hline 1968 & 180 & 52 & 155 & 1950 & \\
\hline 1969 & 120 & 40 & 110 & 1120 & \\
\hline 1970 & 150 & 38 & 119 & 1368 & 3694 \\
\hline
\end{tabular}

Figure 36. Shaoshan visitor statistics from 1953 to 1990 . The second column records the tourist number, measured in ten thousand people. Figure scanned from Shaoshan Chorography Committee, Shao Shan Zhi [Shaoshan chronicle](1993), 331.

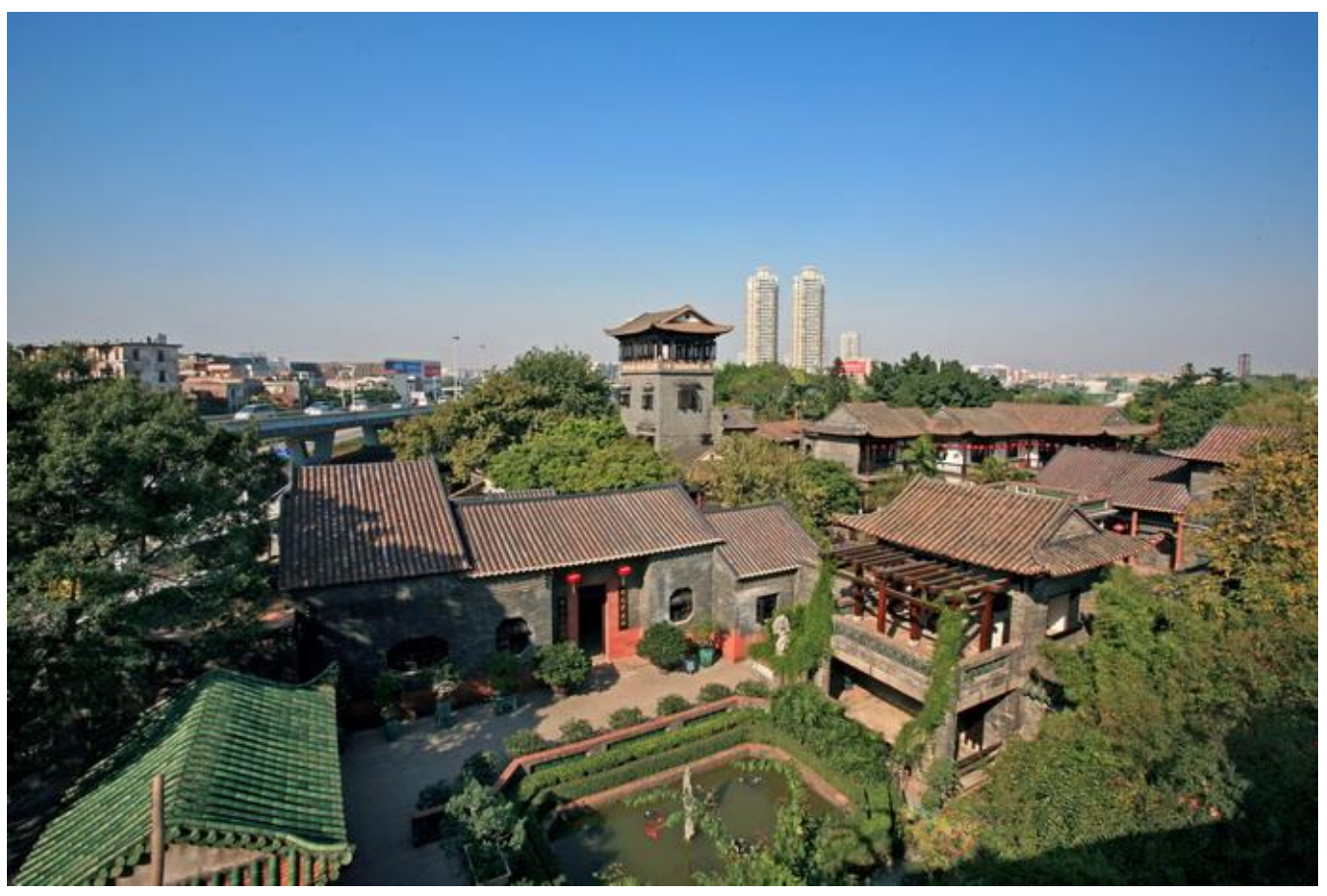


Figure 37. Ke Yuan (Ke Garden), Dongguan City, Guangdong Province, China. Image from "Keyuan quanjing” [A panorama of the Keyuan Garden], Keyuan Museum (www.dgkeyuan.org), http://www.dgkeyuan.org/gujian_view.php?id=84.

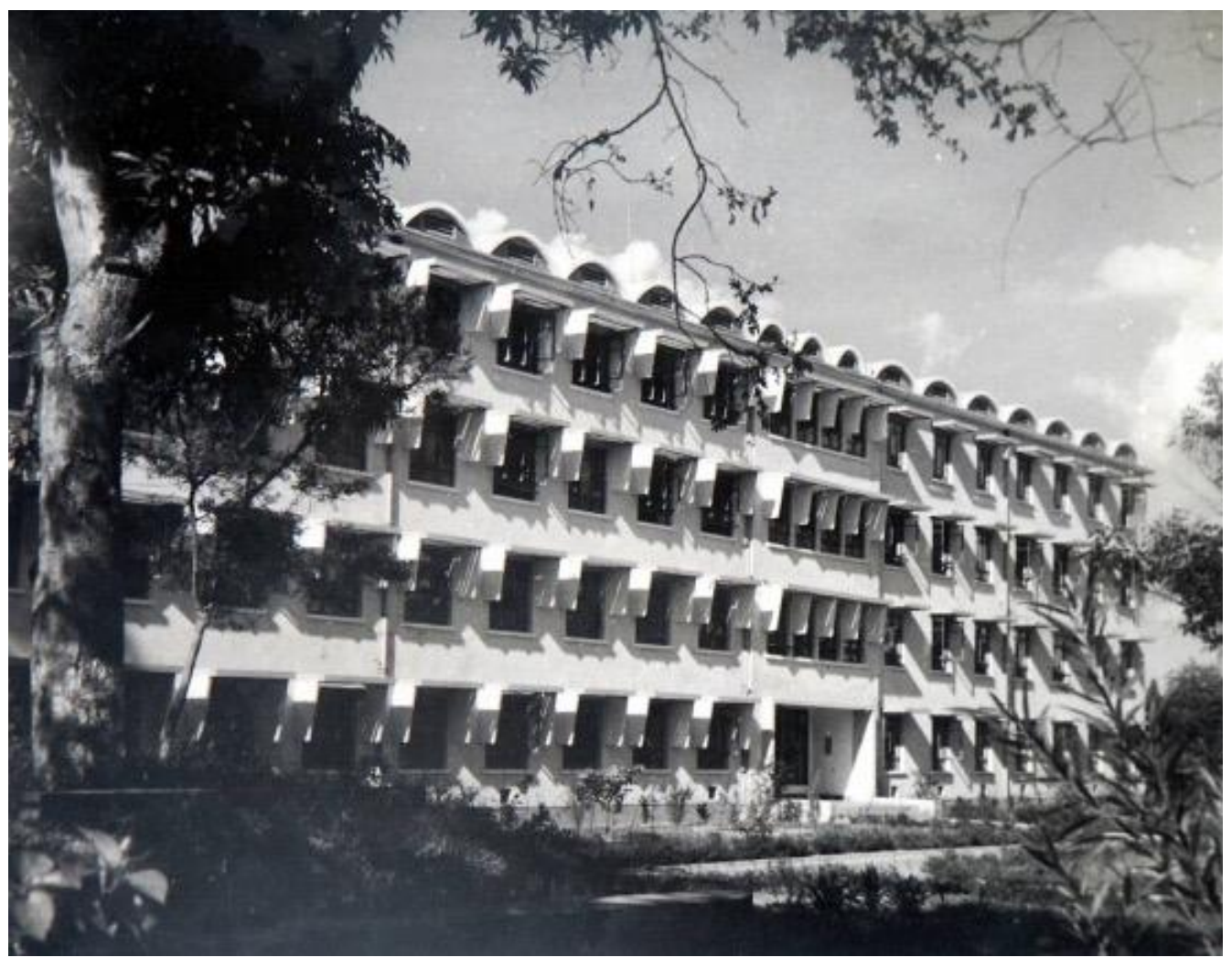

Figure 38. Xia Changshi. Principal Building of the Sun Yat-sen Hospital, Guangzhou, Guangdong Province. 1957. Image from Shi Liang, Research on the life and works of Xia Changshi (master's thesis, South China University of Technology, 2007).

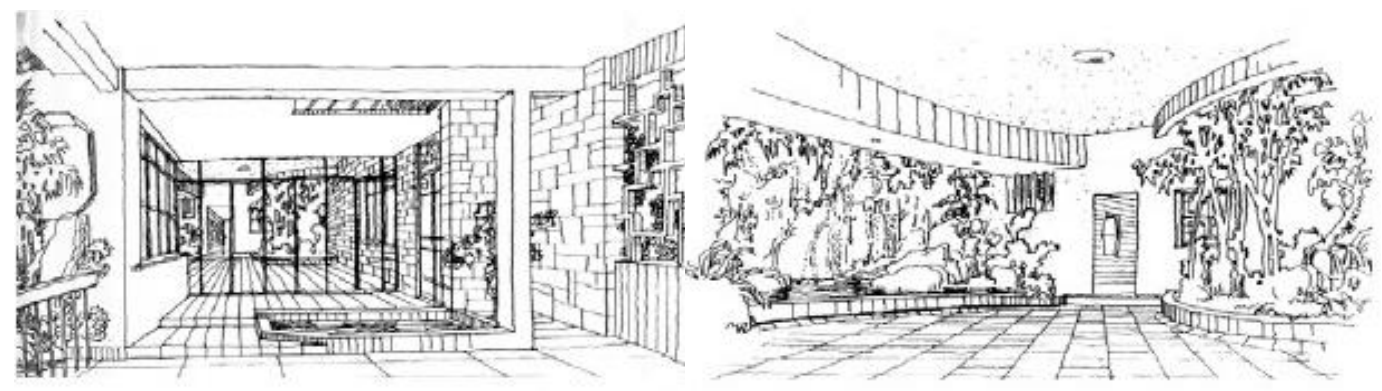

Figure 39. Mo Bozhi, Sketches of Shuangxi Villa. The Works of Mo Bozhi. Image from Zhuang Shaopang, "Research on the Architectural Creation and Thought of Mo 
Bozhi” (PhD diss., South China University of Technology, 2011).
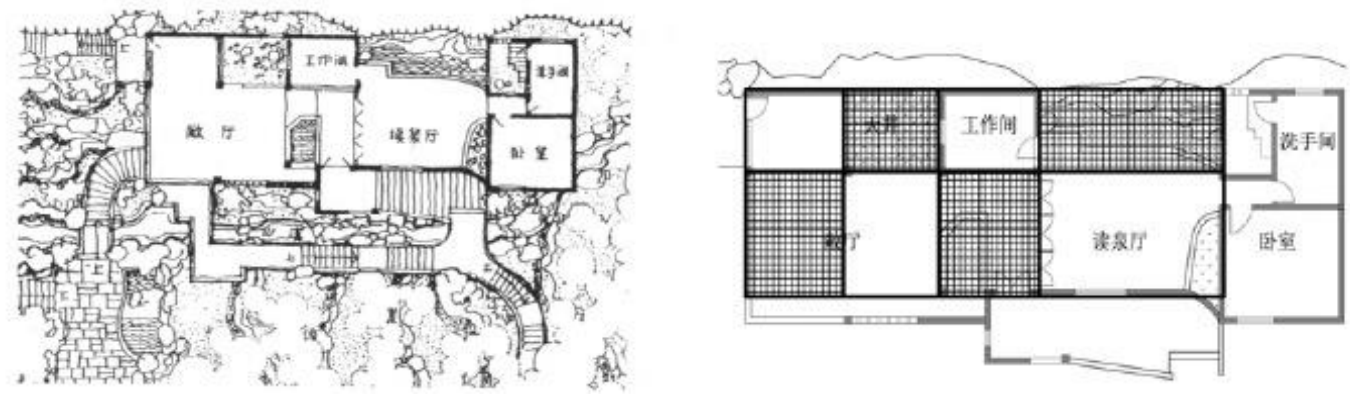

Figure 40. Zhuang Shaopang. Diagram showing the transition of exterior and interior of Shuangxi Villa. Image from Zhuang, "Mo Bozhi."
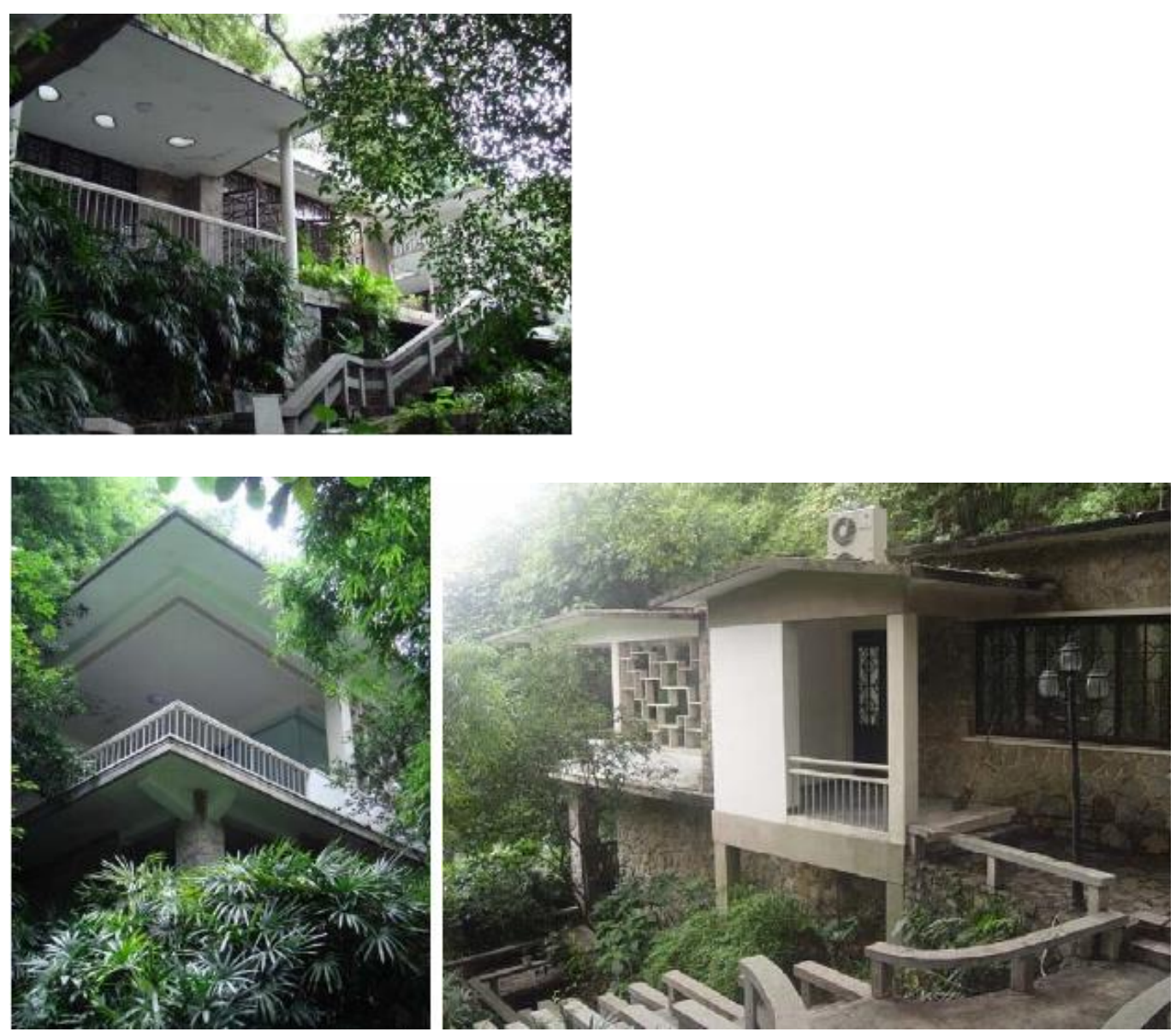

Figure 41. Photos of Shuangxi Villa, by Zhuang Shaopang. Image from Zhuang, "Mo Bozhi." 

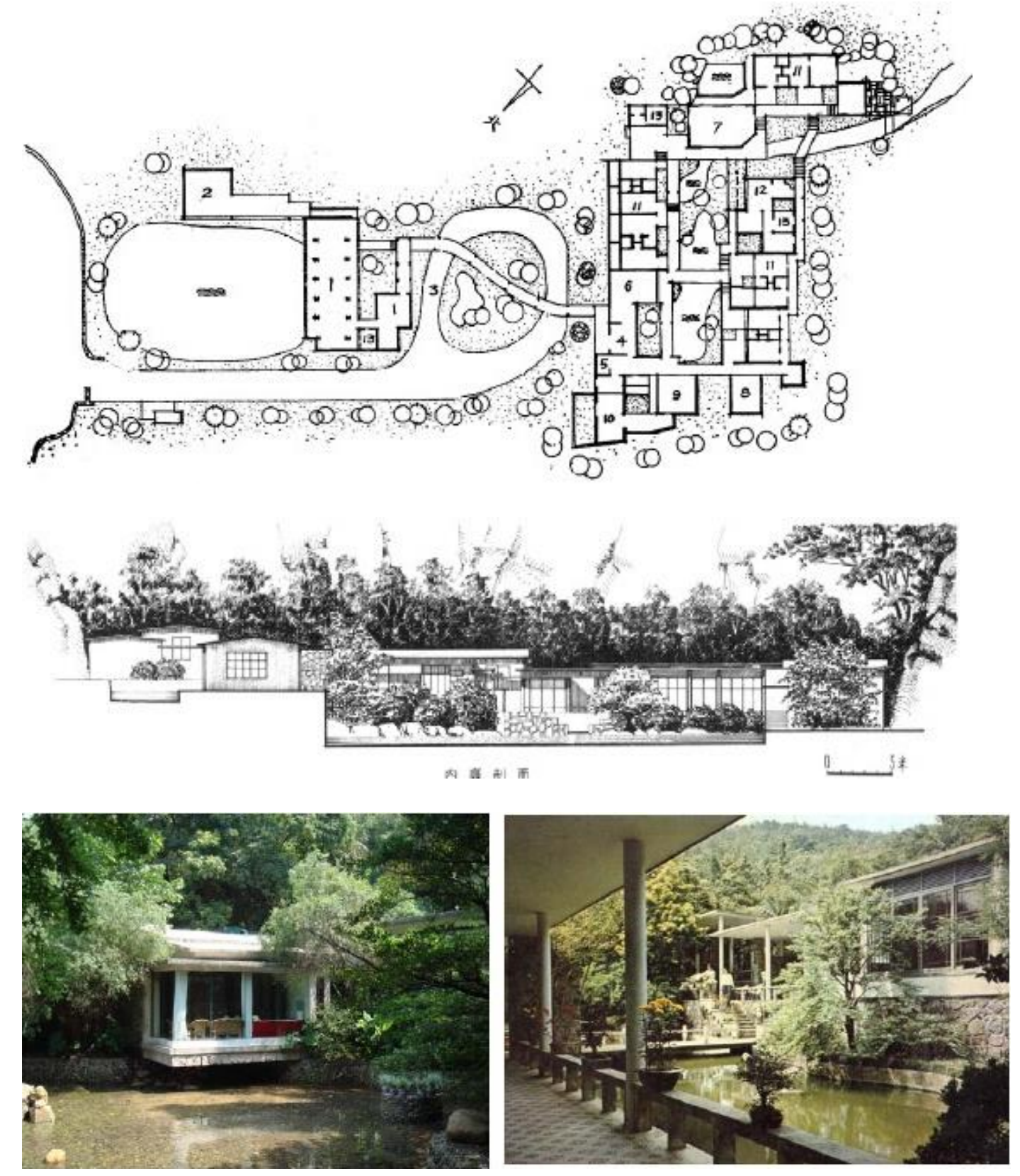

Figure 42, 43. Mo Bozhi, plans and photos of the Mountain Villa. Photos by Zhuang Shaopang. Images from Zhuang, "Mo Bozhi." 


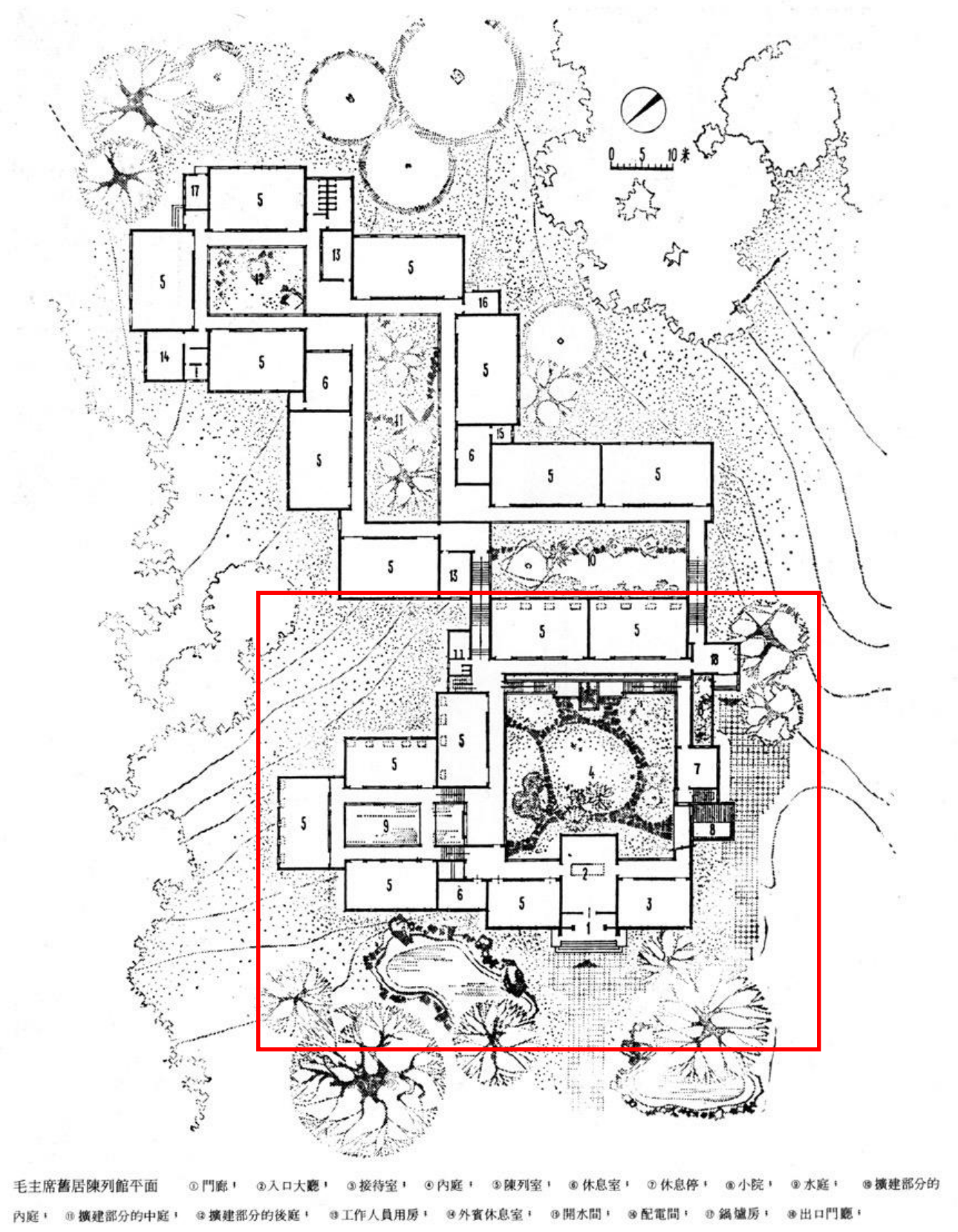

Figure 44. Plan of the Exhibition Pavilion for Comrade Mao Zedong's Old House. This museum was expanded in 1969, with three yards added after yard 4, numbered as 10,11 , and 12 . The area in the red rectangle is the construction in 1964. In the plan, No. 1 is the entrance, No. 2 is the lobby hall, No. 3 is the reception room, No. 4 is the "green yard," No. 5 are exhibition rooms, Nos. 6 and 7 are relaxation rooms, No. 8 is a small yard, and No. 9 is the "water yard." Photocopy from Hunan Shaoshan Revolutionary Committee, "Shaoshan in Construction," 3. 


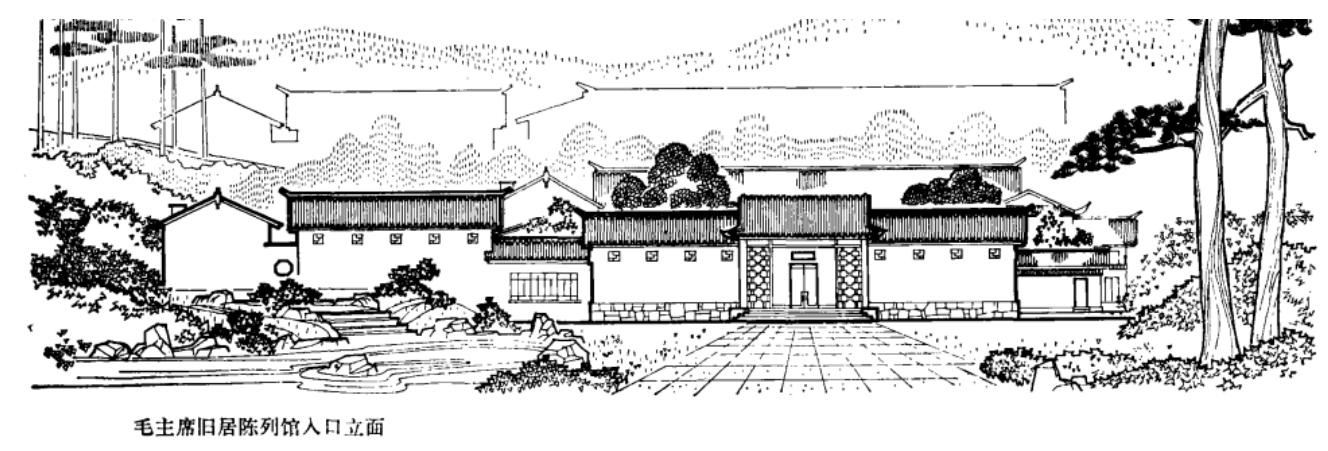

Figure 45. Facade of the Exhibition Pavilion for Comrade Mao Zedong's Old House.

Photocopy from Hunan Shaoshan, "Shaoshan," 4.
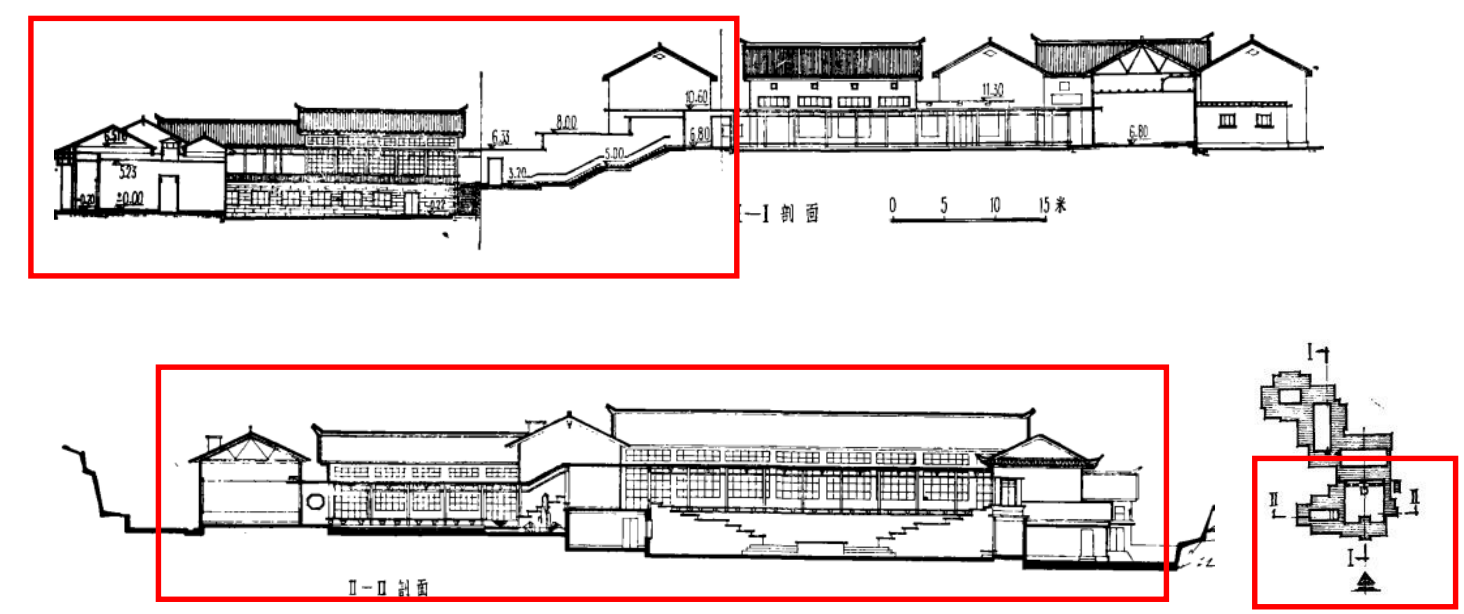

Figure 46. Section of the Exhibition Pavilion for Comrade Mao Zedong's Old House.

In I-I section, the part in the red rectangle is the construction in 1964. Photocopy from Hunan Shaoshan, "Shaoshan," 4. 


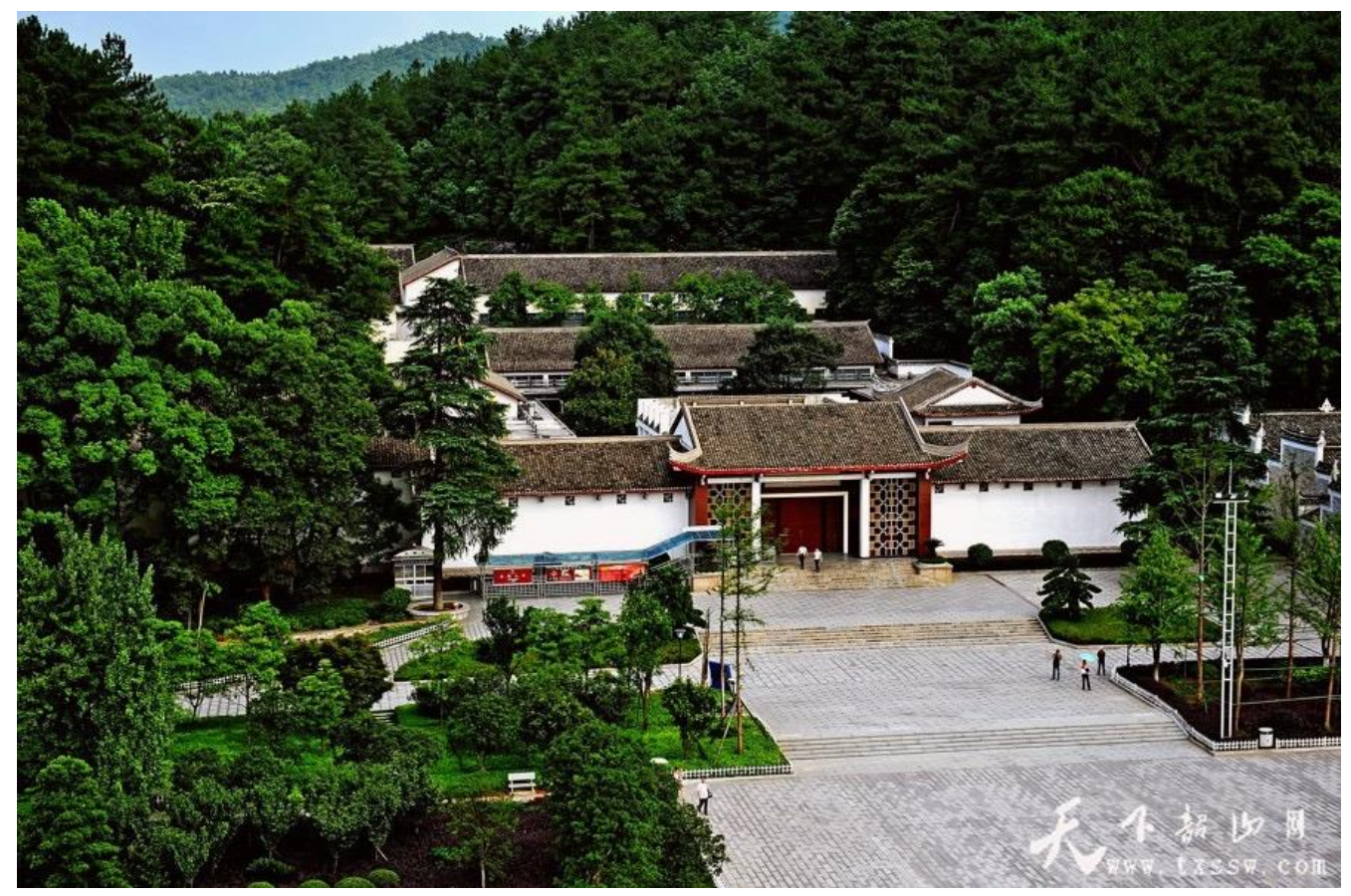

Figure 47. Overview of the Exhibition Pavilion of Comrade Mao Zedong's Old

House. Image from “Mao Zedong jinian guan” [Memorial museum of Mao Zedong],

last modified November 21, 2013, http://www.zspt.cn/Item/10215.aspx.

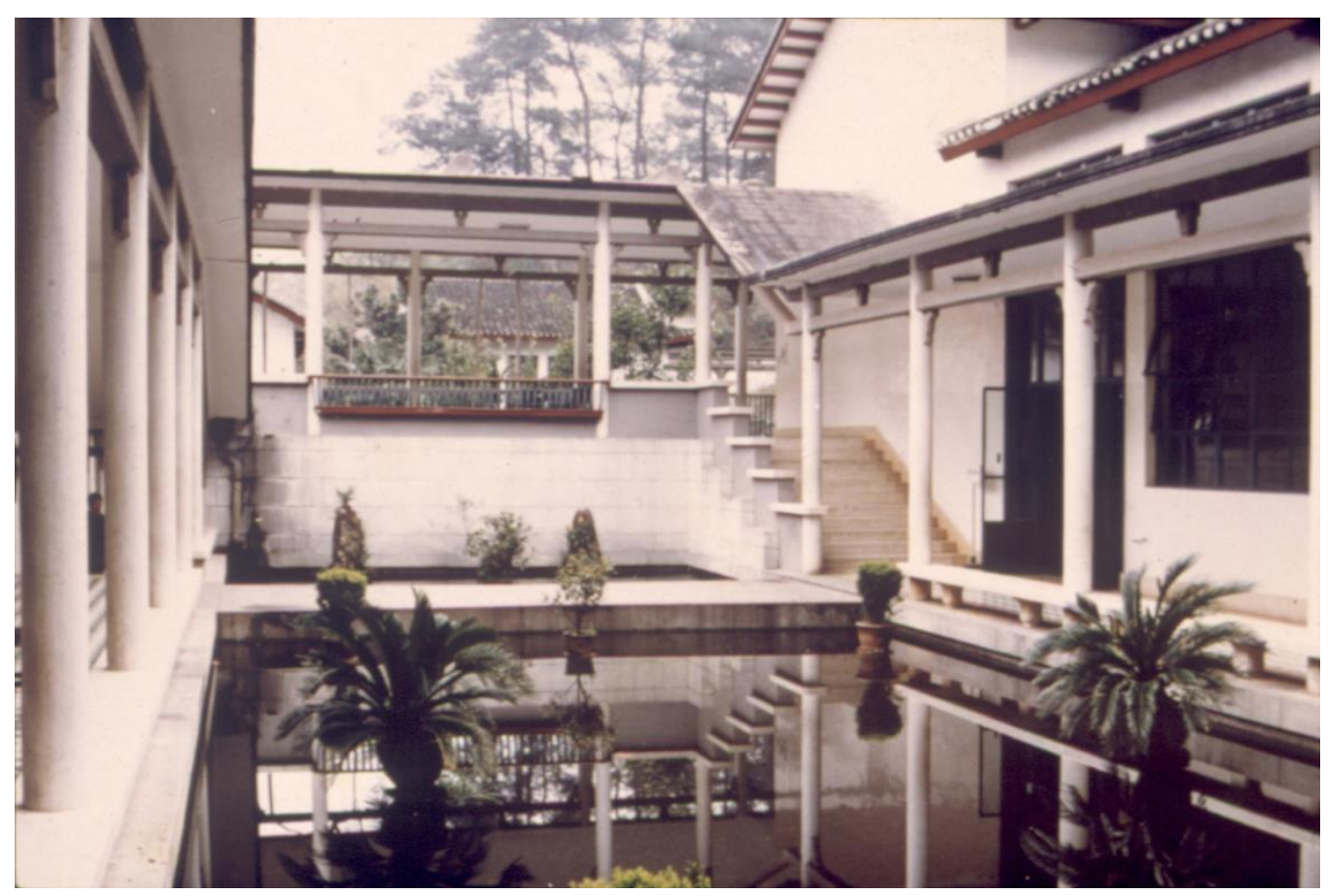

Figure 48. "Water yard" of the museum, built in 1964. Photo by Zou Denong. 


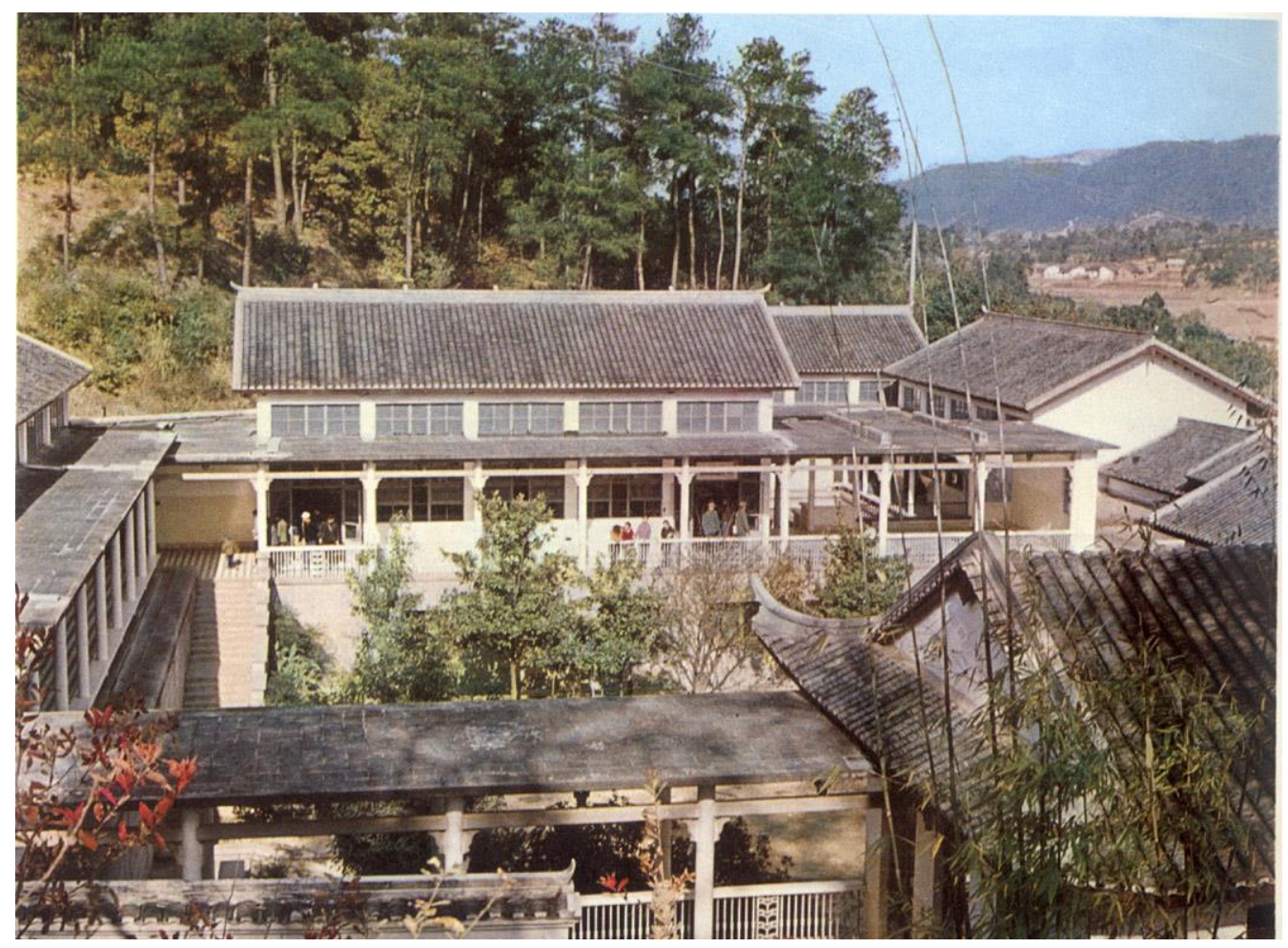

Figure 49. "Green yard" of the museum, built in 1964. Photo by Zou Denong.
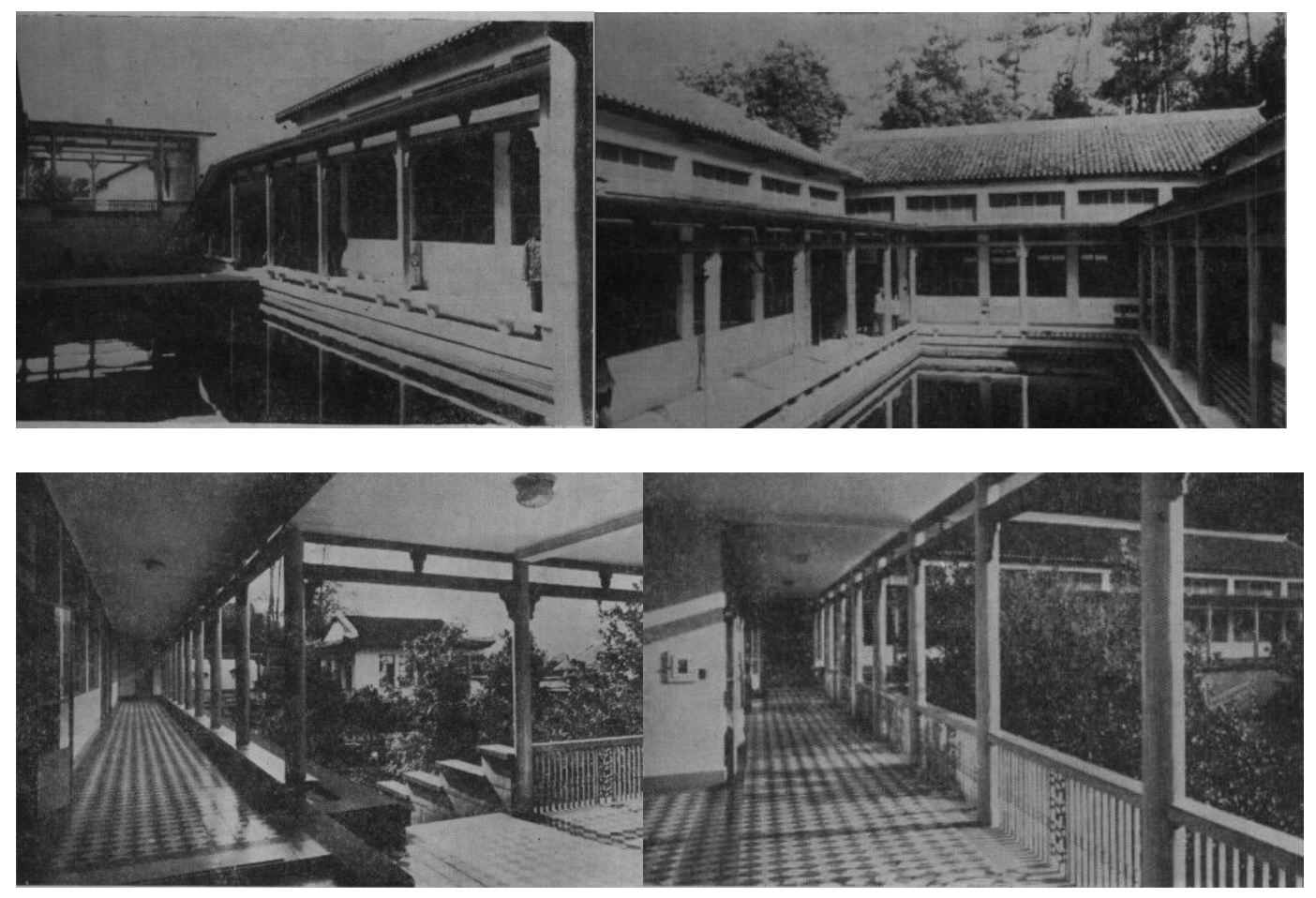

Figure 50. Interior garden and corridor of the Exhibition Pavilion. Image from Hunan Shaoshan, "Shaoshan." 


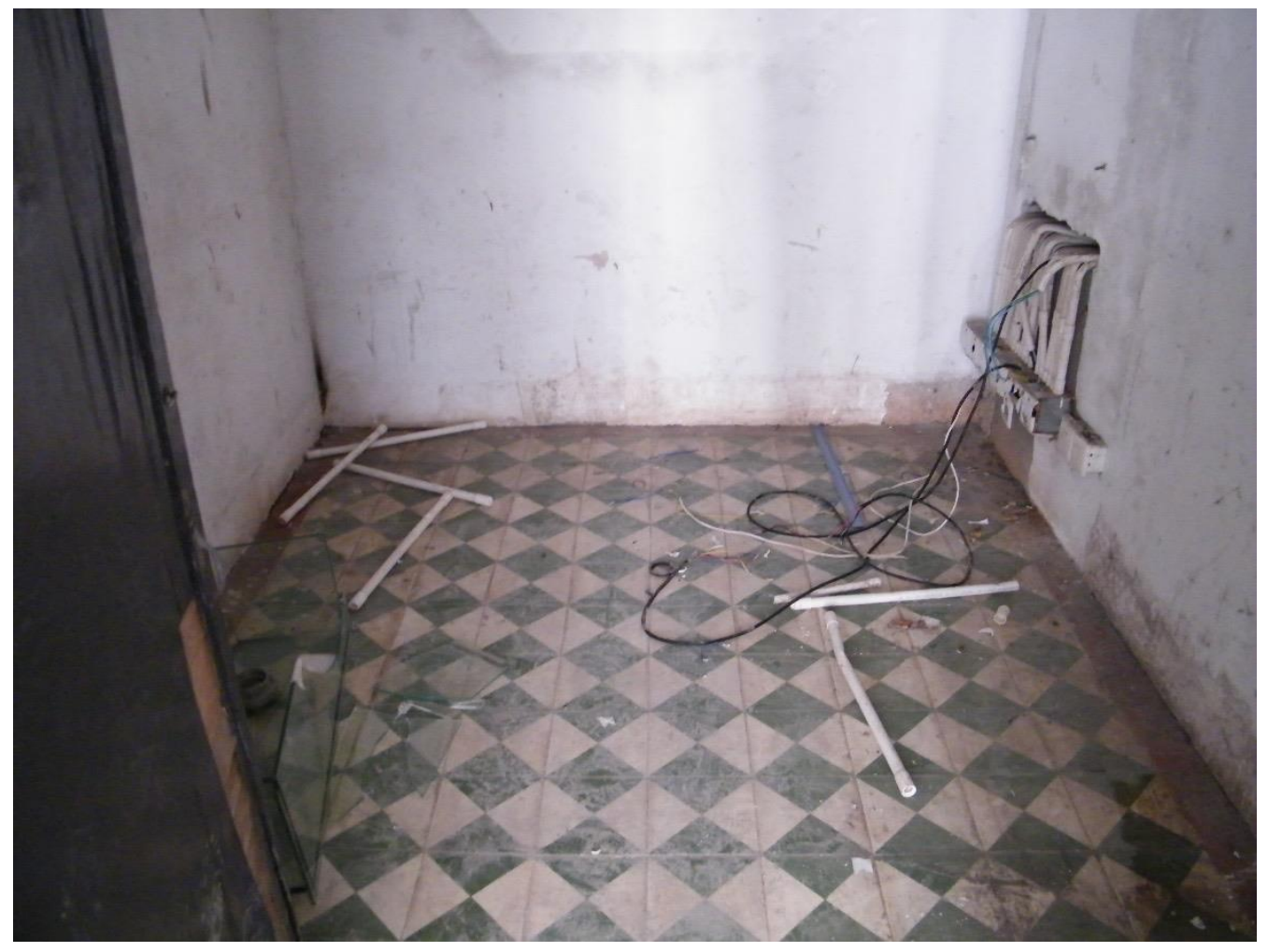

Figure 51. Quadrille pavement of the museum. Photo by the author.

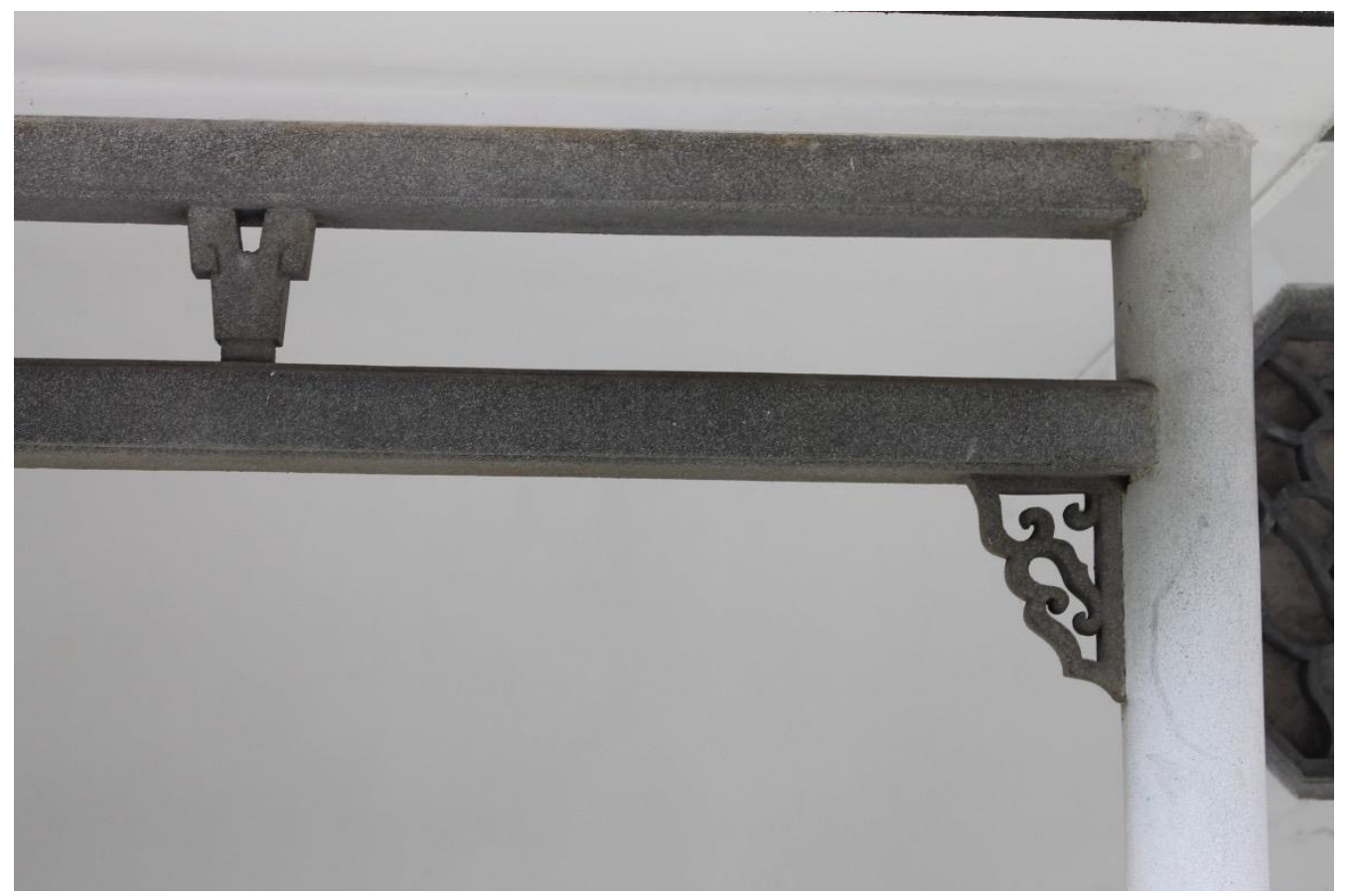

Figure 52. Decorative detail in the yard. The window on the far right has a sunflower pattern. Photo by Lai Delin. 


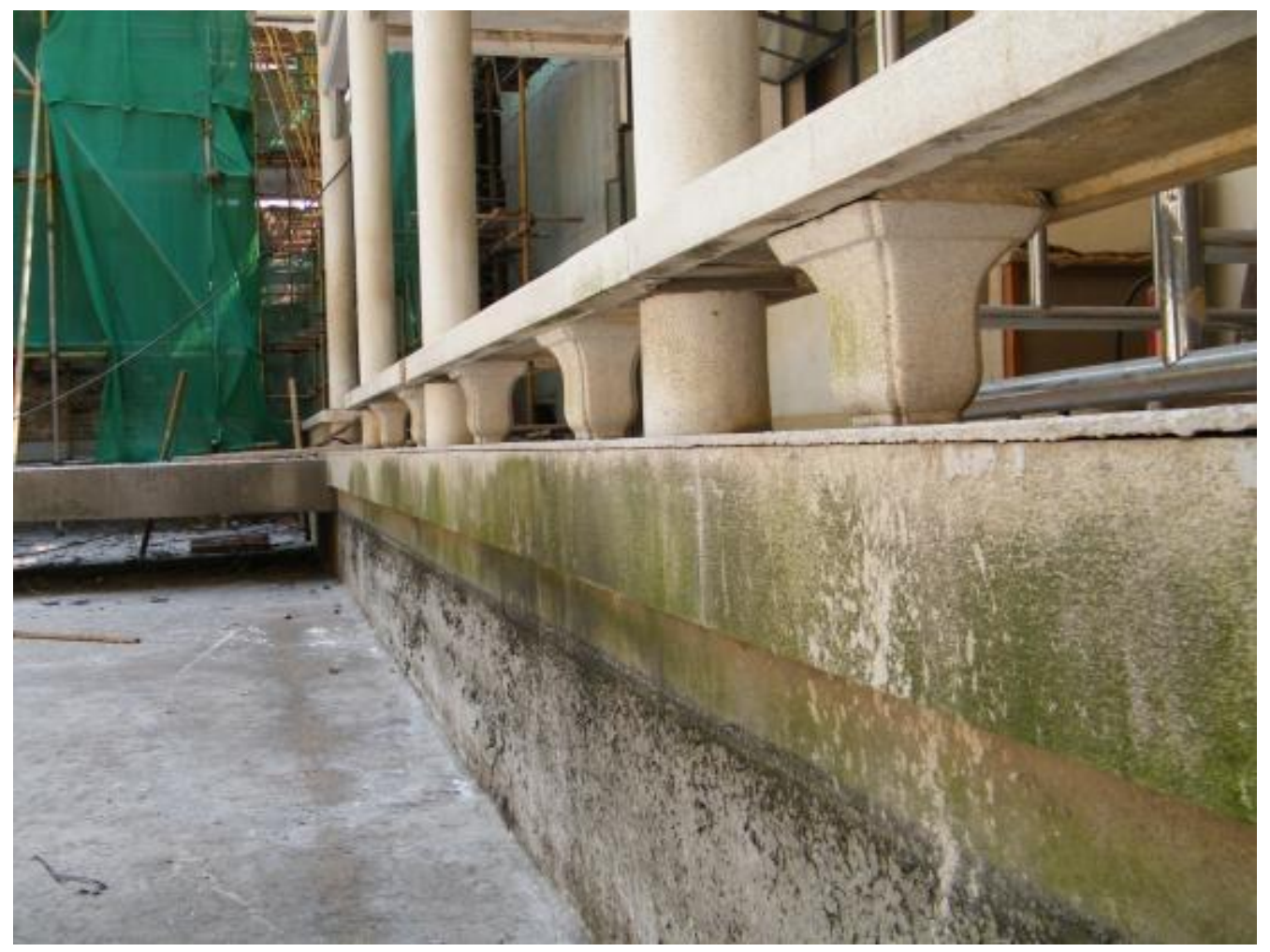

Figure 53. Delicate moldings of the museum. Photo by the author. 


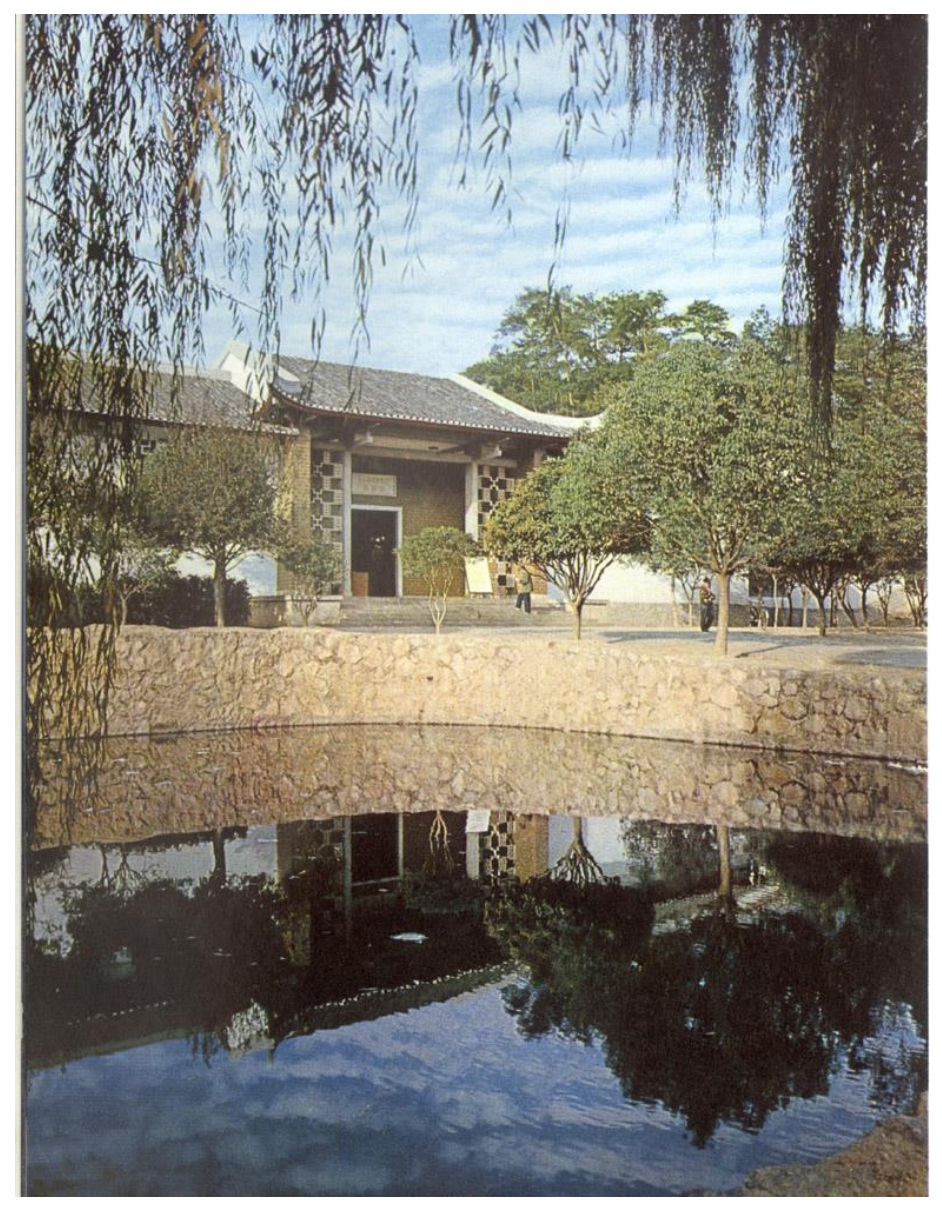

Figure 54. Entrance of the museum. Photo by Zou Denong.

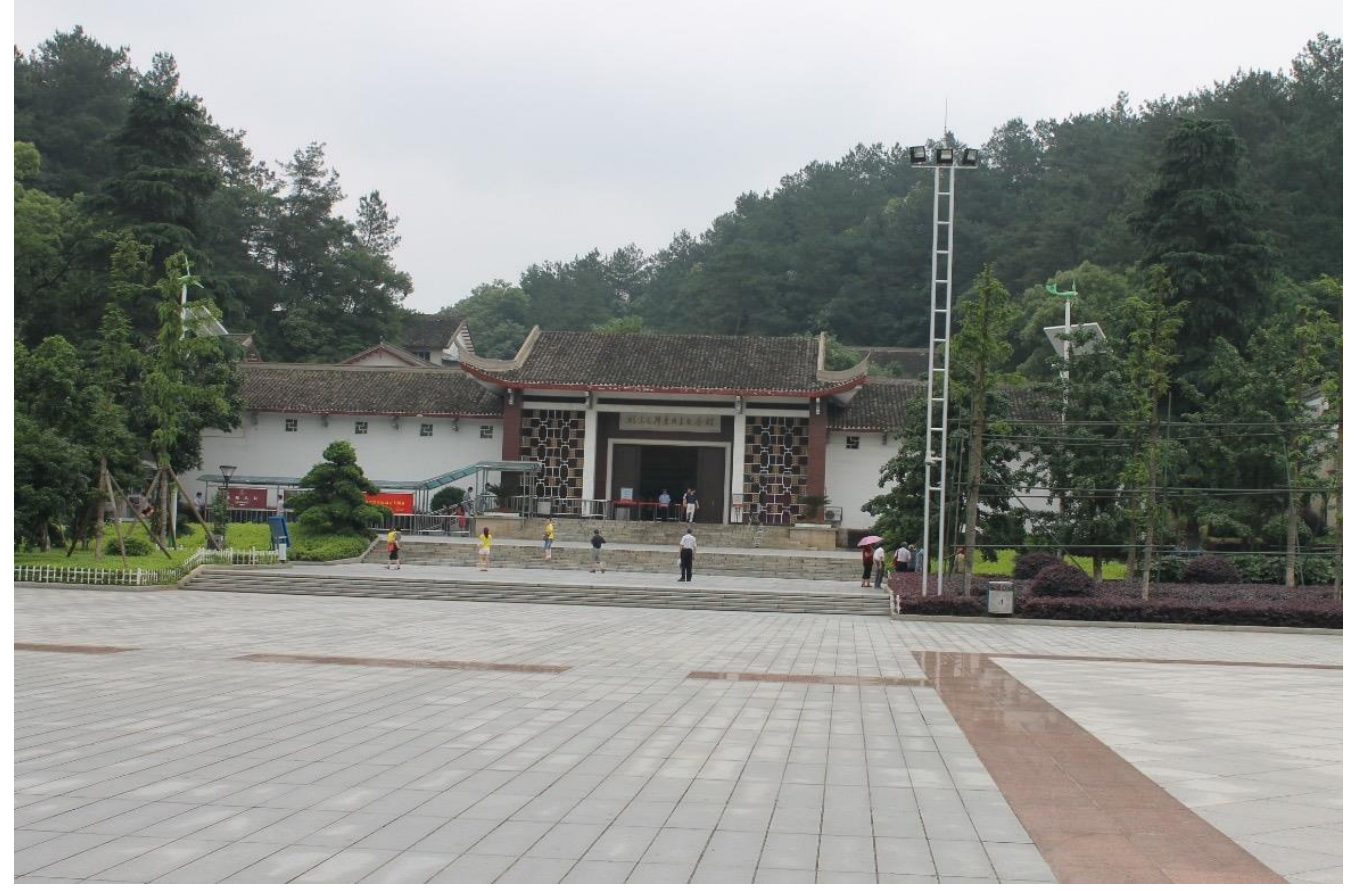

Figure 55. Facade of the museum. Photo by Delin Lai. 


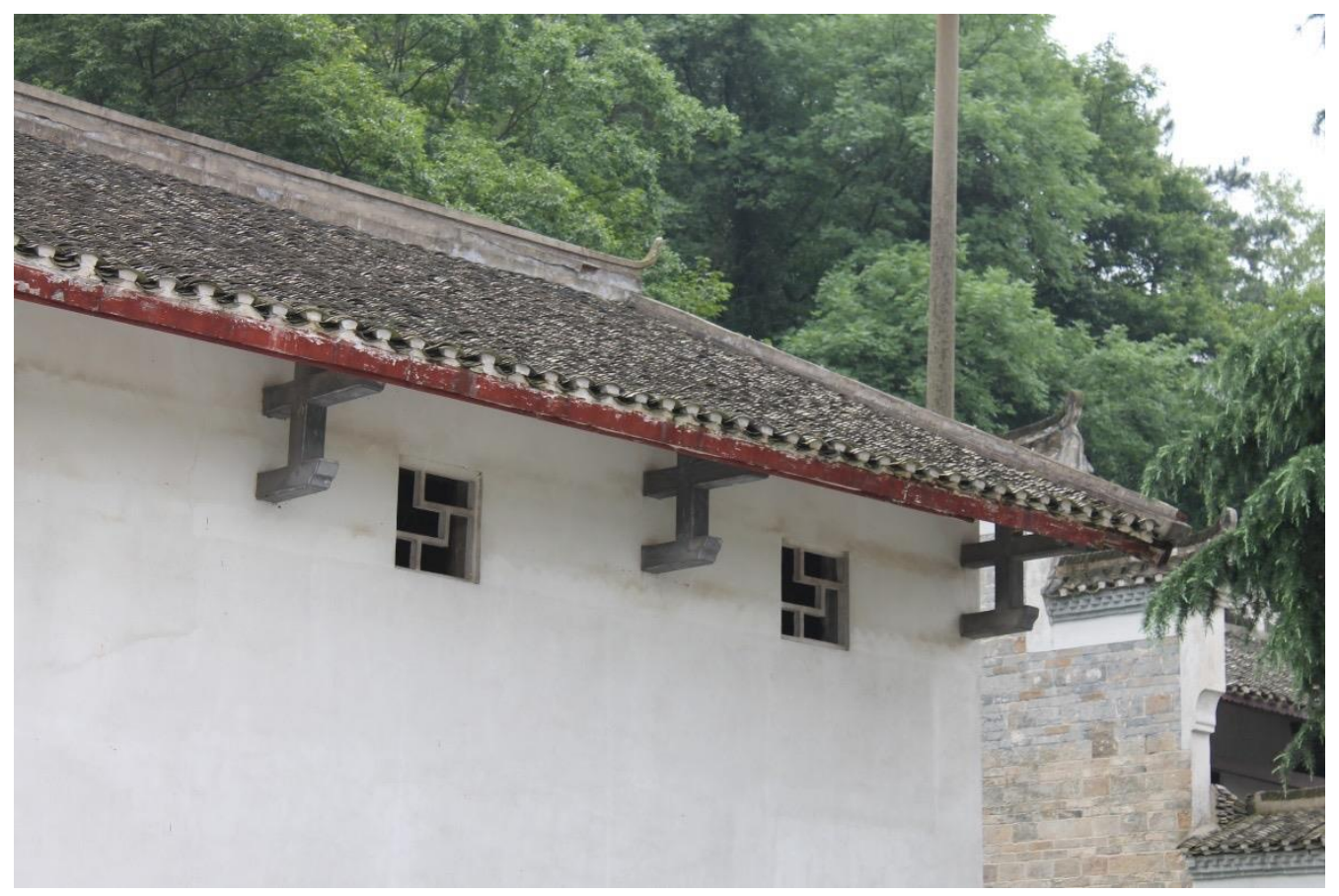

Figure 56. F-shaped structural detail of the museum. Photo by Lai Delin.

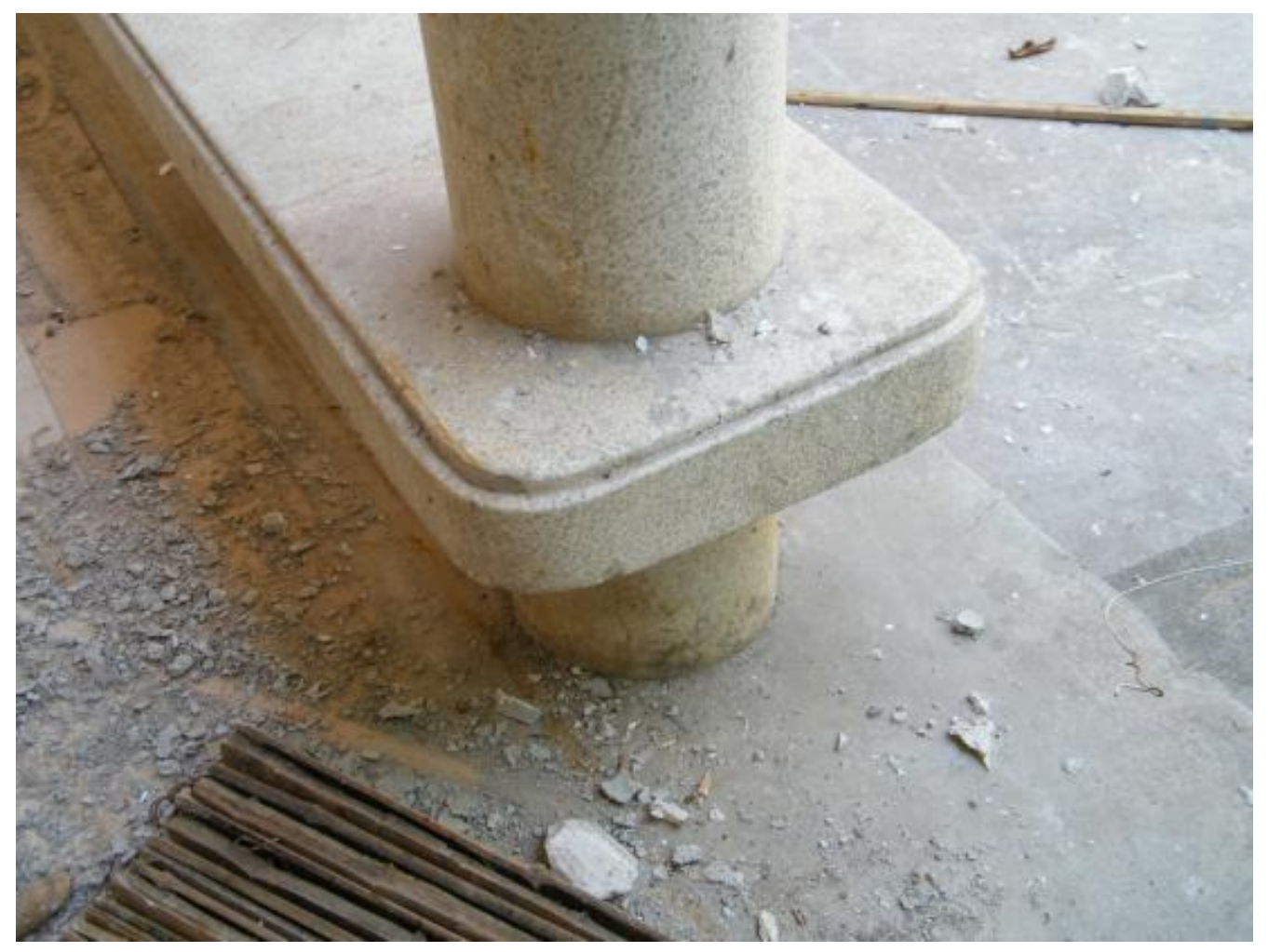

Figure 57. Delicate details and artificial materials. Photo by the author. 


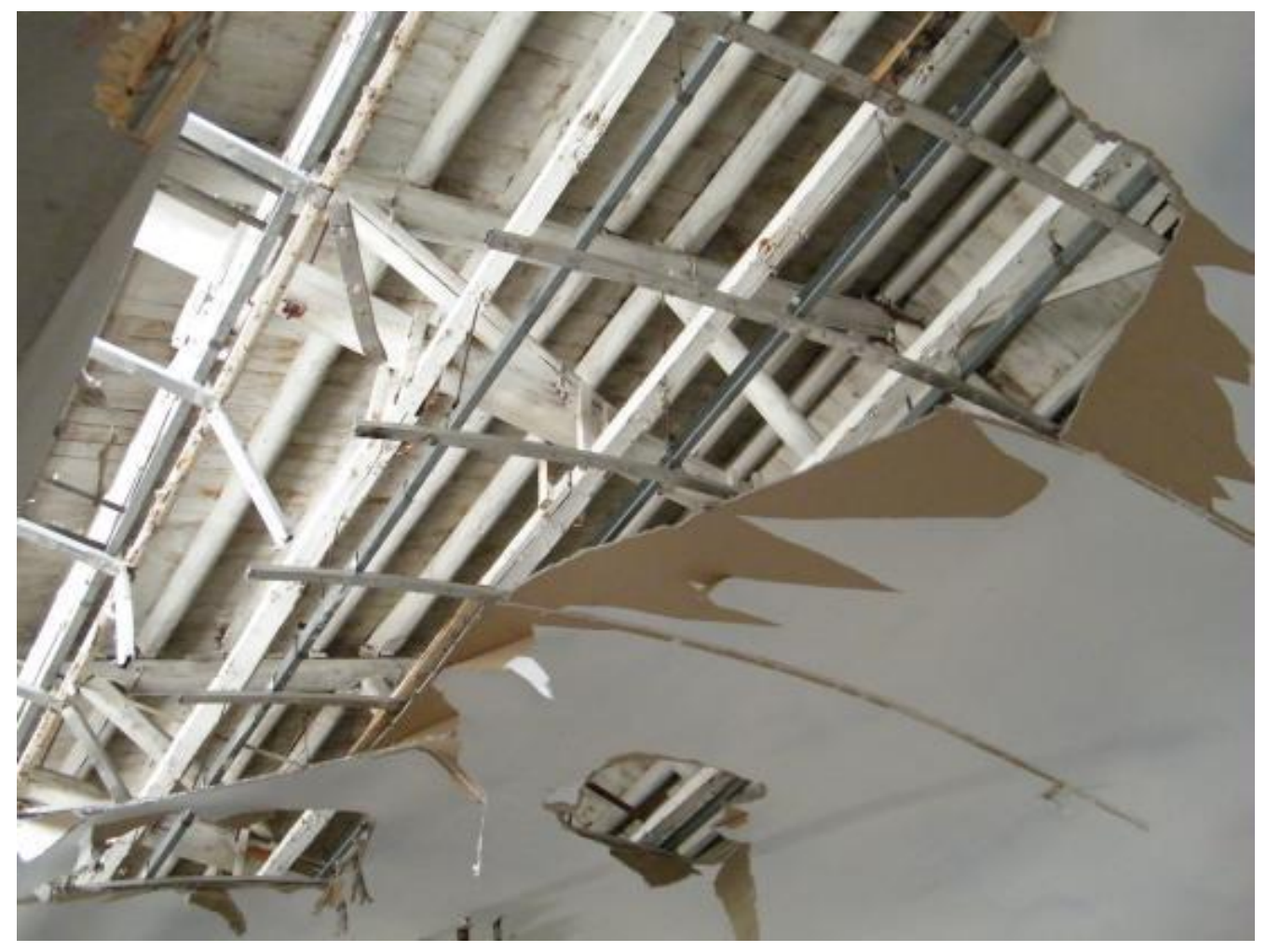

Figure 58. Wooden upper structure of the museum. Photo by the author.

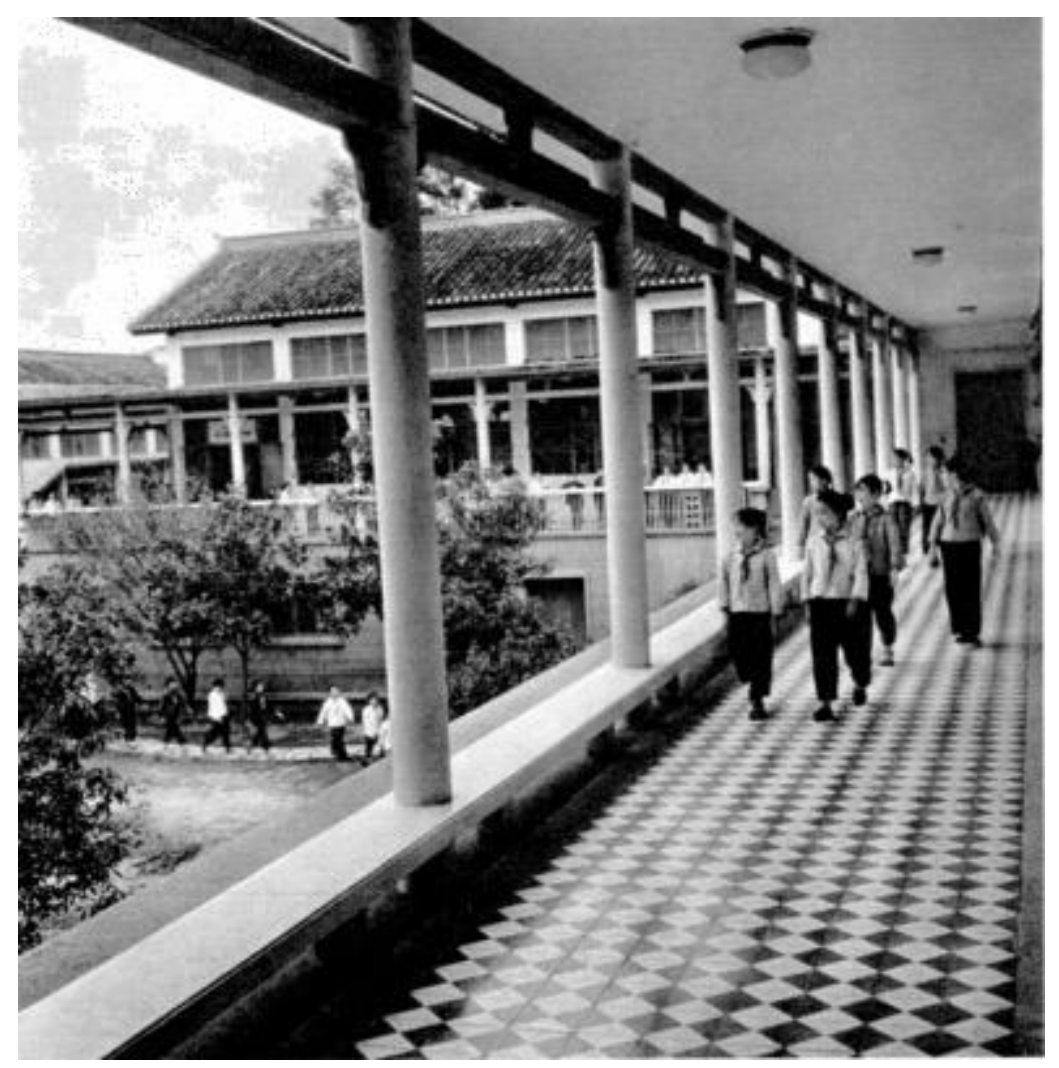

Figure 59. Visitors to the Exhibition Pavilion. Image scanned from "Exhibition 
Pavilion," Shao Shan.

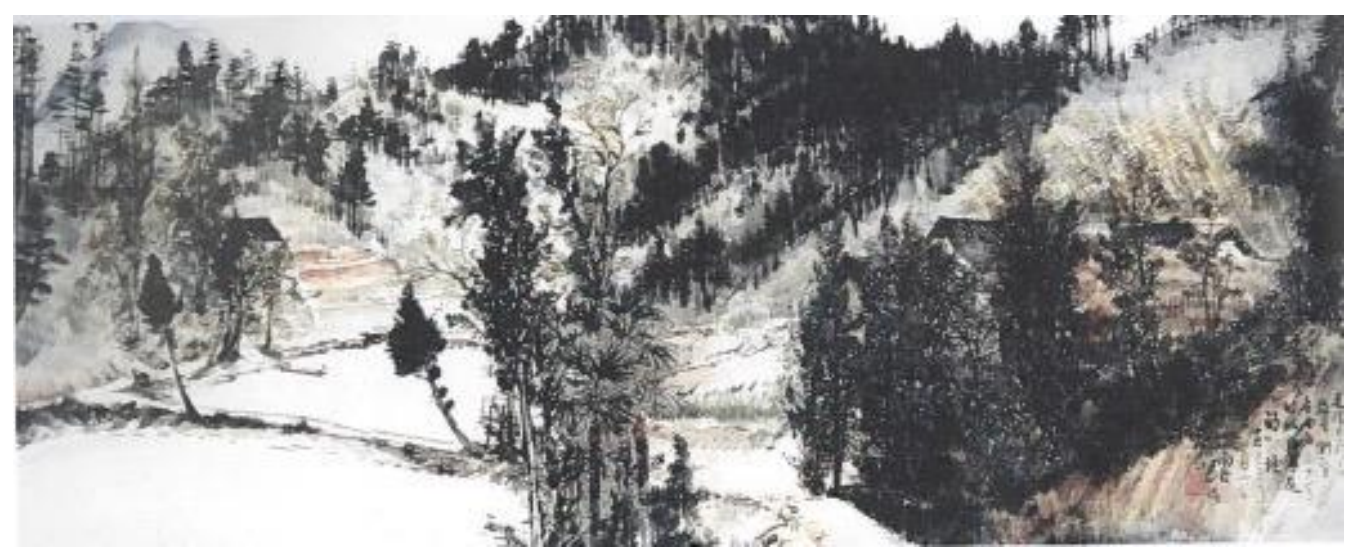

Figure 60. Li Xiongcai, Maozedong tongzhi guju cewang [Distant View of Comrade Mao’s Old House], April 18, 1955, 29.3cm × 74.7cm, Guangzhou Art Museum. Image scanned from Wan Xinhua. Sheng Di Shao Guang: 20 Shi Ji Zhong Qi Zhong Gguo Hua Zhi Shao Shan Tu Xiang [The sacred place Shaoshan: Shaoshan iconography in Chinese traditional painting in the mid-20th century](Beijing: Cultural and Art Publishing House, 2011).

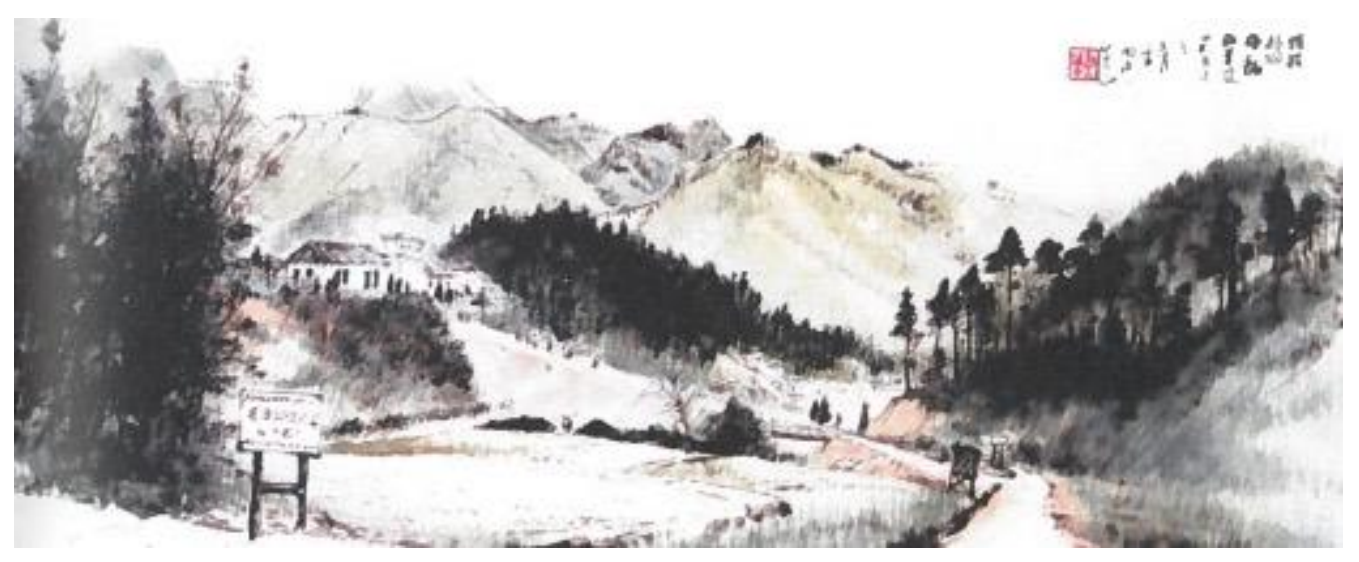

Figure 61. Li Xiongcai, Cong Zhaodaisuo tiaowang shaoshan xuexiao [Distant View of Shaoshan School from the Guesthouse], May 2, 1955, $24.5 \mathrm{~cm} \times 74.5 \mathrm{~cm}$, Guangzhou Art Museum. Image scanned from Wan, Sheng Di Shao Guang, 15. 


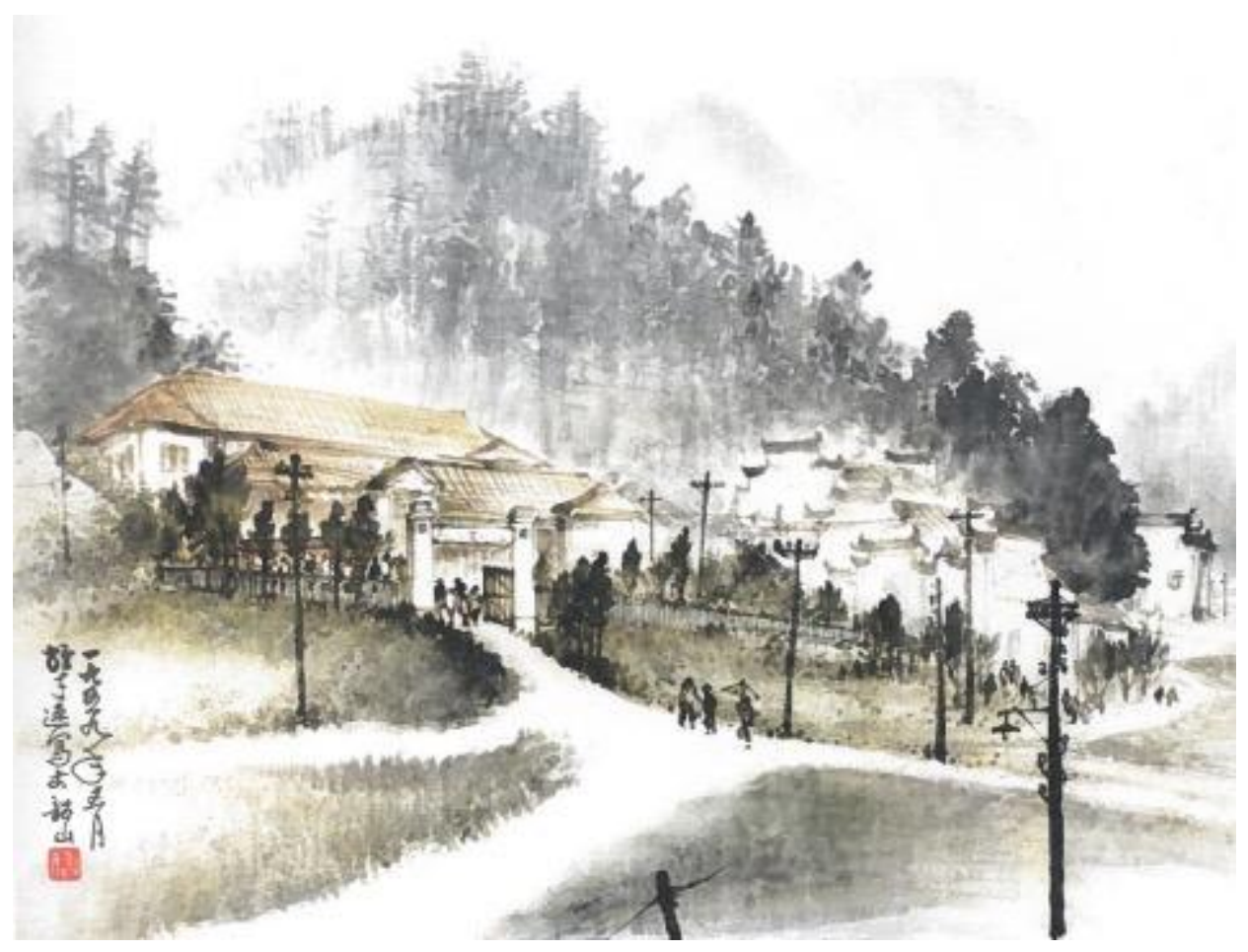

Figure 62. Li Xiongcai. Shaoshan wenhua guan. [Shaoshan Cultural Center], May 1959. Image scanned from Wan, Sheng Di Shao Guang, 19.

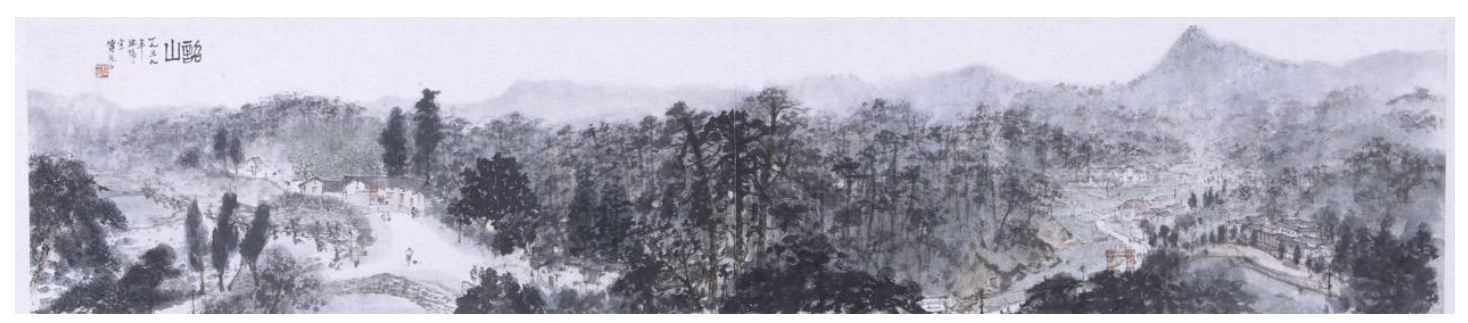

Figure 63. Fu Baoshi, Shaoshan tu [Shaoshan Scroll], June 1959, 27.7cm $\times 136.2 \mathrm{~cm}$, Nanjing Museum. Image scanned from Wan, Sheng Di Shao Guang, 30. 


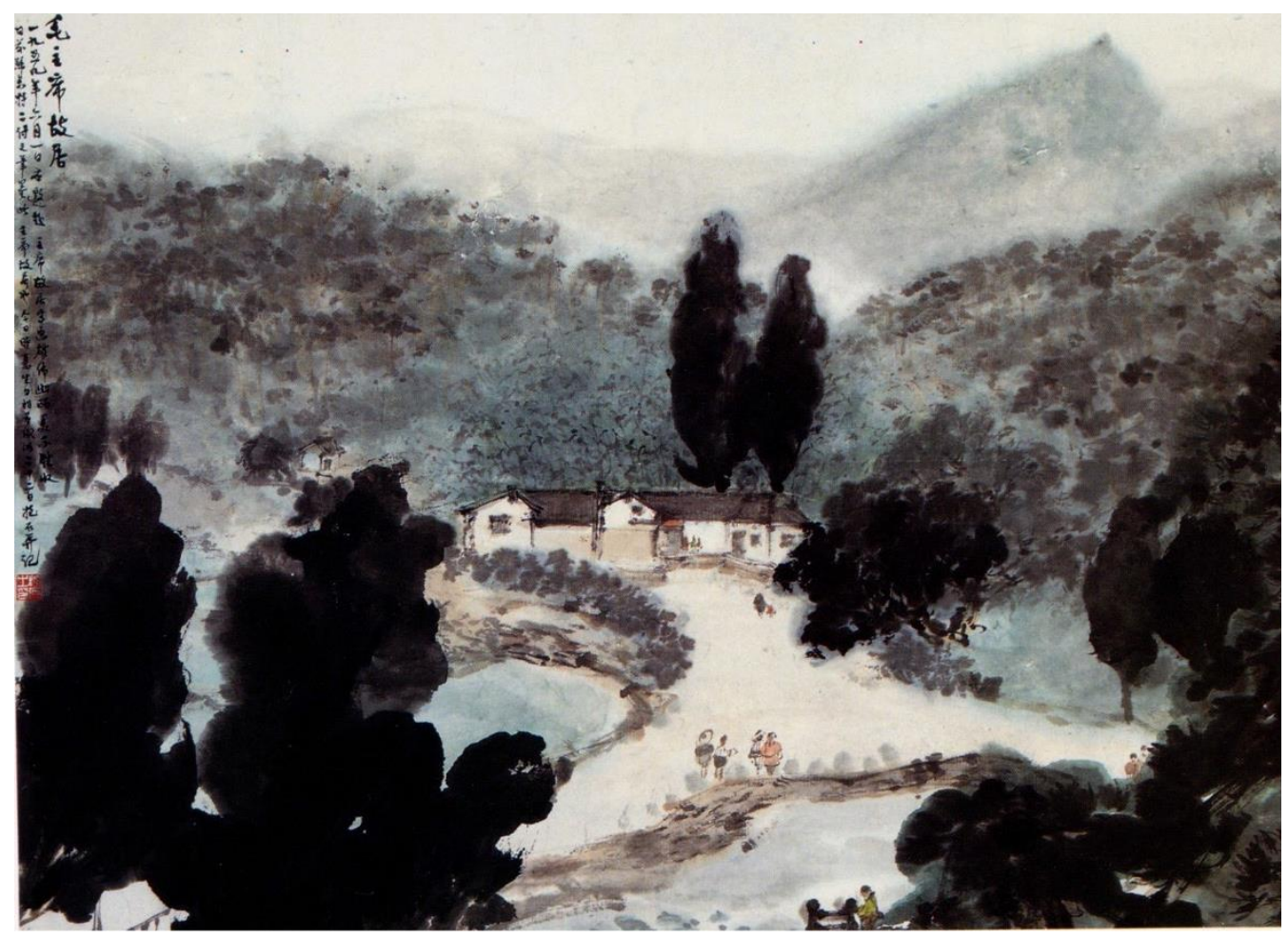

Figure 64. Fu Baoshi. Maozhuxi guju. [Chairman Mao's Old House], June 22, 1959, $45.7 \mathrm{~cm} \times 62.6 \mathrm{~cm}$, private collection. Image scanned from Wan, Sheng Di Shao Guang, 39.

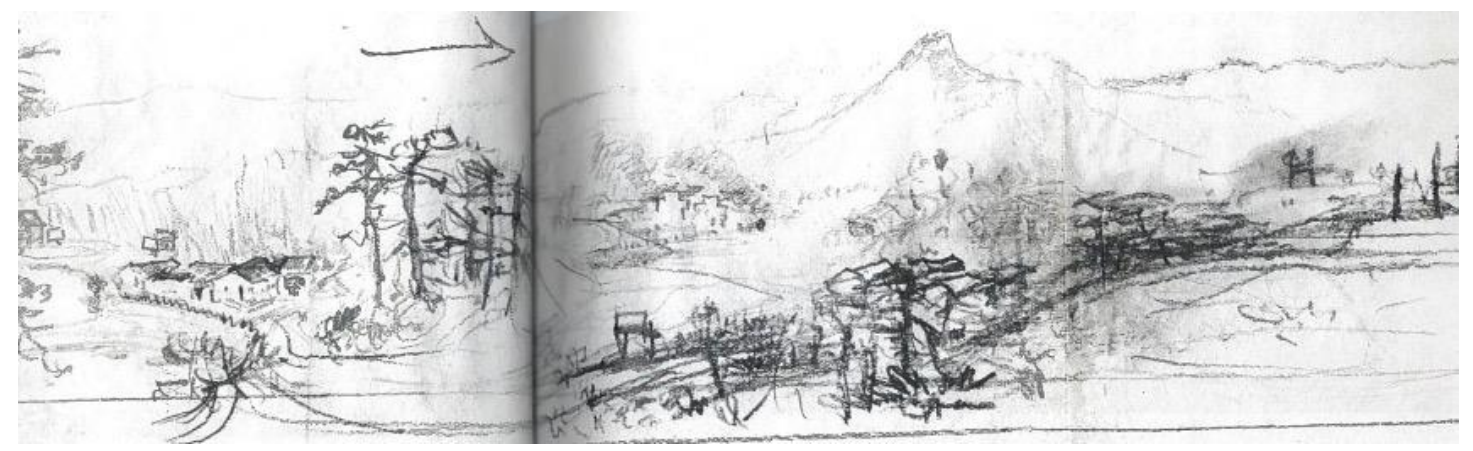

Figure 65. Fu Baoshi, Sketch of the Shaoshan Scroll, 1959. Image scanned from Wan, Sheng Di Shao Guang, 29. 


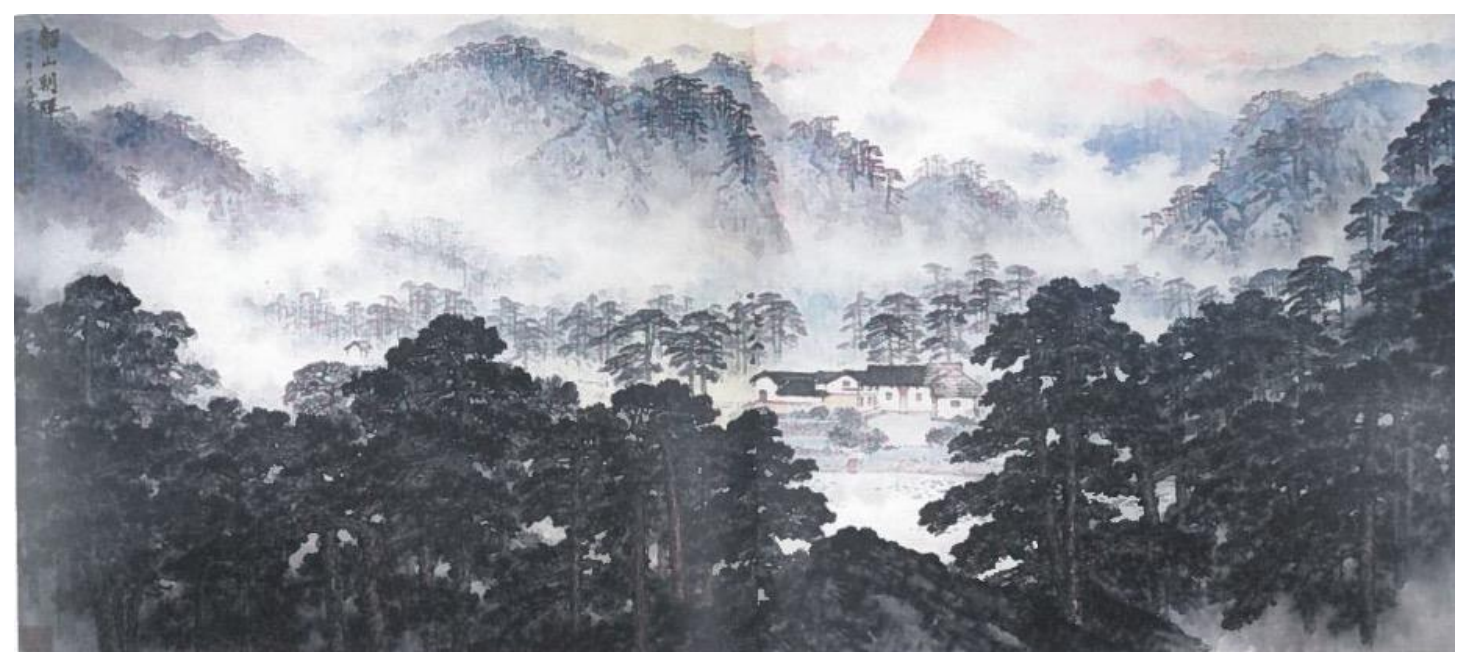

Figure 66. Song Wenzhi, Shaoshan zhaohui [Dawn in Shaoshan], June 1977, 159cm $\times 380 \mathrm{~cm}$, Chairman Mao’s Memorial. Image scanned from Wan, Sheng Di Shao Guang, 95.

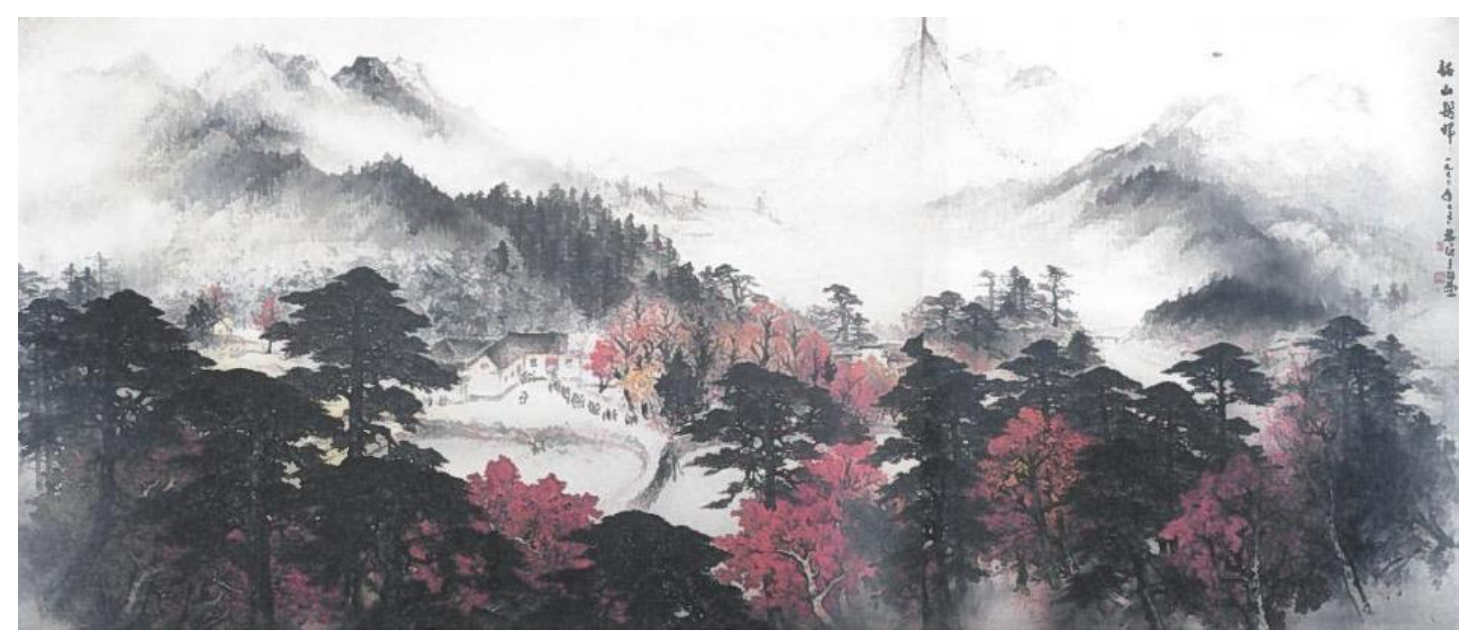

Figure 67. Li Xiongcai, Shaoshan zhaohui [Dawn in Shaoshan], July 1977, 159cm $\times 380 \mathrm{~cm}$, Chairman Mao’s Memorial. Image scanned from Wan, Sheng Di Shao Guang, 100. 


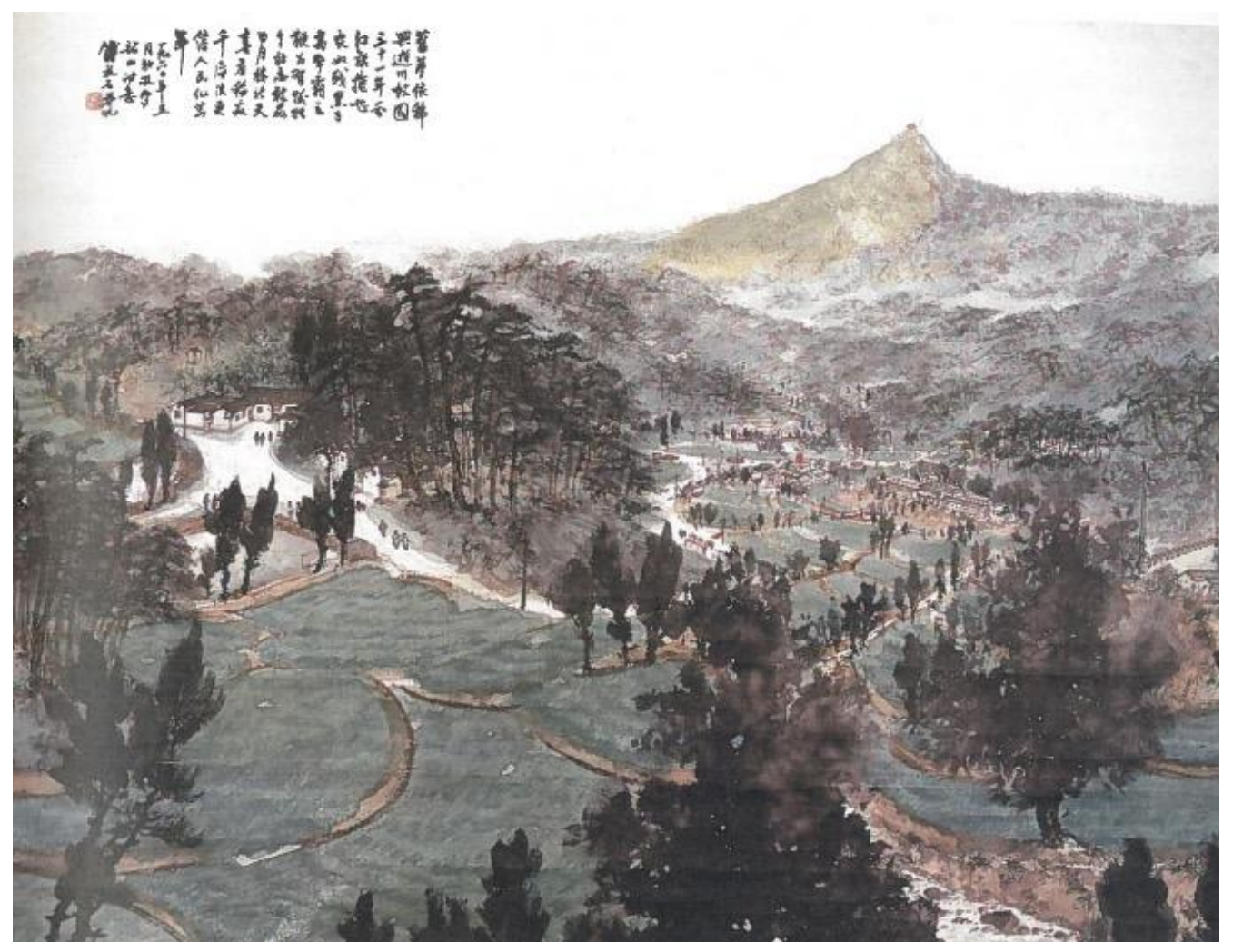

Figure 68. Fu Baoshi, Maozhuxi qilv dao shaoshan shiyi tu [Poetic painting of Chairman Mao’s poem “To Shaoshan”], May 1960, 88.1 cm $\times 116.3 \mathrm{~cm}$, Nanjing Museum. Image scanned from Wan, Sheng Di Shao Guang, 41. 


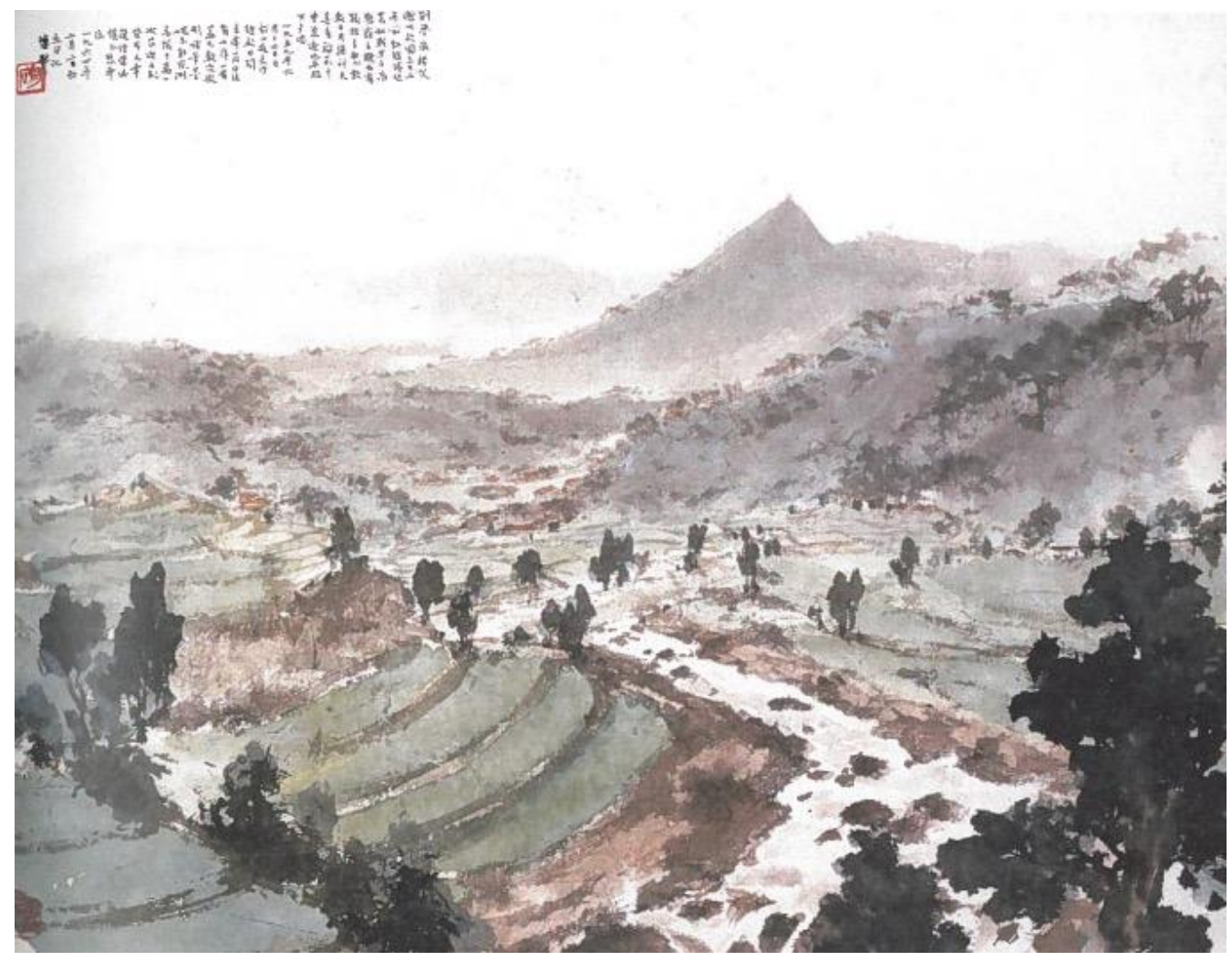

Figure 69. Fu Baoshi, Maozhuxi qilv dao shaoshan shiyi tu [Poetic painting of

Chairman Mao's poem “To Shaoshan”], February 1964, 34.3cm $\times 45.8 \mathrm{~cm}$, Nanjing Museum. Image scanned from Wan, Sheng Di Shao Guang, 43. 


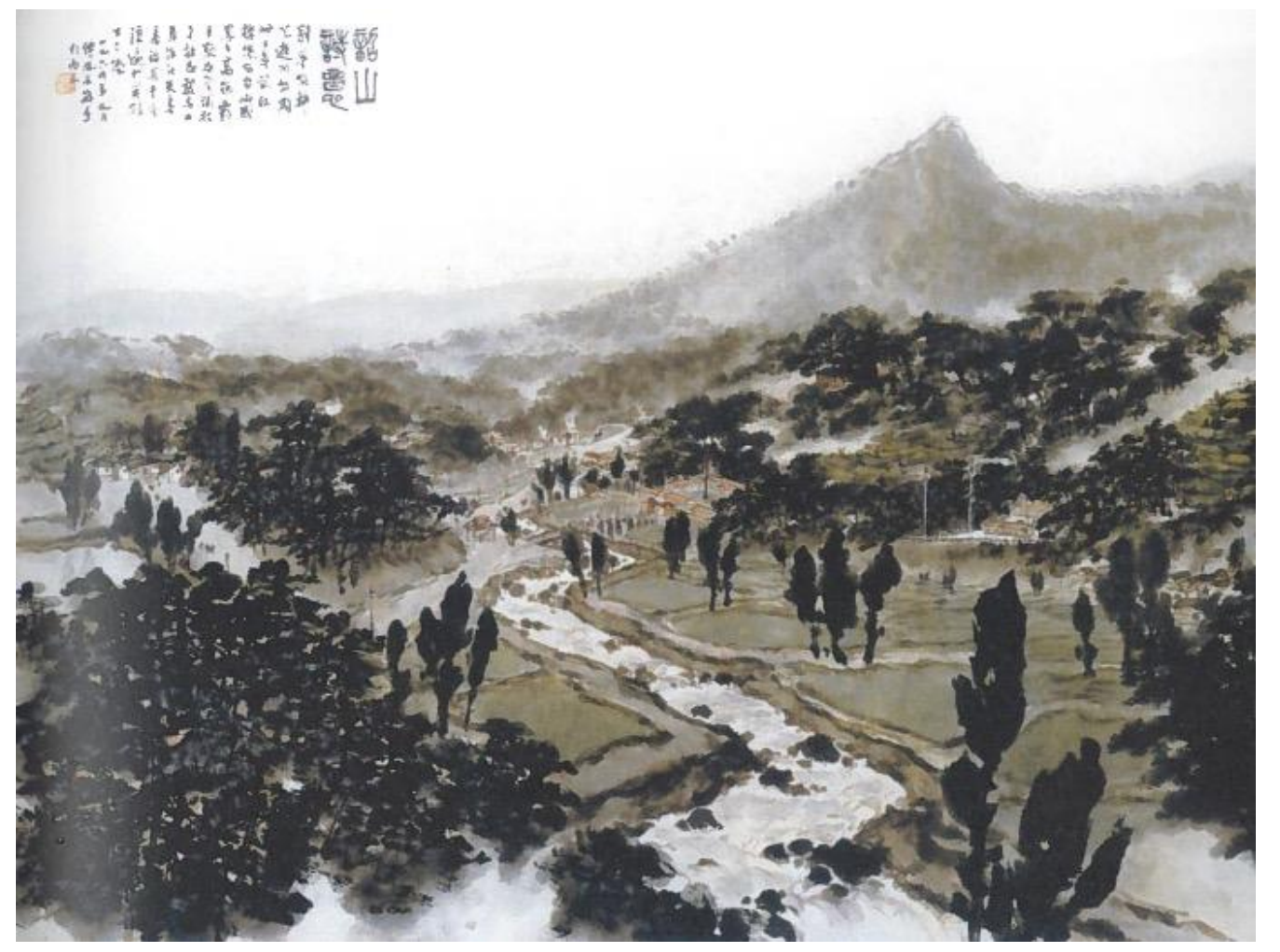

Figure 70. Fu Baoshi, Maozhuxi qilv dao shaoshan shiyi tu [Poetic painting of Chairman Mao's poem “To Shaoshan”], September $1964,69 \mathrm{~cm} \times 92.5 \mathrm{~cm}$, private collection. Image scanned from Wan, Sheng Di Shao Guang, 45.

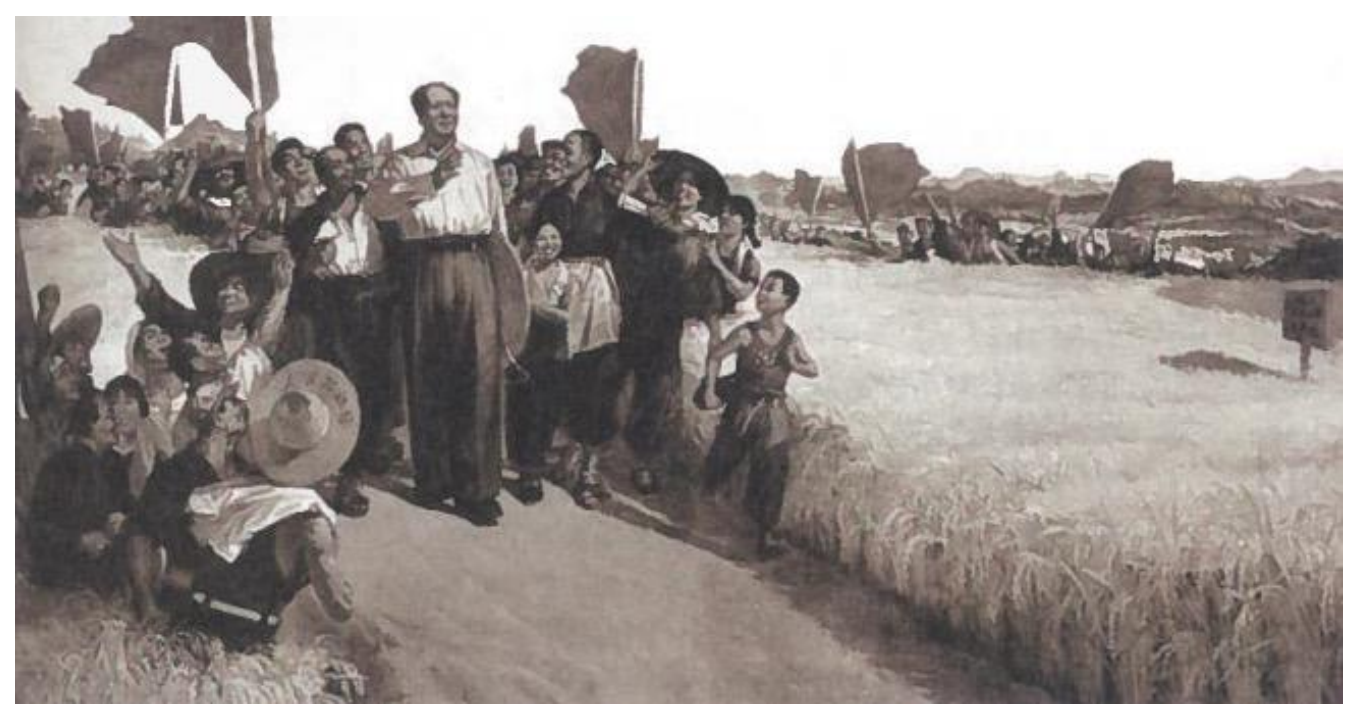

Figure 71. Peng Zhaomin. Maozhuxi 1959 nian hui shaoshan [Chairman Mao returning to Shaoshan in 1959], 1970, 295cm $\times 150 \mathrm{~cm}$, Shaoshan Mao Zedong Memorial Museum. Image scanned from Wan, Sheng Di Shao Guang, 50. 


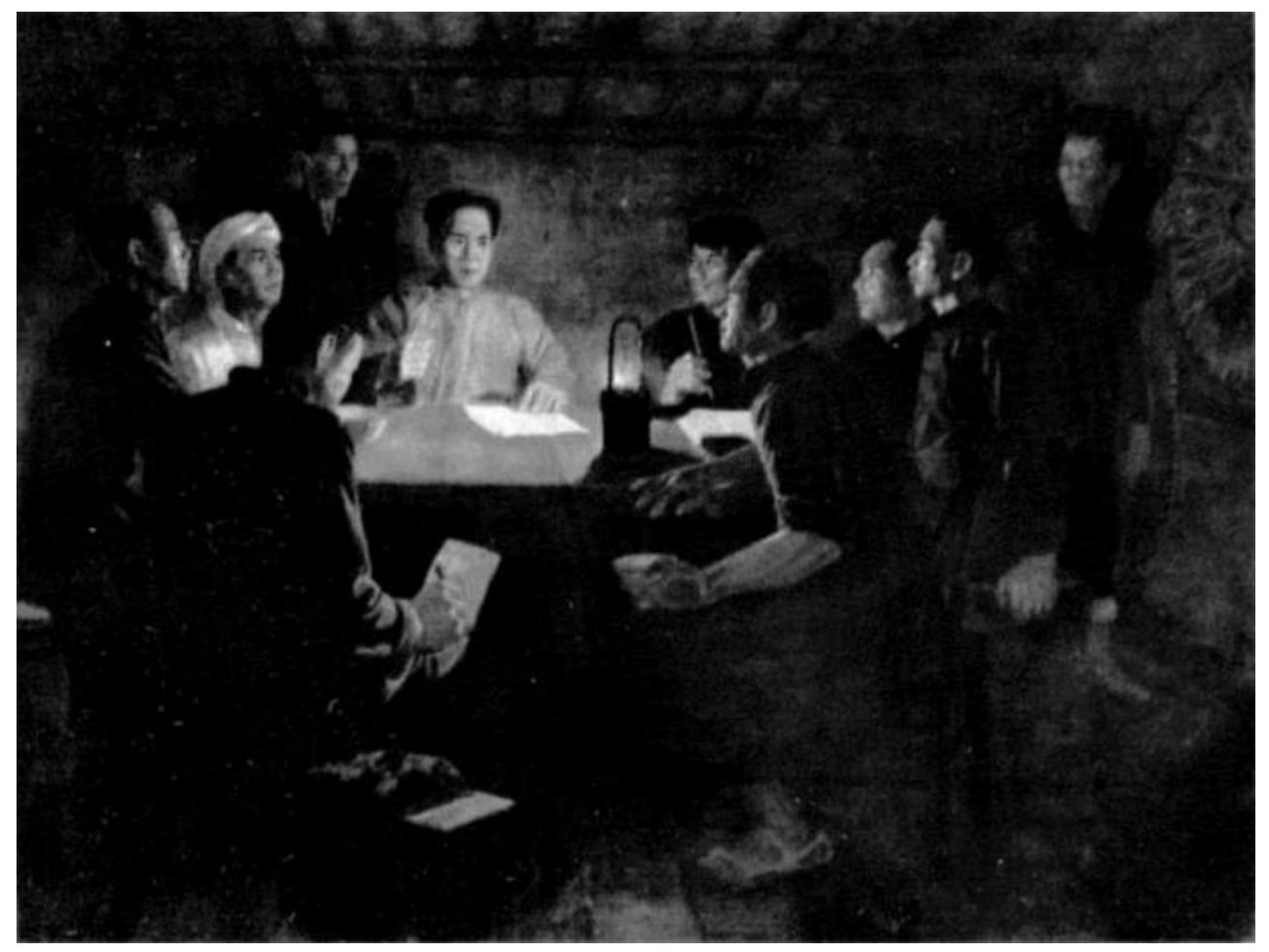

Figure 72. Fu Duzhu, mao zedong tongzhi zai shaoshan zuzhi xue chi hui [Comrade Mao Zedong organized xue chi hui in Shaoshan], undated. Image scanned from Hunan Renmin Publishing House, Shaoshan, 13.

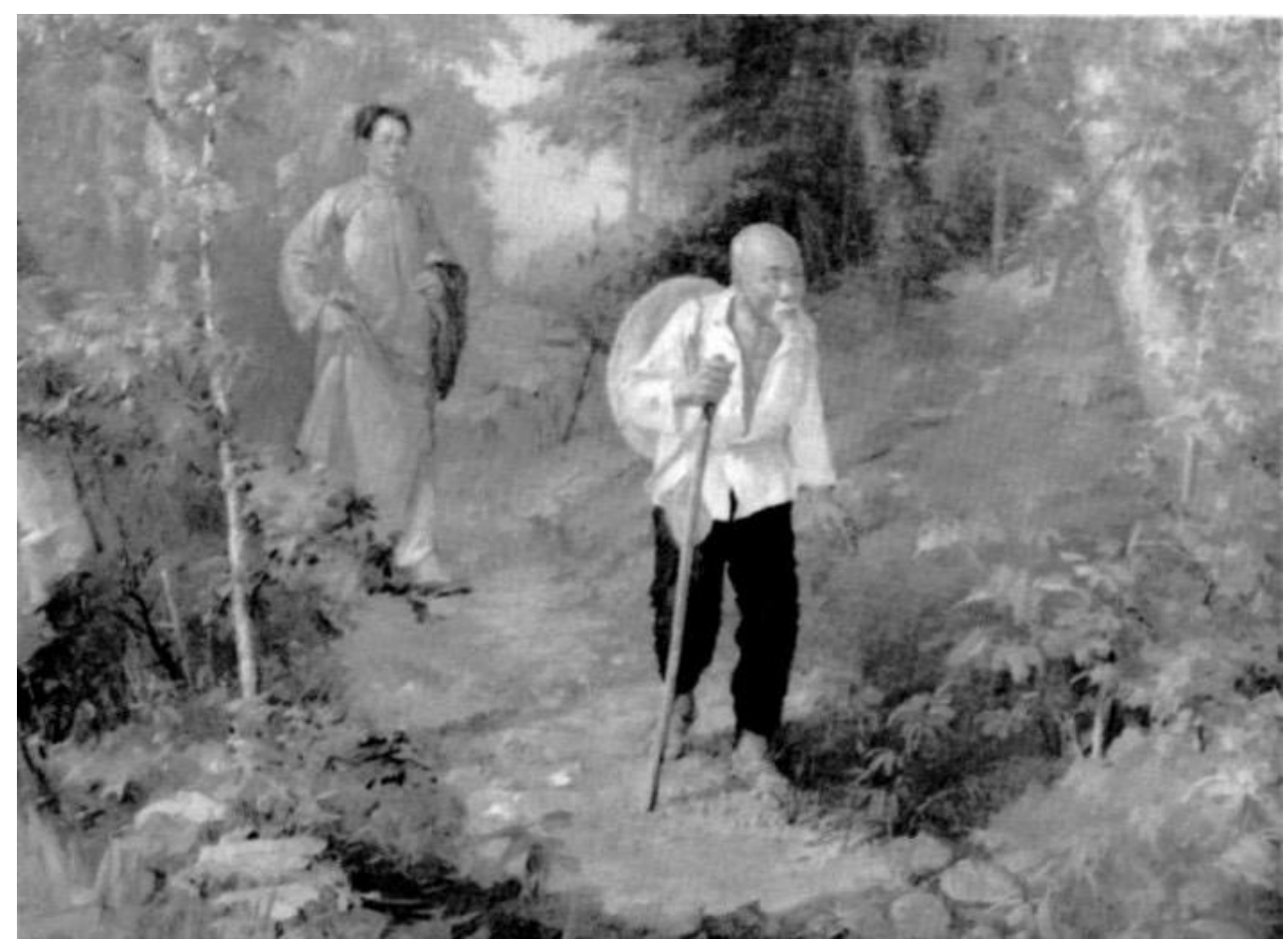




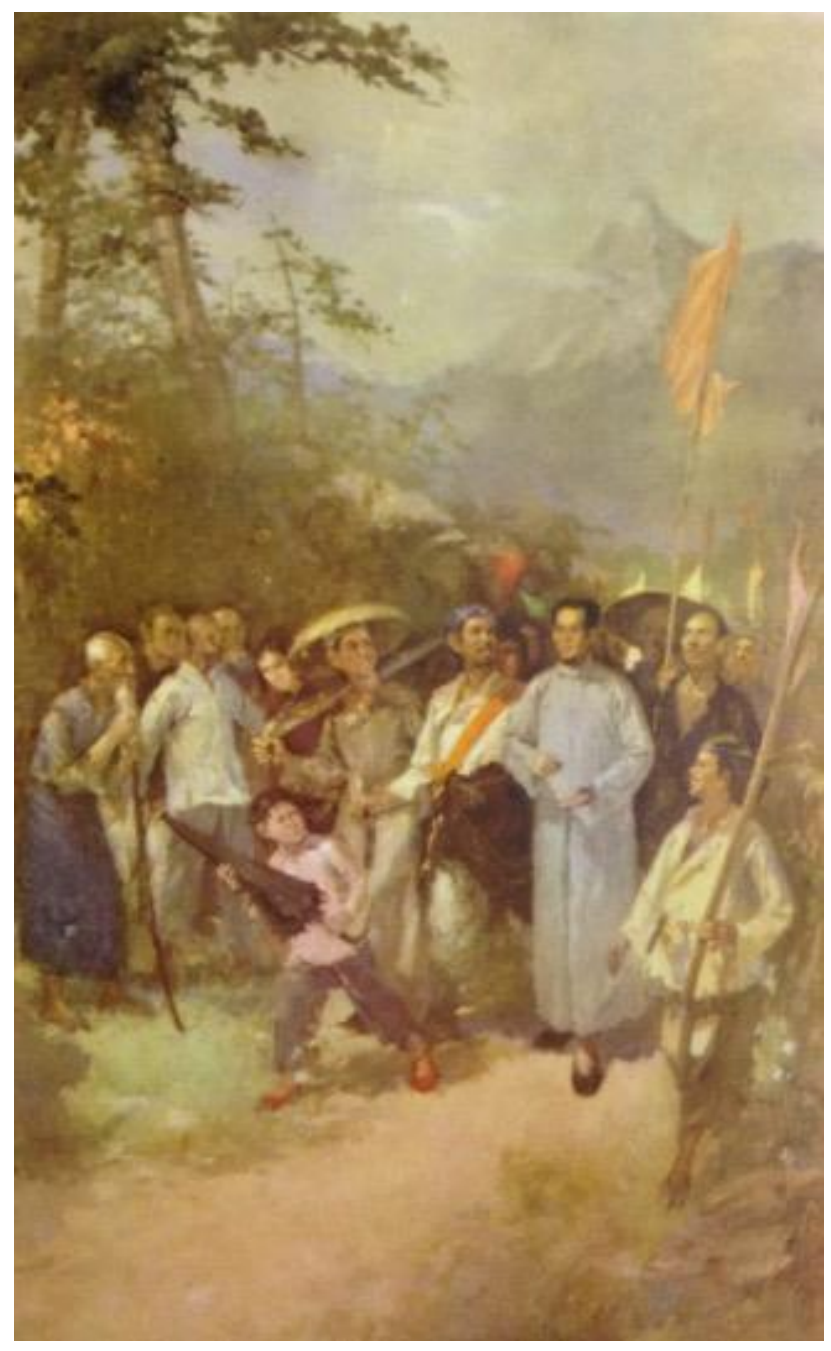

Figure 73, 74. Chen Ziyun, dailu [Guide the way], undated; and Chen Ziyun, Huanying maozedong tongzhi hui shaoshan kaocha nongmin yundong [Welcome Comrade Mao Zedong back to Shaoshan to investigate the peasant movement], undated. Image scanned from Hunan Renmin Publishing House, Shaoshan, 15, 17. 


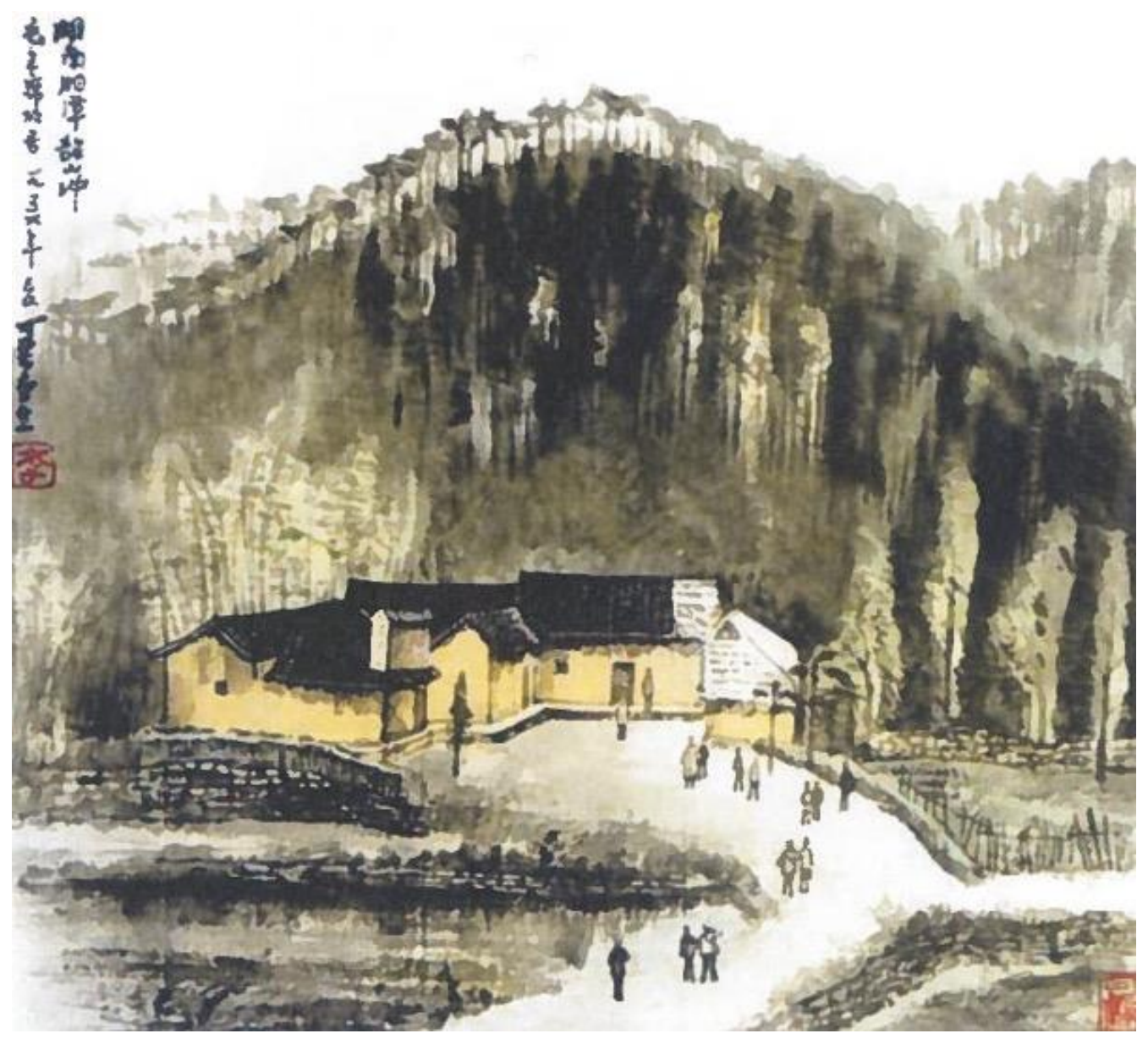

Figure 75. Li Keran, Maozhuxi guju [Chairman Mao's Old House], 1956, 40.5cm ×

44cm, private collection. Image scanned from Wan, Sheng Di Shao Guang, 68.

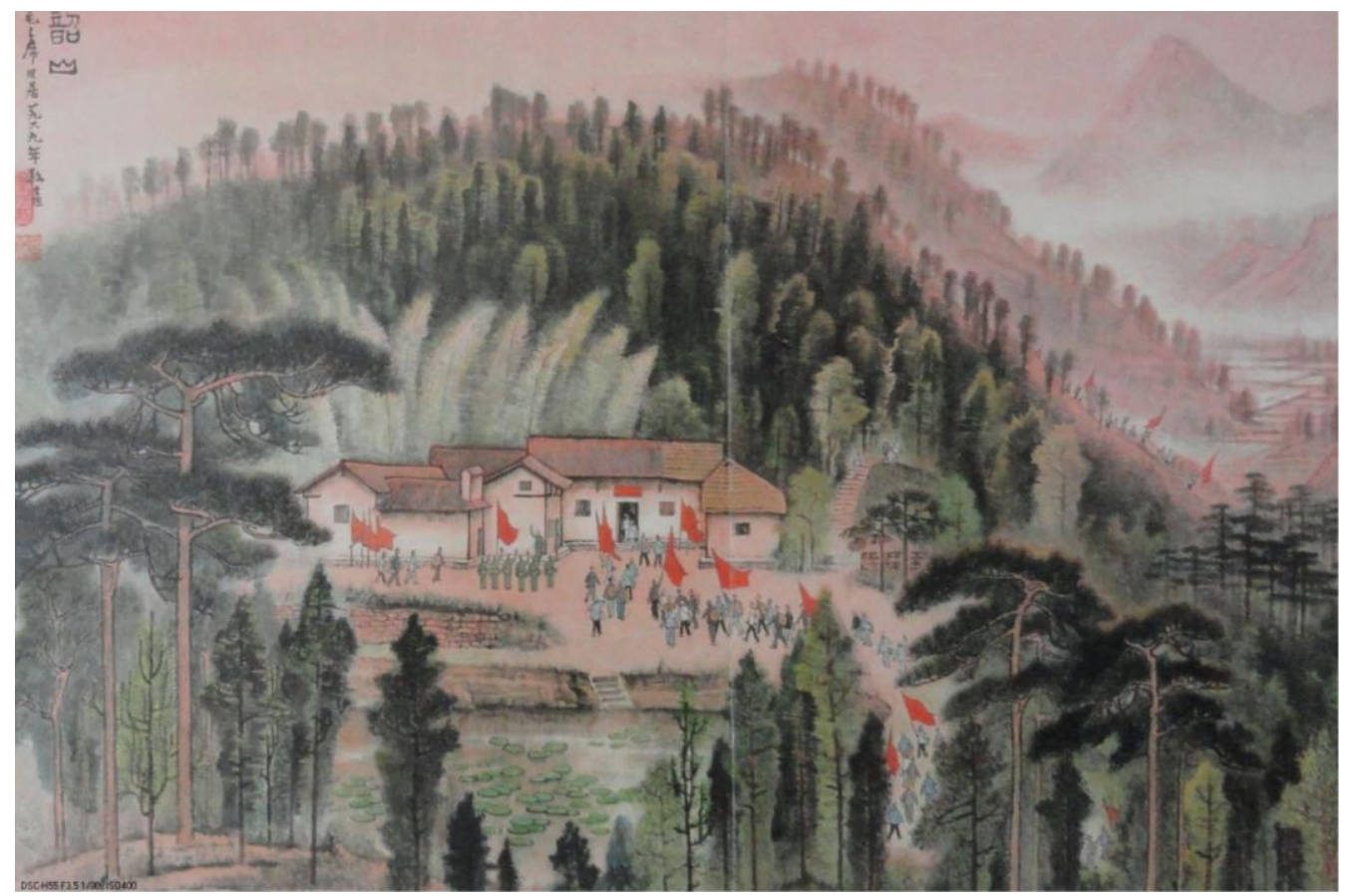


Figure 76. Li Keran, Geming shengdi shaoshan [Sacred revolutionary site Shaoshan], $1971,71 \mathrm{~cm} \times 107 \mathrm{~cm}$, private collection. Image scanned from Wan, Sheng Di Shao Guang, 69.

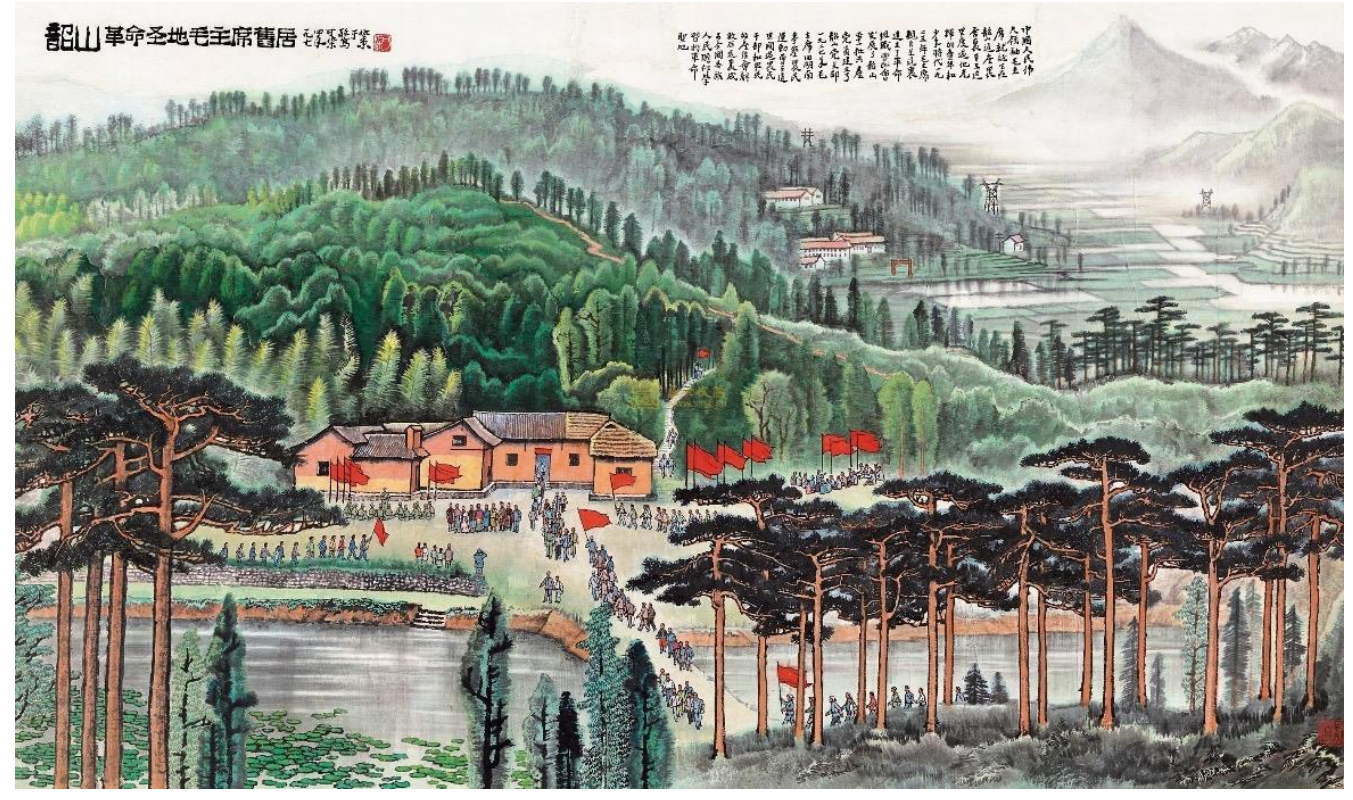

Figure 77. Li Keran, Shaoshan geming shengdi maozhuxi jiuju [Chairman Mao's Old House, Shaoshan the sacred revolutionary site], $1974,141.5 \mathrm{~cm} \times 243.1 \mathrm{~cm}$, private collection. Image scanned from Wan, Sheng Di Shao Guang, 69.

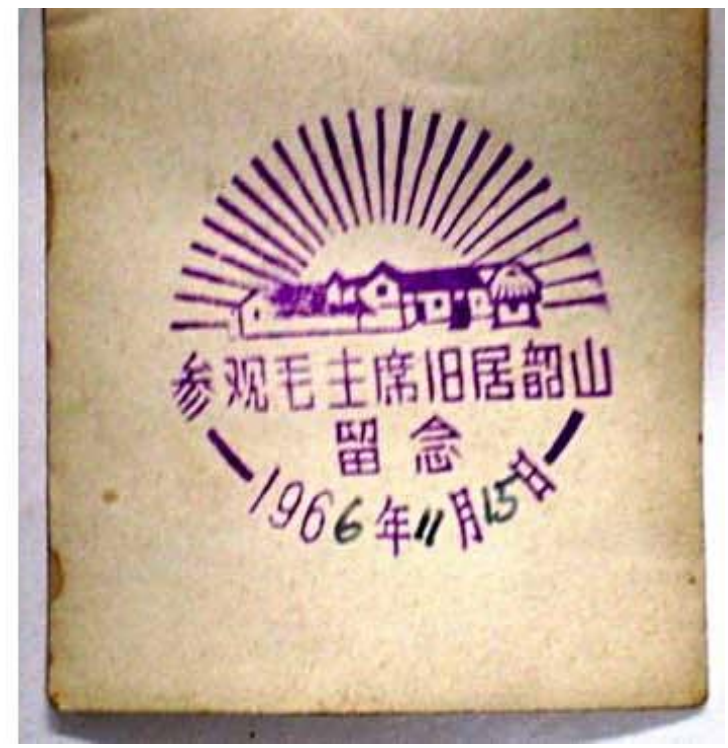


Figure 78. Badge that reads "Souvenir for the visit to Chairman Mao's Old House in Shaoshan; November 15, 1966," Peng Yong, “Canguan mao zhuxi jiuju shaoshan liunian" [Souvenir from visiting Chairman Mao's Old House in Shaoshan], xianxia shaoshan wang (www.txssw.com), September 20, 2009, accessed September 19, 2014, http://www.txssw.com/newsssyx/laozhaopian/3198.html?COLLCC=3578234811\&.

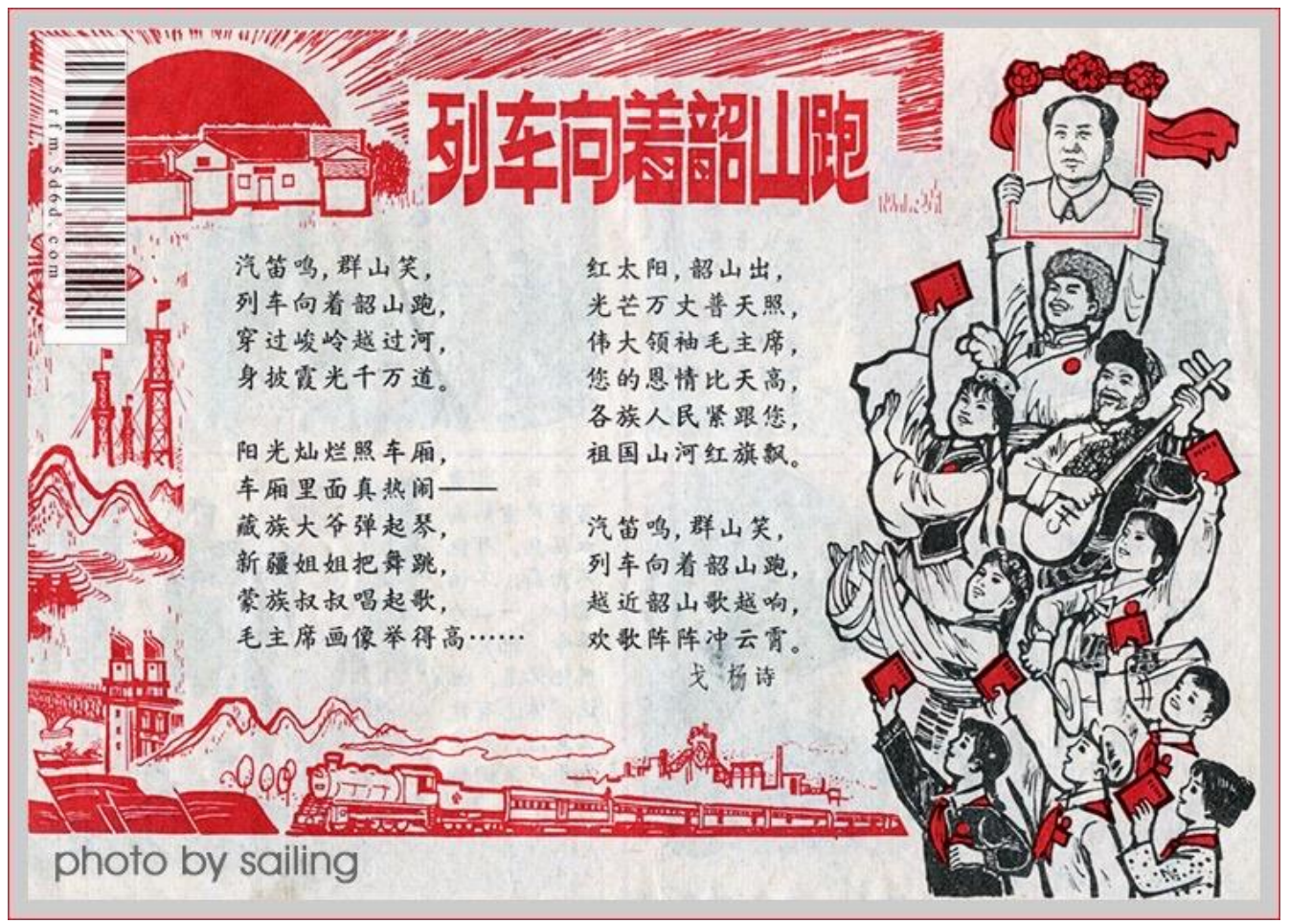

Figure 79. Poster from Cultural Revolution to advertise the railway station in Shaoshan. Si Chen, "nage niandai zuo huoche" [Taking a train in that age], huasheng luntan (bbs.voc.com.cn), September 10, 2009, accessed September 19, 2014, http://bbs.voc.com.cn/topic-2062303-1-1.html. 


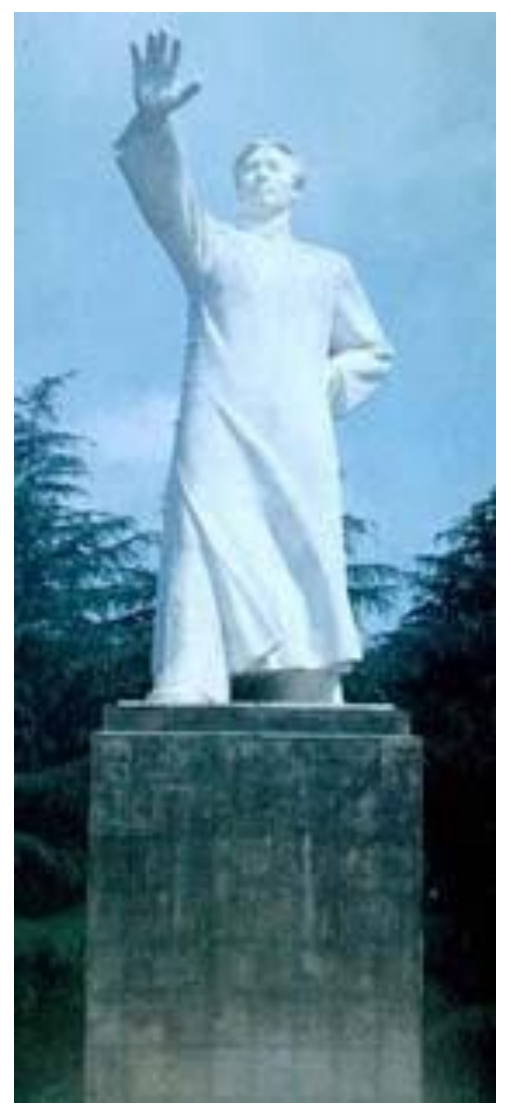

Figure 80. Young Mao's statue in Shaoshan, constructed in 1967. Image from Kangqiao gongzuoshi, "mao Zedong qingnian suxiang” [Statue of Mao Zedong in his youth], www.china-shaoshan.com, accessed November 19, 2014, http://www.chinashaoshan.com/ssfj/mzdqnsx/index.htm. 


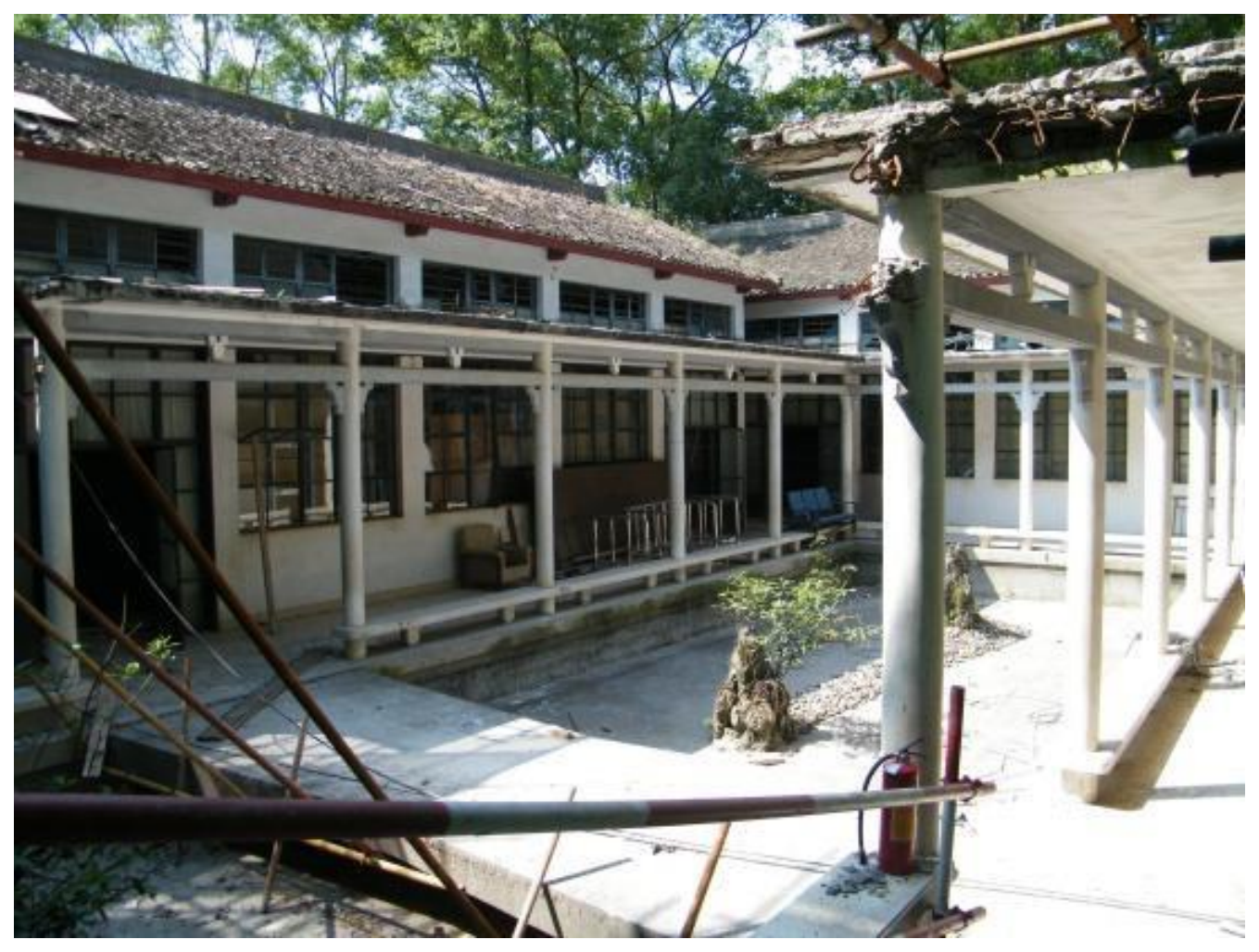

Figure 81. Demolition scene of the Exhibition Pavilion of Chairman Mao's Old House. Photo by the author. 


\section{REFERENCES}

\section{Archive Documents (HPA stands for Hunan Provincial Archives):}

"Guanyu shaoshan chenlieshi de wenti xiang shengwei de qingshi baogao ji Qin Yuping pishi" [Report to Provincial Party Committee about Shaoshan Exhibition Hall and the comment of Qin Yuping], 1 January 1962, HPA 143-1-252.

"Guanyu shaoshan maozedong tongzhi jiuju de jiben jianshe he chenlie gongzuo de qingshi baogao" [Report about the construction and exhibition of Comrade Mao Zedong's Old House in Shaoshan], 11 May 1963, HPA 143-1-252.

"Shaoshan maozedong tongzhi jiuju fuzhu chenlie jihua" [The plan for the complementary exhibition of Comrade Mao Zedong's Old House in Shaoshan], 30 July 1964, HPA 143-1-252.

"Shaoshan maozedong tongzhi jiuju wenti jieda" [Answers to the questions about Comrade Mao Zedong's Old House in Shaoshan], 5 Jul 1963, HPA 143-1-311.

"Maozedong tongzhi jiuju fuzhu chenlieshi shuoming koutou jieshao" [Oral explanation of the complementary exhibition of Comrade Mao Zedong's Old House], undated, HPA 143-1-311.

"Shaoshan maozedong tongzhi jiuju chenlieguan chenlie gongzuo jianbao" [Brief report on the curatorial work of the Exhibit Pavilion of Comrade Mao Zedong's Old House in Shaoshan], 3 November 1964, HPA 143-1-386.

"Guangzhoushi jiansheju zong gongchengshi Jin Zeguang tongzhi guanyu shaoshan guihua yijian de qicao" [Draft of the urban planning of Shaoshan by Jin Zeguang, Chief Engineer of Guangzhou Construction Bureau], August 1963, HPA 213-1-651.

"Guanyu shaoshan jianshe shinian guihua de baogao" [Report of the ten-year plan on Shaoshan's construction], 15 October 1963, HPA 213-1-651.

"Guanyu chengli chouban xiaozu, chouban shaoshan chenlieguan de qingshi" [Report on the foundation of work team and the preparation of Shaoshan's Museum], 11 November 1963, HPA 213-1-651.

"Shaoshan chenlieguan jianshe jihua he jingfei wenti de shenqing" [The construction plan and application for fund concerning Shaoshan's Museum], 23 March 1964, HPA 213-1-738.

"Guanyu gaijian shaoshan chenlieguan gongcheng sudu qingkuang de huibao" 
[Report on the current construction of Shaoshan's Museum], 12 May 1964, HPA 213-1-738.

"Chengji Xu Guangxiao fu buzhang suotan shaoshan chenlieguan wenti jilu ji $\mathrm{Hu}$ Qingpo de tanhua jilu" [Record of Vice Minister Xu Guangxiao's comment on Shaoshan Museum and his conversation with Hu Qingpo], 29 June 1964, HPA 213-1-738.

"Guanyu xiugai zhuxi jiuju menqian shuomingpai de han he shuoming (xiugai gao) de yijian" [Proposal of the illustration plaque for Chairman Mao's Old House], 19 Aug 1964. HPA 213-1-738.

"Bayue sanri gaunyu xiugai zhuxi jiuju menqian shuoming pai de han he shuo ming de huizhi" [Response to the report on changing the introductive plague in front of Chairman's Old House on August $3^{\text {rd }}$ ], 19 August, 1964, HPA 213-1-738.

"Shengwei Zhang Pinghua shuji dui shaoshan chenlieguan de zhishi" [Secretary of Provincial Party Committee Zhang Pinghua's instruction on Shaoshan's Museum], 23 September 1964, HPA 213-1-738.

"Shaoshan yiqi gongcheng jiaojungong yanshou zhengmingshu" [Certificate on the examination of the first period construction in Shaoshan], 28 September 1964, HPA 213-1-738.

"Guanyu shaoshan maozedong tongzhi jiuju weihu he baohu gongzuo de jidian tihui" [Some experience on the preservation and restoration of Comrade Mao Zedong's Old House], undated, HPA 213-1-738.

"Relie huanhu mao zhuxi juxing suxiang luocheng he shaoshan tielu shengli tongche," [Warmly hail the completion of Chairman Mao's statue and the opening of Shaoshan railway station], Dec., 1967, HPA 159-3-3.

"Guanyu shaoshan tielu zhongdianzhan weizhi de tongzhi" [Advice for locating the terminal of Shaoshan's railway station], May. 22, 1967, HPA 159-3-3.

\section{Newspaper:}

LI Wen, RUO Jia, and FANG Di, "Renmin jiuxing danshengdi, fang maozhuxi guxiang xiangtan shaoshancun zhonggong zhibu "[Birthplace of people's savior, visit to the party branch in Chairman Mao's Hometown Shaoshan, Xiangtan], People's Daily, July 1, 1950.

Xinhua News Agency, "Maozhuxi guxiang shaoshan nongmin huandu chunjie tongshi qingzhu tudihuanjia quancun xiqi yangyang" [Peasants in Chairman Mao's hometown happily celebrate the Spring Festival, and the redistribution of land], People's Daily, February 10, 1951.

ZANG Kejia, "Mao zhuxi daishang le honglingjin" [Chairman Mao wearing the red scarf], People's Daily, May 28, 1961. 
MAO Zedong. "Hu nan nong min yun dong kao cha bao gao" [The report on Hunan peasant movement]. People's Daily, July 5, 1951.

AO Enhong, WU Yanbo, CHEN Congzhou, and ZHAO Baofu, "Xinde bolan jianzhu" [New exhibition buildings]. China Pictorial. Vol. 2 (Feb. 1963). Pp 18.

AO Enhong. "Guangbo diantai dalou" [The building of China National Radio]. China Pictorial. Vol. 7 (Apr. 1959). Cover page.

"Mao zhuxi juxing suxiang zai shaoshan weiran yili, shaoshan tielu quanmian jungong jintian zhengshi tongche" [The grand statue of Chairman Mao is constructed; Shaoshan's railway station is opening today], Changsha Evening, Dec. 28, 1967.

Journal Articles:

Rieber, Alfred J. "Stalin, Man of the Borderlands." The American Historical Review, Vol. 106, No. 5 (Dec. 2001): 1651-1691. Oxford University Press.

CHEN, Hua-sheng, "Guangdong's Anti-localism' Campaigns and Factional Conflict (1949-1975)." Research on the Mainland China, Vol. 2, (2008): 1-35. Website: http://iiro.nccu.edu.tw/attachments/journal/add/2/51-3-1.pdf.

CHEN Zhi, WANG Dingzeng, "Shanghai hongkou gongyuan gaijian ji: luxun jinian mu he chenlieguan de sheji [The renovation of Shanghai Hongkou Park: the design of Lu Xun's Tomb and Memorial Pavilion]." Architectural Journal, (Vol. 9, 1956): 1-10.

Design Team for the Great Hall of the People, Design Institute of Beijing's Urban Planning Bureau, "Renmin dahuitang" [The Great Hall of the People]." Architectural Journal, Vol. Z1, (1959): 23-30.

Design Team for Museums, Design Institute of Beijing's Urban Planning Bureau, "Zhongguo geming he zhongguo lishi bowuguan" [The Museum of Chinese History and Revolution)]. Architectural Journal, Vol. Z1, (1959): 33-39.

DOU Yide, "Lingnan Style and Architecture with Chinese Characters." South Architecture. (2009): 4-6.

DU Honglin, Wang Qihui. "Guowai xuejie guanyu zhongguo gongchandang zhizheng yanjiu shulun" [Literature review of the international research on the governing legitimacy of the CPC], Journal of Tianjin Administration Institute, Vol. 15, No. 2 (Mar. 2013): 57-60.

FANG Shimin, LUO Xi, "Research on Product Strategy of Shaoshan's Red - tourism Industry," Journal of Xiangtan University (Philosophy and Social Sciences) (Sept. 2004): 135-138.

GAO Jucun, "Shao shan mao ze dong jiu ju chen lie guan xiu jian shi mo" [History of 
the construction of Shaoshan Exhibit Pavilion of Comrade Mao Dedong's Old House]. Literature of Chinese Communist Party, No.4 (2006): 37-40

GAO Jucun,"Shao shan mao ze dong tong zhi ji nian guan de you lai" [Origin of Shaoshao Mao Zedong Memorial Museum]. XiangChao (Aug. 2006):47-50.

HAN Xumei. "Hu nan te se min ju yan jiu bi jiao" [Comparative study of traditional folk dwellings in Hunan]. Collected Works of the Contextual Architectural Cultural Forum. (2005): 210-216.

HE Jingtang, "Yi jianzhu dashi she junnan" [Recollection on the Master She Junnan]. Architectural Journal, (Vol.3, 1999): 58-59.

HU Qingpo, "Shaoshan maozedong jiuju chenlieguan zenyang jiancheng de" [How the Exhibit Pavilion of Mao Zedong's Old House in Shaoshan was constructed]. Across Time and Space, (Jul. 2001): 25-31.

Hunan Shaoshan Revolutionary Committee, Hunan Institute of Architectural Design. "Shaoshan in Construction." Architecture Journal. (Jan. 1977): 1-11.

HU Shouren, "Du maozhuxi xin fabiao de shici shishou" Studying the ten poems newly published by Chairman Mao]. Journal of Jiangxi Normal University (Philosophy and Social Sciences Edition), (Jan. 1964): 1-6.

Jianguo, "Difang zhuyi zhongchuang xia de guangdong ganbu" [The cadres in Guangdong who suffered from the 'Regionalism']. Yanhuang shijie, Vol. 10, 2013, Website:

http://www.yhsjzz.com/index.php?m=content\&c=index\&a $=$ show\&catid=105\&id= $\underline{857 .}$

LI Junbo, JIANG Ao, "Review on Corporate Red Culture Assessment," Journal of Xiangtan University (Philosophy and Social Sciences) (Sept. 2006): 72-76.

LI Rui, FENG Jiang, "Timeline of Hsia Changshi's Life \& Bibliography of Hsia Changshi." South Architecture, (Feb. 2010): 46-48.

Lin Fan, "Renmin yaoqiu jianzhushi zhankai piping he ziwo piping" [The people ask architects to begin criticism and self-criticism]. Architectural Journal, (Vol. 2, 1954): 122-124.

LIU Jianqiang, "Shaoshan nongmin yundong yu hunan nongmin yundong kaocha baogao yiwen de fabiao" [Peasant movements in Shaoshan and the publication of the report on the peasant movement in Hunan]. Mao Zedong Thought Study, (May. 2012): 119-123.

LIU Wei, XU Feng, and XIE Mingling, "Building Technology of Traditional Folk Houses Adaptable to Central-north Region of Hunan Province: Taking Ancient Houses in Zhang Guying Village, Yueyang as Example." Huazhong Architecture, Vol. 27, (Mar. 2009): 172-175.

LIU Wentao, WU Mingfan, and WU Jianguo, "Cong maolu dao shengdi: ji shaoshan 
maozedong tongzhi jinianguan" [From farmhouse to sacred land: on Shaoshan Memorial Museum of Comrade Mao Zedong]. Wenshi jinghua (Gems of Culture and History). Issue 2. (1999): 44-47.

LIU Yubo, "Huiguibenyuan: huigu zaoqi lingnan jianzhu xuepai de lilun yu shijian" [Review on the early practice and theory of Lingnan architecture]. Architectural Journal, (Vol.10, 2009): 29-32.

LUO Shu, "Jian xi hu nan chuan tong min ju gou zao" [Study on the techniques of traditional folk dwellings of Hunan]. Yi Hai. (Jun. 2010):148-149.

MAO Zirao, "Shenyang shi renmin dahuitang sheji" [The design of the Great Hall of the People in Shenyang]. Architectural Journal, (Vol.12, 1959): 2-5.

PENG Changxin, "Regionalism and Realism: Xia Changshi's Ideas on Modern Architecture in China." South Architecture. (Feb. 2010): 36-41.

Regional Urban and Rural Planning Office in the Architectural Science Research Institute, "Zunyi shi de jinian tixi guihua" [Memorial system planning for the city of Zunyi]. Architectural Journal, (Vol.11, 1959): 10-12, 22.

San $\mathrm{Mu}$, wenge zhong de "Shengxiang" meishu yundong he guangshang shang de hongse bopu" [The icon arts in cultural revolution and the pop art in squares]. Tribune of Social Sciences, (Jun. 2006): 72-83.

SHE Junnan, "Di zaojia nengfou zuochu gao zhiliang de sheji: tan guangzhou youyi juyuan sheji" [Can high-quality design be created under financial restraints: discussion on the design of Guangzhou Friendship Theatre]. Architectural Journal, (Vol.3, 1980): 16-19.

SHE Junnan, "Linxi: lingnan jianzhu de juren" [Lin Xi, a giant in the development of Lingnan architecture]. South Architecture, Vol.1, (1996): 58-59.

SHE Junnan, "Wo de zishu" [My autobiography]. Architectural Journal, (Vol.3, 1998): 74-75.

Southwest Industrial Architectural Design Institute, "Sichuan sheng nongye zhanlan guan" [Agricultural Exhibition Pavilion in Sichuan Province]. Architectural Journal, (Vol. 2, 1960): 33-35.

TAN Guangwen, DING Lijun, "Linxi" [Lin Xi]. Guangdong yuanlin (Guangdong Garden), Vol. 2, (2009): 73-74.

TAN Luosong, XIE wei, and LIU Jianqiang, " Maozedong yu shaoshan nongmin yundong" [Mao Zedong and the peasant Movement in Shaoshan]. Mao Zedong Thought Study, (Jan. 2012): 39-44.

WANG Jianguo, "Hunan nongmin yundong kaocha baogao jige wenti de bianxi" [Analysis of several problems in the report on Hunan peasant movement]. Mao Zedong Thought Study, (Jul. 2008): 113-117. 
Womack, Brantly, "The Upheld Banner: The Development of Mao Zedong's Political Thought Observed from Report on the Peasant Movement in Hunan." Journal of Hunan University of Science \& Technology (Social Science Edition), (Nov. 2004): 23-34.

WU Guozheng, YU Hanwu, and LONG Wanrong, "Building Technique of Traditional Folk Dwellings - Taking the Dwellings in Hunan as an Example." Huazhong Architecture. Vol. 25, (Nov. 2007):126-128.

XIA Changshi, MO Bozhi, "Mantan lingnan tingyuan" [Discussion on Lingnan Garden]. Architectural Journal, (Vol.3, 1963): 11-14.

Xiangtan Municipal Committee of the CPC, "Mianhuai mao zhuxi, jianshe xin shaoshan" [Commemorate Chairman Mao, construct a new Shaoshan]. Xiangtan tongxun, Vol. 12, 2003, Serial No. 249: 66-67.

XIAO Difei, JIANG Weisong, GAO Heng, Huang Yunmei, YIN Menglun, XU Wendou, MENG Guanglai, SUN Sibai, GAO Lan, "Bitan xuexi maozhuxi shici shishou" [Writing on the study of the ten poems by Chairman Mao]. Journal of Literature, History, and Philosophy, (Jan. 1964): 7-19.

XIAO Yiqiang, YANG Yanwen, "An Essay on Mr. Xia Changshi," South Architecture. ( Feb. 2010): 14-15.

XIAO Yiqiang. "Reasoning on the Modernity of Lingnan Modern Architecture Design." New Architecture. (May. 2008): 8-11.

XIONG Guangqing, "The Enhancement of the CPC's Governing Legitimacy from a Historical Perspective," Academic Exploration, No.1, 2011 (Feb. 2011): 1-8.

$\mathrm{XU}$ Yong, and Xu Zengyang,"Zhongguo nongcun he nongmin wenti yanjiu de bainian huigu" [Reviewing the $20^{\text {th }}$ century studies of the Chinese rural and peasants issues in retrospect]. Journal of Central China Normal University (Humanities and Social Sciences), (Nov. 1999): 1-10.

YAN Puhua, CHEN Tao, and LIU Hongcheng, "The Research on Apartment Layout of Traditional Folk Dwellings in Hunan." Chinese and Overseas Architecture. (Aug. 2012): 49-51.

ZENG Zhaofen, "Yungui liangnan: mo bozhi yu lingnan jiagou" [Returning to Lingnan: Mo Bozhi and architecture in Lingnan]. Architectural Journal, (Vol.9, 1993): 42-47.

ZHANG Heqing, SU Bin, "Implication to the Red - tourism Region of the Late Comer Effects," Journal of Xiangtan University (Philosophy and Social Sciences) (Sept. 2006): 85-89.

ZHANG Zhaoping, "Luxun jinian guan zongti sheji fangan de jieshao" [Introduction to the overall design of Lu Xun's Memorial Pavilion]. Architectural Journal, (Vol.4, 1956): 54-59. 
ZHAO Dongri, "Tiananmen guangchang" [The Tiananmen Square]. Architectural Journal, Vol. Z1, (1959): 18-22.

ZHENG Shucun, "The Transformation of the Governing Legitimacy of CPC and Its Path Choice", Journal of Literature, History, and Philosophy, No.1, 2005 (Serial No. 286): 149-154.

ZHONG Xinquan, "Renmin de jianzhushi: ji jianzhu lao zhuanjia she junnan" [People's architect: recollection on the architecture expert She Junnan]. Architectural Journal, (Vol. 3, 1999): 54-55.

ZHOU Puyi, "Cong beijing jizuo xin jianzhu de fenxi tan woguo jianzhu chuangzuo" [Discuss about the architectural creation in our country based on the analysis of several new buildings in Beijing]. Architectural Journal, (Vol. 3, 1957): 41-50.

ZOU Denong, ZHANG Xiangwei, DAI Lu. "Seeking for the Modernity of Chinese Architecture in 1950s 1980s." Time+Architecture. (May. 2007): 6-15.

\section{Chapters in Books:}

CHEN Mingyu. "Guangfan diaocha zhengji, buduan fengfu guancang" [Continuous investigation and expansion of the exhibition]. In Periodical of Shaoshan Mao Zedong Memorial Museum, 66-70, $2^{\text {nd }}$ Issue. Shaoshan: Shaoshan Mao Zedong Memorial Museum, 1994.

Clark, Katerina. "Socialist Realism and the Sacralizing of Space." In The Landscape of Stalinism: The Art and Ideology of Soviet Space, edited by E A Dobrenko, and Eric Naiman, 3-18. Seattle: University of Washington Press, 2003.

DAI Jiong. "Zhong xiang shao shan mao shi shi xiu zu pu" [The first genealogy of Mao family of Shaoshan in middle Xiang]. 1737.

The Editorial Committee of Biography of Ye Jianying. "Zai 'fan difang zhuyi' de xuanwo zhong" [In the circumstance of 'anti-Regionalism]. In Ye Jianying zhuan (Biography of Ye Jianying), Beijing: Contemporary China Series Editorial Department, 2006.

FU Baoshi. "Zai mao zhuxi de guxiang -- shaoshan zuohua xiaoji" [Notes on painting in Chiarman Mao's hometown Shaoshan]. In Fubaoshi meishu wenji (Art Anthology by Fu Baoshi), Shanghai Ancient Books Publishing House, 2003.

GAO Jucun. "Mao ze dong he ta de fu qin mao yi chang, mu qin wen su qin" [Mao Zedong and his father Mao Yichang, mother Wen Suqin]. In Shao shan mao ze dong yan jiu (Shaoshan's Study of Mao Zedong), 100. Changsha: Hunan University Press, 2011.

Young, James E. "Memory / Monument." In Critical Terms for Art History, edited by Robert S. Nelson and Richard Shiff, 234-250. Chicago and London: the University of Chicago Press, 2003. 
LIU Shengsheng. "Qieshi zuo hao mao zedong guju he jiuzhi de baohu guanli gongzuo" (To fulfill the task of preserving and managing Mao Zedong's Old House and memorial sites]. In Periodical of Shaoshan Mao Zedong Memorial Museum. 2nd Issue, 91-94. Shaoshan: Shaoshan Mao Zedong Memorial Museum, 1994.

MA Yuqing. "Canjia choujian mao zedong shaoshan jiuju chenlie guan de huiyi" [Memory of participating the preparation of Mao Zedong's Shaoshan Exhibit Pavilion]. In Zai shao shan gong zuo de sui yue li (The Days Working in Shaoshan), edited by JIANG Guoping, 388-391. Beijing: China Federation of Literary and Art Circles Publishing Corporation, 2003.

TANG Zhennan. "Zuichu de chenlie fangan he ziliao shouji gongzuo" [The first exhibition program and the collection of the items]. In Periodical of Shaoshan Mao Zedong Memorial Museum. $2^{\text {nd }}$ Issue, 63-65. Shaoshan: Shaoshan Mao Zedong Memorial Museum, 1994.

WANG Yijie, "Zai shaoshan gongzuo de huiyi pianduan" [Some pieces of memories of working in Shaoshan]. In Zai shao shan gong zuo de sui yue li (The Days Working in Shaoshan), edited by JIANG Guoping, 283-290. Beijing: China Federation of Literary and Art Circles Publishing Corporation, 2003.

WANG Zhongjie. Shaoshan nongye hezuo hua gaochao jishi" [A record of the climax of Shaoshan's Agricultural Cooperation]. In Zai shao shan gong zuo de sui yue li (The Days Working in Shaoshan), edited by JIANG Guoping, 388-391. Beijing: China Federation of Literary and Art Circles Publishing Corporation, 2003.

WU Baisong. "Women wei shaoshan chengqi yipian tian" [We support the sky of Shaoshan]. In Zai shao shan gong zuo de sui yue li (The Days Working in Shaoshan), edited by JIANG Guoping, 275-282. Beijing: China Federation of Literary and Art Circles Publishing Corporation, 2003.

ZHU Jianfei, "Guojia, kongjian, geming: beijing, 1949-1959" [A spatial revolution: Beijing, 1949-1959]. In Sixty Years of Chinese Architecture (1949-2009): History, Theory and Criticism, edited by Zhu Jianfei, 46-71. China Architecture \& Building Press, 2009.

$\underline{\text { Books: }}$

Anderson, Benedict. Imagined Communities: Reflections on the Origin and Spread of Nationalism. London: Verso, 2006.

Apter, David E, and Tony Saich. Revolutionary Discourse in Mao's Republic.

Cambridge, Mass: Harvard

University Press, 1994.

Badgley, John H., and John Wilson Lewis. Peasant Rebellion and Communist 
Revolution in Asia. Stanford, Calif: Stanford University Press, 1974.

Bennett, Tony. The Birth of the Museum: History, Theory, Politics. London and New York: Routledge. 1995.

Brown, Peter. The Cult of the Saints: Its Rise and Function in Latin Christianity. Chicago: University of Chicago Press, 1981.

Bruggeman, Seth C. Here, George Washington was Born: Memory, Material Culture, and the Public History of a National Monument. Athens: University of Georgia Press, 2008.

Central Literary Contributions Publishing Bureau, Zhongnanhai Wangshi Zhuizong Baoga [Report on the past events in the Sea Palaces]. Beijing: Central Literary Contributions Publishing Bureau, 2010.

Chang, Jung, and Jon Halliday. Mao: The Unknown Story. New York: Knopf, 2005.

CHEN Lvsheng, Xin Zhongguo Meishu Shi: 1949-1966 [A pictorial art history of the PRC: 1949-1966], China Youth Press, 2000.

Chesneaux, Jean. Peasant Revolts in China, 1840-1949. [New York]: W.W. Norton, 1973.

Cosgrove, Denis E. Social Formation and Symbolic Landscape. London: the University of Wisconsin Press, 1998

Doss, Erika. Memorial Mania: Public Feeling in America. Chicago and London: The University of Chicago Press, 2010.

GAO Hua, Hong Taiyang Shi Zenyang Shengqi De: Yanan Zhengfeng Yundong De Lailongqumai [How the red rose: the reasons and results of the Rectification Movement in Yan'an]. Chinese University of Hong Kong Press, 2000.

Hofheinz, Roy. The Broken Wave: the Chinese Communist Peasant Movement, 1922-1928. Cambridge, Mass: Harvard University Press, 1977.

Hunan Renmin Publishing House. Shao Shan. Changsha: Hunan Renmin Publishing House, 1959.

Karl, Rebecca E. Mao Zedong and China in the Twentieth-Century World: A Concise History. Durham [NC]: Duke University Press, 2010.

Keswick, Maggie, and Charles Jencks. The Chinese Garden: History, Art \& Architecture. New York: Rizzoli, 1978.

Leese, Daniel. Mao Cult: Rhetoric and Ritual in China's Cultural Revolution. Cambridge; New York: Cambridge University Press, 2011.

LI Min, Wo De Fuqin Maozedong [My father Mao Zedong]. Liaoning People's Publishing House, 2000.

LI Rui. Lu Shan Hui Yi Shi Lu [Record of the Lushan Plenum]. Zhengzhou: Henan 
Renmin Publishing House, 1993.

LI Zhisui. The Private Life of Chairman Mao: The Memoirs of Mao's Personal Physician. London: Random House, 1994.

MA Shexiang. Shao Shan Dang An [Shaoshan archive]. Beijing: The Central Literature Press, 2001.

MAO Zedong. Selected Readings from the Works of Mao Tsetung. Peking: Foreign Languages Press, 1971.

MAO Zedong. Selected Works of Mao Zedong. Beijing: People's Publishing House, Jun.1991.

Planning Board of Shaoshan Revolutionary Committee. Hunan Sheng Shaoshan Qu Guomin Jingji Tongji Ziliao: 1969-1979 [Statistics of national economy in Shaoshan district, Hunan province: 1969-1979], 1980.

Propaganda Department of the Party Committee in Xiangtan, Hua Zhuxi Zai Xiangtan [Chairman Hua in Xiangtan]. Changsha: Hunan Provincial Library, Sept. 1977.

Rapoport, Amos. The Meaning of the Built Environment: A Nonverbal Communication Approach. Beverly Hills: Sage Publications, 1982.

Rokkan, Stein, Perter Flora, Stein Kuhnle, and Derek W Urwin. State Formation, Nation-Building, and Mass Politics in Europe: the Theory of Stein Rokkan: Based on His Collected Works. Oxford; New York: Oxford University Press, 1999.

Savage, Kirk. Monument wars: Washington, D.C., the National Mall, and the Transformation of the Memorial Landscape. Berkeley: University of California Press, 2009.

Schram, Stuart R. Mao Tsê-Tung. New York: Simon and Schuster, 1967.

SHI Anhai. Lingnan Jindai Youjiu Jianzhu, 1949-1990 [Outstanding modern architecture in Lingnan, 1949-1990]. Beijing: China Architecture \& Building Press, 2010.

Shaoshan Chorography Committee. Shao Shan Zhi [Shaoshan Chronicle]. Beijing: Encyclopedia of China Publishing House, 1993.

Shaoshan City Chorography Committee. Shao Shan Shi Zhi, 1991-2005 [Shaoshan city chronicle, 1991-2005]. Haikou: Hainan Press, 2010.

Shaoshan Mao Zedong Memorial Museum Chorography Committee. Shaoshan Mao Zedong Tongzhi jinian guan zhi [Chronicle of Shaoshan Mao Zedong Memorial Museum]. Changsha: Hunan Renmin Publishing House, 1999.

Shaoshan Transport Chorography Committee. Shaoshan jiao tongzhi [Shaoshan transport chronicle]. Changsha: Hunan Press, 1992.

Snow, Edgar. Xi Xing Man Ji [Red star over China, Chinese version]. Translated by 
DONG Leshan. Beijing: Liberation Army Art Press, 2002.

Spence, Jonathan D. Mao Zedong. New York: Viking, 1999.

Statistical Bureau of Shaoshan District, Xiangtan City. Xiangtan Shi Shaoshan Qu Guomin Jingji Tongji Ziliao: 1949-1989 [Statistics of national economy in Shaoshan district. Xiangtan city: 1949-1989], 1990.

Terrill, Ross. Mao: A Biography. Stanford, Calif: Stanford University Press, 1999.

Terrill, Ross. Mao: A Biography (Chinese Edition). Beijing: China Renmin University Press, 2010.

The Exhibit Pavilion of Comrade Mao Zedong's Old House. Shaoshan Maozhuxi Jiuju Chenlieguan Jiangjieci, Di'er Gao [Interpretative text of Shaoshan Exhibit Pavilion of Chairman Mao's Old House, second edition]. The Exhibit Pavilion of Comrade Mao Zedong's Old House. Collection of Changsha Library, 1969.

The Exhibit Pavilion for Comrade Mao Zedong's Old House. Shao Shan. Beijing: Cultural Relics Publishing House, 1978.

WAN Xinhua. Sheng Di Shao Guang: 20 Shi Ji Zhong Qi Zhong Gguo Hua Zhi Shao Shan Tu Xiang [The sacred place Shaoshan: Shaoshan iconography in Chinese traditional painting in mid 20th Century]. Beijing: Cultural and Art Publishing House, 2011.

WANG Mingxian. Xin Zhongguo Meishu Tushi: 1966-1976 [A pictorial art history of the PRC: 1966-1976]. China Youth Press, 2000.

Wu Hung. Monumentality in Early Chinese Art and Architecture. Stanford, Calif: Stanford University Press, 1995.

Wu Hung. The Double Screen: Medium and Representation in Chinese Painting. Chicago: University of Chicago Press, 1996.

Wu Hung. Remaking Beijing: Tiananmen Square and the Creation of a Political Space, Chicago: University of Chicago Press, 2005.

ZHANG Pinghua. Zhang Pinghua huiyilu [Memoir of Zhang Pinghu]. Changsha: Hunan Renimin Press, 1989.

ZHENG Xiaofeng, SHU Ling. Taozhu Zhuan [A biography of Tao Zhu]. Beijing: China's History of the Party Press, 2008.

Zhou Xiaozhou Chorography Committee. Zhou Xiaozhou zhuan [A biography of Zhou Xiaozhou]. Changsha: Hunan Renmin Press, 1985.

ZOU Denong. Chinese Modern Architectural History. Tianjin: Tianjin Science and Technology Press, 2001.

ZOU Denong, DAI Lu, and ZHANG Xiangwei. A History of Chinese Modern Architecture. Beijing: Chinese Architecture \& Building Press, 2010. 


\section{Materials in Other Format:}

A. A. Zhdanov. "Soviet Literature - the Richest in Ideas, the Most Advanced Literature" (Speech in the Soviet Writers Congress, August 1934). Marxists Internet Archive (marxists.org). 2004. Accessed Sept. 17, 2014. https://www.marxists.org/subject/art/lit_crit/sovietwritercongress/zdhanov.htm

Hou Yibing, "suiyue bianqian, mao zhuxi xiang jin an zai" [Time passes, how are Chairman Mao's statues now], renmin wang (www.people.com.cn), Dec. 4, 2003, accessed Nov. 18, 2014, http://www.people.com.cn/GB/wenhua/1088/2227972.html

KONG jian, JING xun, "Mao Zedong yu Lu Xun de gongtong yuyan" [The common language between Mao Zedong and Lu Xun], News of the Communist Party of China (www.cpcnews.cn), Feb. 22, 2011. Accessed Sept. 14, 2014. http://dangshi.people.com.cn/n/2013/0222/c85037-20564300-5.html

Liu Ji, "Mao Zedong tan geren chongbai: haishi chongbai wo haoyidian" [Mao Zedong on cult of personality: it is better to worship me], gongshi wang (www.21ccom.net), Jan. 14, 2012. Accessed Nov. 17, 2014, http://www.21ccom.net/articles/lsjd/lsjj/article_2012011351975.html

LIU Kuo, CAO Zhiyu, “1958-1959: yinian jiancheng shida jianzhu” [1958-1959: ten great buildings completed in one year], Ministry of National Defense of the PRC (www.mod.gov.cn), Jun. 27, 2011. Accessed Sept. 5, 2014. http://www.mod.gov.cn/hist/2011-06/27/content_4248227.htm

LI Fengfa, "siren zhongyang lingdaoren de shaoshan xing" [Four generations of the CPC's top leaders and their trip to Shaoshan], Mao Zedong Digital Library (www.mzdlib.com). Accessed Sept. 14, 2014. http://www.mzdlib.com/libszzy/MaoZeDongXingJiuShuJuKu/4826.html

MAO Zedong, "Talks at the Yen'an Forum on Literature and Art" (May 1942). Marxists Internet Archive (marxists.org). 2004. Accessed Sept. 17, 2014. https://www.marxists.org/reference/archive/mao/selected-works/volume-3/mswv3 -08.htm

Mao Zedong, "Zhongguo gongchandang zai minzu zhanzheng zhong de diwei" [The role of the Chinese communist party in the national war], Marxist Internet Archive (Marxists. org), 2004. Accessed Nov. 17, 2014. https://www.marxists.org/reference/archive/mao/selected-works/volume-2/mswv2 _10.htm

Mao Zedong. "Oppose Book Worship," Marxist Internet Archive (Marxists. org), 2004. Accessed Nov. 17, 2014. https://www.marxists.org/reference/archive/mao/selected-works/volume-6/mswv6 _11.htm; 
PENG Yong, "Canguan mao zhuxi jiuju shaoshan liunian"[Souvenir from visiting Chairman Mao's Old House in Shaoshan], xianxia shaoshan wang (www.txssw.com), Sept. 20, 2009. Accessed Sept. 19, 2014. http://www.txssw.com/newsssyx/laozhaopian/3198.html?COLLCC=3578234811 $\underline{\&}$

SI Chen, "Nage niandai zuo huoche" [Taking a train in that age], huasheng luntan (bbs.voc.com.cn), Sept. 10, 2009. Accessed Sept. 19, 2014. http://bbs.voc.com.cn/topic-2062303-1-1.html

SONG Dailun, "zhonggong liren lingdaoren mianhuai mao zedong hanjian jiuzhao" [Rare old photographs showing the CPC's leaders commemorating Mao Zedong], Takungpao (www.takungpao.com). Dec. 26, 2012. Accessed Sept. 14, 2014. http://photo.takungpao.com/politics/2013-12/1363983.html

WEN Yaodong, "Shaoshan da shiji," [Shaoshan chronicle] xianxia shaoshan wang (www.txssw.com), Sept. 29, 2009. Accessed Sept. 17, 2014.

http://www.txssw.com/newsssglj/dashiji/Index.html

XIONG Kunjing, "<Mao zedong xuanji>bianji chuban shimo" [The editorial history of Mao Zedong's Selected Works], News of the Communist Party of China (www.cpcnews.cn), Dec. 05, 2013. Accessed Sept. 17, 2014. http://dangshi.people.com.cn/n/2013/1205/c85037-23756594.html

"Beidaihe huiyi" [Beihaihe meeting], Baidu Wikipedia. Last modified Aug. 8, 2014. http://baike.baidu.com/view/424284.htm

"Beijing shida jianzhu" [The ten great buildings in Beijing], Wikipedia. Last modified May. 22, 2014, http://zh.wikipedia.org/wiki/\%E5\%8C\%97\%E4\%BA\%AC\%E5\%8D\%81\%E5\%A 4\%A7\%Е5\%BB\%BA\%Е7\%AD\%91

"Da xingzheng qu" [Large administrative area], Wikipedia. Last modified Feb. 19, 2014 , http://zh.wikipedia.org/wiki/\%E5\%A4\%A7\%E8\%A1\%8C\%E6\%94\%BF\%E5\%8 C\%BA

"Fandui benben zhuyi" [Oppose book worship], Baidu Wikipedia. Last modified Sept. 22, 2014, http://baike.baidu.com/view/431118.htm

"Fu baoshi," Baidu Wikipedia. Last modified Sept. 16, 2014. http://baike.baidu.com/view/16687.htm

"Great Leap Forward," Wikipedia. Last modified Sept. 11, 2014. http://en.wikipedia.org/wiki/Great_Leap_Forward

"Keyuan quanjing" [A panorama of the Keyuan Garden], Keyuan Museum (www.dgkeyuan.org). http://www.dgkeyuan.org/gujian_view.php?id=84

"Mao Zedong xuanji” [Mao Zedong selected works], Baidu Wikipedia. Last modified 
Aug. 25, 2014. http://baike.baidu.com/view/138481.htm

"Mao Zedong sixiang" [Mao Zedong thought], Wikipedia. Last modified Sept. 14, 2014.

http://zh.wikipedia.org/wiki/\%E6\%AF\%9B\%E6\%B3\%BD\%E4\%B8\%9C\%E6\%8 0\%9D\%E6\%83\%B3\#.E5.8F.82.E8.80.83.E6.96.87.E7.8C.AE

"Mao zedong suxiang," [Mao Zedong statue] Wikipedia, last modified Aug. 1, 2014: http://zh.wikipedia.org/wiki/\%E6\%AF\%9B\%E4\%B8\%BB\%E5\%B8\%AD\%E5\% A $1 \% 91 \% \mathrm{E} 5 \% 83 \% 8 \mathrm{~F}$

"Mao Zedong guju" [Mao Zedong's Old House], www.zjjtm.com. Accessed Nov. 19, 2014, http://www.zjjtm.com/jingdian/jingdian_53.html

"Mao Zedong jinian guan" [Memorial Museum of Mao Zedong], last modified Nov. 21, 2013, http://www.zspt.cn/Item/10215.aspx

"Mao Zedong," Wikipedia. Last modified Nov. 16, 2014, http://en.wikipedia.org/wiki/Mao_Zedong

"Panopticon," Wikipedia. Last modified Sept. 9, 2014. http://en.wikipedia.org/wiki/Panopticon

"People's commune," Wikipedia, last modified Aug. 20, 2014, http://en.wikipedia.org/wiki/People's_commune

"Qiqianren dahui" [Seven-thousand-people conference], Baidu Wikipedia, last modified Oct. 22, 2014, http://baike.baidu.com/view/111392.htm

"Shaoshan fengjing mingsheng qu lvyou shitu" [Map of Shaoshan's scenic areas], zhongguo shaoshan (www.shaoshan.gov.cn). Accessed Mar. 11, 2014. http://www.shaoshan.gov.cn/Photo/ShowPhoto.asp?PhotoID=20\#Title

"Si qing yundong," Wikipedia, last modified Nov. 5, 2014, http://zh.wikipedia.org/wiki/\%E5\%9B\%9B\%E6\%B8\%85\%E8\%BF\%90\%E5\%8A \%A8

"Socialist Education Movement, " Wikipedia. Last modified Jun. 13, 2014. http://en.wikipedia.org/wiki/Socialist_Education_Movement

"Socialist Realism," Wikipedia. Last modified Sept. 2, 2014. http://en.wikipedia.org/wiki/Socialist_realism

"Tiananmen guangchang" [Tiananmen Square], Wikipedia. Last modified Jun. 14, 2014 http://zh.wikipedia.org/wiki/\%E5\%A4\%A9\%E5\%AE\%89\%E9\%97\%A8\%E5\%B 9\%BF\%E5\%9C\%BA\#.E5.8E.86.E5.8F.B2.E8.AE.8A.E9.81.B7

"Tudi geming," [Agrarian revolution], Baidu Wikipedia, last modified Oct. 23, 2014, http://baike.baidu.com/view/35443.htm

"Zhong nan ju" [Central-south bureau of the CPC], Baidu Wikipedia. Last modified 
Dec. 20, 2013, http://baike.baidu.com/view/4791893.htm

MAO Zedong, "Guanyu liji tingzhi zai shaoshan wei maozedong jianfang gei huangkecheng deng de xin [The letter to Huang Kecheng to stop building a house for Mao Zedong in Shaoshan], September 20, 1950. Jianguo yilai maozedong wengao (Mao Zedong's Manuscript after P.R.C was Founded). Beijing: The Central Literature Press.1996.

Hunan TV Center, Hunan Shaoshan Tourism Development Institue. Shenqi de shaoshan [The magic Shaoshan]. Changsha: Golden Bee Audio and Video Publishing Corporation. 1998.

CAI Dedao, Interview with Dong, Zhe, June 21 and 22, 2013, tape recording.

CHEN Zhi. 2009. Research on the Organizational Development and Architectural Creation Process of Architecture Design \& Research Institute of SCUT. Master of Architecture thesis. South China University of Technology. Guangzhou, China.

CUI Zixia. 2012. Research on the Organizational Development and Architectural Creation Process of The Architectural Design \& Research Institute of Guangdong Province. Master of Architecture thesis. South China University of Technology. Guangzhou, China.

SHI Liang, 2007, Research of the life and works of Xia Changshi, Master of Architecture thesis, South China University of Technology.

ZHANG Haidong, "interview with Tan Zhuozhi," Research on the Organizational Development and Architectural Creeation Process of Guangzhou Design Institute (1952-1983), Master of Architecture thesis, South China University of Technology, Jun. 2009, pp: 111

ZHUANG Shaopang, 2011, Research on the Architectural Creation and Thought of Mo Bozhi, Doctor of Architecture dissertation, South China University of Technology. 


\section{CURRICULUM VITAE}

NAME: $\quad$ Zhe Dong

ADDRESS: $\quad 1800 \mathrm{~S} 2^{\text {nd }}$ St., Apt. 52,

Louisville, KY, 40208

DOB: $\quad$ Zhengzhou, Henan, China - September 22, 1988

EDUCATION \& TRAINING: $\quad$ B.A., Architecture

Tianjin University

2007-2012

M.A., Art History

University of Louisville

2012-2014

AWARDS:

Graduate Dean's Citation

University of Louisville

2014

Cressman Fellowship

University of Louisville

2013-2014

Frederic Lindley Morgan Scholarship

University of Louisville

2012-2013

PUBLICATIONS： DONG Zhe. “一个圣地的形成：韶山毛泽东纪念建筑史中的五年” [The formation of a scared land: Five years in the memorial history of Mao Zedong's birthplace, Shaoshan], Twenty-First Century Bimonthly, Hong Kong (accepted for publication).

DING Yao, and DONG Zhe. “天津大学考察意大利库马古城遗址 动态" [Introduction to the investigation of Cumae heritage by Tianjin University], China Architectural Heritage (Sept. 
2011): 226-227.

DING Yao, and DONG Zhe. "A Domus in Cumae," Anthology of the International Symposium on Teaching and Research of Architectural History, ed. School of Architecture, Tianjin University (Nov. 2010): 373-386.

PRESENTATIONS: A Domus in Cumae, 2010, International Symposium on Teaching and Research of Architectural History, Tianjin, China

LANGUAGE: $\quad$ English (Fluent); Mandarin Chinese (Native) 